\title{
ANGEL FACES, KILLER KIDS, AND APPETITES FOR EXCESS: REAPPROACHING MORAL PANIC
}

\author{
By \\ Sarah Louise Wright \\ A thesis \\ Doctor of Philosophy \\ in Criminology
}

submitted to Victoria University of Wellington

in fulfillment of the requirements for the degree of

Victoria University of Wellington

2010 
For Jake. E kore e ae i te kupu taku aroha mōu. 


\begin{abstract}
It is argued that the contemporary era is one proliferated with moral panics (Thompson, 1998). This is just as the concept of moral panic, which has enjoyed nearly forty years of analytical purchase, is being 'rethought' with an impetus to connect its processes with developments in social theory. Underpinning this rethink is a primary question: what are moral panics extreme examples of? It is evident in the literature, however, that there is a varying degree to which a more longstanding question - why moral panics occur - is addressed as part of this rethink.
\end{abstract}

I propose in this thesis that these questions are intimate with each other; that only by understanding why real episodes occur can a supposition of what the concept of moral panic is in an abstract sense begin. Another - related - proposal is that while the conjectural question remains elusive the approach to empirical cases of moral panic be in real-type/ideal-type terms. That is, that at the same time as the concept is employed to understand phenomena occurring in tangible social situations, a reflection upon the concept (the ideal-type) is undertaken in relation to how the real-type case under investigation challenges and/or supports its interpretative parameters.

To demonstrate these relationships and their study, I examine in this thesis the case of 'killer kids', which emerged in 2002 and spanned across the sociopolitical landscape of Aotearoa/New Zealand for the next six years. At the heart of this case was a set of news images of a child, who at twelve years of age had been involved in a heinous crime resulting in the death of pizza delivery person Michael Choy. Seeking to understand how and why these images were fundamental to how this 'real-type' episode of moral panic unfolded in this space and time, I employ a two-component approach inspired by Norman Fairclough's (1995a) Critical Discourse Analysis. The first component deconstructs the realtype case via a three-tiered analytical framework: content, process, and context. The second component reflects upon these tiers (in parts and as a whole) in relation to Stanley Cohen's (1972) application of a 'cycle of deviance 
amplification' in addition to the stages of panic as described in his seminal work Folk Devils and Moral Panics.

From the processual and contextual factors identified at play in the construction of 'killer kids' I conclude with a suggestion that moral panic can be thought of as a set of appetites that come together in an explosive discharge of excess energy. 


\section{Acknowledgments}

Without hesitation I thank first my family; my mum Diana for her bottomless well of faith; my dad Peter for his support and grounding; my brother Mike for his abhorrence for anything remotely conspiratorial (he believed in my story); my sister Nikki for her spirit; but most of all my son Jake for being my inspiration for everything. David, Jesse, Jane, and Fiona all egged me on from afar when needed. A special thank you to my man Todd for his bottles of wine and grammar corrections (which often came together), and his love.

Second, my thanks go to the School of Social and Cultural Studies at Victoria University who have nurtured me through my undergraduate and postgraduate expedition. There are some people I need to mention individually. Mike Hill has long been my mentor and friend. Mike Rowe has almost single-handedly guided me through this thesis, finally corrupting me to the 'dark side' - Criminology. I know that if nothing else, he'll take away from this the story of the student who drew pictures at every meeting and would forget where she had left her car. Fiona Hutton juggled supervision alongside all her other academic commitments and two babies - a true superwoman! Lizzy Stanley held the fort through the final stages and all those niggly extras. Then there is Chamsy el-Ojeili with whom I drank numerous coffees, David Pearson and Allison Kirkman who always stopped to ask how it was going, and Monica Litchi who was a rock with her fabulous computer fixing skills and administrative know-how.

Two fellow students who have become dear friends deserve special mention. Amanda Rohloff shares with me the journey of discovering the ins and outs of moral panic. I couldn't have done without her emails from across the globe in which we read and edited, and argued and agreed. Bronwyn McGovern and I met in our first year of sociology. Since then we've laughed, cried, broken-up, madeup, picked up each other's children, made each other dinner, borrowed each other's clothes and embarked on PhD's. 
My thanks also go to those people who didn't know me personally, but whose time here and there went a long way to achieving my work; Jim Tully at Canterbury University, Saffron Solley at TVNZ, Graham Bell of the Police, Lynne Mackie at the Department of Statistics, Guy Reynolds at the Department of Corrections, Ross Setford of NZPA, Brian McKeon of Victoria University, photographer David White, the staffs of the Victoria University library and the National Library of New Zealand, and seven professional journalists who shall remain anonymous.

Last but by no means least I acknowledge and am grateful for the support of a VUW PhD scholarship. 


\section{Table of Contents}

Abstract .......................................................................................................................................... iii

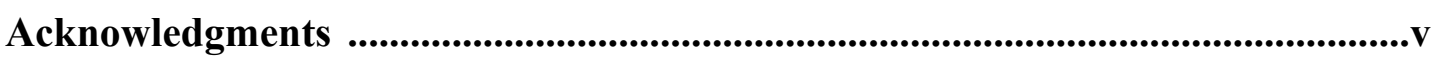

List of Figures .......................................................................................................................... ix

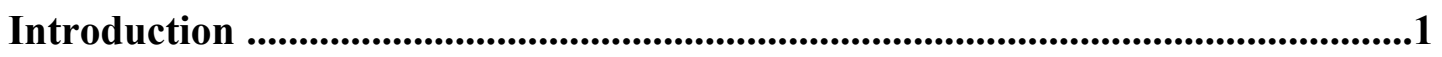

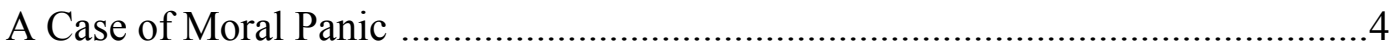

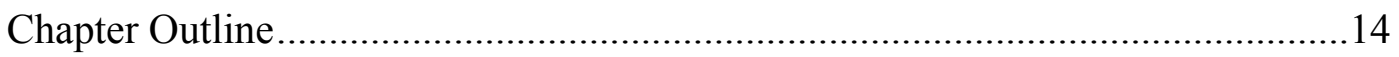

Chapter One: Moral Panic .....................................................................................17

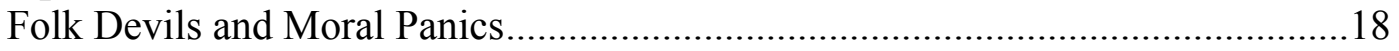

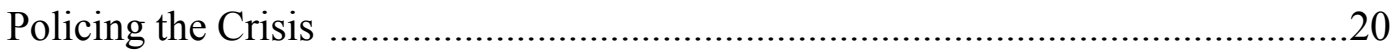

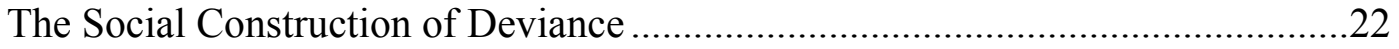

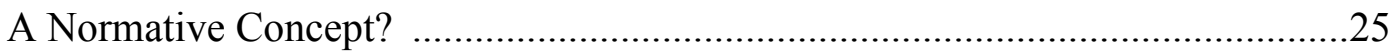

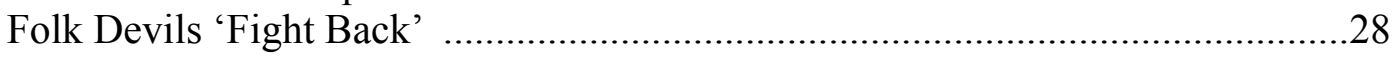

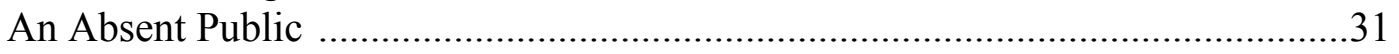

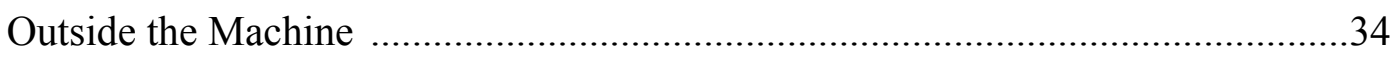

Formulating an Approach to Moral Panic ..........................................................38

Chapter Two: Rethinking Moral Panic .............................................................................41

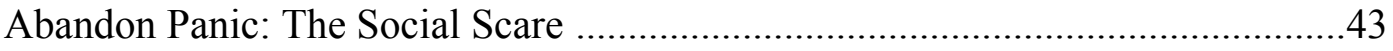

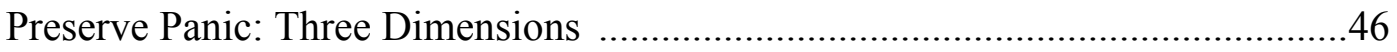

Risk and Morality: The Converging Sites of Anxiety .........................................48

Volatile Episodes: Moral Panic and Moral Regulation ......................................50

Decivilising Episodes: An Eliasian Approach …...............................................53

The Criminology of the Other, the Heterogeniac, and Energy in Excess ...............57

Approaching the Case of 'Killer Kids' ..............................................................63

Chapter Three: Methodology ........................................................................65

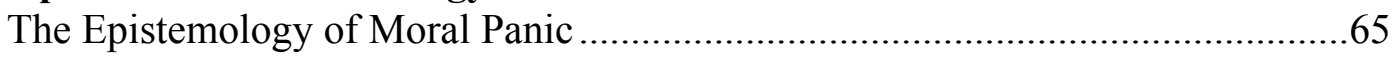

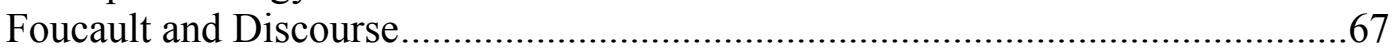

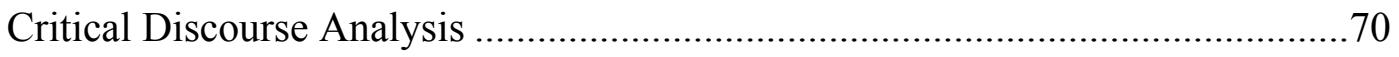

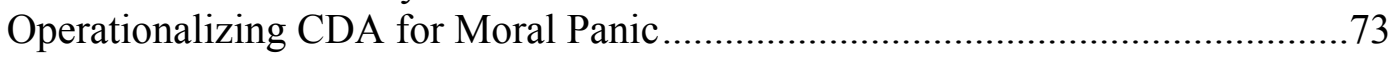

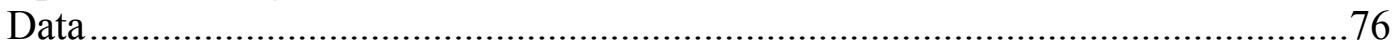

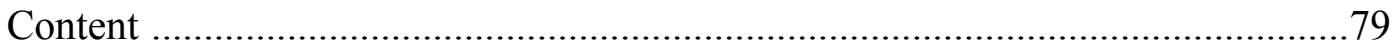

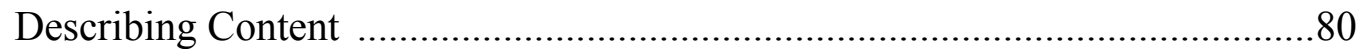

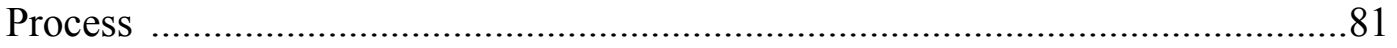

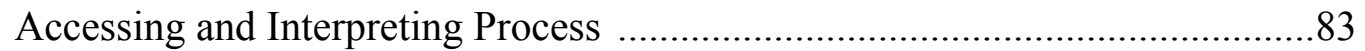

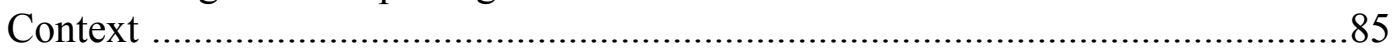

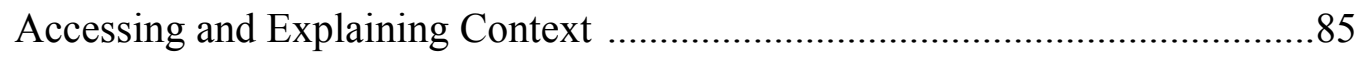

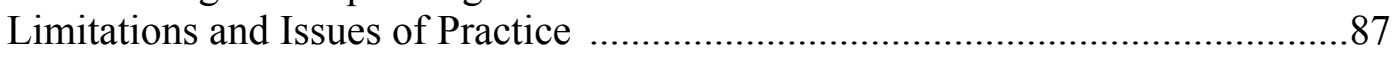

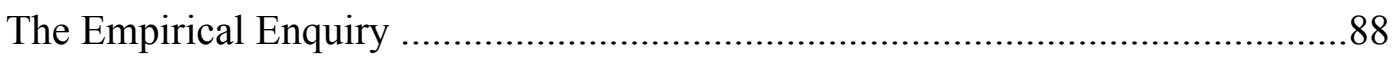

Chapter Four: Three Discourses, Two Phases, and One Moral Panic ................89

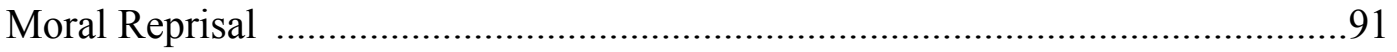

Not your average 12-year-old ...................................................................92

Feral children, the underclass, and South Auckland ........................................93

A lenient justice system ............................................................................96

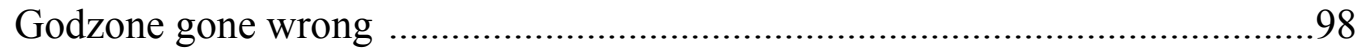




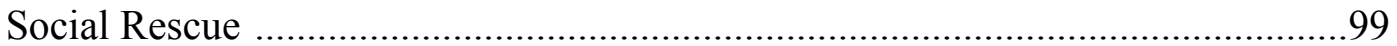

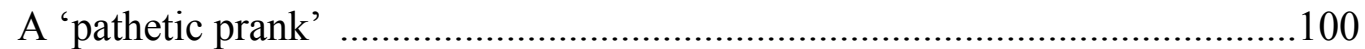

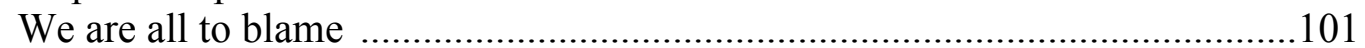

Education, intervention, rehabilitation: 'its not rocket science' .....................103

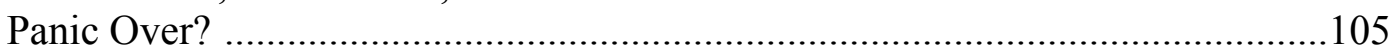

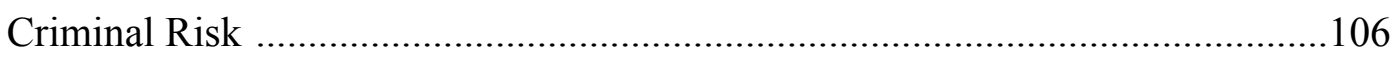

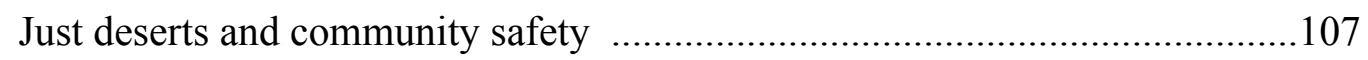

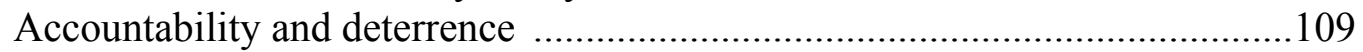

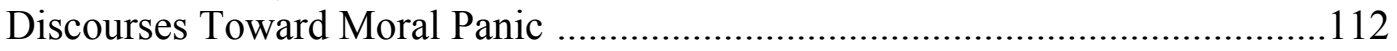

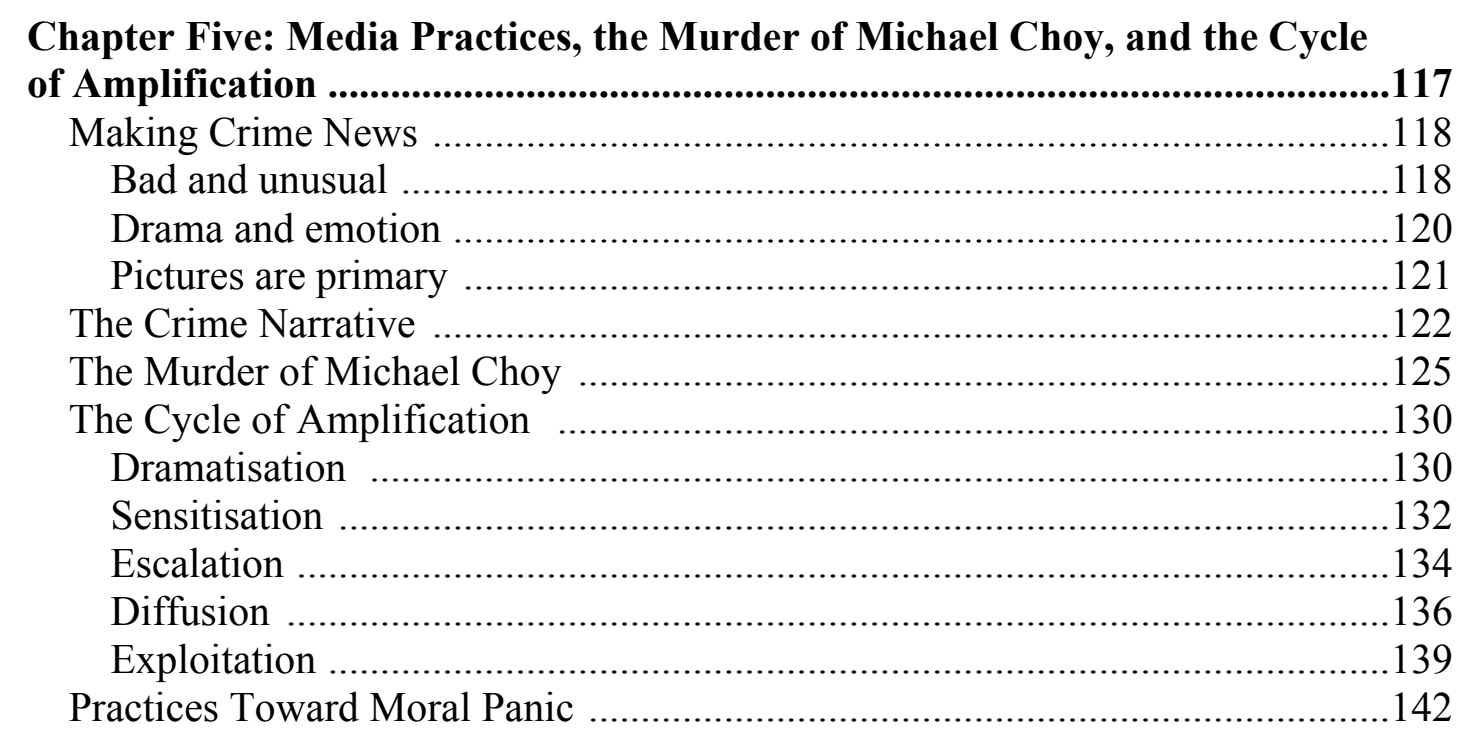

\section{Chapter Six: A 'Holy War', a Punitive Agenda, and the Spectacle of the}

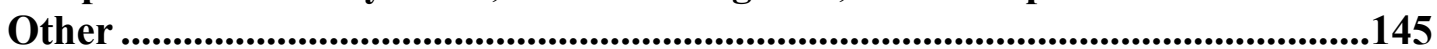

The demonization of Children: A 'Holy War' ...................................................146

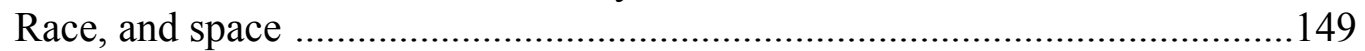

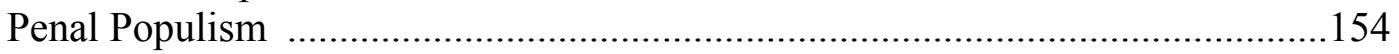

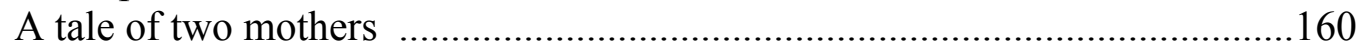

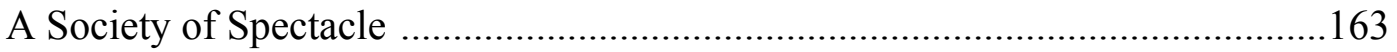

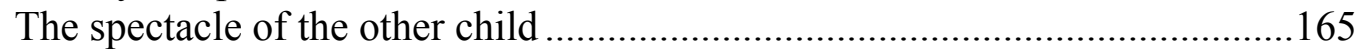

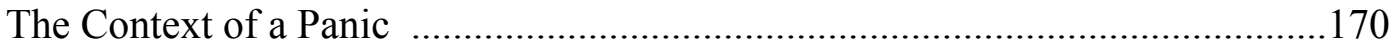

Chapter Seven: Killer Kids, Moral Panic, and the Economy of Excess ............170

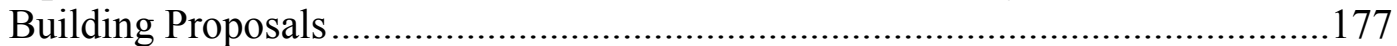

Describing, Interpreting, and Explaining the Case of 'Killer Kids' ...................178

Moral Panic as an Extreme Example of the Expenditure of Excess Energy .........182

Content, Process, Context: An Approach to Moral Panic .....................................189

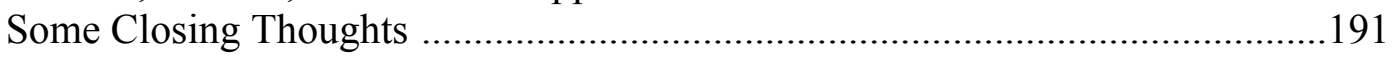

Appendix.........................................................................................................................195

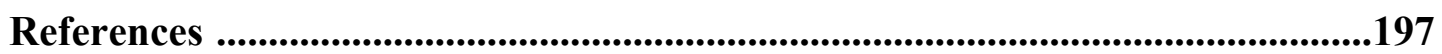




\section{List of Figures}

Figure 1.1. The front page of the Sunday Star Times August 25, 2002 ..................5

Figure 3.1. The dimensions of discourse and processes of discourse analysis for understanding a communicative event, adapted from Fairclough (1995b: 98) ..... 72

Figure 3.2. The dimensions of analysis for understanding a moral panic contextually and theoretically via the relationship between a real-type and an ideal-type .75

Figure 4.1. Apprehension rates of violent offenders by age groups 1998-2008.. 113 


\section{Introduction}

This dissertation is about the sociological concept of moral panic. Stanley Cohen (1972), who developed moral panic in relation to his analysis of the Mods and Rockers in 1960s Britain, defines the concept as follows: ${ }^{1}$

A condition, episode, person or group of persons emerges to become defined as a threat to societal values and interests; its nature is presented in a stylized and stereotypical fashion by the mass media; the moral barricades are manned by editors, bishops, politicians and other right-thinking people; socially accredited experts pronounce their diagnoses and solutions; ways of coping are evolved or (more often) resorted to; the condition then disappears, submerges or deteriorates and becomes more visible (Cohen, 1972: 1).

Reflecting the intellectual and political turbulence out of which it was forged, underpinning moral panic is the assumption of disproportionality; the idea that the social reaction it describes is all out of proportion to an empirical - or any rational sense of - reality. It is this that determines a reaction as a 'panic' and distinguishes it from other episodes of social concern. The facility to reveal the inconsistencies and injustices in how things become seen as troubling has since proved "deliciously alluring" (Goode \& Ben-Yehuda, forthcoming) and the past four decades has seen moral panic applied to everything from paedophile priests to Ecstasy, and from single mothers to terrorism (see Klocke \& Muschert, 2010; Miller \& Kitzinger, 1998). Indeed, the concept's academic success over this time has been described as "whopping" (Goode \& Ben-Yehuda, forthcoming; see also Innes, 2005; Garland, 2008). Ironically, this success has become something of a problem. Scholars sensitive to the complexities of these acute and volatile social reactions no longer agree upon its analytical parameters, while others have been accused of adopting casual analytical standards (Best, forthcoming). At the same time, the terminology has been adopted by media professionals and other laymen who are often quick to label all sorts of different forms and magnitudes of social reaction as 'just another moral panic' with which 'thinking types ought not to

\footnotetext{
${ }^{1}$ Cohen's (1972) Folk Devils and Moral Panics is often cited as the founding work on the phenomena. However, it was Jock Young (1971) who first used the term in The Drugtakers.
} 
bother" (Conway, 2010; see also Cohen, 2002; Hier, 2002a; Hunt, 1997; Jewkes, 2004; Thompson, 1998). Adding to this are two quite significant shifts upon the intellectual scene. Sociology has become preoccupied with Ulrick Beck's (1992) 'risk society', while the 'cultural turn' privileges the postmodern concern with representations alongside an appreciation of audiences as active critics able to see past the masquerades of sensationalist journalism. Moral panic, it is said, with its personified 'evildoers' and its notion of propaganda against a reference to a 'truth', has simply fallen out of fashion (Critcher, 2003). Yet the need to have at hand a concept that can deal with volatile social conflict has never been more essential. It is argued that with increased social plurality, the development of the public sphere and civil society and the decline of class alignments, the means and the space for contests over moral questions to flourish is unprecedented (Critcher, 2003, 2006; Thompson, 1998). Indeed, it is claimed that the contemporary era is "the age of moral panic" (Thompson, 1998: 1).

Anyone familiar with - or becoming familiar with - the panic literature will observe that most scholars will begin their work just as I have here, with Cohen's (1972) opening paragraph. The most recent accounts will follow this - again, as I have - with a brief discussion about the concept's phenomenal success and consequent loss of academic capital. There is often then a statement about how the author intends to contribute to the literature as either a panic defender or a critic. This thesis is about an episode of moral panic, and it is about the concept of panic and a way by which it can regain its former status as an interpretative idea. It is, thus, a defensive account. Finding myself captured by a case that demanded interpretation, and evaluating that moral panic remained the most appropriate way by which this interpretation could be got, the argument developed here is very much a product of an excursion through the vast terrain of panic literature, trying to work out how the concept could get the best out of my case study and vice versa; how my case could shed light on directions in which the concept might regain some authority. I anticipated that my study could also add some muchneeded girth to the small body of panic literature that is Aotearoa/New Zealand focused. There are few published studies of moral panic as they occur in the Aotearoa/New Zealand context despite the concept's popularity with graduate 
students as well as a plethora of episodes that fit the candidature for panic research (boy 'racers', problem dogs, teen drinkers, and 'tagging' to name a few). ${ }^{2}$ Additionally (and fortunately), my treks through the literature were happening at the same time as a project of 'rethinking moral panic' was gaining ground. Concerned, as I was, with salvaging the concept, this project offered me some footing in terms of how to organize the approach to my case study. It is this approach that forms the basis of my contribution to the study of moral panic.

Underpinning my approach are two proposals. These proposals are dependent upon imagining the study of moral panic simultaneously as two separate but interrelated studies: as a study of a real-type situated reaction and the study of an ideal-type transferable concept. It is my first proposal that the ways by which the internal processes of a real-type reaction of moral panic develop must be seen in relation to the context in which it is meaningful. To offer an example, it is a proposal that a panic about Ecstasy will develop differently to a panic about single mothers simply because the threat each poses to societal values and interests, the ways by which the moral boundaries are manned (together with the identities of the 'right-thinking people'), and the diagnoses and solutions pronounced will be fundamentally different. Of course, they may not be fundamentally different which would suggest much about the context/s they belonged to. It might also imply that the concept has an extraordinary authority insofar as its ideal-type formula captures absolutely how real-type cases unfold. Building upon this first proposal, my second proposal is that the relationship between the real-type panic and the conceptual model (the ideal-type) - and by extension a collation of relationships between real-types and the ideal-type - needs to be considered in detail. While both proposals acknowledge that the processes described in Folk Devils were intimate with their subject matter - the Mods and Rockers - this

\footnotetext{
${ }^{2}$ The published works include (in chronological order) Young and Kelsey's (1982) The Gangs: moral panic as social control, Shuker, Openshaw, and Soler's (1990) Youth, Media and Moral Panics in New Zealand: from hooligans to video nasties, Hill's (1998) Satan's Excellent Adventure in the Antipodes, and the less academically orientated but nevertheless sophisticated study of the localized version of the satanic ritual abuse scare A City Possessed by Lynley Hood (2001). Graduate student works include Griffiths (2005) Darkness, death and distortion: a sociological examination of moral panic theory and the Gothic subculture, Matthews (2001) Home Invasion: the role of the New Zealand media in a moral panic case study, and Wallace (2006) Menace or Moral Panic? Methamphetamine and the New Zealand press.
} 
second one also preserves Cohen's (1972) conjecture of the concept as transferable and not necessarily particular. However, it also extends the concept insofar as it asks how the context/s of real-types can inform an explanation of the ideal-type. It hypothesizes that moral panic might be something more than a descriptive sociological tool.

These proposals developed in relation to three variables; the case that captured my attention, the directions in which the project of rethinking moral panic were heading, and the methodological framework employed for making sense of this case in relation to those directions. The next section introduces the case as I encountered it. As my objective is to flesh out why the case demanded explanation, it will include only brief synopses for why the project of rethinking moral panic and the methodological framework would become important for how this study would move forward. These variables will be given due attention in chapters to follow.

\section{A Case of Moral Panic}

On August 25, 2002, a photograph of 13 year old Bailey Junior Kurariki, convicted of manslaughter for his part in a group incident which resulted in the death of pizza delivery man Michael Choy in September, 2001, graced two thirds of front page space of major national newspaper the Sunday Star Times. Unfortunately, I was unable to reproduce this image in this thesis, beyond examination. ${ }^{3}$ The Sunday Star Times, which shares copyright with the photographer, informed me that because it was taken inside a courtroom, they were unable to give me permission to use it. ${ }^{4}$ Taking a lead from Jones and Wardle (2008), who came across an identical embargo, I opted to have the image

\footnotetext{
${ }^{3}$ It is important to note that the Copyright Act (1994) allows such images and other like material to be used without permission for purposes of examination. Thus, the examiners of this thesis were able to view the photograph as it appeared, as I used the original for those copies. It can be seen, however, in the original article (see Wellwood, 2002) and others (see for example: "Welfare Blamed Over Young," 2002; “Teenage Criminal's Terrible Message," 2002). It also appears in another article that can be viewed online ("Kurariki's Release Puts Fear," 2008).

${ }^{4}$ I encountered a similar issue when sourcing film footage of the case from TVNZ, which I note in Chapter Three. Both the Sunday Star Times and TVNZ were unable to give me a firm explanation as to why. Nevertheless, it is significant that the media are able to continue using these images, which they have done repeatedly across the sample that I employ and beyond.
} 
digitally traced, and to supplement it with description, in order to demonstrate why the image was significant. In Figure 1.1. Bailey is the figure shown sitting at a table with his left arm resting on its corner edge.

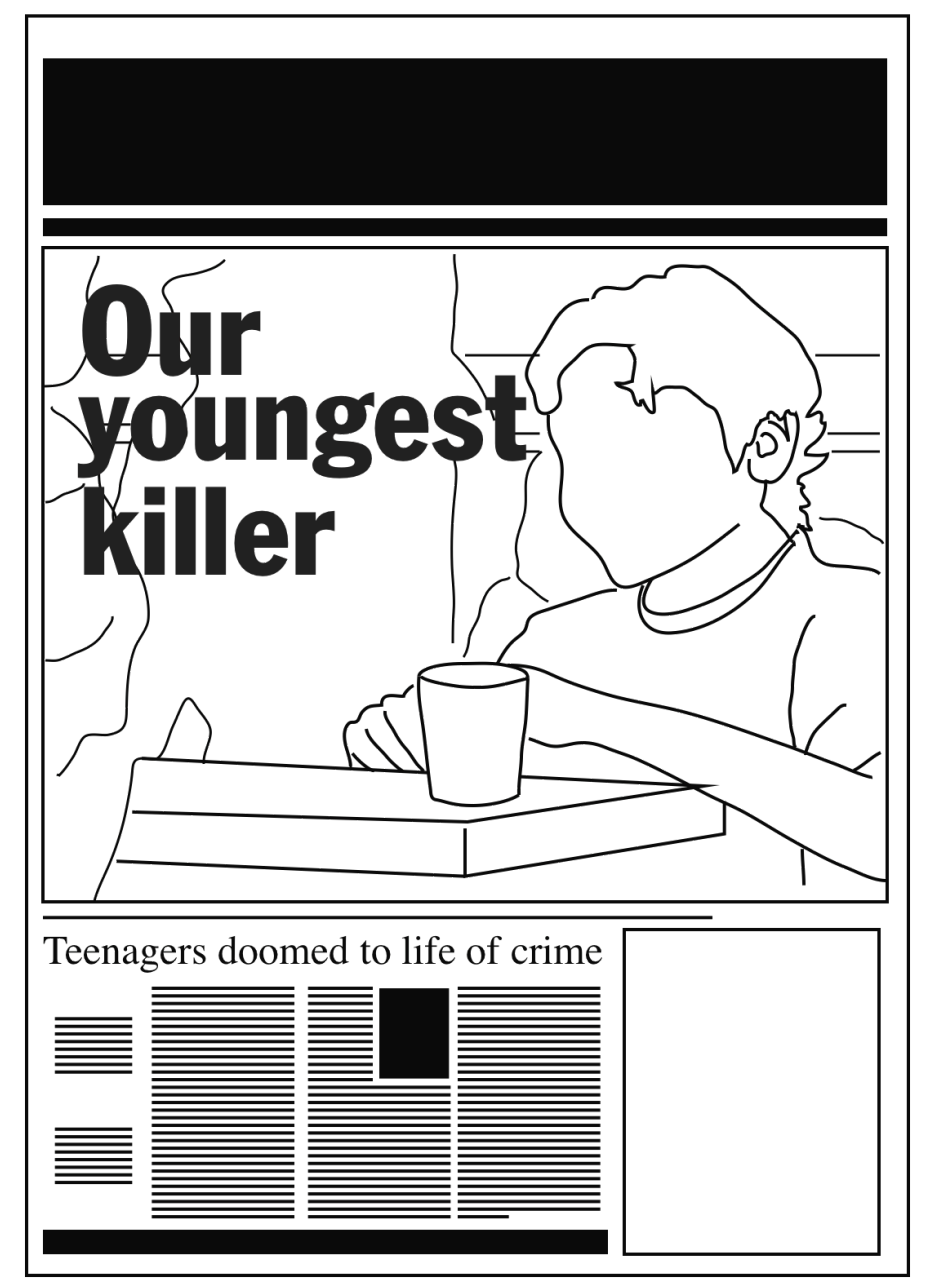

Figure 1.1. The front page of the Sunday Star Times, August 25, 2002.

Bailey is wearing a baby blue t-shirt and his hair is styled to the latest trend for young men. The table that he sits behind was plainly not made for someone his size as its edges reach his mid-chest area. Behind him is the figure of another person who is out of focus, but it is clear that his/her shoulders exceed the length of Bailey's. The shot, taken from his left, is at a 40-degree angle. Something has caught his attention ahead of him and he is smiling, either completely unaware of the photographer or not concerned to present himself to the camera in any particular manner. He is a beautiful child, with even features and smooth skin, and 
seems to be alertly curious, even just for that instance, at whatever it is that he is looking at.

As can be seen, situated within the image, adjacent to and parallel in size to Bailey's face, and in bold font, is the headline "Our youngest killer". The subheadline reads "At 9 he was shoplifting, by 10 he was banned from school, at 12 he helped kill a pizza delivery man", and beneath, the accompanying text continues "Youngest ... At 13 ... could barely see over the court bench ... one of six teenagers ... murderous plan ... he was the worst ... was out of control ... convicted killer ... was Kurariki who gave the command" (Wellwood, 2002).

This was the first print article after the trial, which convicted six teenagers in relation to Michael Choy's murder, and the first time this image appeared. For the most part, reports at the time of the incident and during the trial were intermittent and confined to facts in terms of how the event unfolded, what charges were laid, who was in attendance in court, and so on. However, already a feature of interest were the ages of the group involved, as this was often mentioned in opening paragraphs, particularly that of the as yet to be named Bailey Kurariki who was, at 12 years-old, the youngest person in Aotearoa/New Zealand to ever be accused of murder.

On appearance of Bailey's image in that first article however, coverage of the trial saturated the press. Moreover, attention emphasized Bailey's involvement despite that he had been one of six, and had played a relatively minor role. This marked a definitive shift in focus from pre/during trial reports in which it was clear a group were involved. Significantly, reports were repeatedly accompanied with images of Bailey, all of which accentuated, as did the above photograph, his childlike appearance.

Another prolific factor in post trial reports was an array of statements from significant public figures assigning those who could be held responsible, evaluating whether this was a result of nature or nurture, with many also offering dire predictions if something was not done now. Then Commissioner for Children 
Roger McClay called for an immediate inquiry into 'killer kids' claiming a definitive trend towards violent acts by young people, while both governmental and opposition politicians urged for investigations into the inadequacy of welfare organizations (particularly those under whose care Bailey was at the time of the event). ${ }^{5}$ Lobby groups such as the Sensible Sentencing Trust and other 'expert' individuals argued Aotearoa/New Zealand's rehabilitative approach to young offenders was a failed experiment and that this case only exemplified their previous claims for tougher sentencing. Editorials spoke of Kurariki's “angelic face" and how it was "an emblem of youth corrupted...(disguising a) terrible reality" ("Young and Bad," 2002), while claiming the country's mood as retributive in asking why it (the crime) happened. These agents were also prescriptive for how the 'problem' should be addressed ("Children Who kill: Don't Be Surprised," 2002).

The six responsible for Michael Choy's death were sentenced on September 16, 2002, each receiving what was later identified as 'adult sized' custodial terms. The two convicted for murder, for example, received 'life' terms whereas the youngest of the group, Bailey Kurariki - convicted of manslaughter - got seven years. At this point the initial furor towards the construction of a problem of murderous youth can be seen to wane, only to re-gather momentum and shift its focus towards the management of and prevention of the risky behaviours particular youths were susceptible to. Debates unto this would persist, intermittently, over the next four years, culminating with the development of the Young Offenders (serious crimes) Bill (which sought to reduce the age of criminal responsibility from 14 years to 12) put forth by New Zealand First Member of Parliament Ron Mark. This Bill would be debated periodically for the next two years but would be rejected by parliament as a law in May, 2008, just weeks after Bailey Kurariki was released from prison.

These paragraphs describe what I initially observed of the matter of 'killer kids'. As one development gave way to another I began to consider that there appeared

\footnotetext{
${ }^{5}$ It is from this call for an inquiry that I adopted the term 'killer kids' as a name for the case as a whole.
} 
to be a 'problem' emerging whose trajectory fulfilled the criteria for a moral panic. However, taking into account that the first point of departure for any moral panic analysis is the claim that this particular reaction is one that has been blown all out of proportion to an objective reality, I needed to first determine that such a decree could be made. This was not difficult, as the details of the murder case demonstrate.

On Wednesday, September 12, 2001, a group of youths at an address in Papakura, Auckland, ordered a pizza with the intention to rob the delivery person. When 40year-old Michael Choy arrived, he was greeted by two of the group pretending to be customers. One of these was the youngest of the group who reportedly indicated to one of the elder ones that the assault could commence. This elder boy with a baseball bat then hit Michael Choy on the head and the group stole the food and drinks and ran off. Although mortally wounded, Michael Choy was still able to walk. Another of the group walked him down the road towards his car and took from him his belt-bag containing money. Mr Choy, now alone, then appealed for help from one of the neighbouring properties, but was refused aid by the occupants. He then walked towards his home where he was found collapsed a short time later. He died in hospital at $6.25 \mathrm{pm}$ on the following day.

Over the next week, 15-year-old Alexander Peihopa, 17-year-old Whatarangi Rawiri, 15-year-old Riki Rapira, 16-year-old Phillip Kaukasi, 14-year-old Joe Kaukasi, and 12-year-old Bailey Kurariki were arrested, charged with murder, and remanded in custody until the trial the following July. Given the grave nature of what these youths had been accused of, this action can be fairly assumed as proportionate. However, attention to the case would be suspended until trial proceedings got under way in July, 2002. This was due to some remarkable timing on behalf of the events of the crime themselves. Taking account for world time zones, these events occurred on the same day as the attacks on the World Trade Centre in New York - September 11, 2001. Therefore, where ordinarily the significance of a murder by a group of youths would warrant a fair degree of local print and air space, our media were for the following weeks preoccupied, as were media globally, with events unfolding on the world stage. This would become 
significant for how the case would be subsequently interpreted. In particular, attention would be stirred toward the notion that 'killer kids' were on the rise by a bevy of such cases that would materialize during 2002, many of which were especially visible during the period July - September. ${ }^{6}$

The trial for the murder of Michael Choy concluded with the convictions of murder for Peihopa and Rawiri, and manslaughter for the others, on August 24, 2002. Three days later, 14-year-old Renee Kara O'Brien was sentenced for having struck 60-year-old Kenneth Pigott eight times with a hammer while he was sleeping in his car on March 10, 2002, killing him. She received 'life' (a minimum 10 year custodial sentence). The two friends that had been with her during the attack both pleaded guilty to manslaughter and were sentenced on August 26, and September 11, 2002 respectively. On May 8, 2002, 18 year-old Ese Junior Falealii set out to rob a Pakuranga pizza bar and shot attendant Marcus Doig in the back, ending his life. A week later on May 15, Falealii robbed the Mangere ASB bank and shot and killed a second victim - teller John Vaughan. Falealii pled guilty and was sentenced on July 19, 2002 to 17 years and 9 months; incidentally, the second longest non-parole period for murder handed down in Aotearoa/New Zealand to that date. On July 5, 2002, 17-year-old Daniel Luff detained his ex-girlfriend and her family in their home at gunpoint, which resulted in a shootout with police. Luff was sentenced to a minimum non-parole period of 17 years for the murder of Detective Constable Duncan Taylor, and the attempted murder of Detective Constable Jeanette Page on September 18, 2002, just two days after the sentencing for the Choy case. However, it would not end there. One day prior to the Choy case sentencing, 21 year-old Tanya Burr was stabbed to death by 16 year-old John Wharekura, who later pled guilty and was sentenced to 14 years.

Considering the nature of these cases; that is, as violent, often premeditated murders by young people, in addition to their relation to each other in terms of timing, it is not difficult to imagine that the Choy case would be understood as

\footnotetext{
${ }^{6}$ Chapter Five explores the ways in which the media construction of the events of the trial was significantly affected by such timing.
} 
part of a sharp escalation in youth crime. Indeed, one editor argued not long after the trial for the murder of Michael Choy that 2002 would be seen in Aotearoa/New Zealand's history as "the year of the child killer" ("Children Who Turn," 2002). It is also not hard to envisage why the youngest of these youths (both in the Choy murder itself and among the other crimes) would incite attention. Therefore, the reaction in this sense can also be evaluated as reasonably proportionate. However, that the identification of a social problem to which there would be a bevy of explanations and prescriptions materialized only after the appearance of the imagery of Bailey Kurariki and that the attention to the case itself would concentrate predominantly upon Bailey's involvement over and above that of his co-offenders, brought to light that the focus upon Bailey was becoming extreme. Later, as will be confirmed in this dissertation, as the predicted 'battalion' of murderous youths failed to appear, it could be argued that the reaction and its repercussions would also be out of order. Nevertheless, a perception that society was 'under siege' prevailed for another six years as the following passage reveals:

Armed with weapons and a devil-may-care attitude, rogue youths have terrified the public with a series of deadly attacks ... seven years on since the brutal murder of Michael Choy, New Zealand remains in the grip of teenage attackers (McDonald, 2008).

With Bailey, by this time, having earned himself an exaggerated sense of infamy:

Six others were involved ... Their names are largely forgotten but the baby-faced Kurariki became notorious (Cummings, 2008).

People have become convinced he was the murderer (Workman cited in Cummings, 2008).

My claim is that this episode demanded interpretation simply because this child was depicted as a killer in terms that went beyond what was appropriate for a measure of retribution. Moreover, he stood unwarrantedly alone in the ways by which the murder case was represented, and by which a social problem was constructed. Moreover still, this segregation had been initiated and was sustained 
with the use of a set of media images. My initial questions, therefore, related to the nature of this imagery and what role it served in the unfolding of a social problem. Not only did this appear a pertinent point of analysis for this case study (indeed it was an almost natural selection of what to focus on, given the shift of focus to Bailey upon the imagery's appearance), but there is an increased emphasis among scholars across the spectrum of social and cultural analysis upon the significance of images in the construction of social life (for some excellent examples, see Biber, 2007; Holland, 2004; Jones \& Wardle, 2008; Wardle, 2007; Young, 1996). Moreover, it seems that nowhere is this more essential than in the analysis of media images of crime:

... today the visual constitutes perhaps the central medium through which the meanings and emotions of crime are captured and conveyed to audiences. Indeed, we would suggest that it is the visual that increasingly shapes our engagement with and understanding of, key issues of crime, control, and social order (Greer, Ferrell \& Jewkes, 2007: 5).

However, there was no simple means by which I could 'add in' the analysis of the image given the expanding body of work that sought to deal with what Featherstone (1991) terms the aestheticization of everyday life (see also Debord, 1977; Evans \& Hall, 1999; Lister \& Wells, 2001; Matheison, 1997; Poster, 2002, Young, 1996). In addition, our 'readings' have become more complex as we incorporate the insights of cultural studies and psychoanalysis, feminism and post colonialism; all of which place emphasis on the 'gaze' in the social practices of observation, surveillance, and visual pleasure. Yet, as Walter Mitchell (1994: 13) argues, "we still do not know exactly what pictures are, what their relationship to language is, how they operate on observers and the world, how their history is to be understood, and what is to be done with or about them."

Nevertheless, my observation that pictures had sparked a moral panic required explanation. To begin with there were some central questions to be asked of this initiation. How and why could the imagery of Bailey Kurariki prove so commanding? Was the unit of the imagery important: the photograph? Or was it what it depicted: a criminal child, a brown child? Would the imagery continue to 
be commanding throughout the panic sequence? How would its role in the sequence bear upon the processes of the ideal-type as described by Cohen (1972)? What was happening in the socio-political environment at this time that could shed light on these questions?

A review of the contemporary moral panic literature brought new requirements; how could these initial questions inform, and be informed by, the ways in which the project of 'rethinking moral panic' was developing? It became clear that moral panic was undergoing review to see how it might be connected to developments within social theory. This was an imperative exercise insofar as the analytical concept appeared to have had lost authority at the very same time that real-type cases were on the rise. At the heart of this project of rethinking moral panic was (and is) an impetus to find the answer to a 'bigger question' that has to date eluded panic analyses. That question, as Critcher (2008: 1139) aptly puts it, is "what, if anything, are moral panics extreme examples of?" It is a question concerned with contextualizing the processes of the ideal-type concept in order to provide an explanation for moral panics as they are witnessed in real social situations. The ultimate aim, it seems, is to theorize the concept. However, I contend that this exercise is premature insofar as understandings often focus upon the operation of the internal processes of panic in their approaches for why a said panic emerges, in addition to varying degrees of acknowledgment of the bearing of real-type episodes upon these processes. My objective was to demonstrate how context matters, and how the interpretative processes of panic must be relevant to empirical realities. I propose that these are the first crucial steps toward a theoretical understanding of the analytical concept.

The next task was methodological; in what way could I address the questions developed so far? Taking heed of the concerns of contemporary moral panic scholars to incorporate discourse analysis within the research agenda, I drew upon the three-tiered model of Critical Discourse Analysis (CDA) formulated by 
Norman Fairclough (1995b). ${ }^{7}$ For Fairclough (1995b), any communicative or discursive event is made up of three parts that are interconnected but analytically separable. A discursive event is first written or spoken text. It is second an instance of discourse practice - the production and interpretation of text. Third, it is a piece of social practice. What this means is that any discursive event can be seen as both socially shaped and as socially shaping. Correspondingly, for Fairclough (1995b) there is a three-part approach for analysis - description, interpretation, and explanation. Further, importantly, Fairclough (1995b) contends that the analysis of a discursive event be examined alongside an analysis of its relation to its 'order of discourse'. This is an abstract way of describing particular configurations of discourses that can be identified as belonging to a particular social space or subject to a particular organizational logic (Chouliaraki \& Fairclough, 1999). An order of discourse can be affected by the discursive event, and the discursive event can affect its order.

I imagined the case study of 'killer kids' (my real-type panic) as a discursive event (as an instance of text, discourse practice, and socio-cultural practice). I then imagined the concept of moral panic, in its ideal-type form, as an 'order of discourse'. In this way I could examine how the context of the episode was important to how it materialized and examine the relationship between this realtype case of moral panic and the ideal-type concept. I could also address each component concurrently by working my analysis across the three aspects of the communicative event in a revised framework that encompasses the study of the 'order of discourse': content (to explore the material features of a panic), process (to look at the practices that gave rise to these material features in relation to the practices of the conceptual model), and context (to examine the environmental factors upon which this relationship between material features and practices rely and the conjectural space in which we might locate the concept). ${ }^{8}$

\footnotetext{
${ }^{7}$ My choice here is not accidental. The critical element of CDA addressed my concern to retain the deconstructive - normative - element of moral panic. The debate about the role of normativity in contemporary panic analyses is discussed in Chapter One.

${ }^{8}$ This framework and the methods it informed are discussed in more detail in Chapter Three.
} 
This approach to moral panic allowed for some interesting findings. This was a material episode that spanned three discourses and two phases. Its drama was as dependent upon a sequence of judicial decisions specific to the trial as it was upon routine media story making. It exposed that active in Aotearoa/New Zealand's socio-political environment across the period of 2002-2008 was an operation against particular children, an expanding punitive agenda, and a spectacle in which the 'other' was subject to a racialised regime of representation. Moreover, despite my anticipation that the material features would impose themselves upon the conceptual model, obliging modification, the challenge by this real-type moral panic to the processes of the ideal-type would be subtle. More significant was how removed from any impending content these processes were revealed to be; how descriptive they remain. Nevertheless, my proposal that panics need to be situated and that context matters in thinking about how the ideal-type can be explained would be validated. Through locating 'killer kids' within its context I was able to conjecture that what moral panic might be an extreme example of is something far more existentially confronting than the project of rethinking panic has thus far imagined.

\section{Chapter Outline}

The thesis is comprised of seven chapters, designed to be read in clusters. Chapter One conducts a close examination of the concept of moral panic as it was developed through the foundational works of Cohen (1972, 2002), Hall, Critcher, Jefferson, Clarke, and Roberts (1978), and Goode and Ben-Yehuda (1994a, b). The second part of this chapter seeks to understand some of the ways by which the concept has been marginalized through exploring in detail some of the substantial (and a few less developed) critiques. In the main, the objective of this first chapter is to get to know moral panic and to construct the platform upon which the contemporary scholarly project of 'rethinking moral panic' would grasp a foothold. Chapter Two examines the development of this project of 'rethinking moral panic'. The aim is to position the proposals of this study in relation to the work of four scholars; Sheldon Ungar (2001), Chas Critcher (2003, 2008, 2009), Sean Hier (2002a, 2003, 2008), and Amanda Rohloff (2008, 2010). At this point I 
also introduce an idea emerging from recent scholarship in the sociology of punishment, reflecting upon how this idea has come about through consideration of the context of late-modernity and thereupon how it might be useful for reimagining the study of panic. Chapter Three spells out the methodology for the study. It revises the proposals forged in Chapters One and Two and introduces a framework inspired by CDA with which to address these. It examines how this framework informed the methods with which the study was carried out. It also gives the details of, and justification for, the sample used and the sources employed.

The next three chapters cover the empirical part of this dissertation. In these chapters the phenomenon of 'killer kids' is imagined as a 'discursive event' within the critical discourse analysis paradigm. As I proceed, I show how this 'event' can be considered in relation to the ideal-type processes of the concept of moral panic; how, despite its unique beginning and its inimitable trajectory, it offered very little of a challenge to the concept's interpretative parameters. Chapter Four examines the content of the episode; the ways in which the narratives of 'killer kids' developed in relation to the trial for the murder of Michael Choy and its interpretations in the media across the sample period. Chapter Five moves behind this picture to examine the practices and identities involved in the episode's construction. First, it interprets the case against an examination of the criteria by which media professionals choose events for news and the practices by which they subsequently transform these events into stories. Second, it examines what was and who were at work in energizing the momentum required to build the media story into a sense of social crisis that would extend from an acute reactive phase into a lengthy period of constancy. Chapter Six is concerned with the social context in which the narratives, practices, and identities of 'killer kids' belonged. Working with a set of cues from the previous chapter, three social phenomena are identified to have particular bearing upon why this episode materialized in the way in which it did. The chapter concludes with some disclosures about the ways by which Bailey Kurariki continues to be demonized beyond the boundaries of an observable moral panic and questions what this 
might mean for understanding the ideal-type concept as an 'extreme example' of something.

Chapter Seven concludes the study with a review of the empirical findings, a suggestion of what moral panic might be an acute example of, and a reflection upon why the approach employed for this study was significant. 


\title{
Chapter One
}

\author{
Moral Panic \\ ... moral panics are condensed political struggles to control the means of cultural \\ reproduction. Studying them is easy and a lot of fun. It also allows us to identify and \\ conceptualise the lines of power in any society, the ways in which we are \\ manipulated into taking some things too seriously and other things not enough \\ (Cohen, 2002: xxxv).
}

This chapter will explore the development and evolution of the sociological concept of moral panic though the foundational works of Cohen (1972), Hall et al. (1978), and Goode and Ben-Yehuda (1994). It will be seen how the concept was initiated as an unintentional 'interactionist' episode, interpreted as a strategy employed to orchestrate hegemony and divert attention from a capitalist crisis, and subsequently moved into a collective behaviour framework whereupon the focus moved to the role of claims-makers in defining, amplifying, and diffusing a social problem. The chapter will then discuss and evaluate an assortment of critiques that have been directed at the concept in the course of its movements over the intellectual terrain; namely, the notion that moral panic is a polemic rather than an analytical concept, that it lacks an appreciation for the plurality of reactions that can accompany moral assertions, and that it neither accounts appropriately for how the public respond nor how an engagement with that public can be achieved. At the end of the discussion, I explore how the idea of moral panic rests upon an assumption that it functions to alleviate social uncertainty by marking the moral boundaries of the particular society in which it materialises and why this has become problematic.

In the introduction for this dissertation I argued that my proposals for the study of killer kids developed in relation to three variables: the case under analysis, the directions in which the project of 'rethinking panic' were heading, and the methodology employed for making sense of this case in relation to those directions. The objective of this chapter is to become acquainted with the moral panic concept and appreciate its relevancy for the study of 'killer kids' but also to 
learn why and from what bedrock the contemporary project of 'rethinking moral panic' has developed. ${ }^{9}$ Concluding this chapter, I examine how the development of the concept, along with the critiques, has an initial bearing upon my approach to 'killer kids' and my proposals for panic study. A full 'thesis statement' is formulated at the end of Chapter Two, and stated again in Chapter Three as I explain how the Critical Discourse Analysis framework enables my proposals to be put into action.

\section{Folk Devils and Moral Panics}

A scuffle between a few groups of youths in Clacton at Easter in 1964 prompted spiralling over-heated concern about what came to be seen as a series of episodes of vandalism and mob violence by two adolescent factions identified as the Mods and the Rockers. The media sensationally over-reported these episodes, the police increased their vigilance and over-zealously employed crowd control tactics, and local people urged that something legislative be done, while it was rumoured that vigilante squads were formed by tradesmen seeking to protect their property. Further, local members of parliament issued statements of probable solutions, editors articulated their opinions, interest groups pushed for policy statements to be formalised, and the courts sought to 'clamp down' upon these volatile disturbances.

For PhD student Stanley Cohen (1972), this episode demanded interpretation and it would become the subject of his dissertation; later to be developed into his seminal text Folk Devils and Moral Panics. Informed by the 'transactional' or 'interactionist' approach to deviant behaviour (see Becker, 1963; Lemert, 1951), his analysis developed in relation to an emphasis on the set of reactions to the Mods and Rockers; how were they identified, labelled, controlled? Why did the reaction take particular forms? What were the myths, stereotypes, and methods of control that erupted from the interaction between the deviants and society?

\footnotetext{
${ }^{9}$ This project is the focus of discussion in Chapter Two.
} 
The structure of his explanatory framework is justified firstly, through understanding how information is received about the behaviour in question; second-hand, via the media. This link between the media and the creation of folk devils; how the nature of information increased both the scale of deviance and the degree of societal reaction toward it was usefully made with Wilkins' (1964) 'deviance amplification cycle'. Still, the 'panic' became more than an ordinary case of deviance amplification (initial event, societal reaction, increase in deviance, increase in reaction and so on), particularly as the key processes of the media (exaggeration, distortion, prediction, symbolization) tended to have an amplification effect independent of actual events.

Cohen (1972) visualised the process as a flow of initial deviance (the event in Clacton) that led to an inventory phase of interpretation whereupon the seriousness of the event and subsequent episodes were exaggerated. Thereupon, the public, the police, and the press were sensitised to reinterpret neutral or ambiguous stimuli as potentially or actually deviant. As these latter features fed back on each other there was an over-estimation of the deviance, which then led to an escalation of control towards it, in turn heightening awareness of the potential threat. In other words, a moral panic could be conceptualised as a reaction to a condition, person or group of persons that is or who are defined as a threat that is out of proportion to any actual threat it or they may pose.

While Cohen (1972) identified that there were many actors in the drama he was at particular pains to emphasise the role of the media and much of his analysis is devoted to understanding this role. From the beginning, Cohen (1972) contends the media reinforced the sense of expectancy and gave shape to the rumours and ambiguous situations; it served to frame the picture of what was happening and what was to happen. But it went beyond publicity per se; by reporting such events and rumours the media triggered off events of a similar order through lowering the threshold of 'readiness' for the potential Mod or Rocker, and offering him/her the symbols and stage directions with which and upon which he/she was to perform. It is this mobilisation of action (either as the deviant or as the reactor to 
the deviant) that Cohen (1972) argues cannot do without an adequate means of communication such as the mass media.

Folk Devils is often called to account for its emphasis upon the 'what' and the 'how' of moral panic at the expense of addressing the 'why' (see Jefferson, 2008; Shuker et al., 1990), something that Cohen (2002) himself acknowledges. But the 'why' was attended to in the study, albeit briefly. Cohen (1972) interpreted the clashes on the beaches as a response to an emerging consumption culture characterised by high wages, a commercial youth movement, and an elevation of wild pop heroes (such as the Rolling Stones and The Who) into national idols. The newly affluent teenagers (the Mods) could revel in this emerging scene, but for working class teens (the Rockers) there were still structural barriers to participation. These teens would rebel against their situation and create their own excitement on the beaches, where their rivals would join them. Cohen (1972) located the response to these clashes (the ensuing moral panic) as a retort to the permissive post-war society that had allowed for this consumer culture (and its differential access) to develop.

While Cohen's (1972) moral panic is understood largely as an unintended and unanticipated construction, Hall et al. (1978) argue that moral panic can be a strategy employed by elites to orchestrate hegemony and divert attention from a systemic (capitalist) crisis. It is this analysis that I consider now.

\section{Policing the Crisis}

A brutal robbery of an Irishman by a group of black youths in Handsworth, England in 1972, initiated a resounding press, judicial and public response about a 'frightening new strain' of crime known only to date in America - mugging. This was despite that the event, though horrific, was neither new in its character nor particularly unusual. Nevertheless, the response would evolve into a notion that the British 'way of life' was at threat and install a perception that the weak liberalist position that Britain had taken on law and order issues in the post-war period was to blame. In turn, this would justify a series of severe control measures 
that were directed at black inner city youth who were seen to be responsible for the wholesale denigration of the moral fabric.

Sceptical about the speed in which the idea of mugging took hold, and about the rearticulation of old forms of street crime under this new and imported label, Hall et al. (1978) interrogated first the relationships between the media and the 'control culture'. ${ }^{10}$ They found that the media turn to 'accredited experts' in order to maintain the news values of 'impartiality' and 'objectivity' and these experts, in turn, become primary definers whose framing of events becomes the most significant in terms of how they are subsequently understood. Hall et al. (1978) also saw that the media became secondary definers as they transformed these primary definitions into everyday language. Part of this transformation involved adopting the public voice; claiming to speak for the public. This would then justify further assertions on behalf of primary definers who would call upon this voice as evidence that such assertions were required (or desired), and these assertions would then be used to support additional secondary interpretations. In other words, the amplification cycle that would create an ideological closure around the issue of mugging would be set in motion by virtue of routine news practices and the structural reciprocal relations between the media and their institutional sources (see Jefferson, 2008).

Second, in order to understand the role the folk devil (the mugger) would play in the panic, Hall et al. (1978) examined what was happening in the wider sociopolitical environment at that time. Drawing from Gramsci, they conjectured that the early 1970s was a time where hegemony - consent to authority - was in crisis. This was due, in large, to economic recession. They concluded that the specific concern about mugging would operate to re-direct social anxieties away from the real issue to one about 'law and order'. Put another way, in order for dominant interests to remain dominant, the periodic failure in capitalism needed to be shielded from popular view, and this was achieved by 'whipping up' an issue as a problem that could be held responsible for the deprecation of a respectable work

\footnotetext{
10 'Control culture' is a term borrowed by Cohen (1972) from Lemert (1951) and it refers to the police, the courts, welfare organizations and the like; those institutional bodies responsible for the regulation and control of deviant behaviour.
} 
ethic (which was related to a decline in jobs) at the same time as it would unite the lower and middle classes. This issue would be race.

Effectively, Policing the Crisis reworked the understanding of power in a moral panic insofar as official reaction was seen as not just 'reactive'; it was "part of the circle out of which 'moral panics' develop" (Hall et al., 1978: 52). Accordingly, Hall et al. (1978) defined (or redefined) moral panic as an ideological event in which a specific and historical crisis is developed and managed. This has had some implications for how Policing the Crisis has been received which I will consider in a moment. For now, I want to turn my attention to moral panic as it has been conceived in the American context through the scholarship of Eric Goode and Nachman Ben-Yehuda (1994).

\section{The Social Construction of Deviance}

Goode and Ben-Yehuda (1994a, b) situated the trajectory of moral panic within a collective behaviour framework, defining it as irrational or "a kind of fever...characterised by heightened emotion, fear, dread, anxiety, hostility and a strong sense of righteousness" (1994a: 31), and therefore a particular form of constructed issue. Like Cohen (1972) there is a concern for the processes of definition, but there is astutely more of a focus on organised interests and the role of claims-makers, their alliances, and the ways in which they seek to gain public attention (and support). In part this shift in emphasis was a response to a perceived lack of clarification on Cohen's (1972) behalf and especially for application in the United States. Here, the media in particular are seen to be less centralized and tend to rely less on sensationalist journalism than does the British counterpart (Critcher, 2003: Victor, 1998) and so the processes whereby a local event transforms into a general problem depends more upon the rhetorical activities of interested parties and their access to the appropriate channels. For Goode and Ben-Yehuda (1994a, b) what distinguishes a panic from general social problems and specific moral crusades can be determined through the 
identification of five 'criteria'. ${ }^{11}$ First, there must be a heightened concern over behaviour of a group and the consequences this behaviour poses for wider society. We can measure the manifestation of this concern through opinion polls, proposed legislation, interest group calls for action to be taken, social movement activity, and by public commentary by way of media attention (Goode \& Ben-Yehuda, 1994b: 156-157). Second, a dichotomisation occurs between 'them', the folk devils, and 'us', the responsible and law-abiding citizens. Their behaviour are seen to be threatening to the values, interests, and possibly the very existence of society as 'we' know it, and so there is hostility towards this designated enemy. Often this involves identifying the deviant in terms of a stereotype (the Mod or the Rocker and his style of dress and demeanour; the 'mugger' and his ethnicity and/or class position). Third, there must be a consensus within society, or at least considerable segments of it, that the threat proposed is very real and serious. Further, Goode and Ben-Yehuda (1994b: 158) are explicit about the implicit assumption in the term 'moral panic' of disproportionality. That is, that the threat, costs, and figures proposed by claims-makers are wildly exaggerated and do not coincide with an objective reality. Finally, moral panics are volatile. They typically explode, reach a pitch, and then subside just as suddenly. Some panics leave no impact on the legal, moral, and social fabric, while others become institutionalised as organisations are established to deal with the 'problem'. Even so, Goode and Ben-Yehuda (1994b: 169) argue that all panics leave informal normative traces which in effect prepare us for later panics and that this connectivity may be seen early on in that it was the Mods and Rockers who paved the way for the later scare over youth delinquency; mugging.

Goode and Ben-Yehuda (1994a, b) further recognised that panics could be usefully categorised in terms of three distinct models that are differentiated by dimensions of motive and responsibility. The first model; the grassroots panic, suggests that while concern may manifest within other sectors such as the media

\footnotetext{
${ }^{11}$ Social problems are void of the folk devils upon whom the anxiety of the public is projected and lack the characteristic 'fever' of a panic. Moral crusades, on the other hand, are mobilised by specific moral entrepreneurs who adopt an issue to further their own interests. A panic may result from a crusade, but in the main, a panic will have a variety of interested parties, and either advertently or inadvertently will appeal to a wider and more diverse constituency (see Goode \& Ben-Yehuda, 1994; Critcher, 2003).
} 
or among political bodies, it is the deeply felt attitudes and sentiments of a broad area of lay society that appear threatened. The second model; the interest group panic, asks whether the cause is ideological or moral or to do with advancing a material or status position of a group, although invariably there is a "happy coincidence" (Thompson, 1998: 9) of both principle and interest. The latter model; the elite engineered panic, is employed most often to avoid a genuine solution to a real problem whose presentation would undermine elite interests. ${ }^{12}$ Although we might position Cohen's (1972) case study as an interest group panic and Hall et al.'s (1978) analysis of mugging as a classic example of an elite engineered one, all three are to be seen as 'ideal types' that when applied will illustrate different aspects of a panic. Goode and Ben-Yehuda (1994a) suggest further that no panic is explicable by means of a single model; the grassroots model in particular is a naïve one in isolation in that it cannot take account of how raw concerns are intensified and mobilised.

Reflections upon the foundations which these three works have constructed view that within the 'one' original project of moral panic there are two broad formulations, each with different strengths and weaknesses. Thompson (1998) argues that what we may call the American tradition (Best, 1990, 2001; Goode \& Ben-Yehuda, 1994a, b; Jenkins, 1992, 1998, 1999), because it favours analysis through the interest group model, tends to lose the 'cutting edge' as it rejects the more radical concern to disclose social control processes and ideological conflict in favour of a focus on the work of claims-makers. There is at the same time a lack of recognition of the media both as a powerful and independent claimsmaker, and as the primary institutional vehicle for the dispersing of claims (Jenkins, 1992 for example, makes an outright denial that the media can create a panic), although this oversight may be dependent, as Critcher (2003) suggests, on the differences in the structure and nature of the press between the two countries. The British tradition (Cohen, 1972; Hall et al., 1978) on the other hand, insists on

\footnotetext{
${ }^{12}$ Alternatively, those in positions of power may 'wag the dog' or seize the opportunity to direct anxieties. Burns and Crawford (1999) argue the Columbine shootings allowed Bill Clinton to divert attention from the Whitewater investigation and his own sexual misconducts, whereas in response to the Bulger murder Tony Blair is said to have "employed a dead toddler to shift Labour to a hard line on law and order" (Cohen, cited in Jewkes, 2004: 72).
} 
the divide between what is real and what is mediated at the expense of analysis of representations in their own right. Thompson (1998) would call for a fusion of the two into one explanatory framework; one that would sever the hold of theoretical ethnocentrism in centralising the common ground but also employ crucial insights of both. Critcher (2003) however, remains firm that they are distinct; one argues of processes at work (the British tradition) while the other argues for attributes that can be identified. Correspondingly, he argues that we extend the employment of 'ideal types' and term the first a processual model of moral panic, and the second an attributional model of moral panic.

In the next sections I consider the ways by which the concept (in both its processual and attributional formulations) has been subject to a range of criticisms since its initiation; from the criterion of disproportionality as reliant on normative assessments to questions regarding the applicability of the 'original project' within the political, cultural, and social environment as it stands differentiated in relation to the analyses of 1960 s and 1970s. I turn the discussion to these critiques now.

\title{
A Normative Concept?
}

\author{
People may panic in a fire, but this does not imply that the building is not burning \\ nor that there is no threat (Waddington, 1986: 258).
}

The notion that moral panic is a polemic rather than an analytical concept has become something of an Achilles heel for panic research (see Rohloff \& Wright, 2010). The critique is most fervently directed at Hall et al.'s (1978) consideration of moral panic as an envoy for dominant ideology, as it is seen as far more an exercise of neo-Marxist scholarship than it is a contribution to the sociology of deviance (see Jones, 1997; McRobbie \& Thornton, 1995). ${ }^{13}$ However, panic studies across the board are similarly assessed. Hunt (forthcoming) for example, contends that the panic analyst is suggesting that the claims made by panic participants are irrational; that the claimants are at best 'misguided' and at worst

\footnotetext{
${ }^{13}$ Jefferson (2008) suggests this is an unfair assessment insofar as the mugging account worked with a commitment to grounded theorizing and was critical of a reductive Marxism.
} 
'crazy' (see also Garland, 2008). Indeed there may be overtones of this in research dealing with more extreme panics (the satanic ritual abuse one is a case in point) or where claims are made on behalf of moral entrepreneurs or other parties who exploit an issue for their own political or economic advancement (see Best, 2008; Goode \& Ben-Yehuda, 1994b). However, Critcher (2006: 3), a panic defender, also claims:

The moral panic classification does not imply rational appraisal, considered reaction or appropriate remedies. As the words connote, what we are contemplating is a state of panic where emotion rules over reason.

My own reading of the irrationality of panic is that it is the overall reaction (the claims and responses inflamed and augmented via a cycle of amplification) that is assessed as 'out of order' rather than the individual actions of people based upon what they know or feel (see Best, forthcoming; de Young, 2004). The issue then becomes about the measure of proportionality against which the reaction in question is argued to be in excess of. As Cohen (2002) argues, it is difficult to measure emotion, symbolism, and representation in quantitative terms. Indeed, it is only with a prior commitment to externally erected goals of social justice, human rights, or equality can we expect to make a evaluation that $\mathrm{R}$ (the reaction) is an inappropriate response to A (the action) (Cohen, 2002). However, for Cohen (2002) this does not mean that we need dismiss the idea and enter an arena where our claims are not accorded privilege; questions of proportion can be made empirically even when the evaluation is of, say, the rhetorical means of problem construction (see also Best, 2008).

However, furthering the reception of moral panic as polemic was Cohen's (1972) intention to expose reactions that were not just out of proportion by a qualitative measure but tendentious (slanted in a particular ideological direction) and misplaced (aimed at something which was not the 'real' problem). This has lent to the empirical task a tradition of exposing the (irrational) moral outrage as something on behalf of 'the right' end of the political spectrum which in turn positions the analyst firmly on the 'left-bank'. Garland (2008: 22) observes: "one reads of very few instances of 'moral panic' analysis being applied to episodes 
where the underlying moral concern appears to be shared by the sociologists who invoked the term". Yet, as McRobbie (1994b) points out, whipping up a moral panic is an effective way by which conservatives secure support; it is their chief 'campaigning arm'. Critcher (2006) too, identifies that issues over the moral state enable the 'right' to distinguish itself, particularly if the left can be seem to have adopted similar policies (economic policies especially).

Other critics argue that often an issue's candidacy for a moral panic can be regarded as trivial, especially when more significant and damaging events that could and perhaps should command social apprehension exist (see Jenkins, 2009; Jewkes, 2004). Cohen (2002: xxii) responds that this is exactly why interpretations of deviance need to be studied; how it is we are apathetic and indifferent to torture, political massacres, and social suffering in distant places while exuding relative hysteria over such things as video 'nasties' and alcopops. Perhaps instead of exposing these 'bad' panics, Cohen (2002) argues, we might encourage the same inflammatory processes towards 'good' panics whereby we can then "overcome the barriers of denial, passivity and indifference that prevent a full acknowledgment of human suffering" (Cohen, 2002: xxxiii). However, it is clear that in such cases the terminology of 'panic' would need to be abandoned. As Garland (2008) notes, the reaction to the events of September 11, 2001 clearly fit all the criteria for a moral panic (at least in the attributional sense). Yet there appears to be a marked reluctance to identify this reaction as a panic. Jenkins (2009: 2) puts it well: "whoever heard of a legitimate panic, or of well founded hysteria"? (original emphasis). Constructing a social problem that should be a social problem would also negate the disproportional element of 'panic', and a 'good' panic would dissolve the function of deviancy in terms of reconstructing moral boundaries (see Durkheim, 1984; Cohen, 1972; Erikson, 1966).

It does seem inevitable that in employing 'moral panic' to understand a social reaction one will be accused of undertaking positioned research, and, if not dismissed for labelling reactors as 'delusional', then certainly scrutinised for the appraisal of proportionality. Best (1993), with sympathy for the panic analyst, suggests that the accusation (and scrutiny) is better directed at the enterprise of 
sociology itself and its promise to 'improve' the world once we have deconstructed and understood it. Cohen (2002) suggests that though panic's 'folk meaning' subscribes to a concept designed to expose dominant interests, there may be a continuum along which we view the relationship between moral panics and political ideology; from the abstract analytical to the invested critical (see also Rohloff \& Wright, 2010). In Chapter Two I explore how studies involved in the project of 'rethinking moral panic' tend to focus on the analytic end of such a spectrum and later, how my own approach to the case of 'killer kids' may offer a way by which panic research can be received as both a political endeavour and an analytical study. I want to now turn the discussion to an argument that normativity aside, the concept of moral panic as it was developed in the 1960s and 1970s has limited value for research in a contemporary context.

\section{Folk Devils 'Fight Back'}

Moral panics are totalitarian products of democratic systems (Critcher, 2006: 14).

One of the more astute criticisms of each of the proposed ideal-type models of the moral panic concept is that they lack an appreciation for the plurality of reactions that can accompany moral assertions. McRobbie (1994a, 1994b), in particular, contends that the expansion of 'new moral minorities'; pressure groups, associations, voluntary organisations, and other grassroots political bodies serves to give folk devils both the vehicles and the support networks through which they can 'fight back'. She notes the panicking that took place at the heart of the conservative government in Britain following the murder of toddler James Bulger by two ten year-olds in Britain in 1993 which saw a launch of a vicious attack upon single mothers. ${ }^{14}$ However, this never gained ground as a full panic; contestation from single parents, their supporters, and indeed women from across the political spectrum worked in unison to redefine the agenda to one that recognised the strengths and capabilities of mothers who raise children both

\footnotetext{
${ }^{14}$ In Chapter Six it will be shown how the 'mother factor' would come into play in the episode of 'killer kids'.
} 
single-handedly and in dire poverty (McRobbie, 1994a). ${ }^{15}$ De Young (2004) is another who emphasises the ways by which folk devils can challenge their demonisation. In her assessment of the satanic ritual abuse phenomenon, she attributes the social capital retained by the child care providers (as nurturers) together with their ability to use effective oppositional language (in stating 'this is a media witch-hunt' as opposed to 'I didn't do it') as one of the reasons the alleged (and satanic) nature of abuse was exposed as a purely constructed phenomenon (de Young, 2004). In addition, McRobbie and Thornton (1995) argue that the pessimism of moral panic (particularly Hall et al.'s version) cannot imagine that the victims (the folk devils) might celebrate this status as a right of generational passage, nor that panic could be employed by various marketing outlets as "priceless PR campaigns" (McRobbie \& Thornton, 1995: 565). ${ }^{16} 17$

Another problem for the materialisation of the 'ideal' models is the ways by which the media environment has both expanded and diversified. McRobbie (1994b: 201) argues that this 'new' media are far more politically savvy than the 'original' project allows for, while at the same time are competitively conscious. One way to gain an edge on the market is to routinely sensationalise the ordinary and/or to cast oneself in the role of moral guardian (McRobbie, 1994b). Either of these developments could independently create the prerequisites for moral debates, and upon that stimulate the conditions for panic (see also Aldridge, 2003). ${ }^{18}$ On the other hand, political strategies today are seen to materialise as media strategies (see Hier, 2002b) as the past distinction between the media, politicians, and social control agencies becomes less clear, and as social 'reality'

\footnotetext{
${ }^{15}$ This is not to imply that there was no panic at all. The Bulger panic was one of Britain's most explosive, with resounding effects. The most significant of these was the way in which the idea of childhood was disturbed (see Green, 2008a; Hay, 1995; Young, 1996).

${ }^{16}$ To some degree this recognises the oft overlooked aspect of Cohen's (1972) work; that the roles of the Mods and Rockers were self-consciously played out in that youths appropriately posed for photographs and wore the expected attire as they turned up to watch the anticipated (predicted) event. What drew the crowds that then became the event was chiefly the entertainment feature! ${ }^{17}$ Some critical ideas developed from these observations in relation to the Aotearoa/New Zealand context can be found in Griffiths (2005).

${ }^{18}$ Hunt (1997) furthers this point in his contention that we may be experiencing a crisis of moral language itself; that the media have whole heartedly adopted the lingo of moral panic simply because the notion offers this back; it has become the primary means through which to articulate that which is moral.
} 
is increasingly tied up with representation (see McRobbie \& Thornton, 1995; Silverstone, 2007).

This would suggest that the task of deconstruction has become both thornier and more urgent than has previously been considered. Indeed, not all panic scholars are persuaded that these cultural developments lend themselves to more active and open confrontation nor that that confrontation will necessarily be heeded. As Hier's (2002a) example of resistance from 'ravers' to the problemisation of 'raves' as drug spaces demonstrates, the socio-political position of the potential folk devil remains a crucial variable in their ability to resist the deviant label. ${ }^{19}$ Ideally, as Cohen (1972: 167-168) argues, the folk devil will occupy a position of high visibility but with little social status; they will be outsiders that is, in the sense they are structurally and politically weak. ${ }^{20}$

A quite different but just as pertinent issue as the challenges posed by the changes across the social and cultural landscape thus far described is the appearance of 'risk' problems. Ungar (2001) for example, argues that Urlich Beck's (1992) thesis that we are now in a 'risk society' suggests that our 'sites' of anxiety are changing and therefore models for analysis are required. For other commentators the challenge is to see where risk and moral issues meet; how risk problems are politicised and how then the identification of an impurity or threat to "the care of the self' is articulated in moral terms (see Critcher, 2003; Garland, 2001; Thompson, 1998). Conversely, Cohen (2002) contends that problems of risk and problems of the moral order remain analytically distinct if we take into account how stylised screams of tabloid headlines work to create fear and hostility and where vigilante action is premised upon emotive anger, outrage, and resentment (see also Scott, Jackson, \& Backett-Milburn, 1998). These arguments and their implications for moral panic research are considered in more detail in Chapter Two.

\footnotetext{
${ }^{19}$ How Facebook, Twitter, and other social network sites might shift the balance of power is yet to be assessed in the literature.

${ }^{20}$ In later chapters it will be seen how Bailey's inability to speak in his defense became a markedly important feature in the extent to which he was labelled deviant, and indeed remains so.
} 
Despite the changed media environment, the enhanced ability for folk devils to contest their status, and the appearance of 'risk' problems, it is generally agreed that the cornerstone of any panic is the outcome; the 'way of coping'. In other words, the process is complete where there appears an imposition of one way of thinking about something; a singular definition or discourse unto the 'problem' at hand, which, more often than not, manifests through legislative change (Critcher, 2003; Goode \& Ben-Yehuda, 1994b; see also Best, 1990). Invariably how this singular definition attains legitimacy depends on the idea that there is concern on behalf of the public. This is the focus of discussion in the next section.

\section{An Absent Public}

... to take constructions of public opinion as evidence of consent is both intellectually and politically dangerous (Stabile, 2001: 263).

Interestingly, Cohen's (1972) study documented that the reaction on behalf of the public was not necessarily congruent with the reaction of the media and social control agents, and that it was the actions of only particular publics (some moral action groups, some commercial interests, some individuals) and their varied interpretations of the 'problem' that came to the attention of the legislators. Nevertheless, most panic analyses have a working assumption that the public (as a whole, or at least a significant segment of it) is involved and that the role of active and imaginative audiences are to comprise a significant part of the research agenda (de Young, 1998; Goode \& Ben-Yehuda, 1994a; Miller \& Kitzinger, 1998). In practice, however, public concern has proved difficult to establish and as a result tends to be inferred directly from sensationalist media coverage (see Goode \& Ben-Yehuda, 1994; Burns \& Crawford, 1999; Welch, Price, \& Yankey, 2002 in particular). This is problematic. It not only assumes the media as an objective and non-commercial space for civil debate and that 'the media' is one unified entity, but it also, paradoxically, presents 'the people' as an ignorant monolithic mass; subject to, and agent-less in relation to media propaganda. Yet the media as an objective medium is questioned by philosophers such as Habermas (1989) and civil society theorists such as Alexander and Jacobs (1998). 
Moreover, the idea that what the media says is what the public thinks leans towards the hypodermic model of the media effects debate; a debate that has polarised thinking between the media as having a sustained influence and audiences as active consumers. Most contemporary theorists working with the media recognise and develop their methodologies from both sides of the debate; that texts affect, but that also audiences can resist (see Surette, 1988; Kitzinger, 2004).

Then again, Hall et al.'s (1978) analysis of how the media work with a 'public idiom' in a panic accounts for how the press both speak in terms the readership will relate to at the same time as they assume themselves as the 'voice' of the people. Because this 'voice' is then fed back to the elite bodies as public opinion (the 'people' are spoken for) there is somewhat of a 'magical circle' at work whereby the actual public are surpassed. ${ }^{21}$ In this way, the variable of public opinion "functions rather like the trope of the silent majority; it signifies only insofar as politicians and journalists want it to signify within the context of a given argument" (Stabile, 2001: 265). ${ }^{22}$

More recent panic assessments have undertaken that panic narratives must be seen as capable of engaging a relation with audiences in order for the 'magic' to unfold, and in view of that have sought to ignite how an engagement with the public may be achieved. Drawing upon Althusser's (1971) conception of how ideology moves from something abstract or external and into 'being', moral panics are conceived in these assessments as ideologico-discursive formations that interpellate through points of resonance with lived subjectivities (Hay, 1995, 1996; Hier, 2002a, 2002b; de Young, 2000, 2004). ${ }^{23}$ As Hier (2002a) describes,

\footnotetext{
${ }^{21}$ This 'magical circle' was conceptualized by the Centre for Contemporary Cultural Studies (CCCS) (1975: 76), of which Stuart Hall and Tony Jefferson of Policing the Crisis were a part. ${ }^{22}$ Stabile (2001) argues that it is notoriously difficult to capture 'public opinion' without large scale in-depth research tools. Using formal channels such as polls are problematic as they are often monopolized by elite interests which have no structural homology to informal channels of social communication. Stabile (2001) contends that it would defy the logic of the capitalist media to have opinion 'trickle up' in this way; that one of the functions of crime news (in particular) is to deny a diversity of opinion.

${ }^{23}$ Althusser (1971) conceptualized interpellation as the precise operation by which ideology acts to transform individuals as subjects. This can be imagined as a common-place everyday police
} 
this is a critical interpretation of ideology that assumes that how a person perceives his/her world will have an immediate application to how they act within it. For the most part, however, these assessments seek to annul the critique of normativity by demonstrating that panic participants might behave rationally at ground level, however 'irrational' or disproportional their collective action can be assessed as. The actual public remains absent.

Commentators who are less austere (and less committed to the notion of an ideological agenda) also question the degree to which public sentiment is required (or symbolically called upon) to move any legislation through (see Miller \& Kitzinger, 1988; Schlesinger \& Tumber, 1994). In the Aotearoa/New Zealand context a case in point is the vocal and hot-tempered opposition by large sections of the constituency to Member of Parliament Sue Bradford's colloquially termed 'anti-smacking Bill' in early 2007. The Bill made it to law despite this response, and remained in law despite that $87.6 \%$ of voters voted against it in a 2009 citizens initiated referendum. ${ }^{24}$ Critcher (2003) adds that the media, politicians, and many pressure groups may be seen as permanently oriented towards the moral agenda and therefore research should concentrate upon what he denotes as the powerful 'P's'; the press, pressure groups, politicians, the police, and the public. $^{25}$ Recognition of this alliance may also solve the problem of how to account for panic eruption and subsequent decline. Critcher (2003) suggests that the intensity (volatility) of panic is a direct reflection of the media's desire for novelty. In other words, the 'news attention cycle' determines that a problem will be seized upon, exploited, then dropped as a new problem takes its place.

Removing the variable of public sentiment from the empirical equation still leaves the question of when a 'problem' assumes the greater momentum of a panic. As Thompson (1998: 20) argues, panic narratives and all their discursive tricks do not

\footnotetext{
'hailing'; "hey... you there" whereupon the individual recognizes it is he/she being spoken to and by turning to respond becomes a subject.

${ }^{24}$ Similarly, Jewkes (2004) points out that the public is often indifferent or even resistant to issues we might view as political crusades (anti-smoking and 'safe sex' campaigns are given as examples).

${ }^{25}$ Critcher (2006) is referring here to public opinion which is invoked.
} 
"exist in a vacuum". In the next section I discuss how this location of why panics happen is too often left aside in the interests of determining what they $d o$.

\section{Outside the Machine}

The real Devil, whose shapes the early puritans were trying to establish, was the same devil that the Mods and Rockers represented (Cohen, 1972: 162).

Moral panics are understood to 'work' much like other cultural events (royal weddings, coronations, state funerals) in that they stimulate the sense of an 'imagined community' (see Anderson, 1983). Indeed, the practices of a panic fashion an enemy to mark the distinction between 'us' (the upstanding citizenship) and them (the wrong doers). It is through the identification of the outsider that social groups create and recreate themselves, and the sense of who 'us' is, is reconstructed each time a new enemy appears. ${ }^{26}$ Cohen (1972) compellingly linked the response to the Mods and Rockers as a declaration about moral boundaries, arguing the period "can be seen as constituting what Erikson terms a 'boundary crisis', a period in which a group's uncertainty about itself is resolved in ritualistic confrontations between the deviant and the community's official agents" (Cohen, 1972: 162). This is not to say, however, that the Mods and the Rockers were consciously picked out to clarify normative contours, but rather, that both their behaviour (by nature of its visibility) and their position (as structurally weak) at that particular time provided a sufficient enough forum in which to dramatise and articulate issues previously blurred in ambiguity, more clearly.

The problem is not that this 'blurred in ambiguity' variable is incorrect, but that in practice it is often correlated with the idea of a free-floating 'anxiety' which is notoriously difficult to deconstruct (see Hunt, 1999). ${ }^{27}$ Indeed, the success of a panic is often used as an indicator of social anxiety, without other evidence to suggest that anything is actually there (Critcher, 2003). In recent times, our 'age of moral panic' has been attributed to, congruously; the 'age of anxiety' that is

\footnotetext{
${ }^{26}$ This reflects the "elasticity of evil" (Cohen, 1974: 5); the idea that as societies change, so does the terms and conditions upon which inclusion and exclusion depends.

${ }^{27}$ The idea that a panic is caused by anxiety is intimate with the normativity factor, which, as argued, assumes that the 'panic' identified has erupted upon something more or other than a reasonable assessment of social facts (see also Hunt, 1999; Rock, 2007).
} 
characteristic of the late-modern era (Critcher, 2003; Thompson, 1998). Giddens $(1990,1991)$ formidably describes this era as a state of a sense of change and instability across politics, economies, cultures, the collapse of traditional authorities and identities, the disembedding of time and space. Precisely, argues Jewkes (2004), it is these negative characteristics of modernity that stimulate our need for the sense of community (see also Greer, 2004). However, the notion that instability and anxiety are features unique to contemporary times is somewhat problematic. Considering that prior to the 1970's (the era after which is commonly denoted as late-modern), the prevalence of war (both civil and international), numerous economic recessions, and profound leaps in technological advancement: from cars to computers to nuclear weapons, Tonry (2001: 523) contends:

\footnotetext{
In every era, I suspect, people attribute much that they dislike or disapprove to the seemingly unprecedented changes of their times, and, with the benefit of imperfect memory and good-old-days nostalgia, believe that the changes in their lives are more consequential than those of other times.
}

Nevertheless, the idea that moral panics erupt in communities and societies that are 'anxious' is often now a priori assumption of research, and so attention tends to direct itself to what effects the panic in question has in terms of restoring stability (see Critcher, 2003, 2006). This is important, as questions of effect, function, and impact are an essential part of panic research. As Goode and BenYehuda (1994b) argue, not only are successive panics built on earlier ones, but that in the interval period (panic free) the legacy of prior panics provide the means with which to regulate or condone the behaviour that was deemed harmful or deviant in the first place. In this way, "even seemingly transitory panics are not 'wasted"” (Goode \& Ben-Yehuda, 1994b: 169). However, Cohen (1972) argued that more moral panics would be generated not because they have an inevitable logic, but because society (western, it is presumed) regularly makes problems for some of its members and then condemns the solutions such members find. Asking why they do this at particular spaces and times is crucial for understanding why the devil in question takes a particular form, where the lines of power reside and 
how 'we' are subject to 'manipulation'. Indeed, perceptive of where Folk Devils fell short, Cohen (1972: 150) writes:

... the reaction itself ... is often left unexplained. Models such as deviance amplification deal well enough with what happens in the machine (the feedback and snowballing effects during the reaction sequence) but inadequately with why the initial reaction takes place and even less adequately with why the sequence itself might come to an end. For these problems we have to look outside the machine and outside the theatre.

Several studies since have looked 'outside the machine' in order to discover why this or that episode occurred. Three that are exceptional in this regard are Hall et al.'s (1978) analysis of mugging, Jenkin's (2005) study of the construction of sex offenders across $20^{\text {th }}$ century America, and de Young's (2004) assessment of the satanic ritual abuse phenomenon. I want to briefly outline these works in order to identify how (and why) context matters. In Chapter Two I situate my emphasis upon context in relation to these studies.

As discussed, Hall et al. (1978) argued that early 1970s Britain was on the verge of a political 'crisis' as an economic recession threatened to reveal the inequalities inherent in capitalism. The elite, whose interests were under threat, would employ and exploit the Handsworth 'mugging' as evidence to suggest that the 'crisis' felt at grassroots level was actually one of 'law and order'. Thereupon, a key question for Hall et al. (1978) was how a spectrum of consent for the exercise of a coercive law and order campaign was achieved; why different classes who had become increasingly polarised both economically and politically would, at this injunction, share the same social and moral perspective on crime. They found that the call for tougher measures was articulated through an appeal for 'common sense' at the local level, and that at the basis of this appeal was the sense of Englishness. In other words, the 'problem' was to be found in working class immigrant labour, the absence of a respectable work ethic and the lack of appropriate discipline which posed to threaten the everyday person and his traditionalist, conservative, and very English values. In this way, power was exercised to re-construct an 
imagined community in order for power to be exercised to restore stability in the interests of that power.

De Young (2004), on the other hand, located the satanic ritual abuse (SRA) phenomenon within a union of three culturally significant 'master symbols' of the 1980s: the menacing devil, the vulnerable child, and the psychological trauma model. Though each of these symbols could be seen to have its own cultural history and generate its own anxieties, they enjoyed something of an omnipresence as a trio in the 1980s as they operated as 'proxies' for the much deeper cultural strains inherent within religious fundamentalism and women's increased involvement in the labour market, while at the forefront was a pseudoscientific profession eager to legitimate its practice. They would also come together several times in what might be seen as a set of pre-empting episodes to the SRA panic. ${ }^{28}$ Yet none of these would have quite the same impact as the SRA which was impelled with just the right meta-narrative to resonate with and act as an expression of these deeper tensions. This narrative wove together the ultimate threat to vulnerable children - traumatic sexual abuse within circumstances of satanic malevolence (de Young, 2008).

Jenkins $(1998,2004)$, a historian, traces the shift in social responses to adult/child sexual relations in the American social, cultural, and political landscape from the late $19^{\text {th }}$ century until today. He identifies three distinct periods of interest group activity (leading to moral panic) which constructed and reconstructed the problem which is now understood as child sexual abuse (CSA). The first panic erupted with a campaign to raise the age of consent with a coalition of feminists, moral crusaders, and religious reformers claiming widespread venereal disease and the trafficking of young girls. The second panic is described as the 'age of the sex psychopath'. Central to this episode was the image of the crazed sex offender, propagated by sensational media stories of sex-related murders, developing psychological and psychiatric 'expertise', and a body of legislators keen to profit politically. The third manifestation - the most current - is denoted as the 'child

\footnotetext{
${ }^{28}$ These include small-scale panics over heavy metal rock music, the strategy game 'Dungeons and Dragons', and devil-worshipping punk youth in Jamestown, New York.
} 
abuse revolution'. Though largely due to a campaign on behalf of feminists calling attention to male oppression in familial settings, a familiar nexus of moral conservatives, the media, and legislators (all with their own agendas) created a sense of national urgency to the 'unqualified evil' of CSA (Jenkins, 1998). Like de Young (2004), Jenkins $(1998,2004)$ views each episode's content as a direct reflection of spatial and temporal social, political and ideological 'tensions' which provide the bedrock for (and are crystalised by) the entrepreneurial efforts of campaigners.

In Chapter Two I propose that the question of why a panic occurs is more imperative than ever, and examine the degrees to which this question is addressed as one of the 'bigger questions' of the project of 'rethinking moral panic'. In the closing section of this chapter I want to consider the development of my approach to the case of 'killer kids' thus far.

\section{Formulating an Approach to Moral Panic}

Cohen's (1972) notion of an ideal-type concept to be used as a heuristic, transferable tool across case studies appears consistently valuable. This is reflected both in the way moral panic has been perpetually used and by Goode and Ben-Yehuda's (1994a, b) reworking of its formulae for the American context (see Critcher, 2003). I configured that part of my task would be to conserve moral panic as just this; an ideal-type concept. Nevertheless, the intimacy with which Cohen (1972) developed the concept in relation to the Mods and Rockers, and the way by which Hall et al. (1978) exposed the structural relationship between the state and the civil sphere; identifying in course how political processes can operate in the distortion of reality in their analysis of the mugging phenomenon demonstrate that this ideal-type is relative to material events, or real-type episodes of panic. Similarly, Goode and Ben-Yehuda's (1994a, b) identification of three models differentiated by the variables of motive and responsibility presupposes that some of the attributes will be achieved via different means and others would play out according to who was driving the respective campaign. Moreover, Critcher (2003) argues that no model can account for overhead narratives or 
underlying themes between cases of moral panic. Therefore, I would need to be receptive to the events (and narratives and themes) of my real-type case and how they could be seen in relation to the ideal-type. Fortuitously, this corresponded to my anticipation that there would unfold a unique trajectory in the case of 'killer kids' (given that there had been a unique initiation) and my intention to observe this trajectory.

Looking toward the analysis of my case, the next task was to assess which idealtype model would be appropriate to use; the processual or the attributional? Critcher (2003) argues that in practice, it is the former that has thus far grasped the common features between panics (an issue emerges as a threat, moral entrepreneurs support it, experts pronounce diagnoses, and the state institutes repressive measures) whereas some of the attributes of the latter have proved problematic (concern and consensus in particular are noted to be difficult to measure). Moreover, I needed to anticipate the relatedness of the contexts in which these models were developed with Aotearoa/New Zealand's socio-political environment. Drawing from the small body of moral panic literature developed in this country, and from my own preliminary observations, I ascertained there are two notable particularities about the media sphere here; first, that similar to the British context Aotearoa/New Zealand has a centralised media; second, that the relationship between the press and the police is, in the main, symbiotic (see in particular Matthews, 2002; Wallace, 2006). Moreover, the local literature had, in the main, employed the British sense of the concept. These factors determined that I favour the processual model. Of the two most well known uses of this model - Cohen's (1972) analysis of the Mods and the Rockers and Hall et al.'s (1978) account of mugging - I settled upon proceeding with Cohen's (1972) interactive model as my ideal-type. There are two reasons for this. Though the mugging analysis assured a more accurate capture of the dependent relationships between the press and the police than Cohen's (1972) blanket notion of a 'control culture' could, and it could relate intricately to my early suspicion that the variable of race played a key role in how the imagery of Bailey Kurariki was construed with connotations by the press, its political backcloth was at odds with my intention to preserve the idea of panic as a transferable, heuristic concept (see 
Cohen, 1987). Moreover, Cohen's (1972) model is the most employed (including by Hall et al.) and best understood within the panic literature; indeed, it is Cohen's (1972) opening paragraph that Critcher (2003) determines as the processual prototype.

In the second half of this chapter I discussed some concerns with the concept's criteria of disproportionality, and of its political tradition. I argued that the notion of a panic as 'irrational' is not - as some critics argue - directed at the actions of panic participants but the overall reaction as it evolves from the interactions of those actions. I also discussed how panic's 'folk meaning' as a concept designed to expose dominant interests was inherently sociological, and that there could be a continuum of investment according to each analyst's persuasion. Critics also identified a more delicate balance of relations between the media, agents of social control, claims-makers, and folk devils than the original model could account for. Others questioned the engagement with a panicking constituency. These, I argued, only demanded that analyses are more vigourous in their assessments of the interlocking variables of representation, media strategies, and sensationalism, and the ways by which these can operate to initiate and sustain the construction of a 'problem' without grassroots support. I then identified that on the whole, panic assessments have placed too heavy an emphasis on the function of a reaction while issues of cause remain vague. Following in the tradition of Hall et al. (1978), de Young (2004), and Jenkins (2005), I wanted to understand why the phenomenon of 'killer kids' had erupted in this space and time; why, specifically, it was the imagery of Bailey Kurariki - and not the murder of Michael Choy itself - that had set the reaction in motion. To do this, I would need to look beyond the boundaries of the conceptual model of moral panic-outside the machine.

In Chapter Two I explore how recent efforts toward 'rethinking moral panic' also seek answers to why a panic occurs on route to the address of another 'big' question; what are moral panics extreme examples of? It is from the directions this project is heading that I argue my analysis of a real-type in relation to an ideal-type be extended to imagine how the contextual location of panic reactions can inform a theoretical location of the concept. 


\section{Chapter Two}

\section{Rethinking Moral Panic}

For MPs to be a robust concept, its operationalization needs to be clear and coherent

(Klocke \& Muschert, 2010: 299).

In the introduction to this thesis I identified that the concept of moral panic had lost its former interpretative authority and how this was due, in the main, to its own success. In Chapter One I explored the evolution of the concept and examined the critiques and social developments that have been seen to further weaken its sway. In this chapter, Chapter Two, I explore the ways by which a new wave of thinkers seek to renew panic's analytical authority. This task is underpinned by a primary question: 'what are moral panics extreme examples of?' (see Critcher, 2008, 2009a). It is a question which aims to locate the concept within developments in social theory with a view to explain its processes. It is evident, however, that there are varying degrees to which these thinkers also locate their empirical 'real-type' panics within the social, cultural, and political contexts in which they emerge.

In Chapter One I argued that I would approach the study of moral panic as a realtype empirical case that could be seen in relation to the ideal-type analytical concept. I intimated that the ideal-type required regular assessment as its interpretative parameters needed to be relevant for how real-type cases unfolded and I would be asking how the case at hand challenged the parameters of the original model. I also argued that the question of why panics happen was too often circumvented with a focus on who started them and what they (panics) did, and that a central objective of my research was to understand why the case of 'killer kids' had emerged in Aotearoa/New Zealand when it had. As Cohen (1972: 172) avows:

It is not enough to say that witches should not have been burnt or that in some other society or in another century they might not have been called witches; one has to explain why and how certain people get to the stake now. 
If indeed this is the 'age of moral panic', then a concern for why panics materialise and certain people get to the stake is surely more important than ever. Moreover, if the ideal-type is intimate with real-types then it follows that what moral panics are extreme examples of is fundamentally intimate with why they occur. This observation extends my proposals for a real-type/ideal-type relationship. Indeed, I contend that the study of moral panic be of a configuration of relationships between a real-type episode and the ideal-type concept. One is to examine how a real-type panic challenges and/or supports the ideal-type parameters of an accepted model. One is also to situate a real-type within its context. How one might situate the ideal-type theoretically is drawn from how these first two relationships are configured. My central objective for this chapter is to look at the ways the new ideas have addressed this configuration and where, thereupon, my proposals fit amongst them.

The discussion to follow is structured by 'thinkers' and in the order by degree of departure each thinker places upon the real-type in relation to the ideal-type, as this has implications for each respective assessment's ability to address the contextual/theoretical relationship. The first thinker under discussion is Sheldon Ungar $(1992,2001)$ who contends that conditions identified as specific to latemodern industrial societies demand a new research agenda as they not only confound the sites of social anxiety but also indicate a shift in processes through which conviction is sought. The second is Chas Critcher (2003, 2008a, 2008b) and his proposal for how we might think 'beyond' moral panic through viewing it in terms of three dimensions: processes, discourses and moral expressions. Third, I look at the scholarship of Sean Hier (2002b, 2003, 2008) who argues that risk issues mean more moral panics, in addition to how we can view panics as shortterm volatile moments within the ongoing and more routine project of moral regulation. Fourth, I overview the work of Amanda Rohloff $(2008,2010)$ who locates moral panic within the sociology of Norbert Elias; viewing panics as short-term decivilising episodes that emerge from civilising campaigns. Last, I introduce a line of insight on behalf of Simon Hallsworth (2000) and Ian Loader 
(2009) that has not yet been considered in the study of moral panic, but it is one in which my proposals for an approach to moral panic appear reflected. Moreover, as will be seen in later chapters, this literature offers a fruitful direction by which to develop a conjectural understanding of 'killer kids'. Though in many ways this is a selective choice of thinkers given a plethora of emerging literature on the legacy of moral panic (see Altheide, 2009; Innes, 2005; Garland, 2008; Young, 2009) and how to overcome its discontents (Klocke \& Muschert, 2010; Jenkins, 2009; Welch, 2006, 2007), it is also contingent upon how the debates between these scholars (for example, Hier in response to Ungar, Critcher in response to Hier) are making important headway for how moral panic can be imagined in terms that extend its understanding.

For the first thinker in my consideration of the project of rethinking moral panic, Ungar $(1992,2001)$, the 'anxiety' of real-type social reactions can no longer be evaluated as inappropriate or disproportional as it is difficult to establish the objective realities of the problems of a risk society.

\section{Abandon Panic: the 'Social Scare'}

Underlying Ungar's (2001) assessment is that risk issues - which now command our attention over and above other types of issues - are not temporal and spatial threats to a particular social order, but to the life and biology of the planet and its inhabitants. What is more, these issues are unpredictable, uncalculable, and possibly irreversible. For Ungar (2001) this real-type development renders a number of methodological assumptions of the analytical concept of moral panic the ideal-type - problematic. First, if a risk problem is scientifically uncertain (thus there is no objective measure), how can one establish that concern is disproportionate to the level of threat? Second, where a panic is seen to be the result (intended or not) of efforts of moral entrepreneurs and claims-makers, a risk society issue needs a 'real world' event to precipitate concern and direct interest group enthusiasm (Ungar 1992). Moreover, it is Ungar's (2001) contention that the media are more likely to report the 'facts' of risk problems - given the 
reservations of scientific claims - than they are with moral assertions where there is relatively more licence to be creative (and thus sensationalist). Finally, it tends not to be the vulnerable or 'distinguishable social types' that are designated as 'folk devils' but the powerful (political authorities, commercial interests) who find themselves the target of risk focused campaigns. Succinctly Ungar's (1992, 2001) argument is:

... claims-making on risk society issues is, in comparison with conventional moral panic issues, hedged in by more apparent and sticky trajectories, by a more equal balance of power on the part of rival claims-makers, and by a comparative absence of distinguishable types of folk devils that evoke deep-seated hostility and fear (Ungar, 2001: 287).

Further, Ungar (2001) suggests that efforts towards containment are attempted through a 'post market coping model', and not the erection of 'safety' discourses in the reconstruction of normative boundaries that are typical of moral panics.

Despite these observations Ungar (2001) is still keen about the idea of a conceptual tool with which to deconstruct a social reaction. Moreover, his proposal for an alternative concept draws intricately on Cohen's (1972) panic model. But for Ungar (1992) the 'social scare' is less specific and is devoid of the normative measures that plague moral panic assessments and so therefore is better able to conceptualise anxieties of the risk society. He explains:

Social scares entail acute episodes of collective fear that accelerate demands in the political (or related) arena. Accelerated demands urge extraordinary responses solutions that tend to be costly, often simplify problems to the point of caricature, seek to leap-frog prevailing processes for evolving solutions, and can verge on the draconian... These demands may or may not be acted upon, depending on factors such as the scare intensity and whether it persists, is renewed, or simply disappears (Ungar, 1992: 485).

Ungar's (2001) emphasis upon real-type reactions and argument for why a panic model is no longer applicable is important insofar as it recognises that changing 
environments require that conceptual tools be revisited (there is a relationship between real-types and ideal-types). It is interesting then that his model of the 'social scare' has much in common with moral panic, which would suggest that the ideal-type (of moral panic) is not dramatically challenged by the shift to a risk society. He identifies, for example, that responses (to the fear of risk) are in simplified, 'caricature' and 'draconian' terms, which inadvertently suggests that there is some form of external measure to which the proposed solution (too far) extends to. This, in turn, implies that the criteria of disproportionality can be established. Ungar (2001) also overstates the role of claims-making in a panic. As argued in the last chapter, panics are distinct particularly in the alliance between political, institutional, and lay groups who are sensitised, and it is this which facilitates the over-estimation and escalation towards a perceived problem (Cohen, 1972; see also Goode \& Ben-Yehuda, 1994a on the difference between panics and moral crusades). Moreover, moral panics often require precipitating events. In Hall et al.'s (1978) elite engineered, Cohen's (1972) interest group panic, and Kitzinger's (1999) assessment of the 'paedophile in the community' crisis as a grassroots panic, it can be seen that each was set in motion by a key 'real-world' incident (the Handsworth mugging, the brawl in Clacton at Easter, and the murder of Sarah Payne respectively).

This aside, what can be most astutely observed of Ungar's $(1992,2001)$ work is that he draws upon a realist (or materialist) conception of the risk society theses. In other words, his view is that things such as global warming, nuclear weaponry, and bioterrorism - threats to the existence of human life - demand our attention simply because they are actual, factual risks. Consequently, the question of what the model of a social scare is an extreme example of or how the logic of its processes might be explained is not important. Hier (2003), however, takes issue with this materiality. Indeed, Hier (2003) goes so far as to challenge the ontology of external risk, observing that despite their departures the common thread in theories of late-modernity is 'risk' as a concept invoked to explain uncertainty and 
deal with unawareness. ${ }^{29}$ In other words, social actors employ the idea of risk and are 'risk conscious' as it offers a sense of calculation and control in late-modern societies characterised by uncertainty (and where there is uncertainty of knowledge) (see also Furedi, 1997). In this way, its processes can be explained as a operation of governance.

In a further section I examine Hier's (2002a, 2008) location of risk talk within practices of moral regulation, alongside his identification that the risk society nevertheless has implications for how moral panics appear. Prior to examining these implications more closely, I want to turn to Critcher (2003, 2006, 2008, $2009 \mathrm{a}, \mathrm{b})$ who argues that the capture of specificities of any 'real type' reaction (be that anxiety about a real-world risk, or hysteria about a phantom menace), is better got by firmly engaging with moral panic as a transferable, heuristic iideal type'.

\section{Preserve Panic: Three Dimensions}

Indeed, of all the scholars involved in the project of 'rethinking' moral panic, it is Critcher (2003, 2006, 2008, 2009a, b) who places the most emphasis upon the concept as a heuristic conceptual tool, or 'ideal type'. However, he is critical of the eclectic and sometimes slapdash application of both Cohen's (1972) processual and Goode and Ben-Yehuda's (1994a, b) attributional models, at the same time as he is sympathetic to a range of the critiques directed at moral panic. To evaluate and propose how we might overcome the critics concerns, using secondary data Critcher (2003) applies both models across a range of 'case studies' - from ecstasy to video 'nasties' to paedophilia - with the view to find both 'constancies' and those aspects of each real-type case that moral panic cannot account for. He concludes that we cannot yet do without 'moral panic':

\footnotetext{
${ }^{29}$ Hunt (2003) also challenges the ontology of risk that has given the impetus behind Beck's (1992) 'risk society'. He argues that despite the greater potential impact of today's risks, there appears no qualitative distinction to justify an epochal change (Hunt, 2003).
} 
Where an issue, in whatever form, emerges as a symbolic threat; where the media as a whole accept a single definition of the problem; where there are organised groups supporting the panic and none disputing it; where expert opinion does - or can be presented to - support the diagnosis of the problem; where the state, however laggardly, does institute repressive measures, then we have the basic requirements of the ideal type fulfilled (Critcher, 2003: 154).

It is those cases where there is variation from this ideal type that a full-fledged panic fails to materialise (see also Jenkins, 2009). On the other hand, all real-type cases that Critcher (2003) overviewed exceeded beyond the boundaries of the models; that is, each case had features which moral panic analysis alone was unable to reveal (see also Rocheron \& Linne, 1989). In particular was the presence of discourses, often specific to each issue, that either informed by or were generated by the panic; sexuality to Aids for example, hedonism to rave/ecstasy, and innocent children to child sexual abuse. Critcher (2003) then examines what moral panics $d o$ - namely, the reaffirmation of the moral boundaries of society through the nomination of outsiders (see Erikson, 1966). He contends that moral panics can be understood in terms of three dimensions: as a set of identifiable processes (for which an 'ideal type' model is useful), as sets of discourses (pertaining to the real-type issue), and as expressions of moral values (their functionality).

There is, however, little room for an examination of how a real-type panic may bear upon the ideal-type via Critcher's structure. In part this is because he employs secondary data and so the subtleties of each reaction is lost. But it is also because the practice he prescribes can only capture differences between the variable episodes, conditions and/or persons or groups of persons through the interplay of processes and discourses as they materialise within an episode. At the same time it looks for excesses beyond the model. Further, with emphasis placed upon how the discourse that emerges as dominant works as an achievement of moral certainty, the emphasis is upon the function of the panic in lieu of the 
question of 'why' it occurred in the first place. ${ }^{30}$ A later submission (Critcher, 2009a); that one would ask what wider discourses inform and relate to the dominant discourse in the bounded reaction (explicated by either of the models), and who it is that defines who is 'at risk' is tentative about what this could mean for how the ideal-type concept can be rethought.

Thus far then, for Ungar $(1992,2001)$ the challenge of real-type social reactions and real-type contexts both renders the concept of moral panic problematic and mitigates the need for further reflection, whereas for Critcher (2003, 2006, 2008, 2009a, b) the ideal-type is abstract enough to explain many different reactions so long as the basic descriptive criteria is met. However, the question of why such reactions occur and where the concept might be located within theory remain elusive. In the next section my attention turns to the work of Sean Hier (2002a, 2003, 2008) whose assessment of real-types intricately informs the 'extreme example' question (of the ideal-type) but that, paradoxically, his notion of how to explain the concept risks becoming too general to capture the exceptionality of 'panic'.

\section{Risk and Morality: the Converging Sites of 'Anxiety'}

Hier's (2002a, 2003, 2008) contribution to the project of 'rethinking moral panic' is both extensive and complex. As indicated, Hier (2003) agrees with many cultural theorists who view that moral ends are now achieved with the use of risk language. Mary Douglas, for example, argues that "risk provides the secular terms for rewriting scripture" (that is, of what constitutes $\sin$ ) (Douglas, 1992: 26; see also Garland, 2008; Lupton, 1999; Moore \& Valverde, 2000; Mythen, 2007;

\footnotetext{
${ }^{30}$ However, Critcher $(2003,2006)$ is aware of the complex beginnings of a problem unfolding, and that his template under-represents a full analysis of the inter-workings of the moral agenda. Moreover, in a more recent work (Critcher, 2009), the moral regulation literature is identified as a means to understand why some social objects and subjects become moral targets. What is interesting further, is that for most perspectives that undertake discourse analysis, and particularly those who analyse media text, discourse practice is seen as a means through which textual analysis can be linked to socio-cultural analysis; that is, the aim is to show the dialectical relationship between the materialisation of texts and the wider social practices in which they are embedded (see Fairclough, 1992, 1995a; Laclau \& Mouffe, 1985; Matheson, 2005; Van Dijk, 1988a, 1988b, 1991; Wetherell, 2001).
} 
O’Malley \& Mugford, 1991; Sparks, 2000). Indeed, Critcher (2003) identified in his assembly of panics that 'risk talk' was a predominant feature; who was at risk of Aids, the risk to party goers, risk inside and outside familial structures. Garland (2003: 64) takes a systematic view of this connection:

\footnotetext{
... as chains of interdependence grow longer, and shared moral codes grow thinner, risk management has become a necessary moral technology, operationalizing liberalism's twin concern to maximize freedom of action and to reduce that freedom's harmful consequences (emphasis added).
}

Ultimately, for Hier (2003: 19), if "post moral techniques and discourses of risk management have ended up doing old moral regulation work", then this would suggest that it is not so much that sites of anxiety are shifting, but converging.

Might this explain the 'age of moral panic'? Somewhat, though here Hier (2003) adopts a functional explanation of panic. He suggests that in the context of existential (and ontological) insecurity, a sense of 'community' has an urgency to it as it operates to affirm belonging in a world of generalised strangers and confronts the individuation modernity initiates (see also Jewkes, 2004). This is why we are seeing more moral panics, as what panics 'do' is identify a threat to the group (which in turn becomes a group in the identification of a threat). However, the erection and re-erection of the borders of community are now done under the guise of 'safety' (i.e. the amelioration of risk). Hence we no longer have 'folk devils' that may be cast aside, but dangerous others that we must be protected from (Hier, 2003).

Hier's (2003) work to this point emphasises that the character of real-type moral panics is changing. This, he contends, can be instructive for what causes moral panics, and thereupon what we might invisage what the concept can be seen as an extreme example of. Adopting a critical conception of ideology whereby the relation between the production of meaning and the function such meaning extends to is problematised, Hier (2002b, 2008) argues that an examination of how panic discourse works to recruit its members and demonise its target will 
reveal the foundations from which it emerged (see also de Young, 2004, 2008). In an extension of his 'rethink' of moral panic, Hier (2002a, 2008) argues that the proxies of risk, harm, and personal responsibility that are characteristic of contemporary panics are also visible in more routine practices of moral regulation under neo-liberalism. In the next section I examine how he locates the volatility of moral panic within a context of wider practices of governance. I then consider how his 'rethinking' of moral panic addresses the relationship between real-types and the ideal-type.

\section{Volatile Episodes: Moral Panic and Moral Regulation}

Drawing on Valverde's (1994) model of moral capital, Hier (2002b) envisages the 'moral' as dispositions and habits that are constituted through and naturalised through a process of a 'calling' to engage in particular practices of 'care for the self'. That is, we are now asked to take on responsible forms of personal risk management. ${ }^{31}$ But how is this assured? Hier (2008) argues the notion of the responsible individual sits against a collective subject position of 'harmful other/s'. This/these are abstract subject/s that represent the potential threat that risky behaviours pose, and the potential harm that could entail from those threats. Hier (2008) offers the example of the discourses which call us (individually) to drink responsibly and how these sit in tension with (and yet rely on) the discourse which represents the collective harm of the drunk driver. In other words, I will (it is my moral calling to) manage my drinking so as not to become the 'risky' other (harmful to the wider group), and to manage my activities to avoid becoming subject to such harm. Yet I know of these duties only with the drunk driver's ethereal presence.

However, moral callings are not always heeded (or seen not to be heeded). At such conjunctions the abstract subject position is filled by identifiable person/s. The threat then becomes more specific and the harm less preventable via our own

\footnotetext{
${ }^{31}$ The 'calling' is on behalf of spatially and temporally situated bodies such as the church, professional organizations and interest groups. For Hier (2008) the state only comes into the equation by responding to limit the agency of those who do not heed 'calls'.
} 
actions of risk aversion. Thereupon, a collective discourse of risk management moves in against an immediate and personalised dimension of harm; the everyday dialectic (of individual risk management against the collective dimension of harm) is momentarily reversed. Put simply, when everyday practices of regulation in which the subject is asked to act responsibly fails, this subject is seen as a danger and limitations are then put upon his/her agency via defensive activity on behalf of the wider group. For Hier $(2002 b, 2008)$ these are moments of moral panic; or, moral panics are a volatile manifestation of routine processes of moral regulation.

Hier (2003) recognises the relationship between real-types and the ideal-type in that he critically assesses real-type discourse to inform his idea of what the idealtype can be seen as an extreme example of. However, at the same time he puts paid to that relationship as, akin to Critcher's (2003, 2006) fortification, he weakens the boundaries of the ideal-type by locating its volatility within wider social processes that are common, general, and less than fantastic. Indeed, in response to Hier's work, Critcher (2008: 9) suggests that the relocation of moral panic into the field of moral regulation risks "encompassing potentially any topic within its remit" (emphasis added). This may be because Hier's focus is also upon the discourse inside a panic, and while he acknowledges that contextual shifts have lent to changes in how panic discourse appears, he lacks attention to the ways by which such shifts may allow us to view why panics erupt in the first place or have altered the very foundations upon which modern panics emerge. This is reflected in his attribution of 'insecurity' as a causal variable in the 'age of moral panic' which I argued in Chapter One was problematic. Critcher (2008, $2009 \mathrm{~b}$ ) goes on to argue that better specification of the scope of moral regulation is needed whereupon we might clarify the boundaries between those issues that are merely dissident of regulatory discourses and those that are more likely to erupt into panics. He suggests a dimensional categorisation (separate to his own three-dimensional framework for the study of individual cases of moral panic) based upon how an issue is discursively constructed; as a threat to basic values (the moral order dimension), the extent to which there is a proposed solution (the 
social order dimension), and the regulation of others insofar as it requires the ethical formation of the self (the governmentality dimension) (Critcher, 2008, 2009b). It is those issues that score high on the first two (child sexual abuse, violent crime, asylum seeking) that are potential panics; issues such as smoking, obesity, and sexually transmitted diseases score high only on the third, and as such, are not likely to generate the same language of 'evil'; their perpetrators probably less subject to the same degree of social expulsion. ${ }^{32}$

Critcher (2008) also questions whether the moral regulation literature shares the agenda of critical research, observing Hunt's (1999) outright rejection of any potential relationship (between panic and moral regulation) in addition to a similar hesitancy on behalf of Moore and Valverde (2000). ${ }^{33}$ Hier (2008) is quite clear that his intentions for 'rethinking panic' in terms of regulatory processes are about moving beyond what he terms the 'revisionist works' (in particular de Young, 2004; McRobbie, 1994a; McRobbie \& Thornton, 1995) which still rely upon "cognitive, behavioural, and normative measurement criteria" (Hier, 2008: 180). Hier seeks, in other words, to understand panic as a 'rational' response however 'irrational' its appearance seems to the analyst or what prejudicial ends are served. However, as argued in Chapter One, it is the whole reaction that is denoted by panic researchers as 'irrational', after it has been subject to processes of inflammation and amplification independent of any one party's control. Moreover, as Critcher (2009: 32) contends:

If there is no disparity to identify between the reality of the social problem and its representation - if perhaps the distinction between reality and representation is denied - then the whole political point, the urge to social justice, has been lost.

It appears thus far that the contextual question (the location of real-type panics) has yet to bear upon the extreme example or theoretical question (the location of

\footnotetext{
${ }^{32}$ Though, there remains in this categorisation, a focus upon the aspects of function in place of aspects of cause.

${ }^{33}$ This may reflect the tendencies of analyses informed by Foucault's 'governmentality' to view concerns as conceptually and epistemologically incompatible with sociological approaches (see Garland, 1997).
} 
the ideal-type) in the terms that I have proposed. I want to now turn to an emerging perspective that seeks to view the relationship by employing the sociology of Norbert Elias. This is the work of Amanda Rohloff $(2008,2010)$.

\section{Decivilising Episodes: an Eliasian Approach}

The argument begins with Elias's (2000) developmental idea of civilisation as a process entailing an increase in interdependencies at the local level and the growth of state authorities at the structural level. ${ }^{34}$ That is, as populations grow, the division of labour increases so societies become more complex, differentiated, and increasingly dependent on each other. This corresponds with an increasing monopolisation over the control of violence and taxation on behalf of the state. Fundamentally, individuals are compelled towards increasing self-restraint as the state moves into a more executive role; a long-term process that also generates increased mutual identification and a corresponding decrease in cruelty (Rohloff, 2010, see also Mennell, 1990). However, such civilising processes were not conceived of by Elias (2000) as linear and unproblematic; indeed often "several types of change, even in opposite directions, can be observed simultaneously" (Elias, 2000: 450). Elias (2000) termed these 'opposite' changes 'decivilising processes', and others have since proposed that we can identify these through 'symptoms' and criteria (see Mennell, 1990; Fletcher, 1997). However, as Rohloff (2010) argues, while decivilising symptoms may appear as the reversal of civilising symptoms, it does not follow that decivilising processes are civilising processes in reverse. In fact, the long chains of interdependencies and the advances of technology that are characteristic of civilising processes may enable decivilising processes to materialise. ${ }^{35}$

\footnotetext{
${ }^{34}$ Elias (1984) uses the terms 'civilized' in a detached (non-normative) sense to represent the configuration of state processes, social interdependencies, and the internalization of constraint among individuals.

${ }^{35}$ Elias (1996) sees the Nazi regime as a primary example of where civilizing processes give rise to decivilising trends.
} 
Rohloff's $(2008,2010)$ argument is that moral panics can be seen as a short-term decivilising episodes that arise, in part, from civilising processes. There appear three main characteristics to the Eliasian concept of decivilising processes:

... a shift away from self restraint towards restraint imposed by external authorities; the development of behaviour and sensibilities that generate the emergence of less even, stable, and differentiated patterns of restraint; and a contraction in the scope of mutual identification between constituent groups and individuals. When these occur they are likely to be accompanied by a decrease in the state monopoly of violence, a shortening of interdependencies, and a concomitant rise of fear, danger, and incalculability (Pratt, 2005b: 259).

For Rohloff $(2008,2010)$ the similarities with panic are striking when we consider, for example, the attribute of 'concern' and the impetus that 'something must be done'; 'hostility' and 'volatility'; and the creation of an 'other' or 'folk devil' who leads to a decrease in a shared identification and an increase in cruelty (whereupon calls for extreme measures to counter the problem and its perpetrators are deemed legitimate). ${ }^{36}$ But to avoid merely applying decivilising symptoms to a moral panic and determining that panics are indeed decivilising episodes (much the same way as one might apply a heuristic moral panic model and state that this phenomena qualifies as a moral panic), Rohloff $(2008,2010)$ argues for the empirical assessment of the interplay between civilising offensives (deliberate attempts by a person or group to initiate changes in behaviour of another person or group - to 'civilise' them) and long term processes (both decivilising and civilising). For Rohloff $(2008,2010)$ the identification that offensives (though they are means through which increased 'civilising' is sought) may contain decivilising symptoms, opens up the conceptual space for examining campaigns such as those undertaken by 'moral entrepreneurs' (Becker, 1963) during moral panics.

\footnotetext{
${ }^{36}$ Similar to his criticism of Hier (2002a, 2008) Critcher (2008) would note that Rohloff (2008, 2010 ) is here interchangeably employing the attributional model of moral panic with the processual.
} 
Using a figurational approach, Rohloff's $(2008,2010)$ research focuses firstly on the content of the documentary An Inconvenient Truth presented by former United States presidential candidate Al Gore. This she identifies as a moral entrepreneurial campaign. Locating several themes akin to panics (for example the event of hurricane Katrina as a prediction of things to come; the imagery of Katrina to symbolise potential devastation) this real-type occurence is explored in terms of its relationship with either civilising or decivilising symptoms. Her conclusion is that we might view moral panics as decivilising episodes which both further and counter civilising processes. The call for increased self-restraint with regard to the consumption of consumer goods in An Inconvenient Truth, for example, may be seen as reflective of longer term processes of increasing mutual identification. That is, there are/were already trends evident of increased foresight and recognition of the interdependencies of human beings with nature; already movements toward consumer restraint. Gore's campaign and its prophecies of doom attempts to accelerate this pattern.

Rohloff's $(2008,2010)$ focus is upon how moral panic can be located as an extreme example of something by looking at the relationship between real-type episodes and their contextual locations. Consequently, of the thinkers involved in the project of 'rethinking moral panic', it is her assessment that is most in line with my proposals. However, there is little of a distinction between a real-type episode and the ideal-type concept and therefore an evaluation of this relationship. This can be seen in her anticipation that entrepreneurial efforts may initiate new categories of deviance by creating a moral divide between those who adhere to the callings of the campaign and those who do not. In itself, this development may stimulate panic, however, Rohloff $(2008,2010)$ suggests that it is increased interdependencies that are more likely to generate conditions within which moral panics thrive (and hence our 'age of panic'). In line with Beck (1992) she argues that the expertization of knowledge may be seen as a long term unplanned civilising process (akin to the monopolisation of violence). But knowledge has to be mediated, and so a monopolisation of knowledge (on behalf of experts) coinsides with a demonopolisation of knowledge (the mediated version). In addition, 
increases in technology have enabled a plurality of claims in a variety of mediums to be heard (McRobbie \& Thornton's (1995) 'multi-mediated social worlds'). This contributes to make claims of danger increasingly incalculable, and increasingly contestable, both of which have implications for the success and failure of panics.

Like Hier, Rohloff $(2008,2010)$ is also keen to dispute the notion that moral panics erupt on the back of 'irrational' behaviour. Her argument is that the goal of establishing disproportionality relies on an involved analysis (from an invested position), and thus closes research to the possibility that a social reaction may not be an irrational peculiarity. This is why the figurational approach is attractive. It circumscribes a relative detachment principle (where the sociologist is neither completely involved, nor completely detached from the subject matter), which is viewed as being more conducive to increasing the 'reality congruence' (and decreasing the 'fantasy content') of knowledge (see Bloyce, 2004; Dunning, 1992; Elias, 1978; Maguire, 1988). Rohloff's position is that questions such as 'how do particular social problems lend themselves to panic construction?' and 'how do particular people become subject to disidentification?' are still conceivable, but that they must come after the reaction in question has been subject to inquiry so as to lessen the bias of the researcher intruding into the research (see Rohloff \& Wright, 2010). However, if the 'judgement' is to be made only after the research is done, would the research upon which to make such an assessment be undertaken in the first place? Indeed, the question turns from 'whose side are we on?' (Becker, 1967) to 'why are we doing this?'

In the last section of this chapter, I turn my attention to recent scholarship in the sociology of punishment where the concern for the relationships between realtype phenomena and contextual trends, and between conceptual notions and theoretical locations unfold in a way that reflects the real-type/ideal-type, contextual/theoretical formula that I have proposed for the study of moral panic. Moreover, these works are not overridden with a motivation to diffuse a charge of 
normativity. In turn there emerges a remarkable idea that may be informative for a renewed understanding of panic.

\section{The Criminology of the Other, the Heterogenaic, and Energy in Excess}

Garland (2001) interprets contemporary criminology in terms of two new currents: the 'criminology of everyday life' and the 'criminology of the other'. ${ }^{37}$ The first is late modern in character - it accepts crime as a fact and manages the risk of crime in terms of situations and opportunities. It aims, not to change individuals, but the systems of approaching them, of dealing with them. Its philosophy is:

... a matter not of shared values but of smart arrangements that minimize the opportunities for disruption and deviance. This is a very self-conscious, very sophisticated approach to social order in a complex differentiated society. It flies in the face of traditionalist ideas that see order as emerging out of moral discipline and obedience to authority. But it also subverts the old welfare state of belief, that for society to work, solidarity must extend to all members who must be made part of an all-encompassing civic union (Garland, 2001: 183).

The second emergent criminology is distinctly anti-modern. It upholds order, reinstates authority, asserts an absolute moral agenda, and thrives on the notion of common sense. Offenders thus, are 'intrinsically wicked', dangerous others who threaten our way of being. Social order here requires, in no uncertain terms, a social consensus, but it is a consensus of "a pre-modern, mechanical kind - based upon a set of shared values not a pluralism of tolerated differences" (Garland, 2001: 185). Distinguishing between the two criminologies, Garland (2001: 184) writes:

If the criminology of everyday life de-dramatizes crime, treating it as a routine part of the normal scheme of things, this other criminology re-dramatizes it - depicting it

\footnotetext{
${ }^{37}$ Both, notably, are a response away from the correctionalist criminology (or penal modernism) of past decades and its perceived failures.
} 
in melo-dramatic terms, viewing it as a catastrophe, framing it in the language of warfare and social defense.

Garland (1996, 2001) interprets the irrationality that underpins this 'other' criminology as a 'strategy of denial'. Drawing upon Nietzsche's (1963) claim that the modern state can only exercise tolerance and mercy in times where it is secure in its own power (and territory), Garland (1996) identifies the criminology of the other as a symbolic reassertion of state power that occurs when its sovereignty has been challenged; when the limits of the state have been revealed for their capacity. In such times, the consistent challenge that is presented by the criminal needs to be dealt with more fervently than in times of perceived security, and this is often achieved via a "recourse to a dramatic and festive display of violence" (Hallsworth, 2000: 149).

There are already parallels to be made between Garland's (1996) notion of dangerous others and Hier's (2003) conception of the 'enemy stranger' as a new form of 'folk devil' in contemporary 'risk' focused moral panics. Both initiate increased state action and facilitate the erection of boundaries between us and them. However, unlike Hier's generality in his conjecture of what moral panic might explain, there are limits in terms of applying Garland's (1996) argument beyond panics that are not specifically crime centred, or have as their precipitating event a criminal act. In what I see as an important extension of Garland's work, Hallsworth (2000) locates the criminology of the other within a re-emergence of an economy that is undermining many aspects of the modern project.

Drawing on the work of Georges Bataille, Hallsworth (2000) argues that the irrationalism and emotionalism of the 'criminology of the other' reveals its place within the 'heterogeniac'. This is a term used by Bataille to describe features of social life that escape categorisation within the 'restricted economy of limits' - an economy that emerged with capitalist exchange and relations of productivity which now permeates through all areas of modern social life. Hallsworth (2000) argues that the shift towards principles guided by this restricted economy can be seen in how modern penal systems were reorganised from premodern 
'spectacular' and 'festive' displays of law enforcement to a productivist ethic of redemption and rehabilitation, conducted under a panoptic order. He contends:

Like Weber's religious ghosts in an age of rationalisation, the modern penal order had little space for excess in a world defined by a more rational calculating ethic in which the 'cruel and unusual' would have no place (Hallsworth, 2000: 152).

For Hallsworth (2000) the punitive shift that can be seen gaining ground in many western nations in contemporary times is an indication that the features relegated to the heterogenaic are again surfacing and combining to undermine the positive practices and outcomes of a utilitarian approach to justice. He provides some formative examples, from the ferocity of the Californian three stikes law which has seen 192 people incarcerated for life for the possession of marijuana to the mandatory 15 year sentence in New York for the possession of two grams of cocaine (the same sentence is given in this state for murder) (Hallsworth, 2000: 154). However, this is where a notion of a normative judgement becomes somewhat mute. Though intrinsic to punishment is the expression of emotion (and this is regardless of what rational or instrumental ends are added into the equation, see Steen \& Bandy, 2007), on the whole responses to crime can be located along a continuum that has at one end the values of liberty, due process, and human rights, and at the other end security, crime control, and retribution. A response or punishment that is too far along the former end sees the state fail in its obligation to ensure order and one that is too far along the latter risks intruding into citizen rights. Therefore, though ultimately there is still a sense of 'judgement' on behalf of an assessor, there is a balance to attain that relies on a measure that is more particular than one defined by left or right politics (indeed, it transcends these paradigms) (see Tonry, 2001). This is arguably why scholars are less likely to concern themselves with - or be accused of - polemic assessments. Moreover, as Steen and Bandy (2007) suggest, what tempers any trend of responses and ensures (in the end) this balance is fiscal realities. Incarcerating 192 people for life for a relatively minor offence is an unnecessary burden on the tax-payer; one that impinges on the economic security of the law-abiding. 
Nevertheless, reflecting upon Hallsworth's (2000) argument, and seeking to explain why current punishment trends sit too far along the security/control/retributive end of the spectrum, Loader (2009) identifies that responses to crime do not exist outside of and in isolation from other social/cultural/political phenomena. Indeed, in order to examine trends and movements within the penal realm, one must consider the relations between these trends and movements with other, more general social practices that can be characterised by a tendency towards excess. He argues:

Consider for a moment the following features of contemporary social life: cheap air travel; SUVs (coupled with an increase in the size of all types of car); chocolate in breakfast cereals; double-sized Mars bars; rising rates of childhood obesity; the disappearance of 'small' cups of coffee (or indeed of any take-away beverage); cheap alcohol; the quick and easy availability of credit; the instant access to information, images, goods and people afforded by mobile phones and the Internet; cosmetic surgery; the social worship of footballers, celebrities and entrepreneurs; the explosion of corporate pay; 20/20 cricket, multi-channel television and so on and so on. What these seemingly disparate things commonly give effect to and symbolise is the idea that the world is - or at least ought properly to be - organized so that one's immediate desires can be instantly satisfied in ways which often permit one to disregard, perhaps even trample over, the interests, feelings and well-being of others. It is a world that pays homage to self-regarding self-fulfilment; where speedy access to what one craves is paramount; where the great enemies are obstacle and delay (Loader, 2009: 242).

For Loader (2009) the excess in all of these things, together with the beliefs underpinning demands for security and punishment in the modern era, is marked by and can be explained by an appetite which is propogated by a familiar cluster of features (familiar, that is, for a student of moral panic); increased understandings of and sensitivity to risk, a climate of anxiety, increased media attention, an absence of community, political responsiveness to lay desires (in a climate of deference) and so forth. I will reflect on this common ground in a moment. For now I want to briefly demonstrate how these ideas can be seen in the terms I have proposed for the study of moral panic. 
First, the 'criminology of the other' and the 'criminology of everyday life' describe real-type responses to crime. Hallsworth's (2000) location of the 'criminology of the other' in the spaces of the heterogeniac then makes the direct leap - much like Rohloff - into a theoretical reflection. However, Loader (2009) intersects with the notion of an appetite. This can be seen as conceptual insofar as it might be applied to other like phenomena, which he then locates within a context that is particular to late-modern times. Within this nexus of ideas there can be configured a systematic course from real-types to ideal-types, and from an understanding of the contexts in which that relationship resides, an opening for imagining in a more theoretical sense how that relationship can be explained.

Loader (2009) makes moves in this direction by asking why the contextual features described above are all-pervasive in the late-modern era. His answer, along with others (see Pratt, 2008), is that the appetite in each sphere he describes above reinforces another, which in turn reinforces another, reflecting a dialectical relationship between social phenomena and its contexts. He also identifes a tendency (on behalf of the lay public) to intrepret security as identity which is exploited for commerical gain by security market operatives, and by a fantastical claim on behalf of power-seeking political bodies that there can be a 'risk-free' society (see Loader, 2009). Both bear upon and augment the sensitivity to 'risk' and the condition of anxiety. However, I believe that Bataille himself can be instructive here. Fundamentally, Bataille's (1988) belief was that all human (and other worldly) activity has surplus energy; that is, energy that goes beyond what is required for any particular task. This is because all tasks have natural limits on their operation and on their expansion (or sovereignty, as Garland argues). Kosalka (1999) gives the example of how plants use the energy from the sun. As the light and energy from the sun's rays are received, most goes towards the plant's continued survival. The excess is used for either growth or reproduction, or, if that limit has been met (for example, the plant's life cycle is at a stage where reproduction is no longer viable) the excess energy is used for the beautification of folliage, or simply expended onto the ground. In human societies, when the limits of a task have been met, such excess energy manifests in glorious ways 
such as art, laughter, sex, festival, poetry and feasts, or in catastrophic ways like warfare. Indeed, the ways by which a society expends its surplus energy defines that society - as festive, or as destructive. Bataille's (1988) main point, however, is that this surplus energy needs to be discharged. This poses problems for the late-modern era in which we currently reside. The restricted economy of limits that now permeates through social life does not have pre-thought mechanisms for channelling this energy when those limits of expansion have been met, quite simply as its governing principle is the notion of scarcity, not excess. ${ }^{38}$ As Thompson (1997: 606) argues, all that which cannot be assumed under the control of resources for the purposes of capitalist production and exchange; the "unproductive expenditure, profitless exchange, [and] ritualistic, sacred and symbolic activity" is rendered unintelligable and relegated to the margins of everyday life - to the spaces of the heterogenaic.

It can be imagined at this point that such un-discharged energy put aside by the restricted economy of limits would, in due course, manifest itself in uncontrolled and unpredictable ways. It would give reason for the reappearance of a punitive urge and the development of policies that resemble the 'spectacular' and 'festive' displays of the pre-modern order. It could explain the appetite for excess that Loader (2009) identifies, for an appetite gobbles and consumes and discharges energy as much as it might ask for more. Perhaps then it can also explain the freefloating 'anxiety' and 'insecurity' of the late-modern era that are said to propel moral panics and, if it can be imagined that the heteorgeniac has reached a point of overflow - of limit - henceforth the 'age of moral panic'. But can it explain the time-honored processes of moral panic within which the logic of the amplification cycle resides? Is it more than a set of descriptive stages? In the concluding chapter I will revisit these questions in light of the empirical study of 'killer kids' and propose that it indeed can, and that it is.

\footnotetext{
${ }^{38}$ In pre-modern societies the 'gift' and its close cousin the 'sacrifice' was a way to discharge excess (see Bataille, 1988; Kosalka, 1999; Hyde, 1983).
} 


\section{Approaching the Case of 'Killer Kids'}

In Chapter One I argued that I would approach my case study of moral panic as a real-type episode that could be seen in relation to the ideal-type concept. That is, the study of 'killer kids' would be assessed in terms how it met the features of an ideal-type model at the same time as how it deviated and challenged the concept. In the introduction of this chapter, Chapter Two, I identifed that at the centre of a contemporary project of 'rethinking moral panic' was a primary question: what are moral panics extreme examples of? I then suggested that if this was the age of moral panic, then the question of why a panic occurs was more important than ever. Moreover, if the ideal-type was intimate with real-types then what moral panics could be seen as extreme examples of is fundamentally intimate to why they occur. What I would learn about aspects of the particular socio-historical context in which 'killer kids' emerged would be important for imagining how the concept of moral panic can be explained. This is what distinguishes my account from other analyses where context has mattered. As reviewed in the last chapter, both de Young (2004) and Jenkins (2005) superbly located their respective panics within the particular social, cutural, and political environments in which they appeared. But these scholars were not concerned with how those locations could inform an understanding of the concept of moral panic. Hall et al. (1978) remain the exemplar insofar as they understood panic processes as strategically employed to manage a crisis in the interests of the powerful. However, as argued, such an 'elite-engineered' formulation impedes the transferability of the concept for assessment of interest-group and grassroot driven panics. ${ }^{39}$

A review of the work of four scholars contributing to the project of 'rethinking moral panic' revealed that the relationships between the material (real-type) and the conceptual (ideal-type) and between the contextual (why) and the theoretical (extreme example) was acknowledged variably and assessed in different ways.

\footnotetext{
39 Though arguably a strict Marxist account would view the actions of interest groups and communities to be motivated by a 'false consciousness' which the elite would then make the most of by jumping on board in amplifying the said issue and/or implementing institutional measures. As argued in Chapter One, Jefferson (2009) is adamant that Policing the Crisis was not an example of strict top-down Marxism.
} 
Ungar (1992, 2001) placed emphasis upon the material/contextual association which he argued rendered the concept of moral panic problematic. Critcher (2003, 2006, 2008, 2009a, b) focused upon how the concept might be renewed for application across material cases, but left alone how these cases might initiate changes in how the concept is conceived. He was also tentative about whether context mattered. Hier's (2002a, b, 2008) emphasis was upon how the material which he assessed via discursive configurations of risk, harm, and responsibility informed a theoretical idea of moral panic as a volatile manifestation within the more routine processes of moral regulation. This conjecture, however, meant that reactions to relatively benign matters could be seen in the same terms as those that normally stimulate 'panic'. Rohloff (2008, 2010) examined material/contextual/theoretical connections using the figurational sociology of Elias. However, she did not conceive of an 'ideal-type' panic, at the same time as she was concerned to demonstrate the 'rationality' of panic reactions. I then brought into the fold directions unfolding in the sociology of punishment which I argued demonstrated more of a systematic development of the relationship between the material/conceptual and of the relationship of this first connection to the contextual/theoretical. This line of scholarship, though not yet connected to moral panic research, promised to be useful for shifting the approach to panic in clear real-type/ideal-type terms and in such a way that considers how each location (the contextual and the theoretical) can enlighten the other.

With this call in mind, the first task is to employ an approach to case-studies that can guide research in real-type or material, and ideal-type or conceptual terms. The second task is to imagine a way by which the material/conceptual relationship can be extended to include a contextual/theoretical relationship. In the next chapter I discuss how a Critical Discourse Analysis framework would offer a way by which to approach both tasks while retaining a commitment to the idea of 'social justice'. 


\section{Chapter Three}

\section{Methodology}

Method must always be a creative enterprise (Carney, 2010: 31).

In Chapter One I proposed the study of moral panic be approached via the relationship between a real-type material case and the ideal-type conceptual model. In Chapter Two this was extended to include a contextual and theoretical relationship. The assignment for Chapter Three is to explore the ways by which I put these proposals into action for the study of 'killer kids'. Fundamental to my approach is Fairclough's (1995b) three part framework for Critical Discourse Analysis (CDA). I first examine the relationship between a moral panic epistemology and a 'discourse analysis' perspective. Second, I look at how the CDA framework can assist in addressing my proposals and in what ways I amended its categories for a suitable approach for moral panic. Following, and third, I examine the methods this approach informed for the study of 'killer kids'. Because the way in which I structured the approach would have implications for what data would be acquired and used, a synopsis of my data and the collection process is discussed alongside the discussion of methods.

\section{The Epistemology of Moral Panic}

Moral panics are understood as phenomena constructed from the actions of social agents. By corollary, the sociology of moral panic holds that such phenomena can be deconstructed and examined for its disproportionality against a measure of empirical 'reality'. Hence, while it is a constructionist epistemology that underpins the study of these acute and volatile social reactions, it is a contextual constructionism whereupon a value of 'truth' - evident within the specific socialcultural-political environment - is called upon in assessment. These terms and the distinctions between them require some discussion. Burr (2003) argues that a social constructionist epistemology has, broadly, four central tenets. First, research is critical about taken-for-granted understandings. It holds that the world and its objects, subjects, actions, and processes do not reveal themselves 
unproblematically, and that there are no unbiased observations. This is in stark opposition to an empiricist or positivist epistemology which holds that the social world can be uncovered via the same 'scientific' method employed for understanding the physical world, and that there are laws of generality that can be applied across all human societies. Second, knowledge is historically and culturally dependent. Burr (2003) offers the example of the ways non-western terms and understandings are often unable to be translated into western terms and understandings. ${ }^{40}$ The point is there is no essentialism or universalism to human knowledge. Third, knowledge is created and sustained through social interaction. Fourth, and following, knowledge and action go hand in hand. Scholars concerned with social problems - to which the sociology of panic has a close affinity identify that constructionism comes in two varieties (see Best, 1995; Spector \& Kitsuse, 1977). Strict constructionsists argue that 'truths' are constructs as much as any other construct, and as such there is no distinction to be made between them (in assessment). Contextual constructionists - as suggested above - do distinguish between constructs, and 'truths' are employed to test the validity of competing claims.

So why turn to discourse? Phillips and Hardy (2002) suggest that the excavation of 'discourse' is the methodology that constructionism informs. ${ }^{41}$ Others have rightly observed that moral panic lacks a method as such, of its own (see Klocke \& Muschert, 2010). Essentially it can be said that moral panics, because they are constructed through talk and depend upon mediation, are discursive events (see Critcher, 2009b). This is not a fresh observation; indeed, the Mods and Rockers and the mugging episode were both deconstructed by how they were 'talked about' (see Cohen, 1972; Hall et al., 1978). However, new understandings about how and why discourse works in the ways it does have challenged moral panic assessments to adopt a more vigorous and thorough exploration of discourse. For some this has remained prospective (see in particular Cohen, 2002; Thompson,

\footnotetext{
${ }^{40}$ It follows that the reverse is also true. In the Aotearoa/New Zealand context a case in point is the term 'sovereignty' which, in Maori, has no exact translation.

${ }^{41}$ However, there are other means by which the act of 'deconstruction' can be done (see Burr, 2003).
} 
1998). For others it has transformed the research agenda (see de Young, 2004; Critcher, 2003, 2006; Hay, 1995; Hier, 2002a, 2008). A discourse perspective would become central to the ways in which I conducted the study of 'killer kids' and for the approach to moral panic that I both employed and would propose for further research. Before examining specifically how, I want to begin by probing the notion of discourse through the scholarship of Michel Foucault.

\section{Foucault and Discourse}

Foucault's work is the most crucial in the development of a range of approaches that we may broadly group as 'discourse theory'. Essentially, Foucault was concerned with how meaning is produced through connections between particular statements and practices which thereupon "systematically form the objects of which they speak" (Foucault, 1972: 49). In other words, our understanding of and knowledge about our world is derived from the regularities in how it is spoken of, written about, and acted upon. This is not to say that 'things' in our world do not have a concrete reality, but that they do not have meaning outside of how we speak, write, and act with or upon them. As Laclau and Mouffe (1985: 108) explain,

\footnotetext{
An earthquake or the falling of a brick is an event that certainly exists... But whether their specificity as objects is constructed in terms of 'natural phenomena' or 'expressions of the wrath of God', depends upon the structuring of a discursive field.
}

Broadly, Foucault used the term 'discourse' to refer to the 'general domain of all statements', or all utterances and text that have meaning and effects. ' $A$ discourse' refers to a regularity in which we may identify an 'individualized group of statements' that structure our knowledge about a more specific something (Mills, 1997). However, a discourse is never just one statement or text or action but the articulation of a knowledge about a something across a range of texts and institutions. Where there is the same referent, style, and support for a way of saying and doing among a number of statements then we have a 'discursive formation': a system of dispersion (Hall, 1997). 
Crucially, Foucault argues that a discourse can only produce objects and subjects, and divisions and classifications through regular application and with consistent acceptance (Hall, 1997: 49). This depends on the relationship a discourse has with power - institutional power, political power, economic power and so forth. He suggests that a claim to 'truth' resides at this intersection between knowledge and power. That is, nothing is absolutely 'true', a truth becomes once it has assumed an authority (via application and acceptance) and produces effects under that authority (Rose, 2001: 38). Despite this power/knowledge nexus, discourses are always in competition and must labour against other discourses and social practices over questions of legitimacy. This is because power circulates, or "needs to be thought of as a productive network which runs through the whole social body" (Foucault, 1980: 119). A top-down and repressive perspective of the production of 'truth' ignores the microphysics of power; that regularities between discourses may surface from within any level, location, or sphere of society and facilitate change in the way we think, speak, and practice.

Indeed, Foucault's argument is that there is no trans-historical continuity in our knowledges and practices as historians would suggest; rather, that history is a series of radical breaks and ruptures between periods and between one discursive formation and another (Hall, 1997). At the same time, there is no 'author' of knowledge in the sense that there is a specific 'someone' or 'something' that precludes these breaks and ruptures. Discourse 'works' through creating 'subject positions' and we locate ourselves within the position that makes the most sense to us. In other words, as we subject ourselves to meanings, power, and regulation, we become its subjects and it is through us that knowledge is practised and legitimated. However, it is not inevitable that all individuals in a particular period will be subjected and so discourse must organize itself in ways to make sense and to be persuasive (Hall, 1997; Gill, 2000). It follows that discourse will always be historically and culturally located, and this is reflected in Foucault's investigations into the ways discourse delimits the field of knowledge in specific areas of social life in particular historical periods. 
Already it can be seen that there are some key alliances between the study of moral panic and Foucault's more descriptive - what he terms genealogical approach. His essential characteristics of discourse; that it is a social action, constructed and related to institutional contexts, and that it constructs or has identifiable effects in that it delimits a field of knowledge, establishes who is to speak, and prescribes ways in which it is possible to speak about a particular object, issue, or process (Mills, 1997; Wetherell, 2001) are particularly relevant to moral panics. Panics are located in the media, parliament, and pressure groups, include and exclude topics, and lay down the ways by which a problem is perceived (see Critcher, 2003). Further, the notion of power as something that circulates, rather than coerces from above relates to Goode and Ben-Yehuda's (1994a, b) categorisation of panics via their origins with the public (grassroots), moral entrepreneurial or institutional propaganda (interest group), or the top down (elite-engineered). Furthermore, Foucault's notion of the 'subject' and the implication that knowledge is not a deity that produces itself identifies that worldviews and 'subject positions', social relations, and 'reading positions' are how panic discourses mobilise participants (see also Kress, 1989). Employing both these understandings (that is, of power and the subject) promises much for the analysis of how folk devils are able to 'fight back' against their demonisation (see de Young, 2004; McRobbie, 1994a, b).

Despite these alliances, it is the issue of normativity that proves most problematic in attempting to unite Foucault with moral panic. The 'measure' against which one decides a panic reaction is "fundamentally inappropriate" (Cohen, 1972: 204) is but a claim to an essential truth - which for Foucault does not exist. ${ }^{42}$ This has led Critcher (2003) to suggest a panic analysis need only (and that it is legitimate to) appropriate from Foucault the essentials of discourse (as described above) alone. I considered at this point that, though important, these essentials still left

\footnotetext{
42 However, Locke (2004) argues that it might be possible to measure the claims to truth (the claims of moral panic participants) against a 'regime of truth' (an established, accepted knowledge) though privileging the latter on the basis of its endorsed authority. Of interest to the panic analyst would be the ability of claims to erect and cement themselves as impending regimes.
} 
me with a void in terms of how to navigate the relationships between my twin proposals: between the real-type case and the ideal-type concept, and between the context of the real-type and a theory of the ideal-type. Moreover the notion of an ideal-type described by Weber (1904/1949: 90) as a methodological "utopia [that] cannot be found empirically anywhere in reality", appeared at odds with Foucault's genealogical approach. Indeed, comparing the two thinkers on this point, Poster (1984: 15) argues "Foucault prefers to show the limits of the present by juxtaposition with a different past, not with an ideal". ${ }^{43}$ Further, because his focus is upon how discursive and practical conditions facilitate truths and meanings, he refutes the notion that there may be a deeper reason or source theory - for their emergence (see Dreyfus \& Rabinow, 1982). Then again, despite the significance of Foucault's work to the study of discourse, as Gill (2000) observes, there are at least fifty-seven varieties of discourse analysis (which she groups according to their relationships to wider theoretical traditions) from which to choose one's approach. One that offers much to the concerns for this thesis is Critical Discourse Analysis (CDA).

\section{Critical Discourse Analysis}

It is necessary to first comment upon the term 'critical'. The study of discourse is by its nature critical despite that there is a continuum along which to differentiate postmodern approaches (which adhere to a strict constructionist interpretation) and approaches that are more focused upon exposing the unequal power relations in talk and practice (and thus adhere to a contextual constructionism). Indeed, as Locke (2004) explains, even Foucault's approach - with its abhorrence for essential truths - was critical insofar his 'method' sought to challenge traditional approaches to thought; to expose tensions and incompatibilities to be found within concepts that were hitherto believed to be contained. Nevertheless, there can be seen a spectrum of critical approaches to discourse; their shared aim is to embed the data within its social context, for data to be viewed as situated, constructed occasioned (Gill, 2000), and therefore amenable to change (Locke, 2004). Wodak

\footnotetext{
${ }^{43}$ However, see Dreyfus and Rabinow (1982) on the similarities in practice between Foucault and Weber.
} 
(2001) adds that a critical approach involves situating oneself from the data, taking an explicit position (political, cultural, historical - or all three simultaneously), and reflecting on one's work as scholarly; an interpretation (see also Gill, 2000).

Most predominantly associated with Norman Fairclough (1989, 1992, 1995a, b), CDA sits on the more political end of the spectrum of critical approaches. It works with the tenet that there is unequal access to discursive resources, and thus one's task is to expose the often opaque relationships of determination between talk, text, and social practice and the wider socio-cultural environment with all its power relations and power struggles. This foundation appears to fit, quite naturally, with Cohen's (2002: xxxv) proclamation about panics:

... moral panics are condensed political struggles to control the means of cultural reproduction. Studying them is easy and a lot of fun. It also allows us to identify and conceptualise the lines of power in any society, the ways we are manipulated into taking some things too seriously and other things not seriously enough.

Position aside, it is the three-part framework for the study of discourse that was principally attractive of CDA to this study. Fairclough (1995b) identifies that there are three dimensions of any communicative or discursive event that are interconnected but analytically separable; it is written or spoken text; it is the production and interpretation of that text-discourse practice; and it is a moment of social practice (Fairclough, 1995b). Crucially, each 'part' sits in a dialectical relation with each other part. Text, for example is both constituted by and constitutes its production and interpretation and its moment as a piece of social practice, and so this approach is an understanding of the embedded nature of text at the same time as it recognises the potentially transformative properties of that text. These three dimensions of discourse are related by Fairclough (1995b) to three processes of analysis: description, interpretation, and explanation. The relationships between the three dimensions and their processes of analysis are demonstrated in Figure 3.1: 
Figure 3.1. The dimensions of discourse and processes of discourse analysis for understanding a communicative event, adapted from Fairclough (1995b: 98).

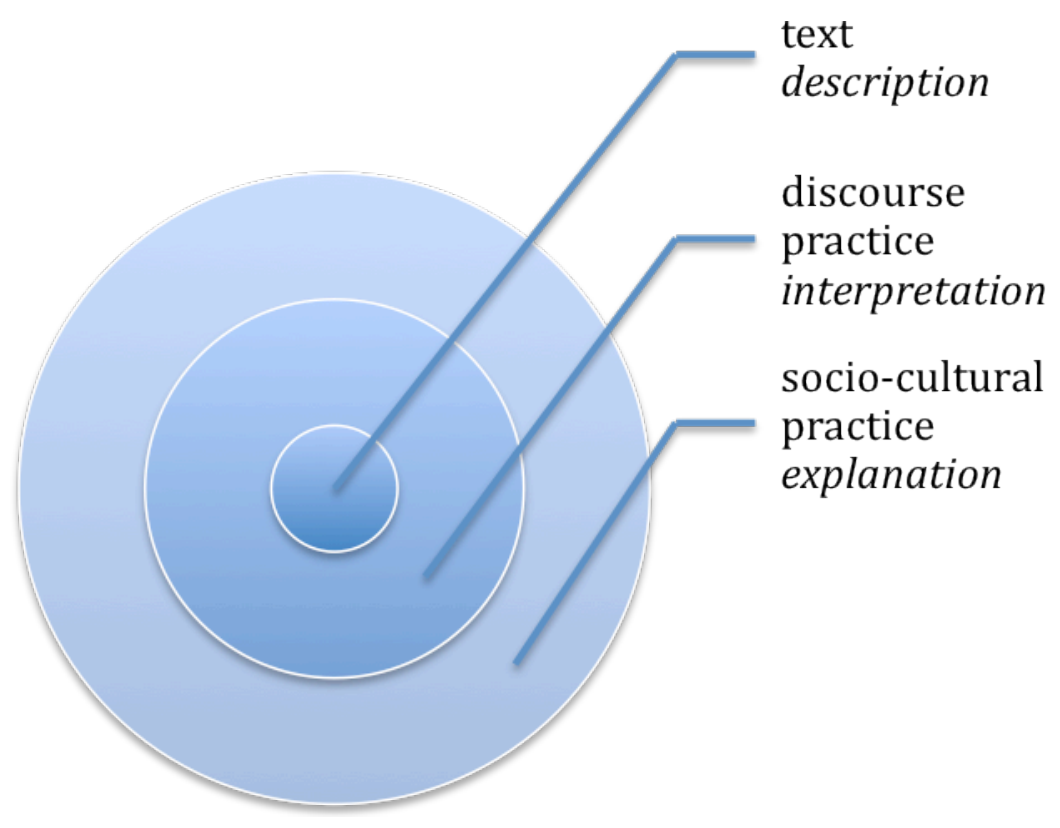

Fairclough (1995b) goes on to say that the analysis of discourse (or $a$ discourse) involves two complementary foci; of 'communicative events' and of the 'order of discourse'. A 'communicative event' or 'discursive event', as indicated, is 'an instance of language use" (Fairclough, 1993: 138) that is examined via the relationships between the three interrelated dimensions (text, discourse practice, socio-cultural practice). Fairclough (1995b) argues that the CDA analyst should always be concerned here with continuity and change; that is, how the communicative event continues familiar ways of expression, and supports familiar cultural notions, at the same time as how it may be creative - using old resources in original ways and challenging meanings. The 'order of discourse', on the other hand, refers to the "totality of discursive practices of an institution and the relationship between them" (Fairclough, 1993: 138), or the "discoursal organisational logic of a field" (Chouliaraki \& Fairclough, 1999: 114). ${ }^{44}$ It follows that orders of discourse are made from particular configurations of discourses and genres (discourse types), and the analyst is to (again) examine how such

\footnotetext{
${ }^{44}$ Another way of articulating (and understanding) an 'order of discourse' is to view it as Discourse (capitalised - see Gee, 1999) or as a discursive formation (Foucault, 1969).
} 
configurations both shift and stay the same in relation to the context of social and cultural changes. Fairclough (1995b) stresses that these (communicative event, order of discourse) are not alternative foci, but two corresponding perspectives that one may swing between in analysis.

\section{Operationalising CDA for Moral Panic}

How are these qualifications of CDA significant for the purposes of this dissertation? I suggest that a real-type moral panic (say, about drugs, or child sexual abuse, or murderous teenagers) can be imagined as a 'communicative event'. In turn, the ideal-type moral panic can be imagined as an 'order of discourse'. It is Fairclough's (1995b) argument that the analysis of discourse practice (which is the link between the textual and the socio-cultural) is, in part, an examination of how far the communicative event draws upon the order of discourse (normatively or creatively) and how far it then affects the order of discourse - reproducing or recreating its boundaries and relationships. In moral panic terms it is an assessment of the relationship between a real-type (constituted by text, discourse practice, and socio-cultural practice) and the ideal-type.

I identified in Chapter Two that I would need to contextualise my real-type panic in order to answer one of the big questions; why? By imagining the case of 'killer kids' as a communicative event, and via the three-process framework for analysis, I could examine the ways by which the episode materialised (and how they materialised) was dependent upon what was going on in the socio-political environment at that point in time. ${ }^{45}$ However, I also needed to imagine how the

\footnotetext{
${ }^{45}$ This structure is not dissimilar to Critcher's three dimensions for the study of panic, to which I am indebted for direction (see also Garland, 2008; Valverde, 2006). However, in Critcher's proposal, processes are made up from discourses, and it is within and from the discourses that we can determine what part of the moral order had been offended. Critcher's 'discourse' then, refers to text and discourse practice within a bounded panic trajectory (processes, or set of practices) and in relation to a socio-political context. As argued, this approach does not address either 'bigger question' of moral panic research (that is, why this or that panic has occurred and of what are moral panics extreme examples of) for the reason that it leaves undeveloped the relationship between processes and context. By employing discourse as Fairclough (1989, 1992, 1995a, b) proposes - a three part inquiry of text, discourse practice, and social practice, we can begin to view from where a particular panic discourse emerges and dissipates; that is, the socio-political context becomes as much a part of how and why a text (and a discourse) materializes as opposed to a semi-detached and after-the-fact feature. In this way, the concept of 'discourse' becomes more than a connective variable; it is the central means through which we can view how the processes
} 
ideal-type (informed by my real-type) could be understood theoretically in order to offer an answer to the other big question; what are moral panics extreme examples of? Fairclough's view was that 'orders of discourse' were very much embedded within their socio-cultural environment. In other words, what the order might be 'an example of' was as much a material question as why the communicative event had materialised in the way it had (see Jorgensen \& Phillips, 2002). This reflects that an 'order of discourse' (in Fairclough's terms) is not quite as allegorical as an 'ideal-type' and so the ways by which an 'order' might be understood via connections to social theory are not essential, if necessary at all. However, inadvertently, this qualification would fit with my proposal that the project of 'rethinking moral panic' had moved too hastily in locating panics theoretically, and that the answer to what the concept of moral panic (the idealtype, or order) was an extreme example of was dependent upon a collation of contextual answers (the why of real-types, or communicative events). For the proposals for the study of moral panic put forward thus far, I amended Fairclough's three-part framework for an analysis of the relationship of the communicative event with the order of discourse, as Figure 3.2 demonstrates.

of panic come into play, and how and why the content of those processes belong within a particular socio-historical period and to a particular socio-political environment. 
Figure 3.2. The dimensions of analysis for understanding a moral panic contextually and theoretically via the relationship between a real-type and an ideal-type.

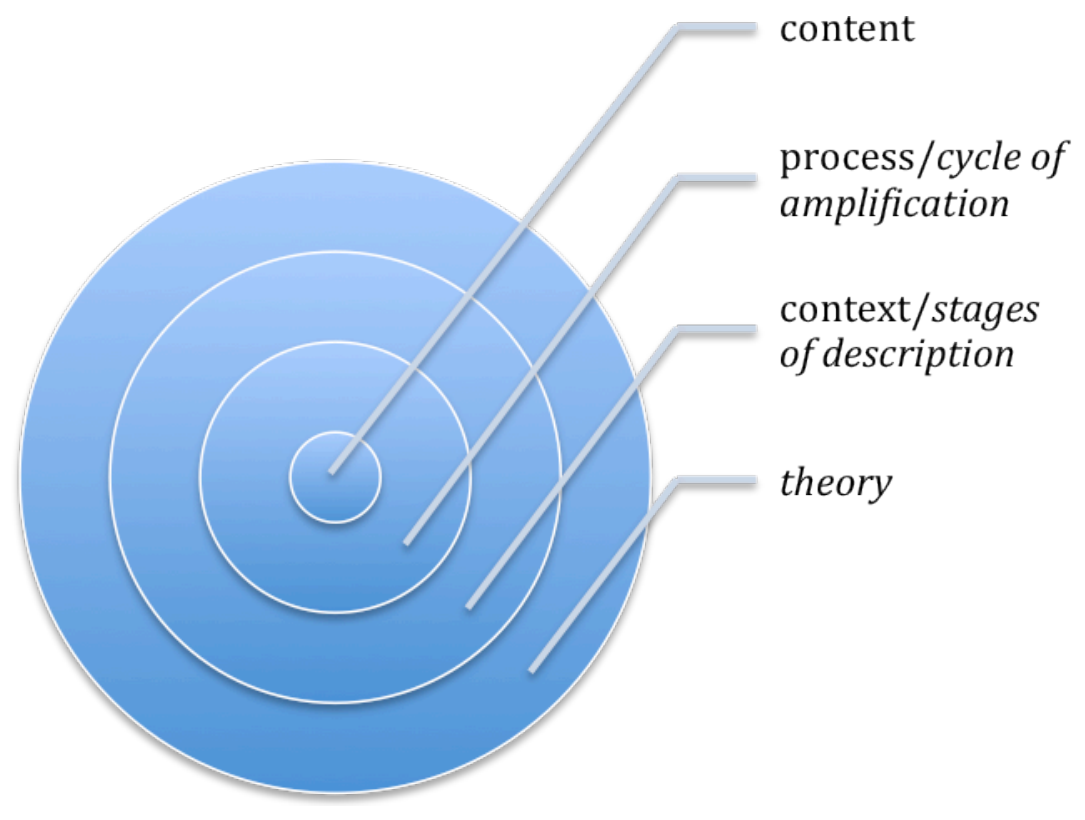

Figure 3.2. is not a substitute for Figure 3.1, but can be seen as an extension of it. Where Figure 3.1 prescribes specific processes of analysis (description, interpretation, explanation) alongside each dimension of the communicative event in question (text, discourse practice, and socio-cultural practice), Figure 3.2 identifies at what points an analysis of the relationship between a communicative event (a real-type) and an order of discourse (an ideal-type) can be seen. It encompasses the notion that the practices of discourse are as much a part of an order as they are particular to a communicative event. The three dimensions of the communicative event remain, but with changes. First, I have changed the category of text to content. Although Fairclough (1995b) argues that text is multisemiotic and thus able to capture other modes of communication such as images, photographs, sounds and so forth, the term content, I argue, more aptly captures the idea that there is something inside of (and independent of) each and any mode that gives it its meaning. I have also reworked 'discourse practice' into process and 'socio-cultural practice' into context. The former is to reflect the ways by which a moral panic develops via processes of amplification (which include discourse practices); the latter I changed not so much to reflect a change in 
category, but for it to 'fit' procedurally (and aesthetically) with the other changes. I examine each of these revisions further in the sections below. Further, because a moral panic can be distinguished as having stages in which processes unfold, I wanted to imagine that the ideal-type moral panic (the concept) could be seen as having two levels at which it has identifiable 'discoursal arrangements'; one internally at the level of discourse practice (process), and one externally at the level of the communicative event as a whole. Thereupon, there are two levels at which analysis can look at the relationship of the real-type with the ideal-type. The first; the cycle of amplification, can be explored during an examination of the second part of the communicative event; discourse processes. The second; stages of description, can be looked at adjacent to the analysis of the communicative event as it comes to a close with the study of context. ${ }^{46}$ As argued above, theory the third part of the ideal-type equation - comes after the real-type/ideal-type relationship (as it pertains to the communicative event) has been explored.

In sections below I focus upon the relationship of my methodology - this amended analytical structure - with the methods employed. Indeed, I have organised the sections by the real-type categories of empirical enquiry; content, process, and context, pausing to reflect upon how I would examine the relationship with the adjacent categories of the order of discourse (at each level) and the proposition for what moral panic might be seen as an extreme example of (theory) where appropriate. Prior to this, I give a detailed synopsis of the data employed. However, as mentioned earlier, the amended structure determined that further sources were needed, and I identify these where appropriate.

\section{Data}

I determined that primary data set for the episode of 'killer kids' could be found in the media coverage over the course of the issue; all 'hard news' reports, articles, editorials, and features relating to the event of the murder of Michael Choy, the trial and incarceration of the youths convicted, and the formulation of the Young

\footnotetext{
${ }^{46}$ The 'stages of description' can be seen in relation to Cohen's opening paragraph; the stages (or parties) by which a moral panic can be identified; the 'processes of amplification' refers to the interaction between those stages (or parties) involved.
} 
Offenders (serious crimes) Bill from the period of the time of the event (September, 2001) until the period immediately after Bailey Kurariki was released from prison in April, 2008. This sample period is important for although the image of Bailey did not appear until August 25, 2002, as I am working with the hypothesis that 'panic' erupted only upon its appearance, it is imperative to view data back to the date of the event itself to ascertain the nature of the shift in media coverage thereafter. Moreover, the issue remained relatively newsworthy between 2002 and 2008. Immediately after Bailey's release, however, media attention waned. $^{47}$

From the print press, I chose to use four broadsheet newspapers that are published daily in each of the four main cities of Aotearoa/New Zealand; The New Zealand Herald (Auckland), The Dominion Post (Wellington), The Press (Christchurch), and The Otago Daily Times (Dunedin). ${ }^{48}$ Although all of these four are readily available alongside regional papers in all cities and towns relative to location (The Dominion Post is available in Wairarapa for example; The Press can be bought in Blenheim), I also chose several regional papers; the Waikato Times, the Taranaki Daily News, The Southland Times, The Manawatu Standard, and the Nelson Mail. The choice of these publications was determined in part by access (these can be found on the same database as the main four, whereas the nine other English language regional newspapers could not be located this way), and in part as their respective audiences were significantly larger than the other, smaller papers. But fundamentally, the choice to also look at regional papers was because preliminary analysis showed that while at most times the storylines between both the main and regional papers were consistent, there was, at particular periods, a distinct variation. The murder of Michael Choy occurred in South Auckland (an area oft termed 'the Badlands' for its profuse poverty and gang related problems) and it may have been that the 'big' and distant issue needed to be given specific resonance to the smaller issues closer to home. In light of this, I also chose two weekly newspapers available in all cities and towns to provide a consistency

\footnotetext{
${ }^{47}$ Though, as I point out in Chapter Six, he remained 'newsworthy'.

${ }^{48}$ I term these 'broadsheet', though the Aotearoa/New Zealand press environment has a conspicuous absence of alternative genres or 'tabloids'.
} 
'check' of sorts; to ascertain what points of the story appeared to resonate across the board; the Sunday Star Times and the Sunday News. One further note; I have included (but not differentiated) three associated websites as part of this data set that are the online versions of the printed press; www.nzherald.co.nz (The New Zealand Herald), www.odt.co.nz (The Otago Daily Times) and www.stuff.co.nz which is the website of Fairfax Media, the press organization that owns the remaining publications stipulated in this sample. These websites were important to include for two reasons. First, though at the beginning of the working day reports and articles in print are also published here, the sites are able to be updated regularly. Therefore some articles that appeared on these sites did not appear in print. Second, it can be assumed that many people source their 'news' (either solely, or in addition to other media) from such sites. 'Stuff' (www.stuff.co.nz) for example, boasts one million browsers daily.

Using the newspaper database EBSCOhost and employing the search terms 'Michael Choy' or 'Kurariki' I located 344 relevant articles within the period August 2001 - May 2008, in digital form. Using this information, those articles with accompanying images were then retrieved in their original print form from the National Library of New Zealand archives $(n=71){ }^{49}$ This was to ascertain how many different images were used and which of them were used in relation to which discursive thread or theme (described below). I chose not to locate all original articles predominantly because my interest was less in the aesthetic features of format (layout, etc.) and more in the substantive ways in which threads and themes (and images) were dependent upon narratives and sources.

The second part to my data sample was the televised coverage. Aotearoa/New Zealand has six free-to-air television channels; three with regular news slots and current affairs commentary. I chose to approach the public-owned channel Television New Zealand (TVNZ) for their coverage, namely as this is Aotearoa/New Zealand's largest television broadcaster and, perhaps, the one with the most clearly defined 'social' responsibilities. It is argued, for example:

\footnotetext{
${ }^{49}$ This number does not include the images of Bailey as an 18 year old, which appeared at the end of the sample $(n=15)$.
} 
The TVNZ Charter provides a guide to our broadcasting responsibilities and makes it clear that TVNZ's role is to reflect and explore what it means to be a New Zealander. To New Zealanders this unique and special responsibility means quality television that educates, informs and entertains through local home grown programming and the best of international programming (TVNZ, 2008).

Though by principle it is television that is the most 'visual' of media, locating the televised imagery in its original form proved difficult. I was able to purchase copies of original news bulletins and programmes relating to the event and the issue, yet all frames in which Bailey (and his co-accused) appeared were restricted for resale, just as the newspaper images were, and thus 'blacked out'. Therefore, I had to rely upon my own ad hoc recordings captured at those times I was alerted to Bailey's appearance in the news which I then matched with TVNZ's provided 'shot-lists' (that is, written descriptions of what was in the frames originally). Moreover, this part of the sample is not complete due to the expense of the copies and restricted funding on my part. Through a number of negotiations with TVNZ's purchasing officer I aimed for a balance between the visually and the verbally dominant bulletins and programmes, the 'hard news' versus commentary, and chose accordingly $(n=32)$.

\section{Content}

I define content as the substance or material in 'text', which is analytically distinct from its form or style. ${ }^{50}$ At the surface of the communicative event, it is here where meaning is accessible, and patterns of meaning can be traced. It is useful at this point to make a distinction between text and discourse (as it will be seen, both are important in how the content of 'killer kids' could be examined). Text, for Fairclough (1993: 138), refers to "the written or spoken language produced in a communicative event". 'Discourse' is used in two senses of the noun. As an abstract noun it refers to "language use conceived as social practice" (Fairclough,

\footnotetext{
${ }^{50}$ Social semioticians argue that this is artificial; that the content of a message cannot be separated from its form or from the perspective and interest that are embedded within (see Hodge \& Kress, 1988). However, Valverde (2006) argues that by bracketing the question of 'how' and 'in whose interests', the fine texture of representations - and the slight but significant differences between content and form - can be examined more thoroughly.
} 
1993: 138), or all utterances and texts that have meaning and effects. As a countable noun, it refers to a "way of signifying experience from a particular perspective" (Fairclough, 1993: 138), or a regularity in which we may identify an 'individualised group of statements' that structure our knowledge about a more specific something (Mills, 1997). The two nouns can be distinguished with the use of an indefinite article; thus we can refer to 'discourse' (abstract) and 'a discourse' (countable). ${ }^{51}$

\section{Describing content}

Fairclough's (1995b) prescription for the description of text is primarily linguistic; that is, how vocabulary (words), grammar (combination of words), cohesion (connections between sentences), and text structure (organisational properties) make up the intricate and intimate properties of text. Cohen (1972) argues that a key part of the inventory of a moral panic is the employment of an explicit melodramatic vocabulary, the use of sensational headlines and metaphors of crisis that work to provide the context in which the event is to be understood. Moreover, at times, the practice whereby key significations are made can be markedly opaque. As Cohen (2002) contends, moral panic discourses are apt at the clandestine operation of drawing out connections whereby this issue is made to appear similar to that other known issue of trouble (this sort of thing), as leading to other unknown potential troubles (it's not only this), or as becoming, on its own terms, an issue of full-size trouble (it will get worse). It is how they achieve appeal, and work to become dominant against their competitors.

However, a conventional CDA analysis usually works with single texts, whereas a moral panic analysis deals with large amounts of data. Moreover, moral panics are characterised by volatility, amplification, and a rush to narrative closure or the imposition of one meaning over an event or issue by various claims-makers and parties. A crucial point of interest is the development of, and the nature of (and the intensity of, across real time) competition between meanings put forth. My task, as I took it, was to trace the meanings (content) created in text and thereafter

\footnotetext{
${ }^{51}$ Where there can be identified a particular discourse - we may use a definite article 'the discourse'.
} 
to examine connections and dislocations between threads of meaning (the volatility of competition and amplification) in addition to exploring their relationships to real time (temporality). In the first action I would be looking for traces of combinations, connections, and organisations that produce meaning and in the second action, I would be looking for how those meanings would come together to construct countable discourses.

Mindful of these qualifications, in practice I followed Gill's (2000) relatively generalised schema for the analysis of discourse in my approach to content. The first step was to employ a spirit of 'sceptical reading'; to tentatively employ my task objectives in 'reading' and organising the data, but to also let the data speak (so to speak) for itself. I began by identifying key passages and statements within each piece, and collating these according to their common threads of meaning across pieces. To give an example, the notion that Bailey Kurariki was an unusual child appeared consistently as a statement for much of the most immediate part of the sample, making for a discursive thread of meaning. Moreover, many subsequent threads of meaning appeared to rely upon this notion as a point of reference for how they developed. As I progressed I then returned to each piece and looked for dissident statements to the discursive threads identified thus far, both evaluating their consequence to the wider sense of emerging meaning, and exploring regularities among them (which would suggest a 'new' thread). This process, as Gill (2000) proposed it would be, required a great deal of going back and forth, forming hypotheses and then testing them against 're-readings'. Of the 376 print and broadcast articles analysed, 104 were included in the final write-up as evidence. These articles had statements within them that most demonstrated the threads materialising in each 'discourse'. Full results of this analysis are presented in Chapter Four.

\section{Process}

For Fairclough (1995b) the analysis of practice examines institutional practices, the intertextual and interdiscursive practices (that is, the ways in which other texts and discourses are used in the construction of the text under analysis) and 
thereupon, the relationship of the communicative event with the identified 'order of discourse'. Each of these will be discussed in turn. As argued above, I have employed the term process to capture the ways by which the discursive practices in a moral panic amplify an issue into something larger than it could have, or should have become. Yet, CDA's 'practice' procedures are still applicable with some specifications. For a moral panic, institutional practices are those primarily of the media, simply because though not all moral panics begin or end with the media (the satanic ritual abuse scare is exemplary - see de Young, 2004; Victor, 1998), or even have the media as their central vehicle, most do. Critcher (2003) outlines the qualifications between the press and a panic. First, the events that often begin a panic tend to be excellent assortments of raw materials for creating or crystallizing attention around a 'good story' (examples), and a 'good story' is crucial for commercial saliency. Second, because such events are usually about or related to deviant acts or persons, the press is able to draw on the simple and yet powerful inferential structure of good versus evil as an explanatory framework. Third, claims-makers and moral entrepreneurs are able to reach a much wider audience with media attention and so the media is often their first (and most important) ally. Thus, as Cohen (1972: 7) argues, "the student of moral enterprise cannot but pay particular attention to the role of the mass media in defining and shaping social problems".

The second part of the practice stage for a CDA approach involves a focus on consumption; the identification of how readers do actually respond (Locke, 2004). However, in a moral panic consumption practices can be seen as immersed within the practices of production. To clarify, I need to revisit, briefly, the debate regarding the role of the public in panic development. I discussed in Chapter One how this role is an empirical quandary insofar as it is difficult to access public concern on a vast scale and in a time-frame that coincides with the typical volatility of 'panic'. 52 Thus panic theorists have tended to equate public attention with media attention at the same time as they have assumed the public as a monolithic mass who indubitably consume media content (for example Burns \&

\footnotetext{
52 The links between discourse and social action is also an identified problem of CDA (see Scollon, 2001; Jorgenson \& Phillips, 2002).
} 
Crawford, 1999). More convincingly, the public's role has been questioned as a necessary variable; its sentiment excused on the basis that the public are spoken for (Critcher, 2003, 2006; Hall et al., 1978), with a more practicable approach being to assume that the panic narrative seeks and is able to mobilise participants and that it does this through inviting (interpellating) through points of resonance with lived subjectivities (see de Young, 2004; Hay, 1995, 1996; Hier, 2002a, b). Examining responses therefore, is an examination of both the relationships between the powerful P's (the press, politicians, the invoked public, pressure groups, and the police - see Critcher, 2003) and the ways of speaking (the texts and discourses) by which they 'define up' the issue in question and construct the countable discourse/s of content (see Cohen, 2002). In this way, it is almost a disclaimer of moral panics that intertextual and interdiscursive practices will be present as by nature they (moral panics) are parasitic upon other texts and discourses in order to dramatise the issue and to sensitise potential 'panickers'. Moreover, the ways by which one discourse emerges as dominant occurs via a reverse process - the clearance of other texts and discourses. ${ }^{53}$

\section{Accessing and interpreting process}

To deconstruct the more overt processes of news-making, particularly, for this case, in relation to crime reporting and the relationships news-makers have with their sources for crime facts and opinion, I recruited seven professional journalists and asked a series of semi-structured questions relating to the ingredients for a 'good story', how raw events are made communicable, and what sources are called upon (for the full questionnaire/interview schedule, see appendix). Despite the vast body of literature to draw from in terms of the institutional practices of the media (see Abel, 1997; Altheide, 1996, 2002; Ericson, Baranek, \& Chan, 1991; Hall et al., 1978; Hall, 1980; Surette, 1988), taking heed of Fairclough's (1995b) assertion that discourse practice is the mediator between the textual and the social and cultural (that is, in real-type terms), I wanted to refrain from relying

\footnotetext{
${ }^{53}$ See Critcher (2009b) on the hierarchies of moral panic discourses.
} 
solely upon secondary resources as they would only afford a part-way account of news-making processes as they pertain to Aotearoa/New Zealand. ${ }^{54}$

Using the snowball method, which relies on referrals from first connections to generate additional connections, contact was made with approximately 100 journalists working here and overseas (these, however, had trained and worked in Aotearoa/New Zealand prior to leaving). Of these, twenty-five returned the call, but I was only able to secure seven of these to follow through to participation. Colleagues had, prior to the process of recruitment, informally warned me that journalists were the hardest group of people to enrol for academic study, in part because of their suspicions of our craft, and in part because their profession demanded they be constantly 'on call' should a story present itself. Thus, I was excited to have got seven participants on board. ${ }^{55}$ Moreover, the quality of their contributions annulled any sense that the quantity of respondents should have been higher.

I began my analysis by organising the interview/questionnaire data into themes, guided by the questions I had asked and again by Gill's (2000) approach to interpreting discourse. I used these themes as an interpretative scaffold for interpreting how the events of the murder of Michael Choy and the subsequent trial of the six youths accused had been portrayed in the press via the documentary data. In order to then see where the proverbial news story ended and the momentum of moral panic took over, I then looked for evidence of the processes of amplification; sensitisation, diffusion, escalation, dramatisation, and exploitation. I was tentative in this exercise, aware that I needed to be sensitive to the real-type development of a 'crisis' with all the nuances and departures that this might have in relation to the ideal-type. Thereupon, I examined the relationship between the real-type crisis unfolding and the internal processes of the moral

\footnotetext{
${ }^{54}$ An awareness also, that crime reporting in Aotearoa/New Zealand was an area underresearched, cemented this decision.

${ }^{55}$ Evidence from six of the seven respondents made the final analysis.
} 
panic 'order of discourse' (ideal-type): the cycle of amplification. ${ }^{56}$ The full analysis can be found in Chapter Five.

\section{Context}

Fairclough (1995b: 57) describes socio-cultural practices as "the social and cultural goings-on in which the communicative event is a part of". The analysis of such goings-on involves the examination of the relationship between the processes of discourse and social processes. Essentially this is achieved via an evaluation of how it was possible for the particular combination of texts and discourses to materialise in the way in which they did in relation to the different levels of the socio-cultural environment - the immediate situational context, the wider context of institutional practices, and the even wider frame of society, history, and culture. Whereas the last stage examines the relationship between the real-type moral panic and the ideal-type (at least at the internal level or processes of amplification) this stage explains this relationship insofar as it is a consideration that the context of which a reaction is part is fundamental to its materialisation; that is, what is inside the theatre is dependent upon what is outside the theatre (Cohen, 1972).

\section{Accessing and explaining context}

Fairclough (1995b) argues there are two parts to the examination of socio-cultural practice (or context). One is to first locate how the text (content) and practices (process) are reflective of context (affected by), and the other is to view how they can be seen as an instance of social practice (affecting of). In practice the relationship between the ideal-type (internally, the cycle of amplification) and the real type explicated in the last (interpretative) stage revealed a compilation of features upon which the cycle unfolded towards a particular direction (rather, a particular discourse, to be identified in Chapter Four). I took this compilation as my guide to a direction for what parts of the 'social' to consider.

\footnotetext{
${ }^{56}$ I need to remind here that it is Cohen's (1972) conception of the ideal-type that I am employing in this study.
} 
However, I was wary of the multiple levels at which the socio-cultural analysis can be explicated, insofar as they offered considerable leeway for recourse into the explanatory variable of anxiety in response to social, moral, or economic breakdown (real or constructed). My argument is not to doubt that there are times where anxiety is a legitimate answer. Indeed, as Garland (2008) identifies, there are many cases where the facilitating conditions towards the construction of a moral panic are in turn successfully illustrated as surface manifestations of deeper sources; anxiety, ambiguity, and insecurity (see also Chapter Two). My argument, here, is that assessments on a whole be more rigorous and more certain with such claims; that analytically (and methodologically) there are clearer links made between surfaces and sources (see Rock, 2007). Therefore, though I did draw from literary sources, in order to remain 'grounded' in context I also drew from an eclectic mix of the text, the interviews with my respondents, editorials, opinion columns, letters to the editor, film reviews, media releases, and websites that were present in and around the same space and time of the primary data sample. It must be acknowledged that this part of the analysis depended heavily on my location within the context in which the episode unfolded. Though I employed the compilation of features that had materialised from the analysis of process as cues to what socio-cultural phenomena might be significant, without my familiarity with such phenomena and its interweavings with other phenomena the final result may have been quite different. Thus, arguably, it is at this point that I may be accused of a polemic assessment. However, as will be seen, it is not the phenomena per se that will be important for my ultimate conjecture of what a panic can be seen as an extreme example of; it is the nature of that phenomena. I suggest that any specific socio-cultural phenomena located for this assessment would exhibit the same character.

It was at this point that I could look at the real-type episode as a whole (a threepart communicative event) and assess its relationship to the ideal-type concept of moral panic in the external sense; stages of description. Did the episode of killer kids fit these stages or depart in a significant way? What bearing would this relationship have upon the concept and thereupon its relationship to what moral 
panics might be seen as extreme examples of? This assessment and the explanation of context are discussed in Chapter Six.

\section{Limitations and Issues of Practice}

When one employs a model in analysis one is always bound by that model to more or less of a degree. Though I was aware that I was to 'let the data' tell the story, and I took great care to be sensitive to its tale, I was concerned about how far the concept of moral panic had ingrained itself on my interpretative thinking. Had I inadvertently worked the data too rigorously against the ideal-type processes of the amplification cycle? Was I blinded, thereupon, to the possibility of another stage, another process at work? Like any scholar, I can only claim that what I have presented here is an interpretation, as Gill (2000) pledged it would be.

Limiting my analysis was my focus upon one case study. As seen, many of the most intricate analyses of moral panic - Cohen's (1972) Folk Devils and Moral Panics, Hall et al.'s (1978) Policing the Crisis, de Young's (1994) The Day Care Ritual Abuse Moral Panic - were one-case studies. This reflects the necessary space required to flesh out the minutiae of real-type panics, but it also means that such accounts suffer from a case-specificity of sorts. My proposal that the idealtype required regular appraisal in relation to real-types, and that the contextual locations of such real-types were crucial to the theoretical location of the concept was essentially a demand that a larger body of empirical work be established, and this is something I have added to in the least possible way. I can defend this by way of my intention to demonstrate an approach to moral panic alongside an analysis of the episode of 'killer kids'. Should the three-part framework outlined in this chapter be accepted as a way forward, perhaps future studies could rework and refine its components for application across two, three, or many cases simutaneously, or, given my argument that context matters, place emphasis upon the context/theory nexus at the expense of content and process in relation to the internal processes of the ideal-type. 
Further, though I had justified that the public were not a necessary variable for the assessment of moral panic, I nevertheless found that I was curious whether there were 'other' interpretations and perhaps, somewhere, grassroots agency on behalf of those 'folk devilled' in this case to 'fight back'. Much of this stemmed from inquiries about my thesis topic from friends and aquaintances, who in turn demonstrated little knowledge about the events of the murder of Michael Choy other than how it had been portrayed in the media. Consistently, for example, Bailey was understood as the 'killer' which clearly indicated that the media are able to sustain their interpretation of events. Another regular theme in comments made was that an 'eye for an eye' justice was the only suitable response. However, when presented with the 'facts' of the case, this attitude consistently changed. With hindsight then, I suggest that the study of public sentiment should be considered as a variable in the development of a panic, if only to establish that there is a lack of understanding, or levels of indifference to what is unfolding between the powerful 'P's' (the press, politicians, pressure groups, an invoked public) which inadvertently permits the amplification cycle to gather pace.

\section{The Empirical Enquiry}

The next three chapters cover the empirical study of the case of killer kids employing the methodological framework and approach outlined in this chapter. In Chapter Four I describe how three countable discourses spanned two distinct phases. In Chapter Five it will be seen that though the real-type case followed the processes of amplification, there appeared no particular logic to their development in relation to each other; rather, the processes were dependent upon a set of material features that operated to propel the cycle from one to the next. These features would provide the cues for identifying - in Chapter Six - that the episode of 'killer kids' resided at the intersection between three social phenomena present in space and time. In turn, it would be these phenomena that would become significant in making connections to social theory. 


\section{Chapter Four}

\section{Three Discourses, Two Phases, and One Moral Panic}

Are our children worse than they used to be? Is this the onset of a wave of hideous child crime, payback for some creeping national deficiency? (Dekker, 2002).

This chapter describes the content of 'killer kids'; the ways in which the episode became meaningful in the media across the sample period. The data is structured into three countable 'discourses' that emerge in a configuration of relationships with each other. The first discourse is a moral reprisal discourse characterized by its attribution of blame to malevolent children, social disorder at the hands of dysfunctional families, and moral decay in the move towards a more 'permissive' society. ${ }^{57}$ The second discourse, a social rescue discourse is set apart to the moral reprisal discourse through its argument for perspective in relation to the inflammatory claims made, for 'the system' to be held accountable, and for the crime to be seen as a result of the social consequences of the free market. The third discourse, a criminal risk discourse, deals with the complex task of addressing 'justice' in addition to community safety and crime prevention. The ways by which it approached these three factors would culminate into the development of a private members Bill proposing the criminalization of children from twelve years of age.

These three discourses operate within two phases: from the appearance of the first news image of Bailey Kurariki up to and including the sentencing of the offenders (from September, 2001 to November, 2002) and from that point until Bailey Kurariki's release from prison in May 2008. The first is an acute reactive phase, where a bevy of explanations and predictions arise with regard to the crime and its perpetrators (and thus we see in this phase the moral reprisal and the social rescue discourses); the second, a less explosive and more lengthy containment

\footnotetext{
${ }^{57}$ This is a familiar discourse to moral panics over violent children, and one perhaps most notably associated with the hysteria over the murder of two-year-old James Bulger by ten-year-olds Robert Thompson and Jon Venables in Britain in 1993 (see Franklin \& Petley, 2001; Green, 2008a, 2008b; Hay, 1995; Young, 1999).
} 
phase, where debate focuses upon the potentialities (both positive and negative) of the custody of the offenders (here, the discourse of criminal risk is dominant).

The discourses have each been organized into the discursive threads from which their whole was constructed. Of the first two discourses (the discourse of moral reprisal and the discourse of social rescue) these threads are presented along a semblance order relating to their account of the crime, the anticipation of an emerging issue, and the identification of a social crisis. It is from the connections and departures in this order that the relationships between the discourses can be seen. The third discourse (the discourse of criminal risk) is presented along an order relating to how to manage risk and then how to prevent it, and it is through the ways by which these measures are sought that the relationships with the 'reactive' discourses become visible.

Before getting started there is a disclaimer to be made. Though the descriptive task is to trace across the top layer of the real-type episode under consideration, because this surface layer is a result of its sustaining layers of processes and of context, there are times at which I do probe beneath it and briefly consider how or why this or that feature has appeared. ${ }^{58}$ Moreover, because the hallmark of a moral panic is the production of a singular, consistent, and incontestable or 'closed' discourse (Critcher, 2003, 2009b) which creates effects that are out of proportion to an empirical reality, there was an ultimate requirement to identify which of the three discourses in attendance commanded the interpretative field of the phenomenon of 'killer kids' and by what measure the effects of this interpretation could be seen as 'out of order'.

At other times, I chose to focus only upon describing despite that what I was describing demanded more attention. A good example of this is the imagery of Bailey Kurariki, which I have argued is central to the development of the episode of 'killer kids'. However, I deal with it only briefly in this descriptive chapter namely because the images themselves did not shift or vary in their content; what

\footnotetext{
${ }^{58}$ In the last chapter, I noted that by Fairclough's (1995b) admission the divide between the three tiers of the CDA framework (upon which my framework is built) is artificial.
} 
did vary - across the episode - were the interpretations of the images and the wider meanings that circled them and it is these that become important in how the threads within the discourses would connect with each other (and disconnect with threads of other discourse/s). The content - or, rather, the preferred meaning (see Hall, 1980) - of the images themselves is better captured in Chapter Five where I look more closely at their production by the media and in Chapter Six where I examine what social-political conditions gave rise to the images' production (as well as their later interpretations and meanings).

I begin with describing the first discourse to arrive on the scene in the reactive phase; the discourse of moral reprisal. This discourse is marked by its disciplinary tone and the way in which it seeks to erect firm boundaries between an inside group and 'evil' outsiders. In this way it can almost immediately be delineated as a panic discourse; however, as the reactive phase developed it would face a hefty challenge from the discourse of social rescue.

\section{Moral Reprisal}

The discourse of moral reprisal began to take form after the image of Bailey Kurariki appeared in the Sunday Star Times on August 25, 2002. However, the groundwork for the threads that would make up this discourse was already under construction with how the media depicted the events of the murder of Michael Choy prior to that appearance. ${ }^{59}$ The scene at which the crime took place, for example, was described as having a long and dark driveway ("Pizza Robbers' Roles Planned," 2002), which was purposely chosen for its dim light and seclusion from the street. Having planned an earlier robbery that was reportedly abandoned when a female delivery person arrived, each role of each perpetrator had been firmly designated prior to the attack ("Pizza Robbers' Roles Planned," 2002) and there had been discussions regarding "how much damage we wanted to do to him" ("Jury Told Of Stolen Pizzas," 2002), to 'silence him' ("Murder Accused Aimed," 2002) before implementing plans for stealing his money, food, and then possibly his car. It was said the accused then placed an order for pizza,

\footnotetext{
${ }^{59}$ In Chapter Five the practices of the media in the construction of the crime story are explored in detail.
} 
and "lay in wait" for Mr. Choy's arrival ("Pizza Robbers' Roles Planned," 2002) whereupon they would carry out their attack with "murderous intent" ("Murder Accused Aimed," 2002) upon an unwitting and defenseless subject.

As will be seen, this would set the tone for how the event would be understood by the discourse of moral reprisal. Another early interpretation of the crime, no doubt due to the timing of Michael Choy's death, was an association with 'terror':

\footnotetext{
The recent killing of pizza deliverer Michael Choy in Papakura by six youngsters, one as young as 12 , was a heinous act as evil as the US tragedy ("Fortuin Pleads," 2001).
}

The aggravated robbery and subsequent death of a pizza delivery man in South Auckland reminds us that evil is also close to home ... [it is] terrorism in suburbia (Sharp, 2001).

The media also placed much emphasis upon the fact that at 12, Bailey Kurariki was the youngest person in Aotearoa/New Zealand's history to be charged with murder. Immediately after the accused were arrested, it was reported: "Gasps of shock greeted the appearance of a sobbing 12-year-old boy in Papakura court" (McLoughlin, 2001). A year later, during the trial, he was described as the "kid next door' ("Murder Accused," 2002) who "was barely able to see over the dock" ("Jury Reach Verdict," 2002). Afterwards, this was identified as "the most chilling aspect of a horrific story" ("Time To Act," 2002). The public would bear witness to this aspect, with that first Sunday Star Times image. In Chapter Five I examine the construction of the image by newsmakers, and in Chapter Six I discuss this image and the others in the set of images of Bailey as units of communication within a regime of representation. Both, it will be seen, informed the text that would, in turn, imply a preferred reading of the image/s. At this point, however, I want to focus on the headline accompanying the first image, which firmly positions it within the discourse of moral reprisal's first discursive thread.

\section{Not your average 12 year old}

The headline reads "Our youngest killer" (Wellwood, 2002; see the digital trace of the original in the Introduction). Indeed, the discourse of moral reprisal's first 
contention was that Bailey Kurariki was no ordinary child; that he was very much the killer the headline claimed him to be. The adjoining text argued he was pivotal in the death of Michael Choy, as it was he who was "nominated to greet him [Mr. Choy], drawing him into the killing zone", and when it came time to strike "it was Kurariki who gave the command" (Wellwood, 2002). The thread would then expand beyond the crime. Former school principals and teachers were cited as describing him as a 'bundle of trouble' even as a new entrant. As he grew older, he was both a chronic truant and was well known to the local police for a series of petty crimes. He had, it was said, been "running riot for years ... terrorizing, beating and robbing other children, encouraging friends to wag school, shoplifting, tagging, sniffing glue and smoking cannabis" (Wall, 2002). One report offered an account of an earlier incident in which Bailey was involved, one that clearly illustrated a predator of "cold-blooded and heartless behaviour" (“Who Is Responsible?” 2002) in the making:

\footnotetext{
The small boy with the cherubic face lingered in a Papakura alley, waiting for his victim to pass on the way to school. Eleven-year-old Bailey Junior (BJ) Kurariki had stalked his quarry and knew this was the route he took each morning. When the boy walked into the alley BJ pounced, punching him repeatedly in the head and leaving him cut and bloodied on the ground. The reason? The boy had 'got smart'. The spiteful attack in February last year was BJ's trademark - he had become feared by children across South Auckland (Wall, 2002).
}

Bailey Kurariki was, in no uncertain terms, "a dangerous little boy" (Newbold cited in Andrew, 2002); a "thoroughly evil little snot" (Clarke, 2002).

\section{Feral children, the underclass, and South Auckland}

However, at the same time that Bailey's role in the crime was seen to stem from his own pathology, he was also depicted as "a textbook case of the child destined to go off the rails" (Rudman, 2002) who "did not stand a chance" ("Time To Act," 2002). In other words, his actions were the inevitable result of his membership of an emerging underclass, who were both ill equipped and lacking in the proper virtues required for appropriate parenting practices. The following passage illustrates this discursive thread well: 
In the end, when people breed, they should take on a never-ending responsibility for their offspring ... too many youngsters produce a baby as an accidental byproduct of recreational sex. If the parents are but children themselves, the chances of that mite flourishing with love, in a stable two-parent home supported by whanau, are minimal. And thus continues a cycle that has already created an under-class of nonachievers, drug-takers and drunkards, people without work living in relative poverty and taking little responsibility for their own plight and that of their families ("Put The Family Back,” 2002).

In a further extension, and despite this association between class and crime, the Choy murder was emphasized as "the latest story in a saga of youth crime that appears to be sweeping New Zealand" (“Time To Act," 2002). Headlines such as "Children Who Kill: Stand By For More" (Mirams, 2002) and claims that the nation should "prepare itself for more violent teenage crime" (Lashlie cited in Mirams, 2002) followed the convictions of the six teenagers. In many respects this section of the discursive thread can be seen as part of the practice of escalation, which I locate and discuss as a process towards a moral panic in more detail in Chapter Five. Important here, however, were the ways by which Bailey was singularly positioned as the archetype:

He (Kurariki) is not unique by any stretch of the imagination (Lashlie cited in Mirams, 2002).

Boys like Kurariki are no longer rouge aberrations ("Young Killer," 2002).

Also crucial were the ways by which Bailey's actions were noted in terms of his practiced criminal 'career'; the five others convicted with him his "associates" ("Young And Bad," 2002) or "partners in crime" ("Choy Sentencing," 2002). This lent to the discourse a suggestion that "young offenders are becoming more sophisticated" ("Sorting Out Children," 2002); that we were to be bombarded with "an ugly rash of young killers" (Dekker, 2002) with no sense of boundaries or responsibilities (Mirams, 2002) operating on a level beyond their years:

Today it has been almost commonplace for children to be committing crimes once the preserve of adults ("Police Need Support," 2002). 
It suddenly seems that young punks are not just troublesome but also potentially

lethal, capable of casual violence of the worst sort ("Young And Bad," 2002).

What is happening in these threads are the beginnings of an identification of a 'folk devil' (Bailey), in addition to the segregation of a part of the community based upon their self-imposed membership of an underclass; the conditions seen to harbor many potential 'Bailey's'. This is the functional aspect of panic discourse at work as discussed in Chapter One; the creation of outsiders, to whom 'we' may look upon in order to remind ourselves of who not to be (see Cohen, 1972; Erikson, 1966). In a moment it will be discussed how the discourse of social rescue would seek to negate this segregation. At this moment I want to pause and look briefly at South Auckland as an implicit variable operative in this segregation; a variable that I will identify in Chapter Six would operate as a 'code' of sorts for the variable of race.

The significance of South Auckland is neutral in a first sense, simply as it was the area in which the crime took place - Papakura is one of its outlying suburbs. However, there have long been connotations between the district and entrenched generational poverty, family dysfunction, crime and disorder and it has since (that is, after 2002) become known as 'The Badlands'. I discuss these connotations and this label in more detail in Chapter Six. For now, I want to look how they would allow for one element in the events that led to Michael Choy's death to slip under the radar of importance. A pathologist at the trial testified that Michael Choy's injuries were not positively fatal, that he could have survived should he have received prompt medical attention. That he was refused aid from the neighbouring property to which he stumbled after being attacked, despite that he was described by the occupants as 'grovelling' and 'writhing' and shouting in a 'desperate tone', was attributed to the notion the neighbourhood was 'dangerous' with "packs of young children" roaming the streets (Purdy, 2001). At the time Mr. Choy's family said they understood this reluctance to open the door and therefore held no grudges towards the occupants. Paradoxically, they later condemned the six young offenders for having not thought about calling for help after the attack: "When he asked for help, there was no help. You wouldn't do that to an animal" 
(Rita Croskery cited in Gay, 2007). Similarly, while the neighbours to whom Michael Choy appealed would face no sanction, the sentencing Judge reportedly argued that the "callous failure" to seek help for Michael Choy was an aggravating factor in the length of the sentences handed down for each of the young defendants (“Seven Years For Bailey," 2002). ${ }^{60}$

\section{A lenient justice system}

The discourse of moral reprisal argued that aiding and abetting the development of this burgeoning bunch of 'seasoned criminals' (both in South Auckland and beyond) was our 'world-leading' youth justice system and its emphasis upon restorative practices, which were identified as feeble in practice, indulgent even: ${ }^{61}$

Let's stop these wishy-washy sentences (Ken Croskery cited in Purdy, 2001).

Some even carry out the dirty work for older accomplices, knowing that if they get caught they will be treated with greater leniency ("Sorting Out Children," 2002).

The Family Group Conference (FGC), whereupon victim/s and their families seek redress from the offender/s and their families without criminal proceedings, was a particular target:

At present, all that can happen is a smack with a wet bus ticket at a family group conference, where it is not unknown for thuggish children and their families to menace further the frightened victims ("Underclass Of Young Crims," 2002).

If this 'soft' approach was not changed, these youths would be 'doomed to a life of crime', an inevitability that Bailey's case was a clear indication of:

The most frightening example of where this [getting away with minor crimes] can lead to is Bailey Junior Kurariki ("Sorting Out Children," 2002).

... like Bailey Kurariki they may already be lost causes ... New Zealand's youngest killer serves as a clear warning to [the rest of us] (“Lining Up To Kill?" 2002).

\footnotetext{
${ }^{60}$ This can only be attributed to the differentiation between the neighbours as being in South Auckland, while the defendants were of it.

${ }^{61}$ Aotearoa/New Zealand's hybrid welfare/justice approach to youth justice implemented as part of the Children, Young Persons and their Families Act (1989) has oft been considered as 'world leading' by academics and justice officials worldwide. For a clear assessment of this claim, and a formative review of the principles underpinning the model employed see Becroft (2003).
} 
Upon this, murmurings towards lowering the age of criminal responsibility to ensure deterrence and accountability began to surface almost immediately, remaining a point of debate through into the containment phase, particularly from the conservative end of the political spectrum:

\footnotetext{
[a call for] the age of responsibility to be reduced to 12 will strike a cord with many around the country, who are worried about the number of children facing charges for crimes as serious as murder (“Sorting Out Children,” 2002).

"It's clear that heinous crimes are being committed by younger and younger people and it's time that if they do the adult crimes they should be confronted with the adult justice system. It's clear we are not dealing with little angels and, in this case, the system needs to deal with them" (Ryall cited in Henzell, 2003).
}

Not surprisingly, much of the responsibility was directed at the incumbent Labour Government who had not only nurtured a 'politically correct' ideology whereupon "it's not seen as the done thing to discipline your kids" (McVicar cited in Batchelor, 2003), but had tended to "gloss over what the youth offending statistics really show", and subsequently had made their plans for 'youth offending teams' comprised of youth workers, police, and other welfare professionals "too little too late" (Andrew \& Warren, 2002).

But by and large, the Choy case was interpreted by the discourse of moral reprisal as yet another incident that indicated the practices of and principles behind our criminal justice system on a whole were failing, particularly in the address to victims. This was an argument that had already become a platform from which conservative parties were putting forward their manifestos. Earlier in the year, for example, in their official campaign launch for the 2002 election, the Act party called for 'zero tolerance' on all offences arguing the 1999 Citizens Initiated Referendum (CIR) on crime where ninety two percent of voters had ticked the box for tougher sentences had been ignored:

Parliament has treated the referendum, and the public, with contempt (Prebble cited in Beston, 2002). 


\section{Godzone gone wrong}

However, more critical than a deteriorating justice system was the perception that Aotearoa/New Zealand had moved from a 'golden age' of an egalitarian and inclusive society, relatively free from the plagues of modern life that other western nations were known to be subject to:

\footnotetext{
Not too long ago, a story such as Kurariki's would have been considered monstrous and unthinkable in New Zealand, an aberration. Now it is becoming a regular jolt to our senses. We cannot allow ourselves to become inured to it ("Time To Act," 2002).
}

That there had been a series of recent occurrences whereby children were both committing and being victimized by violent crime had made "a mockery of the reputation New Zealand once enjoyed as a great place to bring up kids" (“Godzone Failing Its Children," 2002). Indeed, Aotearoa/New Zealand had become, it was argued, "one of the most violent countries in the western world" (McVicar cited in "Youngest Killer," 2003) and the subscription to a 'godzonian' fantasy had blinded people for too long to the harsh reality that 'we' were just as 'bad' as the rest of the world and it was "time to wake up" (Lashlie cited in Collins, 2002).

The discourse of moral reprisal would put forward several explanations for this apparent cultural denigration. Reflecting the designation of 'outsiders', one was that this case was clearly a symptom of the systematic annihilation of moral decency which, in turn, is in every respect associated with the ideal of the nuclear family unit.

\footnotetext{
Liberal politicians, academics and social engineers have presided over the destruction of the sanctity of marriage, the institution of the family and the mystery of sex, the denigration of manhood and fatherhood and have sanctioned the wholesale slaughter of the most defenseless among us, the unborn child ... yet we wonder why the likes of 13-year-old Bailey Junior Kurariki turns out to be the evil, twisted, cruel little psychopath he is (George, 2002).
}

Another diagnosis was more spiritual: 
As a nation we are all reeling by the realization that there are children in our midst that have been turned into killers ... it stems from our society's attempt to rid itself of any meaningful place for religion and spirituality (McBride, 2002).

Further, the crime was seen as an indication of the demise of the human condition:

The killing of Michael Choy was a calculated, premeditated crime that saw an innocent man lose his life for little more that a handful of change. It was a breach of human trust, a vile abuse of the sanctity of life and another body-blow to the bonds of respect and faith in human nature that are vital to holding the community together ("Benefits Disappear," 2002).

Overall, the discourse of moral reprisal constructed a clear trajectory towards the demise of the moral order; from one extraordinary 'evil' child, to dysfunctional families, to a permissive society whose 'wishy-washy' approaches to crime is underpinned by a left-wing 'politically correct' ideology. In this way, the boundaries between 'us' and 'them' were constructed via the variable of class and by political leanings. Later in the chapter I discuss what effects this discourse would wield, why these can be interpreted as 'out of order', and how, on a whole, this discourse contributed to the episode that was 'killer kids'. In the next section I describe the development of a discourse that would challenge the discourse of moral reprisal's claims. This is the discourse of social rescue.

\section{Social Rescue}

For the most part the discourse of social rescue can be seen as a response to the discourse of moral reprisal, inverting the latter's trajectory at every intersection. The following sections describe how this discourse situated the blame for the murder of Michael Choy firmly in the hands of a neo-liberal ideology that was responsible for an under-funded system of welfare services which in turn had let too many children 'fall through the gaps'. The discourse of social rescue also worked to reverse the segregation of outsiders by class, and the demonisation of Bailey Kurariki as a 'folk devil'. This discourse was also relatively self-aware of itself in relation to its nemesis. The discourse of moral reprisal, it was argued, was a "cacophony of hate, anger, resentment, pain and bewilderment" by the 
"swelling tide of the lock 'em up and throw away the key brigade" (O'Conner, 2002).

\section{A 'pathetic prank'}

At the outset an impetus to redefine the behaviour that led to the death of Michael Choy is evident. This is the most overt confrontation between the first two discourses, which inevitably structures the development of each into opposing lines of argument. Where, for example, the discourse of moral reprisal claimed the events of the crime were premeditated, callous - murderous (and subsequently the 'problem' becomes one of a pathological child, a dysfunctional community, and a decaying society), the discourse of social rescue argued for temperance and contextualization:

This was not a 'highly organized unit' carrying out the robbery with military precision ... it was a ragbag bunch of neighbourhood kids ... [and] a harebrained scheme to get some food and some small change (Mansfield cited in "Alleged Murder Decoy," 2002). ${ }^{62}$

Just growing up and testing the boundaries (Moore cited in Dekker, 2002).

In this sense, the notion of an isolated - if not accidental - incident was the most credible and thus, any claim that there was inevitability - by predetermined actors - to the situation was unfounded:

The reality is that there's a bunch of factors in these kids' backgrounds which collided with their age and the group dynamic which resulted in what happened (Latta in "Interview with Paul Holmes," 2002).

... the community, in fairness, should stand back and say that young people - all people, but especially young people - do some things that are really stupid, really bad on occasions but it doesn't warrant them being judged as totally irredeemable, totally without hope (Hogan cited in "No Words", 2002).

\footnotetext{
62 Interestingly the victim's mother Rita Croskery, also, just following the trial, reportedly described the events as a "lark" (Rita Croskery cited in Aronson, 2002).
} 
This dialogue also called for perspective in relation to the figures cited by the moral reprisal discourse; that a few high-profile cases had created an inaccurate perception that youth offending was on the rise. An expert in the field, a youth lawyer, for example, argued:

I've always found it comes in peaks and troughs. I certainly don't believe there is a wave of youth offenders out there ready to swamp society ... There's a view in society that young people are innately evil. That's absolutely ridiculous (Scott cited in Tait, 2002).

Rather, the killing of Mr Choy was no more than a "random incident", in no way indicative of a trend (Hegarty cited in Andrew \& Warren, 2002). Perspective was also urged in terms of what the 'real' problem was, the timing of the event, and of the enduring nature of anxiety about youth crime:

Children remain far more offended against, than [are the] offenders (Dekker, 2002).

Claims of deteriorating youth usually surface in election year and complaints about the younger generation go right back to Pliny in Ancient Rome (Dekker, 2002).

... when you look at the newspapers there were headlines in 1886 deeply concerned about young people out of control and roaming the streets ... Every community takes offending seriously and every generation worries because, trite as it may be, those young people are tomorrow's future. That's probably why youth offending captures public interest ... but contrary to popular belief, its not skyrocketing (Becroft cited in Claridge, 2002).

\section{We are all to blame}

Although the temper of the discourse of social rescue was less formidable than its opponent, the events of the crime were still couched, intermittently, in terms of a bigger problem requiring explanation and immediate remedial action: "it's definitely a warning" (Moore cited in Dekker, 2002). Culpability was firstly thrown in the direction of Child, Youth, and Family Services (CYF), the welfare department under whose custody Bailey had been at the time of the crime. Headlines screamed: "Welfare Failed Boy Killer" (Wall, 2002b) and "CYF blamed for lack of action" ("CYF Blamed," 2002). Though a report into the crime 
had revealed a communication breakdown between police, education, and welfare agencies - each of whom were unaware of each other's involvement in the offender's lives - one police officer was clear where blame lay. Constable Len Johnson claimed that he had applied for a court order placing Bailey into CYF's care in June 2001 because the department's social workers had come up with all sorts of 'master plans' for dealing with Bailey but failed to put them in action and had 'dragged their arses' in response to his urgent requests for them to apply for custody. Thus, Bailey's involvement in Michael Choy's death was "the end result of CYF's failings" (Johnson cited in Wall, 2002b). It was reported that the same social workers would 'lose' Bailey as he ran away from the foster home where he had been placed, and subsequently did not relocate him until after he had been arrested (Wall, 2002b).

On the other hand, Bailey's role in the crime was seen as a reflection of 'the times' and the responsibility therefore community wide; not, as the discourse of moral reprisal had ascribed, to one particular sector, or to one particular set of ideas. One of the lawyers for the defense in the trial for the murder of Michael Choy claimed at the sentencing: "To some extent we are all in the dock today" ("Choy," 2002). A letter to the editor had also earlier summed up this notion well:

\footnotetext{
A child does not turn bad by itself, not even through the influence of its parents and family. It takes sustained ignoring by the whole community (McBride, 2002).
}

It was also argued that modern children faced a number of unique 'life hurdles'. Teachers reported that they knew of a number of 'latchkey kids'; children whose parents worked full time and who regularly returned home from school to an empty house (Dekker, 2002). Another argument was that contemporary kids suffered an unprecedented exposure to vivid violent and sexual messages via the media. This is a claim that tends to be routine feature in social problems involving youth and violence and is normally couched in terms of a 'permissive society' and thus on the conservative side of the fence. It is interesting then, that in this case, a 'diet' of visual and aural violence was seen as fine for well-adjusted children, but those without adequate support in their lives found it hard to separate fantasy from 
reality, particularly if they had regularly witnessed violence in the home (Dekker, 2002). The idea was, however, also refuted:

It's rubbish. It's easy to blame - let's blame television this week. It'll be the music next week and ... the funny clothes they wear after that. There are far more root causes (Scott cited in Tait, 2002).

One of these 'root causes' was the logic of the free market. In essence this was the identification of an underclass, just as the discourse of moral reprisal had done. However, the discourse of social rescue firmly refuted the notion that membership of this underclass was self-imposed; rather, it was the principles and practices of Rogernomics that was systematically responsible for the destruction of an inclusive society; one of the principles of Aotearoa/New Zealand's 'Godzone'. 63

... the number of younger and younger offenders has escalated, signaling a deep social and economic malaise. These youth have come, in the main, from home lives full of violence, deprivation and abandonment, against a background of the marketdriven social and economic policies launched in the 1980s ... Of all of the OECD countries, New Zealand is among the least generous when providing assistance to low income and beneficiary households with dependent children (Robson, 2002).

One area in which Aotearoa/New Zealand had remained in view as "worldleading' however was in its development of youth justice initiatives, particularly the 'family group conferences' that the moral reprisal discourse sought to undermine. However, it was acknowledged that such initiatives were inefficient in isolation from wider practices of care.

\section{Education, intervention, rehabilitation: 'it's not rocket science'}

In addition to addressing poverty as one of the "the conditions that breed children who kill" (Gordon, 2002), untangling the psychological and emotional damage rendered upon individual 'hardcore' children was seen as imperative. This was to involve a multi-agency approach and 'multi-systemic therapy', involving psychologists and other experts working with the offender and his/her family for

\footnotetext{
63 'Rogernomics' is a portmanteau of 'Roger' and 'economic' to describe the free market economic policies implemented by Roger Douglas who was Finance Minister from 1984 to 1990.
} 
an extended period in order to build new patterns of behaviour (Boyd, 2005). Much of the dialogue in this thread depended upon experts within the education system and other social services, many of whom demonstrated frustration at knowing 'what to do' but finding there was little in the way of bureaucratic support with which to do it. Teachers, for example, argued that 'problem' children could be identified as early as primary school but noted the difficulty in getting help within the system (Dekker, 2002). Intervention was also seen as costly. Spokespersons for various truancy services reported a serious lack of funding: "we can't do this [monitor problem children] on the smell of an oily rag" (Crackett cited in "Lobby Seeks," 2002). Additionally, while our youth justice system was fervently defended in principle, in practice it was: "seriously in need of a blood transfusion" (Becroft cited in Boyd, 2005). The implication was that a lack of forward planning on behalf of political bodies was responsible not only for failing to prevent serious crimes (by not intervening early) but costing the taxpayer undue expenditure upon a conviction. As it was summed up in an editorial:

To break the cycle, wayward children have to be identified by kindergartens, schools, doctors and neighbours. Support for parents and children has to come from presently under-funded state organizations. The cost will be great. The cost not to act will be greater ("Wasteland," 2002).

Echoing that neo-liberal ideologies had much to answer for, another commentator argued:

\footnotetext{
We need to look behind the 'no tolerance for crime' slogan. If we had 'no tolerance' for illiteracy, 'no tolerance' for school expulsion, 'no tolerance' for school failure, and 'no tolerance' for neglecting our most vulnerable children, then the youth crime rate would fall dramatically ... It's a shame, is it not, that he [Bailey] had to commit such a terrible crime to get some decent opportunities? (Gordon, 2002).
}

Overall, though the discourse of social rescue acknowledged that "normal, welladjusted kids don't go around killing people" (Johnson cited in "Young Killer Thinks," 2002), it sought to undermine the trajectory of the discourse of moral reprisal through redefining the crime, who was responsible, and the ways by 
which the 'problem' could be appropriately addressed. In this way it can be identified as a 'fight back' discourse (though on behalf of the 'outsiders') (see McRobbie, 1994a). In the next section I once more take a brief pause from the descriptive task and ask the question; did it work?

\section{Panic Over?}

Thus far my analysis has collated and described the two countable discourses that appeared during the reactive phase of killer kids. In a sense my action here has 'flattened' the true picture as I have given equal weight to each discourse's description. The question of whether the discourse of social rescue succeeded in fighting back is essentially a question of which discourse was triumphant over the other; if there was indeed a hierarchical order between the two discourses. The first evidence of an order is rather rudimentary, but important nonetheless. Few articles (both hard news reports and opinion pieces) were solely social rescue oriented; rather, the norm was that articles would open with a statement in the tone of moral reprisal and either follow this opening through, or temper it thereafter - for balance, it appeared - with the opposing view. The significance of this becomes clear in Chapter Five, where professional journalists attest to opening their reports according to what they interpret as the most important details. This is because readers are imagined to read the first paragraph with interest, and will continue only if such interest is stimulated. The second evidence of an order can be seen as the reactive phase came to a close. Panic scholars identify that an episode often dissipates with a repressive (though largely symbolic) change in law, which serves as an indication that something has been done to mitigate the behaviour in question (see in particular Goode \& BenYehuda, 1994; Hall et al., 1978). Here, the initial 'something' that had been done was a set of custodial sentences for the group involved in the murder of Michael Choy that would later be described by the defence team as "adult sized ... manifestly excessive and inappropriate" (Hogan cited in "Boy Did Not Plan," 2003). Notwithstanding the media's favour of the arguments of the discourse of moral reprisal, I can tentatively claim that it is this that indicates it was this discourse's arguments that had secured the interpretative terrain. Because too, the 
sentences would mark the close of the reactive phase it can be inferred that the discourse of moral reprisal was content that their length met its disciplinary objectives.

However, the panic was not yet over. A sense of crisis in which the Choy case was again central would erupt a few weeks beyond the close of the reactive phase into one that was focused upon containing the offenders now that they had gone to jail. Emerging and commanding the interpretative space in this containment phase was the discourse of criminal risk which sought to manage and prevent the criminal for which something had yet to be done. The notion of 'risk' is an implicit feature of both discourses dominant in the reactive phase; the risk of not intervening early and of not responding in a coordinated manner, the risk of a meager approach to young offenders and of the rising number of sole-parent households: "[welfare] numbers to increase ... there will be a lot more Bailey Junior Kurariki's on their way" (Milne, 2002). As the discourse of criminal risk evolves, the discourse of moral reprisal's command can be seen more clearly as the notion of risk is spoken about alongside calls for vengeance. In Chapter Two I discussed Hier's (2003) contention that risk language had become a moral technology. In this case, at the level of description, this conversion transpired more by association (and omission) than it did by how permeable the notion of risk was to the discourse of moral reprisal's understandings. ${ }^{64}$ It will also be seen - at the level of description - that it would be via a challenge by a newly invigorated discourse of social rescue that the containment phase would come to a close.

\section{Criminal Risk}

As indicated, the discourse of criminal risk took centre stage after November, 2002 (upon the commencement of the containment phase) and continued through to May, 2008. I want to commence the exploration of this discourse with an editorial in September, 2003 that markedly captures the temperament which the discourse of criminal risk was both a response to and a part of.

\footnotetext{
${ }^{64}$ In Chapter Five I explore how this association was facilitated by moral entrepreneurship which had adopted the case as the prototype for changes to be made in the criminal justice system.
} 
The type of sentence in our justice system must balance a number of factors: society's odium for a particular crime; the need to keep the community safe from certain offenders; and rehabilitation. It is quite true that home detention, whether at the front or back end of a sentence, should offer a better prospect for rehabilitation and community integration than a prison cell. But the trend towards this being given to serious offenders suggests that the balance has swung too far away from the idea of punishment (“Doing The Time," 2003).

Indeed, what will be seen is that managing the criminal focused upon the first two of these; society's odium and the community's safety. Questioning the notion of justice, the first thread in the discourse of criminal risk began to gather momentum the day following the sentencing of the six convicted youths.

\section{Just deserts and community safety}

Despite the seven year term handed down to Bailey it was argued that he would "probably be out of jail" ("Doubtful The Choy Quest," 2002) after serving only one-third of his sentence. This was anticipated to be a direct result of the new Parole Act, 2002, which signified that the severity of the sentences (for the six youths) was mere lip service. The projection that Bailey would receive parole meant that he would become part of the trend of offenders "leaving prison early for the living room sofa" ("Doubtful The Choy Quest," 2002) and this was seen as offensive, and to “anyone's sense of justice” (Dilemma Over What," 2002).

It was also fairly quickly argued that Bailey was one of the 'chosen few' (that is, as a violent offender so young he cannot be sent to an adult prison) and as such, would be "heaped with special attention" in the form of education, recreation, and cultural opportunities (Bingham, 2002). Leapt upon as yet another example concerning our 'warm fuzzy' and 'offender friendly' criminal justice system with its undue emphases upon re-integrative practices, by November this perception would again find expression in the responses to a visit to Bailey by two All Blacks and so-called horse whisperer Monty Roberts soon after his seven-year term began. This was not 'punishment' it was argued, but 'preferential treatment'; unjust rewards at the wrong end of the crime which, in turn, sent a perilous message to other potentially delinquent youths. One letter to the editor exclaimed: 
Hey, kids, want to get your photo taken with some of the All Blacks? ... It's easy.

Just kill a pizza delivery person (Broadmore \& Broadmore, 2002).

As Bailey's first parole bid approached, claims of injustice gave way to claims for safety. Michael Choy's mother Rita Croskery's was particularly vocal with her view that Bailey was a 'shrewd and cunning criminal' who would be a "real menace" if released early (Rita Croskery cited in Crean, 2003). Another claimant argued, "the streets are safer without him" (Yee cited in Booker, 2003). Indeed, the parole board rejected his bid, reportedly unsatisfied that he would not pose an "undue risk to the community" ("Parole Board Got It," 2004). However, it was still a point that "...the boy got what he deserved ... In the case of Bailey Kurariki justice is still being done" ("Parole Board Got It," 2004; emphasis added), with claims such as "the New Zealand Public is still adamant that the punishment must fully fit the crime" ("Doing The Time," 2003).

What can be seen happening here is that 'risk' is becoming something that is unmanageable insofar as it is coupled with (subject to) the indefinite aspirations of vengeance and without clear indications of how community safety might be assured. The third factor the criminal justice system needs to consider in a sentence; rehabilitation, is for the most part spoken about in terms of 'special treatment' or privilege, which is at odds with the idea of 'punishment'. In fact, the discourse of criminal risk would come to determine that punishment itself was a 'risky' practice. Indeed, expert opinion across the board appeared hesitant about the effects of incarceration. Then Commissioner for Children Roger McClay argued early on:

\footnotetext{
I don't think adult prison's going to help him [Bailey] one iota. He'll come out a well heeled little apprentice for crime in my opinion (McClay in "Jury Reach Verdict," 2002).
}

Just prior to his handing down of two life terms for murder, and between seven and ten years for the remaining four manslaughter convictions, the sentencing Judge also pondered: 
If the prison system turns you out ultimately as more hardened criminals and the public suffers as a consequence, the public would be justified in asking some very hard questions of their political leaders and prison authorities ("Choy," 2002).

At the other end of the sample, whether Bailey would offend again upon release was a prediction that was, quite simply, down to "a dirty big guess" (Newbold cited in Cumming, 2002b). A commentator questioned:

Some of the most formative years of his life were confined in a custodial sentence with other anti-social youth. It's just a breeding ground isn't it? (Lambie cited in Boland, 2007).

It appears that part of this ambivalence was due to the clandestine nature of what went on 'inside' by way of therapy, education, and other means towards the rehabilitation of offenders. Michael Choy's mother would argue:

[its] meant to be all confidential, what he [Kurariki] is doing, and I can't understand why, we as tax payers who are paying for his care ... its costing the country thousands and thousands - millions - for all those people, and why aren't we allowed to find out what's going on down there? ("Rita Croskery," 2003).

If the supervision of risk via the criminal justice system was surreptitious, unknowable, the discourse of criminal risk saw that the means to its control - in relation to young offenders - was to stamp down on them early.

\section{Accountability and deterrence}

All overseas research had shown that "the earlier they come to court, the harder it is to ever get them out of the system" (Becroft cited in Boyd, 2005) by virtue of the compounding nature of prior convictions and sentences upon official responses to subsequent offences and sentences. This was an observation that had hitherto informed Aotearoa/New Zealand's 'world leading' youth justice system with its practices of warnings and diversions; for youth to be made accountable but via routes other than the formal court system. Now, however, it was interpreted to mean that early deviancy led to long-term criminality. To negate this there was a need for deterrence which could be achieved, paradoxically, by 
getting them into court, and early. This was a tender that initiated debate immediately following the trial for Michael Choy's murder and engendered support particularly from the right-wing political party ACT ("Sorting Out Children," 2002). However, with the introduction of the Young Offenders (serious crimes) Bill by New Zealand First Member of Parliament Ron Mark in March, 2006 it became a formal proposal.

The Bill proposed to lower the age of criminal responsibility from fourteen years of age, to twelve. Significantly, though four years on from the trial (although Mr. Mark claimed to have drafted it in 2002 - "Underage," 2006) it appeared to have been the Choy case that was the driving force behind the Bill's formulation:

\footnotetext{
It is those crimes that, left unchecked, create the long-term adult criminal. We believe we will stop some young people graduating to serious crime and ending up like Bailey Kurariki in jail” (Mark cited in "Bill Urges Jail," 2006). ${ }^{65}$
}

Taking on board the discourse of moral reprisal's discursive thread of leniency in the criminal justice system in this sense of the control of risk, ironically it would be in the spirit and language of 'rescue' that 'safety' would be assured. The following exchange between Ron Mark and Breakfast host Paul Henry in an interview following the Bill's introduction demonstrates this well:

PH: People will say what you are doing is branding people, for life, at perhaps the age of twelve, a criminal ...

RM: I'm saving them Paul, by putting intervention in place that enables the police to actually intervene, or at least use as a deterrent ...

PH: Are you worried about saving them, or are you worried about saving society from future crimes they may commit ...

RM: Both, and tragically we're talking about the same thing. We're saving that young person from becoming an adult graduate and an occupant of Paremoremo,

\footnotetext{
${ }^{65}$ This statement is more astute than Mr. Mark presumably intended, as indeed the Bill would have, in effect, dealt with offenders just like Bailey, or rather, in the image of Bailey. This will be seen when I consider the Bill's anticipated effects in a section below.
} 
and therefore a cost and a burden on the tax-payer. We're saving future victims from being confronted with this person ("Underage," 2006). ${ }^{66}$

The Bill would pass its first reading but remain in the select committee stage for two years. During this time, the discourse of social rescue would re-emerge and erect a challenge upon the Bill's assumption that youth were knowledgeable about the law and as such, could, and did, make informed cost/benefit analyses. A professional working with young offenders, argued:

I don't believe there are any twelve year olds that know the meaning of deterrent for one, or the meaning of indictable offence for another, and I don't believe that sending young people into an adult system or being treated as an adult - in this case at twelve or thirteen - is going to deter them from serious offending ("Underage," 2006).

Not long after, the discourse of social rescue described the Bill as an 'abysmally drafted' document put together in response to a problem that simply was not there - "where is the statistical evidence to suggest offending by 10 to 13 -year-olds is spiraling out of control?" (Becroft cited in "If It's Not Broken," 2007). The youth justice system in place was working, it was argued, insofar as those who committed the most serious crimes could already be sent to jail.

Ultimately however, that the Bill was thrown out of parliament on May 21, 2008 (incidentally, four weeks after Bailey Kurariki was released from jail), in turn signifying a close to the containment phase, was largely due to some significant timing and the arrival of a new oppositional ally. I identify and discuss the significance of this ally in more detail in Chapter Five. In the next and final section of this chapter I consider the dominant discourses of moral reprisal and criminal risk and how their effects for the episode of 'killer kids' can be seen in terms of a moral panic.

66 'Paremoremo' is Aotearoa/New Zealand's only maximum security prison. 


\section{Discourses toward Moral Panic}

I noted earlier that the hallmark of a moral panic is the production of a singular and incontestable or 'closed' discourse. In this case I have identified three distinct discourses that appear over two conceptual phases. At the closure of the reactive phase I argued that it was the discourse of moral reprisal that had secured a result in the punitive sentences that were handed down to the offenders in the murder of Michael Choy. I then identified that a sense of crisis would continue beyond a reactive phase to one focused upon containing the offenders within which the discourse of criminal risk would become central. This discourse sought first and foremost to be pragmatic about the management and forestalling of risk. However, because 'safety' was talked about in conjunction with vengeance (informed by the discourse of moral reprisal) and in the relative absence of talk about effective rehabilitation (for which the discourse of social rescue would have been informative), it can be argued that though the discourse of moral reprisal would triumph in the first phase, the second was heavily influenced by its character. In turn, 'risk' was talked about alongside moral objectives, subsequently appearing to become something that was unmanageable in calculable terms. To re-grasp control, the discourse of criminal risk would argue for the prevention of the young offender via early criminalization.

It is at this point that I need to consider how the effects of the discourses can be seen as disproportional effects in a moral panic. Though the sentences handed down to the offenders in the murder of Michael Choy were identified as 'excessive', because this was on behalf of the defense team it is more a subjective assessment that it is a reliable objective marker. Nevertheless, the predicted 'saga' of 'violent teenage crime' posed to follow the Choy case can also be tangibly (and retrospectively) identified as out of proportion. As figure 4.2 shows, though apprehension rates of violent crime appeared to have risen overall during the tenyear period from 1998-2008, in whole numbers it was the 31-50 age group that showed the largest increase, and by percentage it was the over 51 group. Comparatively, the 13 and under group - which the discourse of moral reprisal's 
predictions were about and which the Young Offenders (serious crimes) Bill would later target - had the lowest increases by both measures.

Figure 4.1. Apprehension rates of violent offences by age groups 1998-2008 ${ }^{67}$

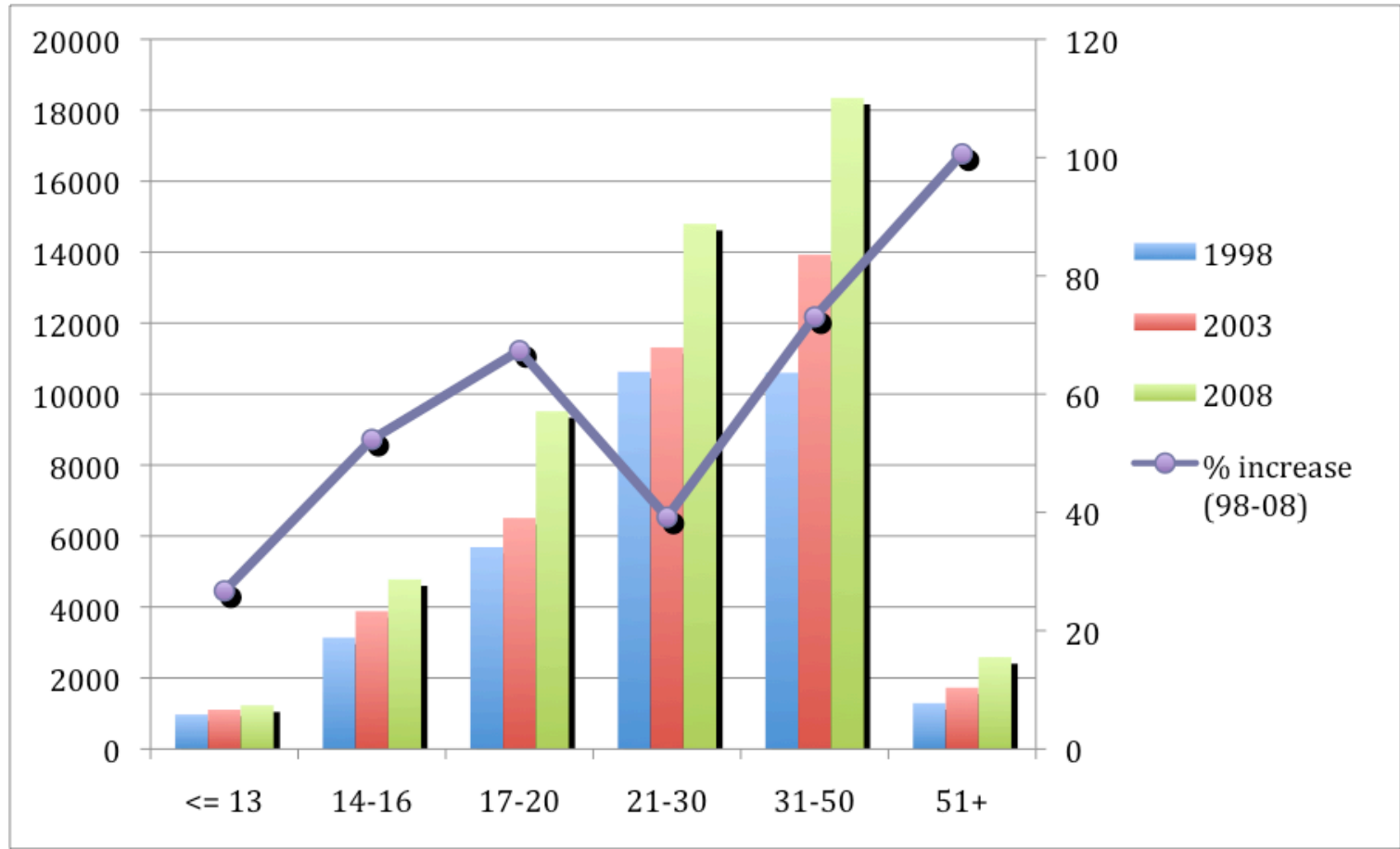

On the other hand, the discourse of criminal risk would have immediate and direct effects upon Bailey Kurariki's jail time as well as a set of anticipated indirect effects upon a particular population. The first of these can be identified as relatively extreme (if not disproportional); the second as tendentious (see Cohen, 1972). At the time of sentencing, Justice Robert Fisher had not set fixed terms; that is, he had not circumscribed that a period of time must be served before any of the youths involved could apply for parole. This may have been as the legislative changes in the Sentencing and Parole Acts of 2002 determined that the proportion of time served (in violent crime cases) was a mandatory two thirds with the possibility of the whole sentence to be served "depending upon individual circumstances" ("Sentencing For All Offenders," 2007). That Bailey was not 'released' in the full sense of the term until his seven year sentence was complete, having been granted 'home detention' in April 2008, demonstrates that

${ }^{67}$ Data compiled from Statistics New Zealand website (www.stats.govt.nz ). 
the change was, in this case, exercised to its full potential. Further, the parole conditions under which Bailey was eventually released were seen as "special" (NZ's Youngest Convicted," 2008), “unusually stringent” (Misa, 2008) so as he would not "pose an undue risk" (“Kurariki Out," 2008).

With regard to the second set of effects, if risk was to become unmanageable in the discourse of criminal risk by virtue of a lack of assurance in relation to safety, later it would at least have a definitive marker. This can be seen in that though the Choy case sparked a sense of nationwide crisis about youth crime, later this crisis essentially returned to the site from which it began - South Auckland. Indeed, the "daily fodder of the Youth Court" (Claridge, 2005) were said to be from South Auckland communities and it was South Auckland that was identified to be rife with 'persistent life-course offenders', or 'career criminals'. This group shared a number of similar characteristics; eighty-five percent were male, eighty percent had drug and alcohol issues, seventy percent were not in school, and at least fifty percent were of Maori or Pasifika descent. ${ }^{68}$ Moreover, because it was this group that would be disproportionately affected by the Young Offenders (serious crimes) Bill should it have passed into law, when the 'risk' of young offenders was spoken about, implicitly the risk of young brown men is what was said. Few commentators made overt statements in regards to this, but when they did, they were clear about its presence. Early in the containment phase one commentator argued, for example:

Most Pakeha see only the face of Bailey Kurariki, who was, yes, part Cook Islander, when they think of merciless little killers (Misa, 2002). ${ }^{69}$

At the other end of the sample it was Mr. Mark himself (who, incidentally, is of Maori descent) who claimed that an established correlation between brown faces and social disadvantage had (and would have) no bearing upon conduct undertaken:

\footnotetext{
68 'Pasifika' is the Samoan term for 'Pacific'. It has come to be used in Aotearoa/New Zealand to denote people of Pacific Island descent - particularly those who are Aotearoa/New Zealand born (see Misa cited in Perrott, 2007).

69 'Pakeha' is the term used in Aotearoa/New Zealand for citizens of European descent.
} 
Don't tell me about being brown and disadvantaged. You couldn't get any more disadvantaged than I was (Mark cited in McDonald, 2008).

By acknowledging a connection between transgression and Maori and Pasifika youth, and by rebutting the social variables that may have bearing upon such transgression, Mr. Mark was in effect implying that it was these youths that were inherently 'risky' and this demographic the Young Offenders (serious crimes) Bill was actively targeting. In Chapter Six I present evidence that suggests that a perception of a link between deviance and the ethnic 'other' has a long cultural history, and how its materialization in this episode was supported by its operation in other socio-political goings-on. ${ }^{70}$

Though a description of content has revealed much about how the episode of 'killer kids' unfolded, Cohen's (1972) seminal analysis sought to demonstrate that moral panics emerge via many players; the campaigns of moral entrepreneurs, the work of the media, the (assumed) concern of the public, and, ultimately, the response of elite figures. The next chapter probes the second layer of the episode of 'killer kids' (processes of the real-type) to identify the players and to examine the ways in which they are fundamental to how the discourses came into being. This will show, provisionally, why it was the discourse of moral reprisal that commanded the stage in both phases and also how the episode came to an end.

\footnotetext{
${ }^{70}$ It is important to note that Mr. Mark's use of the term 'brown' refers specifically to Maori and Pasifika peoples. The term is used in the sense that despite that such youth may not share an ethnicity, a culture, or a history, they do share an experience as 'other' in Aotearoa/New Zealand. I discuss this point again in Chapter Six.
} 


\title{
Chapter Five
}

\section{Media Practices, the Murder of Michael Choy, and the Cycle of Amplification}

\author{
Newspapers select events which are atypical, present them in a stereotypical \\ manner, and then contrast them against a backcloth of normality which is over- \\ typical (Young, 1974: 241).
}

In Chapter Four I identified and discussed the relationships (in the making of a social problem) between three countable discourses; the discourse of moral reprisal, the discourse of social rescue, and the discourse of criminal risk. Concluding from the tangible effects that indicated that a moral panic had occurred, I argued that it was the discourse of moral reprisal that occupied the trajectory towards a crisis over 'killer kids' in the reactive phase. Moreover, its explicit relationship with the discourse of criminal risk, which dominated the containment phase, indicates that it (the discourse of moral reprisal) commanded the interpretative terrain concerning the issue as a whole. Here, in Chapter Five, the task is to examine the practices by which this discourse emerged and prevailed over its competitor - the discourse of social rescue.

I have structured the discussion into three parts. The first part examines how the media construct crime stories (the production of text). I wanted to concentrate specifically on how crime stories are constructed for Aotearoa/New Zealand, as I was concerned to capture specificities to crime reporting in this country. To do this I recruited seven working crime journalists, and asked a series of questions relating to the ingredients for a 'good story', how raw events are made communicable, and what sources are called upon (for the full interview/questionnaire schedule, see the Appendix).

The second part of the chapter employs this backdrop to interpret how the events of the murder of Michael Choy were transformed into a news story. As will be seen, the productive practices of the media would be subject in this case to some 
unusual legal rulings and to some extraordinary timing, both of which were compelling for understanding how the imagery of Bailey Kurariki would become central and how in turn, a sense of moral crisis developed.

The third part of the chapter interprets how a trajectory towards a perceivable social problem that was markedly removed from its observable reality developed via processes of amplification (see Cohen, 1972). This includes the ways by which the practices of news-making continued to come into play and how a constituency was both assumed and recruited into a particular version of events which, in turn, strengthened the sense of ensuing disaster. ${ }^{71}$ Tentatively looking for evidence of the first conception of ideal-type practices of panic (the internal sense of the order of discourse) in action, I then reflect upon why they unfolded in a particular real-type trajectory that would support the success of the discourse of moral reprisal.

\section{Making Crime News}

The focus of the first section of the first part of this chapter is upon how crime news is made. This is important, as though objectivity and transparency underlie our perception of our daily 'news' and the practices of those who assemble it, it is an institutionally subjective set of news values that drives all newsrooms and news reports. News values are the criteria that determine what is newsworthy or not. My respondents testified to three broad sets of news values for the making of crime stories in Aotearoa/New Zealand.

\section{Bad and unusual}

First, media professionals look for bad news; particularly violent bad news. This appears to be a universal feature of crime reports. As Hall et al. (1978: 68) argue:

\footnotetext{
${ }^{71}$ I see this in CDA terms as the consumption of text. I argued earlier that the analysis of the practices of consumption in a moral panic necessarily leaves out an analysis of the public and focuses instead upon the practices by which the event is interpreted and transformed within media space. However, this includes the ways by which the public is invoked.
} 
Violence represents a basic violation of the person; the greatest personal crime is 'murder', bettered only by the murder of a law-enforcement agent, a policeman. Violence is also the ultimate crime against property and against the State. It thus represents a fundamental rupture in the social order. The use of violence marks the distinction between those who are of society and those who are outside it (original emphases).

The journalists I spoke to added that elements of chance and irrationality were important insofar as they provoked an ambiguous emotional response; empathy with the unsuspecting victim at the same time as a sense of one's own potential risk:

Those sudden, senseless, random crimes - they leave a question mark in your mind. There's always something tragic about that wrong place, wrong time scenario. (Respondent A)

A 'great yarn' or great story, would be when a crime occurs that 'could happen to anyone'. When innocent members of the public are going about their daily lives and get tied up in awful situations where it could have been anyone ...I guess a lot of people can't identify with gang-type crimes so they don't tend to be interested in gang on gang murders for example, unless it is an extreme situation like the shooting of Wanganui toddler Jhia Te Tua. When children are involved, it also adds an $\mathrm{x}$ factor. (Respondent C)

Indeed, the more unusual or $\mathrm{x}$-factor qualities a crime had, the more it offered itself as 'good copy'. As an example, one respondent noted the murder of fireman Tony Stanlake, whose handless body washed up on Wellington's South coast in July of 2006.

It was classic ... body on the beach, hands cut off. You know - what it's all about.

(Respondent A)

An additional way by which a sense of the unusual could be got was seen to be by the identities that are involved. Particularly attractive for my respondents were 'fall from grace' situations, especially in relation to deviant sexual activity, drug offences, or abuses of position (Respondents $B, D$ ). One respondent saw the 
involvement of former All Black Joe Karam in the Bain case as broadening the appeal of a case already saturated with newsworthy complications (Respondent E). ${ }^{72}$

\section{Drama and emotion}

Drama and emotion were seen as essential to crime stories.

When there is a crime, naturally there is drama and emotion. That sort of speaks for itself. (Respondent C)

Drama and emotion are the key drivers of any story-telling, either fiction or nonfiction. (Respondent $B$ )

Other respondents saw their emphasis upon drama and emotion as a way to keep competitive within the profession, something they were not apologetic for:

The media needs to keep up audiences and attract advertisers. I can't see anything wrong with entertainment. Conflict, drama, and emotion appeal to readers and viewers. (Respondent E)

I don't think there's any doubt that things are played up much more than used to be - horror, shock value etc - um, and part of that is probably a general, um, it reflects the public attitude I think. Everybody’s blasé about crime, everybody's blasé about murder - it has to be a pretty good murder these days to capture the imagination and you do need to rev things up a bit, maximize the drama. (Respondent A)

Many of my respondents also spoke of the saliency of a 'whodunit' case whereupon they could follow 'unfolding events'. Essential to this was a sense of 'pace', both to retain the public interest, and in which the journalist feels part of the investigation towards a result.

\footnotetext{
${ }^{72}$ In 1995, 23 year-old David Bain was convicted of shooting dead five of his family members in Dunedin in June, 1994. However, it was claimed (predominantly by Joe Karam who had studied the case and published the book 'David and Goliath' in 1997) that the crown case was fraught with inconsistencies and therefore a grave miscarriage of justice had occurred. After a long campaign and a retrial in 2008, David was found not guilty.
} 
In an ideal world [you want] a case that moves quickly from an offence to a reasonably firm result within a week and there are developments each day, where, like, there are requests for information and all of a sudden you've got an arrest ... you know, you want to get a result, you're a little bit like a police officer in that way, you want it to be resolved so there's a happy ending to a horrible story. (Respondent $A$ )

\section{Pictures are primary}

It is said that in television news there has always been a bias towards a good picture as opposed to a catchy story (see McGregor, 2002b). This was reflected in my research. Respondent $A$, for example, argued:

The beauty of TV is that pictures can tell the story better than your voice ever can. You're in trouble; put it this way, if your script is the best thing about the story. (Respondent $A$ )

Indeed the same respondent remembered his move from working as a print journalist to a television journalist as challenging:

It's quite hard to make the transition 'cause in print you do have that license to write quite scripted and its nice, and it took me a while to make the adjustment to TV where actually its not about your words anymore. You're actually writing to the pictures ... You need in TV to reverse the mindset of fitting pictures to words. You need to be on your cameraman's shoulder and say 'what's my best opening shot' so that you know how things are going to look. (Respondent $A$ )

However, it has been observed that images are becoming increasingly important for the print press as papers work to capture a younger market with magazinetype news (see McGregor, 2002b; Jewkes, 2004; Greer, Ferrell \& Jewkes, 2007; Greer \& Jewkes, 2008). Moreover, whatever the medium, it appears that journalists are prepared to go the extra mile to create the perfect picture: 
If you have a mum crying, you lead with that - its very hard to go past that ... its an awful thing to admit, but if you see that a person [interviewee] is holding back tears you'll ask them a pushy question, or an even more intrusive question ... you know, there are buttons you can push ... there's no question you want to wring the emotion out of the story and you're pretty shameless about the fact you do. (Respondent A)

Much of the above discussion indicates that the 'making' of news is inadvertently happening at the point of selection (determined by news values). Nevertheless, once selected, events are subsequently moved through a definitive narrative structure whereupon events are transformed into meaningful stories (see Altheide, 2002; Epstein, 2000; Hall, 1980; Jacobs, 1996; Jewkes, 2004; JohnsonCartee, 2004; Muncie, 1999; Schlesinger \& Tumber, 1994). Thus, I now turn to a discussion of the crime narrative.

\section{The Crime Narrative}

For most of my respondents the narrative structure of all news stories began with the movement of raw events through an 'inverted pyramid' whereupon all of the crucial information is presented in the first sentences. I then asked my respondents where they sourced their information, who they would seek out to find 'balance', and whether it was important to follow an existing angle (one already in the news). Most argued that it was the events themselves that had the main bearing upon the shape of the narrative.

You have to understand its already unfolding in a certain way, that is the story and to seek balance to that would be artificial - it would be like doing a story about the holocaust and a lead came up that Hitler was a vegetarian - you know, at some point you just have to get the story. (Respondent $A$ )

At the same time, other angles were considered important:

To keep a story fresh, reporters are always looking for new angles. (Respondent $F$ )

We always try to discount other angles so we aren't missing anything, or try to find new witnesses, or accounts of what happened etc. (Respondent $C$ ) 
You don't want to be seen as just a mouthpiece ... you earn your stripes as a journalist, you want to be digging and coming up with something that no-one else has got. (Respondent $A$ )

The accessibility of 'other angles', indeed of 'the story' itself, however, was often dependent upon the 'stage' of the event (which usually coincided with a police inquiry) and the sources available. Here, the relationship with the police was significant, but it was one that was often on police terms:

[if] the crime is unsolved, there is no 'other side' to go to. So you are reliant on the police and victims or victim's family for the story. (Respondent B)

The relationship with the police is crucial really ... but there's a mutual mistrust ... because they're using you, you're getting a good story ... Police will often say 'stay and we'll have a press conference'. The police are very good at playing two hands on the one hand they don't want you doing your own stuff so all the media will be at the press conference at 3 o'clock and they'll actually be searching the crime scene again ... I have seen that happen on a number of occasions. (Respondent A)

At that [early] stage of the inquiry the police are generally friendly, co-operative 'its good to see you mate' and that sort of thing and as soon as an arrest is made they go into shutdown. (Respondent $A$ )

Once the event had moved past the investigative stage, and into court:

It is difficult because by the nature of court proceedings it's often one side that is putting up the argument and if witnesses aren't cross-examined it's very hard [to get an alternate angle]. (Respondent $A$ )

These annotations reflect what scholars, particularly those with radical or critical concerns, have long argued; that a structured dependence upon institutional sources for information about crime means that these sources establish the 'terms of reference' for how a crime can be understood, or, in relation to the discussion 
here, they establish the scaffold of the crime narrative (see Ericson, Baranek, \& Chan 1987, 1989, 1991; Hall et al., 1978; Surette, 1992).

Bearing upon the raw (and newsworthy) events as they unfolded in relation to sources and stages, was, however, the scripting of a story. Respondent $D$ was particularly avid about describing crime stories as melodrama, with onedimensional characters (villains, heroes, and victims) and a simplified formulaic arrangement of good triumphing over bad. Within this narrative, we see the 'usual suspects' and 'suitable victims'. Respondent $D$ went on to argue, for example:

Because by definition, crime stories are about people who break society's rules and are consumed by people who don't - the narrative is commonly about an alien Other. It will commonly use race, gender, generational and class stereotypes as a ready shorthand for characterization. (Respondent $D$ )

Such stereotypes must, as must the content of the narrative, be culturally apposite; that is, able to be understood and interpreted by an audience literate in its codes (Barthes, 1977; Hall et al., 1978). ${ }^{73}$ Respondent $D$ insinuated what these might be in Aotearoa/New Zealand:

What would an ideal crime story be? ... A Waitangi Tribunal judge who secretly ran a posse of teenage crack whores on the East Coast who, together with their dole bludging Mongrel Mob boyfriends, ran a protection racket among local pensioners to pay for their habits, while funneling the rest of the booty back up the chain to Judge Dread, who used his clout with the local coppers and iwi to keep things under wraps...until NOW! (Respondent $D)^{74}$

\footnotetext{
${ }^{73}$ This is not to suggest, however, that news narratives are ultimately predetermined, colluded about, or permanently fixed (see Jacobs, 1996).

${ }^{74}$ The 'Waitangi Tribunal' is a legislative body that deals with claims made against the principles of the 'Treaty of Waitangi', a document signed in 1840 between representatives of the British Crown and number of indigenous Maori iwi (tribes). The treaty is often seen as the founding document of the nation of Aotearoa/New Zealand, and in present day it serves as a guide for processes of redress for past colonial harms (see Brookfield, 2006; Moon, 2002; Orange, 1987). The 'Mongrel Mob' is an established gang that is involved in organized crime. Maori predominantly populates this gang. 'Iwi' is the Maori term for 'tribe'.
} 
My respondents claimed that part of the dependence upon such ready shorthands in their crime stories was due to the reduction of complexity and ambiguity of issues so as to 'fit' them to the more general format of 'hard news', and to changes within the industry, particularly for 'investigative journalism'.

\footnotetext{
Reporting is only the tip of the iceberg. It's hard to do it; it's hard to focus it [indepth analysis] into a story format especially on TV, on the 6 o'clock news. There's no scope for it. You've got 'Close-Up'; that's more their area really, but I don't think anybody would feel that we cover social issues particularly well in this country. I don't think we have a particularly informed media and partly that's because we have so few specialists ... it's a fact that most journalists now are multitaskers. (Respondent $A)^{75}$
}

[we have] an under-resourced and overworked news media ... forces converging to create hyper emotional soundbite capsules devoid of social and historical context and meaning. (Respondent D)

How, then, would these institutional news values and the formulaic structure of the crime narrative in Aotearoa/New Zealand have bearing upon the ways by which the murder of Michael Choy was reported? In the next section I look at why the events of the murder were newsworthy, how they would become additionally newsworthy by virtue of their extraordinary timing, a series of significant legal decisions, and the accusative argument of the crown, and how, in turn, the event that would ultimately shape the story would be the imagery of Bailey Kurariki.

\section{The Murder of Michael Choy}

The crime is first, a violent crime: random and senseless (in the sense that the motive was robbery and not murder), perpetrated against a person going about his routine business. It is second, a crime with an unusual factor; the offenders being a group of teenagers, the youngest of whom was also the youngest person to be

\footnotetext{
75 'Close-Up' is a current affairs programme that broadcasts weekdays for thirty minutes in prime time.
} 
charged with murder in Aotearoa/New Zealand's history. Thus, fulfilling par extreme the first two news values, it can be imagined that the event may have been front page news for at least a good few days. However, timing would determine otherwise. As observed in the Introduction to this dissertation, the media were pre-occupied with the exceptionally newsworthy terrorist attacks on the World Trade Centre in New York. Ironically, it was via this diversion that the case acquired a greater sense of newsworthiness.

The High Court trial for the murder of Michael Choy began on July 22, 2002 and the jury retired to consider its verdict exactly one calendar month later. In a pretrial hearing on July 4, however, the presiding Judge made two quite significant rulings. He first continued name suppression for the six accused of murder, and he then rejected an application on behalf of The New Zealand Herald to take photographs inside the court while the trial was in progress. This was cited as an 'extremely rare' move by media watchdogs; one that threatened the nature of the public's 'right' to know, and endangered customary press freedoms ("Gag Order," 2002). Putting aside the judge's concern to minimise the stress of the accused so they were not impeded from participating in their defence, in effect these rulings can be said to have greatly increased the news value (specific to the story) of both the names and images of the accused. Indeed, it is almost as if the media bided their time, and in doing so, were able to capture the events in such way so the story would then meet every crime news value as described above.

Though interest in the youngest offender in the group arrested for the murder of Michael Choy was already high, as reports in the year leading to the trial often opened by calling attention to his age; "A 12-year-old boy was one of eight arrested at the weekend" ("Boy, 12," 2001), "Nine people, including a 12-yearold boy have been remanded in custody" (McLoughlin, 2001b), it would be intensified with the presentation of the first image in the Sunday Star Times on August 25, 2002. Gracing almost the whole front page, the face of the now 13year-old perpetrator Bailey Junior Kurariki emphasises the most extraordinary element of the crime - his childlikeness - as he is smiling as a child would, and 
looking away from the camera as if his attention has been fleetingly caught by something else. This was important insofar as this was also an image of a killer in court after his conviction, and on display for our 'forensic gaze' to reflect on. ${ }^{76}$ Indeed, this double-barrelled depiction of the child and the criminal suggested that both cultural categories were now questionable. ${ }^{77}$

Subsequent pictures would maintain this juxtaposition, continuing to exhibit Bailey in court, and in characteristic youthful acts and expressions. However, just as I was unable to reproduce the first image, neither could I gain permission to use these additional images. Nevertheless, they can be found by sourcing the original articles, some of which are also available online (see, for example, Andrew, 2002; Clarke, 2002; Collins, 2002; Cook, 2007; Dye, 2007; “NZ's Youngest Killer Denied," 2007; Wall, 2002a; "Young Killer Is No Star," 2002). In the main, there were three images of Bailey that were prolifically employed across the sample - although several others in the same vein also appeared intermittently - with a ratio of approximately one per every four and a half print articles. ${ }^{78}$ Notably, images of Bailey's co-accused were not. This can account for why it was after the trial whereupon Bailey was 'unveiled' for the first time that there is a clear shift to a focus upon Bailey's involvement over and above

\footnotetext{
${ }^{76}$ Valverde (2006) describes the 'forensic gaze' and its primary object - the mug-shot image - as a way through which we locate two things; first - the successful apprehension of deviant bodies by the criminal justice system, and second - confirmation of repentance and acceptance by the individual deviant (see also Smith, 1996).

${ }^{77}$ In subsequent uses of the first image of Bailey (as seen in the Sunday Star Times on August 25, 2002) there is clearly a woman to be seen to Bailey's right looking in the same direction as he is. In the first use of this image this woman was 'doctored' out of focus. Where she and her direction of gaze can be clearly seen does not have quite the same connotation of a child's attention caught away. Seemingly this notion was important to emphasize when the image was first presented. ${ }^{78}$ I depend only on the number of times the images appeared in print for two reasons. First, as argued, I was only able to obtain a small amount of the televised material due to access and funding limitations, so thus placed emphasis upon obtaining the relatively more in-depth pieces in the interest of having access to how this case was 'talked about'. Unfortunately, these also happened to be the pieces that tended to leave out visual accompaniments and so a 'count' of the times the imagery appeared in these would be an artificial indication of how many times the imagery might have appeared overall. Of the print data, on the other hand, my sample was comprehensive. Moreover, and second, because print media is less dependent upon visual images, the repeated use of, or appearance of an image or set of images - in print - can be more revealing about how important the imagery is to the story.

${ }^{79}$ In January 2010, the weekly broadsheet magazine Listener ran a cover story titled "Shock and Awe: Photos That Shocked the World". One of these images appears situated alongside photographs of the Bali bombings and adjacent to Michael Jackson holding his infant son over the balcony of a Berlin hotel.
} 
that of his co-offenders. Of the 40 reports in the year prior to the trial for example, 32 mentioned all the offenders, but of the 111 reports immediately thereafter (that is, within the reactive period - from August 25, 2002 up until November 1, 2002) 81 wholly isolated Bailey and his actions in the crime from the group of which he was part. Therefore, the media can be said to have personalised the events through visualising them.

Moreover, there was a close engagement with what was constructed in these images; that is, the juxtaposition of the child and the criminal. We see, for example, how both categories were subsequently (re)constructed - at least figuratively - through the 'conceptual eviction' of Bailey from the category of 'child' (see James \& Jenks, 1996) ${ }^{80}$ Consider the headline that accompanied the first appearance of Bailey in the Sunday Star Times:

\footnotetext{
Our youngest killer: At 9 he was shoplifting, at 10 he was banned from school, at 12 he helped kill a pizza delivery man (Wellwood, 2002).
}

Beneath the image, the text continued to pathologise via a colourful chronology of his deviant behaviour:

\footnotetext{
... described by police as being the worst of the bunch of young killers ... out of control ... flirting with disaster since he was nine ... had not been to school for a year before the killing... had learned to fend for himself ... (Wellwood, 2002).
}

However, due to a further legal anomaly, this 'eviction' was already underway prior to the appearance of the imagery. Bailey Kurariki was a child by law, yet was facing an 'adult' charge. In a move reminiscent of the removal of the legal doctrine of doli incapax in the James Bulger murder case in Britain, the Crown was permitted to bring in evidence to 'prove' bad character, and to argue he knew

\footnotetext{
${ }^{80}$ Beals (2006) makes a similar observation, arguing the media can be seen to employ a notion of 'assumed innocence' to highlight Bailey's departure from childhood. His is a "corrupted innocence" (Beals, 2006: 79, emphasis added). However, in Chapter Six I will argue that a racialised regime of representation would impose an understanding of Bailey as inherently corrupt, and thus never innocent.
} 
'right from wrong,. ${ }^{81}{ }^{82}$ The Crown prosecutor, for example, was cited in her closing address as arguing that the youngest of the accused was "not your average 12-year-old ... [he was] streetwise ... He had a knowledge beyond his years" (“Alleged Murder Decoy," 2002). Demonstrating the media's structural dependence upon the prosecution side of court proceedings, news reports would actively pursue the 'criminal in the making' angle as the headline in The New Zealand Herald the day following the first article demonstrates:

Cherub's long, ruthless criminal career in 13 short years (Wall, 2002a).

It is clear, therefore, that how the murder of Michael Choy came to meet a set of crime news values was, in part, due to the timing of the events, a series of legal decisions, and the accusative argument of the crown. This reflects the dependence of news angles and the construction of a story upon the stages of the event as it unfolds and the sources available, testified to by my respondents. In this case, these stages would bring to the fore a set of news images that would operate to convey all of the information that was deemed crucial about the case: a paradox of the appearance of the child and the knowledge of the criminal. This, in turn, would become the event, and thereupon the crime story would need little in the way of drafting, as the melodrama was already present and the villain already clear. What is more, following Bailey's 'unveiling' the media would have their 'opening shot' and begin to write to the pictures in such a way as to confirm that this was no ordinary child. This marks the first stage in the development towards the reactive phase of the episode in which the discourse of moral reprisal took

\footnotetext{
${ }^{81}$ Doli incapax means - literally - 'incapable of evil' and ensures in English law that cases where children between 10-14 years-old can be held accountable for crimes, they will be held in the 'youth court' which differs in approach to adult court. For an insightful account of the implications and consequences of the removal of this doctrine in relation to the Bulger murder, see Morrison (1997).

${ }^{82}$ In Aotearoa/New Zealand law, details of prior convictions are not normally put before a jury. This has proved a controversial course of action in many criminal cases; a notable one being the trial for the historical rape of Louise Nicholas by several policemen, where the jury was unaware that two of the accused were already in jail for a subsequent rape on another woman (see Nicholas $\&$ Kitchin, 2005). In Bailey's case, the unusual ability for the Crown to bring in such 'character' evidence became the basis of his 2004 appeal for a new trial to the Privy Council which was, curiously, promptly denied.
} 
control. I want to now turn the discussion to the mechanics behind this development; namely, the cycle of amplification.

\title{
The Cycle of Amplification
}

For Cohen (1972) what is discernible about a moral panic is the process by which it inflames itself from the inside, via a spiral of features that he describes as sensitisation, diffusion, escalation, dramatisation, and exploitation. ${ }^{83}$ These, he explains, are parasitic on each other independent of the actual issue in question, which in turn amplifies a perception (of the issue) and escalates the control measures directed at it (Cohen, 1972: 118). In the case of 'killer kids' the first of these features to appear was dramatisation.

\section{Dramatisation}

Cohen (1972: 75) argues:

\begin{abstract}
Deviants must not only be labelled but also seen to be labelled; they must be involved in some sort of ceremony of public degradation. The public and visible nature of this event is essential if the deviant's transition to folk devil status is to be successfully managed.
\end{abstract}

Bailey Kurariki's degradation was conducted in a markedly public and visible way. Indeed, the imagery can be understood as a component within a 'spectacle of socialization' whereupon the impetus to 'display' on behalf of the media (and by extension to 'view' by the public) is propelled by the function of that display to the collective conscience (see Erikson, 1966; Garfinkel, 1956; Garland, 1990; Katz, 1995). ${ }^{84}$ Arguably, the presiding Judge in the trail for the murder of

\footnotetext{
${ }^{83}$ Although Cohen (1972) did not firmly stipulate that this order was particular, I inferred that that was what he intended.

${ }^{84}$ An impetus to 'display' can also be understood in less psycho-social terms; by virtue of a historical relationship between images and the criminal process. Jermyn (2003), for example, argues that the development of photography and the development of modern policing took place in tandem, and that both were bound up in the functions of each other; the former specifically providing the means for surveillance and enabling a growing pre-occupation with classification and order to develop with pace.
} 
Michael Choy anticipated this action - during the trial - as premature, hence his ruling to prohibit cameras in the courtroom. Perhaps he also foresaw the marked shift, on behalf of the media, towards a focus upon Bailey after he was 'unveiled' for the first time.

However, as I have already indicated, it was the accompanying text - the developing narrative - that would promote and cement the 'dramatisation'. Particularly operational was the attachment by the media, to Bailey, of the historically significant 'youngest killer' label as it lexically brought together the illogical association between Bailey's youth and his role in the crime. ${ }^{85}$ Like the imagery, this label was also prolifically employed, becoming almost synonymous with the name Bailey Kurariki. ${ }^{86}$ In many respects, this can be seen as evidence of what my respondents identified as working to 'maximise the drama' because Bailey was not convicted of murder but of manslaughter, an act commonly understood as unlawful but unintentional and described in Aotearoa/New Zealand law as "culpable homicide not amounting to murder" (Crimes Act 1961, emphasis added) for which intention is resolute. The term 'killer' however, definitively implies premeditation via its operation as a verb, therefore implying that there has been prior, and will be future 'killings'. Thereupon it would provide the substance for acts of what Cohen (1972) terms 'spurious attribution' - the process of labelling to support a particular theory or course of action - as the reactive discourses emerged and the energy into panic gathered pace. We see, for example, the extension of the interpretative repertoire of the term killer cold, sinister, and callous; psychopathic, cunning, and evil; wild, monstrous, a primate 'prowling' the streets of South Auckland - that would lend itself to the discourse of moral reprisal. In response, the discourse of social rescue sought to arrest the isolation of Bailey at the same time as it strove to redefine his identity as a mere wayward 'youth'. In this discourse the perpetrators are, instead, the less inflammatory 'high needs offenders', 'troubled children', and 'lost boys'.

\footnotetext{
${ }^{85}$ In this way the dramatisation was a 'dramatisation of evil' whereupon there is a movement from a perception of the act as evil to a perception of the actor as evil (see Tannenbaum, 1938).

${ }^{86}$ Indeed, at the time of writing, the now 19-year-old Bailey Kurariki was photographed by a reporter outside a court hearing for an alleged breach of parole conditions. The lead into the headline to the report is now a familiar one "Youngest killer ..." (Ruscoe, 2009).
} 
The notion of a 'killer' in our midst is also an alert to danger; a call for preventative action in the interests of likely risk to (any) one's personal safety. Additionally, it circumscribes that that risk is perpetual, without end, insofar as it locates the danger upon the character of an offender implicating that they are irredeemable. Demonstrating the intimacy between the features and the circular manner in which the cycle unfolds, it will be seen in a moment that this drama would become important for the ways by which the case would very swiftly be employed - exploited - for the interests of a campaign for more punitive custodial sentences.

\section{Sensitisation}

For Cohen (1972) sensitisation describes the process whereby ambiguous situations are transformed into a more potent and concrete sense of threat. In the case of 'killer kids' this process took quite a unique route. Despite the conceptual eviction of Bailey from the category of the child in the crime narrative and the label 'Bailey Kurariki; New Zealand's youngest killer' in the dramatisation process had together offered a clear preferred meaning to the event, the suggestion that the situation remained ambiguous was nevertheless put forward, and in earnest. Though, as argued above, crime news journalists favour stories that provoke ambiguous responses (and thus it might be imagined that the story might be constructed in terms of highlighting the points at which such a response could be invoked), much of this work took place in editorials and opinion pieces early in the reactive phase (August 25, 2002 to November, 2002). The following examples are typical:

Clearly, something is deteriorating in the fabric of our society. And equally clear is the fact something has to be done ... it is essential something is done ("Time To Act," 2002, emphases added).

[the crime] defies simple explanation ("Who Is Responsible?" 2002). 
Thereafter the initial interpretation of the images (that is, by media figures as they chose which images to use in anticipation of a crime narrative) which emphasized the visible characteristics of the child and the explicit disturbance between semblance and substance (see Young, 1996) was re-invoked, revealing that the eviction of Bailey was not complete, simply perhaps, as his imagery did not violate how a child should appear. ${ }^{87}$ Part of this is arguably due to the prolific (re)presentation of the imagery of Bailey on behalf of a commercially savvy media (utilizing the visual component of the story), but also by the ways that (re)interpretation was suggested. Consider the following examples:

... the face of an angel, but the mind of a cold-blooded killer (Collins, 2002).

The angelic face of Bailey Kurariki ... disguises the terrible reality ("Young And Bad," 2002).

His [Bailey's] mugshot is that of a bright-eyed, fresh-faced youngster full of potential. The reality is that he is New Zealand's youngest convicted killer (Clarke, 2002).

They [young killers] look disturbingly like the kids next door (Dekker, 2002).

... the boy with the angelic face was no angel ("Parole Board Got It," 2004).

Indeed, the threat became understood as one more far reaching than a truant from South Auckland could ever pose:

If such an innocent-looking child can take part in planning and executing such a senseless slaying, what hope is there for retaining the trust of others? ("Benefits Disappear," 2002).

We must ask ourselves how that face of innocence turned into a killer ("Time To Act," 2002).

\footnotetext{
${ }^{87}$ For Jenks (1996), such a link is 'iconologically irreconcilable' and thus it will demand interpretation at the same time as it resists it (see also Young, 1996).
} 
This re-interpretation did have a backdrop, however, with a story angle already 'in the news'. Sixteen months prior to the trial for the murder of Michael Choy, former probation officer and prison boss Celia Lashlie had made some prophetic claims regarding a youngster - whom, satirically, she described as having 'the most angelic face you can imagine' - who was on his way to prison (see "Life Pushing 5-Year-Old," 2001). Though she would be fired from her job for making such claims, it would be Ms. Lashlie who the media would turn to for her 'expertise'.

\section{Escalation}

Indeed, upon the appearance of Bailey's imagery, Ms. Lashlie's words would be accredited as "chillingly accurate" ("Why No Inquiry," 2002); her subsequent "dire predictions of more to come" (Mirams, 2002) saliently offering the sense, in turn, that this was a 'problem' larger than first supposed. Similarly, the then Commissioner for Children Roger McClay was quoted:

I think we will go on getting this kind of thing occurring more and more unless we take dramatic action (McClay cited in "CYF Blamed," 2002, emphasis added).

Forensic psychologist Nigel Latta, who, incidentally, had sat in on the trial, also stressed:

I think the important thing for people to understand is that these kids are no different to hundreds of others out there (Latta cited in “Interview With Paul Holmes,' 2002).

Stimulated by their own endorsement of these 'experts' - "We must listen to the Celia Lashlies" ("Lining Up," 2002) - thereafter, the media took on an angle of the urgency for dramatic action. Headlines, for example, exclaimed:

Time to act on child crime ("Time To Act," 2002).

Sorting out children before they turn on the adults ("Sorting Out Children," 2002). 
Clear warning (Allison \& Markby, 2002).

Lining up to kill (“Lining Up,” 2002).

Teen crime predictions need action (“Teen Crime Predictions," 2002).

The text of many articles would follow this lead:

[the] task is becoming increasingly urgent ("Young Killer," 2002).

... the country's highest priority (“Children Who Turn,” 2002).

Moreover, taking up the point made by Nigel Latta, police representatives and several editors claimed the 'problem' was not particular to South Auckland. In many respects, the label 'New Zealand's youngest killer' preempted this:

Taranaki has not escaped ... there have been recent examples in Taranaki where desperate parents have called the Daily News seeking help with problem children over whom they have lost control ("Sorting Out Children," 2002).

The answer is a hard slog, and a nationwide one. Only last week Timaru's school support worker talked of non-compliant, violent and abusive five-year-olds (“Wasteland," 2003).

The reality is, the youth in Christchurch are challenged by the same things as the youth in Auckland, and there are Bailey Juniors in Christchurch (Hegarty, cited in Claridge, 2003). ${ }^{88}$

For Cohen (1972) the process of escalation - it will get worse - calls for and legitimises responses that are immediate and retaliatory. This is what we see next.

\footnotetext{
${ }^{88}$ It is interesting that the officer quoted here leaves out Bailey's surname as he attempts to locate the problem in Christchurch. I discuss in Chapter Six why Bailey's 'brown face' was significant for his demonization. For now, note that Christchurch is a South Island city, known to have significantly smaller Maori and Pacific Island populations than its northern counterparts.
} 


\section{Diffusion}

What it was that ought to be done solidified along particular lines as particular identities (and respective worldviews) entered the theatre and adopted the 'problem' as their own. It is at this point that a division between the identified discourses is at its most clear. For most 'experts', for example, remedies were to be found at the social-institutional level as blame lay predominantly with the education system and the Child Youth and Family department whose lack of direction and co-ordination had allowed Bailey (and therefore, had the potential to allow others) to 'fall through the cracks'. This, in turn, was largely due to a historical lack of funding (thus, we can locate these actors within the discourse of social rescue). Roger McClay, for example, argued:

\footnotetext{
We might be at a stage where we need to put a group of people together from various agencies ... We seem to find very good brains to work on taxation issues or write reports on why we didn't get the [rugby] World Cup. Why don't we do the same to find out why we've just had the youngest person ever convicted of manslaughter? ("Truancy Linked," 2002).
}

Some media, in turn, were willing to adopt the possibility that the blame was indeed institutional. Broadcaster Paul Holmes, for example, posed the question:

Were [the offenders] failed? Were they all exhibiting behaviours that could have been arrested? Did we fail them? ("Interview with Paul Holmes," 2002).

Largely, however, such a notion was seen to be in opposition to a common sense, which championed both the notions of justice and 'personal responsibility'. Once more, it was editors who led the cause:

The country's mood, as expressed by widespread calls for harsher sentences, is a retributive one ... That response is perfectly understandable. Principles of justice demand a punishment that fits a crime ("Children Who Kill," 2002).

Perhaps only in the past few weeks of the court case have some truths begun to sink in for Kurariki and his friends. They may now begin to have some idea of the 
concepts of personal responsibility and accountability. What a tragedy for them, Michael Choy and his family, and for this country, that these notions, and many other values besides, could not have been instilled by someone long before now. If families will not take responsibility, who will? ("Who Is Responsible?" 2002).

We can blame a society in which everyone has rights and no-one has responsibilities ... in which everyone is a victim except for those of us - and thank God there are still hundreds of thousands - who won't buy into this arid and meaningless manner of living (George, 2002).

Notably, this 'common sense' was often conflated with the deliberations of other 'experts', who would offer the lay view a sense of authority:

The call from Hawke's Bay youth lawyer Don Kennedy for the age of responsibility to be reduced to 12 will strike a cord with many around the country ("Sorting Out Children," 2002).

... the state cannot, nor should, be a parent. Where is the personal responsibility here? ... As Ms Lashlie says, a real shift will come only 'over the dinner table' ("Put The Family Back," 2002).

But more significant was the invocation of the public as crucial to the momentum of a moral panic is the notion that the public is concerned. The often implicit assumption that this was so within the call for responses - the country's mood; will strike a cord with many - continued well into the latter stages of the reactive phase. Tellingly, this (assumption of concern) was exclusive to opinion pieces, revealing how particular voices within the media assume an intimacy with public sentiment, often coming to speak for the public in panic discourse (see Hall \& Jefferson, 1976; Critcher, 2003). Moreover, these opinions were predominantly unified about what the public were feeling:

As a nation we are all reeling by the realisation that there are children in our midst who have been turned into killers (McBride, 2002).

Public outrage ... an angry citizenry ("Young Killer," 2002). 
... public horror ... shock over the case ("Don’t Blame," 2002).

... crime [that] shocked the nation ("Doubtful The Choy Quest," 2002).

New Zealander's are reeling from the fact that a 12-year-old, Bailey Junior Kurariki, was an organiser of a trap that led to the violent death of Auckland pizza deliverer Michael Choy (Robson, 2002).

... expressions of outrage have echoed around the country (O'Conner, 2002).

Later, upon dismissing the conviction and sentencing appeals made by the offenders in the murder of Michael Choy, Chief Justice Sian Elias delivered the court's judgement, in which it was stated that while "youth was relevant in sentencing ... [the court's] consideration had to give way to public interest" ("Sentences Upheld," 2003). ${ }^{89}$

With the entry of other identities (editors, experts, the invoked public) to the episode in the processes discussed so far, the role of the news media could almost be overlooked. However, the processes of escalation and diffusion provide further bad news (it will get worse), more dramatic tension (something must be done), and emotion (the public are angry) fundamental to crime stories and so the self-augmenting loop of the amplification cycle feeds into the newsworthiness of the (perceived) event. In turn, drawing from and contributing to the unfolding of a cycle of amplification is the continuing development of a crime narrative that seeks to identify heroes and villains and come to a finale where good triumphs over bad. In this case, the personalisation of the villain (Bailey) was closely followed by the personalisation of the victim-hero - Michael Choy's mother Rita Croskery. ${ }^{90}$ As one reporter observed towards the end of the sample:

\footnotetext{
${ }^{89}$ I read 'public interest' to refer to 'public opinion' here. However, it is just as likely that Justice Elias may have used the term to mean 'welfare' or 'for the good of'. In 2009 the now Dame Elias would speak at the New Zealand Law Society with concern about the link between popular anxiety and the rise of punitive custodial sentences, and how the principle of 'cool impartial justice' had suffered as a result.

${ }^{90}$ The transformation of victims into heroes can be seen at its most acute in how the victims of the 9/11 attacks are described (see Hume, 2004).
} 
[Bailey's] six bids for parole have been closely followed by the media - with Rita

Croskery's pain laid bare (Cumming, 2008a).

In turn, the quest to make the hero and to complete the 'story' would accord Rita Croskery a generous amount of media attention, and this would become important for the ways in which the case would then be employed for the objectives of a campaign for harsher sentencing. This is discussed in the next section.

\section{Exploitation}

Though the reactive phase continued into early November 2002, for the most part it loses its thrust with the sentencing of the offenders for the murder of Michael Choy on September 16, 2002. As argued in Chapter Four, it is significant that the 'something' that had been done was a set of excessively punitive custodial sentences indicating that it was the discourse of moral reprisal's arguments that had secured the interpretative terrain. It is also significant that at this point the crisis narrative shifts focus and is reinvigorated via encompassing discourse about the enduring risk of the offender/s and their containment for which something had yet to be done. This can be seen in relation to the entry of the Sensible Sentencing Trust (SST), a lobby group that had established itself in the preceding eighteen months as a voice for 'ordinary New Zealanders' disillusioned with the criminal justice system and its focus upon offenders' rights, rather than those of victims. In November, 2002, Rita Croskery lent her voice and experience to the trust (indeed, at the Trust's annual meeting that month, she was elected National Ambassador for Victims). ${ }^{91}$ As a result, just as Rita's involvement would lend the Trust further legitimacy, the news story would now have a definitive hero. In turn the standpoints of the SST would define the terms for how the case (of 'killer kids') could be understood from here on in; that is, overlaid with notions of vengeance. This relationship, and its consequences, can

\footnotetext{
${ }^{91}$ Incidentally, at the time of the sentencing Mrs. Croskery was quoted as "pleasantly surprised" ("Seven-Year Term," 2002) at the seven years handed down to Bailey.
} 
be seen by looking more closely at the ways in which both parties spoke on behalf of each other.

Though Mrs. Croskery was markedly personal in her campaign, describing Bailey, for example, as "a shrewd and cunning criminal ... the mastermind behind [the murder of Michael Choy] ... a real con man" (Rita Croskery cited in "Young Killer Applies," 2003), her comments were also characterized by a definitive agenda to further the trust's retributive ideals; particularly the stand against the practice of parole. ${ }^{92}$ Parole, she argued, was "a failed and dangerous experiment" (Rita Croskery cited in Davis, 2007) and "we do not want another tragedy such as ours ... public safety is paramount" (Rita Croskery cited in "NZ's Youngest Killer,” 2008). To exemplify her points, she would often re-invoke and reflect upon the drama of the reactive phase. Speaking, for example, of why she was opposing Bailey's parole in July, 2007, Mrs. Croskery warned of the dangers of believing in his rehabilitation, and of taking him, literally, at face value:

He has got a brilliant smile. You wouldn't think he was dangerous. He doesn't look dangerous but those are the worst kind, with all the cunning (Rita Croskery cited in “NZ's Youngest Killer Fails," 2007).

On the other hand, spokesman for the SST Garth McVicar took every opportunity to showcase the position of the organisation, particularly the perception of New Zealand as "one of the most violent countries in the world" with a "soft approach to criminals" ("Youngest Killer Tries," 2003), and of our world leading youth justice system as a "politically correct experiment" (Batchelor, 2003). Representing Mrs. Croskery at a home detention application hearing for Bailey in late 2003, he stated:

Until this young killer learns some rules, he should stay where he is ... If he comes out and goes back into the environment from which he came, and starts reoffending, then we've for a criminal for life (McVicar cited in Kay, 2003).

\footnotetext{
92 A SST press release in 2003 states parole is "a tool to unload Prisons and place potentially dangerous offenders back on the streets" (Sensible Sentencing Trust, 2003: para. 2).
} 
Later in the sample he places more emphasis upon the rights of the victim. Here, Bailey remains the proverbial villain:

I can't see any sense in letting people like Bailey Junior Kurariki out ... I think we've got to put the victims first. This whole offender-friendly system we have is past its use-by date ("Parole," 2007).

Unsurprisingly, both Rita and the SST ardently supported the proposal of the Young Offenders (serious crimes) Bill. Mrs. Croskery, for example, said:

Kurariki began his numerous offending from the time he was eight years of age, he was never held accountable for the assaults he committed on other people (Rita Croskery cited in "Parole Hearings Cause," 2007).

However, as is the case with many moral panic trajectories (see Critcher, 2003, 2006), because it was eventually rejected the Bill proved to be merely symbolic. Once more, timing would come into play. As argued, though drafted in 2002, it was not until 2006 (following a redraft and a lifting of the proposed age of criminal responsibility from ten years to twelve) that the Bill was introduced, and it was not until May, 2008 (approximately one month after Bailey had been granted home detention for the remaining five months of his sentence) that it was voted out by a significant majority (ayes: 14 , noes: 107). The Bill had been put on the backburner largely as it was a private member's Bill and these are notorious for the length of time taken to move through the legislative process due to their place in the order of priorities. However, by the time it did come to the fore, a new political force was present - the Maori Party - that had emerged from the fallout of the controversial Foreshore and Seabed Act of 2004. The party had won seven seats in the general election of 2005 and was anticipatorily described the day following as a "potent force" (Thomson \& Milne, 2005) with "significant heft" ("Four-Seat Sweep," 2005). In due course, the party would prove a powerful ally for the discourse of social rescue. 
Indeed, in the second reading of the Bill on May 21, 2008, it was the Maori Party's Hone Harawira who vocalised that the effects, should the Bill be passed into law, would disproportionately affect Maori. He argued:

[a]nalysing the statistics of those who are arrested most, prosecuted most, and convicted most, Maori youth get the prize three times more than anyone else ... this Bill is crap - another knee-jerk reaction to a problem in society that government doesn't know how to fix ... it seems the two major parties have become obsessed with trying to bash Maori kids into submission with these tagging bills and youth offender's bills (Harawira, 2008).

Further, Harawira warned that the Bill could serve to alienate the very constituency it was purportedly responding to:

[a] government that would ban the smacking of children, but react to problems with teenagers by simply getting a bigger and bigger stick, is a government destined for the opposition benches (Harawira, 2008).

Though it is uncertain if it was due to Harawira's challenge that the Bill won so few aye votes, considering it had been afforded a second reading, it is reasonable to assume that the astute foresight at this later stage into the determining effects of the potential legislation contributed to its downfall. Whatever the backcloth, the outcome would mark a significant victory for the temperence of the discourse of social rescue.

\section{Practices Toward Moral Panic}

The task for this chapter was to examine the ways by which the discourse of moral reprisal became the successful discourse in the reactive phase and an influential discourse in the containment phase. I began by examining how crime news stories were made in Aotearoa/New Zealand. I then looked at how, in this case, the story was subject to significant timing, some unusual judicial decisions, and the accusative argument of the crown. Thereupon, the event that would shape the crime narrative would be a set of images that emphasised the illogicality 
between the appearance of a child and the knowledge of the criminal at the same time as they would cement Bailey Kurariki as the lone villain. Setting off a cycle of amplification, the 'drama' was then maximised though an employment of the historically significant 'youngest killer' label at the same time as the images were re-presented for reinterpretation. We see opinion pieces quickly respond through drawing upon the visible qualities of the imagery - the face of an angel augmenting the juxtaposition of what could be seen and what was known, and identifying a threat that proposed to be much more existential than that of one child's evil deeds. Thereafter, having priori identified a hypothetical 'angel faced' killer; Celia Lashlie's prophecies would facilitate the development of the notion that the threat was both imminent and on the increase. Experts, broadcasters and editors (who, in turn, claimed to know what the public were feeling) would then champion solutions of 'eye for an eye' justice and the need for personal responsibility to be taken by offenders and their families, both before and after the crime. Emerging as the victim-hero, Michael Choy's mother Rita Croskery was particularly vocal about such solutions, and about furthering the objectives of a campaign belonging to the SST, a lobby group formed in response to a perception that Aotearoa/New Zealand's criminal justice system had become far too offender-friendly just as a rise in violent crime had become far too real for many victims and their families.

Thus, ultimately, the real-type cycle of amplification unfolded in relation to a compilation of components that were crucial to the success of the discourse of moral reprisal. These components - or 'real-type' features - were the label 'New Zealand's youngest killer', an interpretation suggesting an inherent irrationality between what can be seen and what is known, a story angle that suggested those who look like angels could be evil, a doctrine of 'common' sense, and a vocal victim-hero in Rita Croskery who was heavily involved with a lobby group campaigning for hasher penalties. Nevertheless, each stage of the ideal-type cycle can also be seen independently, and in relation to each of the other stages (signifying the circular process of amplification). In other words, the real-type appears to pose very little challenge to the internal ideal-type practices of moral 
panic (the cycle of amplification). Did this suggest that there was an inherent logic to the cycle, independent of events? Or was there something about the set of features specific to this case that could be seen as archetypical of those of moral panics outside of such logic? What sustains such a compilation of features as productive of a countable discourse that creates a social problem that is largely made of hot air? That these questions emerge at this point emphasizes the importance of exploring why a panic occurs, particularly if we are 'rethinking moral panic'. The next chapter seeks to address 'why' using the third dimension of the approach to moral panic - explaining context. 


\title{
Chapter Six
}

\section{A Holy War, a Punitive Agenda, and the Spectacle of the Other}

\author{
Moral panic targets are not randomly selected: they are cultural scapegoats whose \\ deviant conduct appalls onlookers so powerfully precisely because it relates to \\ personal fears and unconscious wishes (Garland, 2008: 15).
}

This chapter is concerned with exploring the social context in which the episode of 'killer kids' materialised. This is where I explore in what ways the social and cultural 'goings on' made it possible for the trajectory to unfold in the way it did, and reflect on its study as an understanding of why panics happen. I concluded the previous chapter, Chapter Five, with the identification that while the episode could be seen to follow traditional ideal-type processes of amplification, these processes were sustained by a compilation of real-type features. In order of significance these features were: the label 'New Zealand's youngest killer', an interpretation suggesting an inherent irrationality between what can be seen and what is known, a story angle alleging that those who look like angels could be evil, a doctrine of 'common' sense, and a victim-hero who was heavily involved with a lobby group campaigning for hasher penalties. It is my argument that it was these features that enabled one discourse - the discourse of moral reprisal - to be triumphant as the reactive phase of the episode came to a close and to influence the discourse of criminal risk in the containment phase.

What I will put forward in this chapter is that this compilation of features was meaningful and worked effectively towards the creation of a perceived social problem because they were located at the juncture between three social phenomena; the demonisation of children via particular race/space relations, a set of punitive penal practices characterised by a realignment of power, and a society of spectacle in which the exhibition of the 'other' pertains to a racialised regime of representation. I have structured the discussion to follow each of these phenomena in turn, locating each of the features and reflecting on the relationships between them (and how the imagery was central to their operation), as the chapter progresses. 
The second task for this chapter is to examine the relationship of the real-type episode as a whole with the ideal-type concept in an external sense - the stages of description - as illustrated in Cohen's (1972) opening paragraph. This will allow for an assessment of how, or indeed whether, the case of killer kids challenges and obliges the concept's adaptation. As argued in Chapter Two, this is the first step towards an assessement of the 'big question' the project of 'rethinking moral panic' is concerned with - what moral panics are extreme examples of. As I contended, just as the ideal-type is subject to the nuances of real-types, the theoretical question (what the ideal-type is an extreme example of) is intimate with the contextual question (why this or that real-type panic occurred).

Once again, however, I need to stipulate where and why I can be seen to move away from the formula for analysis prescribed in Chapter Three as I proceed in this third tier of the examination of the real-type. In Chapter Four I argued that the separation of the episode into the three tiers of content, process, and context was artificial. Similarly, in Chapter Five I argued that the processes of the cycle of amplification were just that; cyclical and overlapping, and so to separate them was also artificial. Here, in Chapter Six, the location of the real-type features that underpinned the cycle into one or other of the three social phenomena is again forced, perhaps more so than for the previous separations as each feature can be seen in relation to each of the phenomena, and each of the phenomena overlap into and reinforce each other in something of a second order cycle of amplification. For analytical purposes I have located each feature to the phenomena to which it most pertains; where the evidence is at its most clear.

Returning to the immediate task at hand, the first of the three phenomena examined is the demonisation of children via race/space relations. It is here where the understanding of 'New Zealand's youngest killer' can be located.

\section{The Demonisation of Children: a 'Holy War'}

The 'child' is a slippery concept, a product of history and culture rather than a definitive categorization based around the innate qualities of a particular time in 
the life span of a human being (Holland, 2004; Jenks, 1996; Jewkes, 2004). In western societies this product is marked by its relation to adulthood, and denoted by its innocence, naivety, vulnerability, and dependence. Largely, these qualities can be seen as a reflection of the shift from agricultural societies to industry and the corollary 'nuclear' family formation whereupon children have moved from being conceived of as 'chattels' to having immeasurable or 'priceless' emotional value (Jenks, 1996). They are also a product of a host of social, legal, and institutional developments that have ensured children's physical distance from adulthood, and emphasized their unique differences. Alongside the introduction of compulsory schooling, the outlawing of child labour and the development of welfare agencies, professions have emerged to ensure the wellbeing of the young; particularly paediatric and psychological theories and practices of child development and care (Best, 1990; Davies, 1997; James \& James, 2004).

Despite this - the social, cultural, and political history behind the development of 'the child' - we invest in the characteristics of innocence, vulnerability, and so forth as natural characteristics, and understand them as inherent to all children (Davies, 1997; Hockey \& James, 1993). Despite this, we practice childhood as we socialise real children into the norms of childhood, and regulate our own relations with them (James \& James, 2004). Part of this practice is to reproduce not just 'childhood' but society itself, as the idea of the 'child' often symbolizes all that is stable and all that is possible (see Jackson \& Scott, 1999; Jenks, 1996). Furedi (1997) adds that as modern society erodes our solidarity and our experiences become less 'real', more mediated, we cling to the memories of our own childhoods as representations of a less complicated era. It is thus paramount to us to protect the category of 'the child' as it indirectly protects our sense of collective and individual being.

In Chapter Five I argued that the label 'New Zealand's youngest killer' played a key role in the process of dramatisation, simply because it suggested that Bailey Kurariki's actions were far more sinister than his manslaughter conviction warranted. However, Jenks (1996) argues that inherent in the construction of 
childhood innocence is its nemesis: the ever-present spectre of malevolence. When children commit acts of violence they reveal that the 'child' is but a construction, subject like any other to the threat of deconstruction, in spite of what guards have been erected and efforts have been made to ensure otherwise. In this sense, Bailey was guilty of a killing of sorts; indeed, he had slaughtered the belief of the idealised child in Aotearoa/New Zealand, and revealed that our society was not, perhaps, the one we imagined it was. In part then, the label was a challenge to the legitimacy of our practices of constructing and regulating the child, and a demand for immediate and increased control (see James \& James, 2004). This demand was certainly responded to, as the calls for investigations into why kids kill and exclamations about what and who were responsible for our decaying society, evident in the processes of sensitisation and escalation, attest to. However, as I identified in Chapter Five, the discourse of criminal risk would imminently reveal that its targets were specific, that the 'childhood' we knew and cherished was not, incidentally, under assessment. There was an underlying suggestion that there was another terrain of childhood emerging, one that could be located to some children. How this designation would occur will become clear in a moment.

It is pertinent to the discussion of this case that a recurrent overhead narrative in contemporary moral panics is the theme of childhood; those at risk, and those who, by virtue of their un-childlike actions, risk rupturing its conceptual boundaries (Critcher, 2003, 2006). Jewkes (2004) argues that one of the ways we cognitively manage and reconstruct the quintessential child figure is through locating each in stark division to the other: that is, in terms of 'tragic victims' and 'mini-monsters' (see also Valentine, 1996). Over the past two decades, there has been an underbelly of thought pertaining to a rise in these little monsters, and thus a crisis in childhood, something that most commentators locate as commencing with the murder of two year-old James Bulger at the hands of two ten-year-olds in Britain in 1993 (see Davis \& Bourhill, 1997; Green, 2008a; Hay, 1995; James \& Jenks, 1996; Jenks, 1996; Muncie, 2004; Valentine, 1996). Despite that concerns over youth delinquency have been omnipresent across time and space (as the 
discourse of social rescue went to pains to point out), so intense is this new wave of revolt that it is described by Scraton (2002: 15) as "the sharp end of a continuum of child rejection; a sharp end most accurately described as child-hate, in the same vein as race-hate, misogyny or homophobia" (Scraton, 2002: 15). Similarly, Zimring (1999: 260) interprets the revolt as a "holy war" against dissident children.

It is not difficult to reflect upon 'killer kids' and its minutiae as an instance of, or a product of this 'holy war'. As argued, a key feature is the way in which Bailey Kurariki was singled out, pathologised, and to some extent evicted from the category of the child. Moreover, as Shuker et al. (1990) map out, Aotearoa/New Zealand's history is peppered with acute episodes of concern over youth deviance; from larrikinism, truants, and destitute children in the late $1800 \mathrm{~s}$, to concerns over juvenile delinquency in the 1950s and 'hippies' in the 1960s, to the anxieties over 'street-kids' in the 1980s and 'gothic suicides' in the 1990s. All of these episodes can be said to have, as have similar episodes in other western societies now engaged in this 'holy war', paved the way for contemporary concerns to materialise. Nevertheless, it is my argument that the label 'killer' (and its more ominous extensions) could be so effortlessly attached to the face of Bailey Kurariki not simply because he was the latest manifestation of the young deviant, but also because he was brown. In the next section I look at how New Zealand's youngest killer was foremost understood as South Auckland's youngest killer, and how this understanding would underpin a suggestion that brown children as a whole were potentially problematic. ${ }^{93}$

\section{Race, and space}

Very few of the sampled articles make mention of Bailey's race/ethnicity despite that his image is one of an 'other' child: his name - Kurariki - clearly denoting

\footnotetext{
${ }^{93}$ I use the term 'brown' to refer to Maori and Pasifika peoples, in the same way that MP Ron Mark did (see Chapter Five) and also following the lead of McIntosh (2004). My intention here is not to deny the multiplicity of differences between Maori and Pasifika peoples (and indeed, between Pasifika peoples), but to highlight the way in which having brown skin can serve a sole indicator for assumptions made about one's character. It is my argument that in the case of 'killer kids' it did serve in this way.
} 
that he is of 'other' descent. ${ }^{94}$ At the same time, however, it was made abundantly clear that he was a resident of South Auckland; a place that is understood as a 'moral and cultural wasteland' predominantly populated by brown 'others' (see McIntosh, 2004). I will examine this understanding in more detail in a moment. For now, I want to briefly discuss a correlation of the brown 'other' and criminality in Aotearoa/New Zealand.

The association between ethnicity and crime is a longstanding one, and is not exclusive to Aotearoa/New Zealand. Indeed, ethnic minorities disproportionately populate criminal justice systems across the western world (Walters \& Bradley, 2005; De Coster \& Heimer, 2006). In Aotearoa/New Zealand, for example, Maori made up $41.5 \%$ of the total figure for criminal apprehensions in 2009 , and Pasifika peoples made up 9\%. These figures are significant given that Maori make up $14.6 \%$, and Pasifika peoples $6.9 \%$, of the total population (Statistics New Zealand, 2009). Studies have consistently shown that such disparities are not because minority groups are inherently criminogenic, but that they are a direct result of contextual factors such as economic marginalisation and social alienation (see Fergusson, Harwood, \& Lynskey, 1993; White \& Cunneen, 2006). However, such evidence often fails to repudiate the ways in which minorities are subject to racialisation in criminal justice processes, whereby the behaviour and misconduct of minority individuals and groups is explained on the basis of racial characteristics. It is, in other words, an understanding that these groups are more criminally inclined, by virtue of their ethnic origin (Walters \& Bradley, 2005). Racialisation can lead to lead to over-policing and over-charging of minority groups, as well as disparities in convicting and sentencing when compared with majority populations (Collins, 2005; Quince, 2007; Jackson, 1988).

This racialisation of minorities within the CJS is often seen as a reflection of - an extension of - racialisation in other social, cultural, and political spheres. The media is a particular target of critics concerns. Matheson (2007: 93), for example, finds:

\footnotetext{
${ }^{94}$ Bailey is of Rarotongan or 'Cook Island Maori' descent.
} 
There is little evidence of biculturalism in news agendas, but rather a focus consistent over time - on Maori as problems, criminal, radical, dangerous, exotic, deviant; that is, as a racialised 'other' in all the many manifestations of that status.

Most commentators determine that this is because the mainstream media operates from a Pakeha perspective (Abel, 1997; McGregor, 1993; Wilson, 1990). When asked about their construction of crime stories, my respondents were similarly defensive of their practices:

I feel that we report the story regardless of who is the victim and who is the perpetrator and regardless of their ethnicity. (Respondent $C$ )

I don't think there's an agenda. The closest you could get to saying there's a bias is that in any newsroom there's a certain amount of gallows humour. Occasionally you'll reveal some evidence with regards to an offender and someone might say 'Maori or PI, aged between 18-25!' (Respondent $A)^{95}$

Mainstream news and current affairs invariably comes from a mainstream Pakeha perspective and even if the reporter is not Pakeha, it is very difficult to tell stories from a non-mainstream perspective and still be considered any good at your job. (Respondent B)

Yet other critics firmly locate a one-sided discourse deliberately aimed at maintaining Pakeha interests (see Walker, 2002). Indeed, the media is seen as explicitly active in a 'civil surveillance' of types insofar as a major feature of media treatment of Maori (in particular) is the scrutinizing of their activities, organisations, and aspirations (see Hodgetts, Masters, \& Robertson, 2004; McCreanor, 1993; Walker, 1996). Similarly treacherous is when the media (among others) engages in 'dog whistle' politics where things are said in ways where 'everybody knows' what is really being said, simply because it can be difficult to erect a challenge against language that otherwise appears benign. I contend that this is exactly what occurred in the case of 'killer kids.' Further interrogation of the conflation of the link made between criminality and the brown

95 'PI' is shorthand for 'Pacific Islander'. 
'other' at this particular period finds that it was also a time where South Auckland was understood as a place where this relationship was at its most extreme.

In Chapter Four I discussed how the associations between South Auckland and poverty, dysfunction, and crime had lent a valid excuse to the neighbours (to the property where the crime took place) for refusing Michael Choy's pleas for help. I then suggested that the contradiction inherent in the sentencing Judge's handing down of severe custodial sentences in light of the offender's failure to get help was because the offenders were of South Auckland, whereas the neighbours were merely in it. Here, I want to substantiate the understanding of South Auckland as a deteriorating and dangerous place. Media columnist Michael Laws (2008) writes:

Of course, South Auckland is not Afghanistan. Not yet. But it has become a whirlpool of dysfunction over the past 25 years and no amount of national nor civic interventions has made any difference. It harbours more socially alienated individuals than anywhere else in New Zealand. Even the acting mayor of Manukau [Gary Troup] admits that it is evil. That is also an unfortunate fact for the tens of thousands of its inhabitants who do not kill, rape, sell drugs, join gangs or bludge off the welfare state. They have to live among those that do and have their home portrayed as a sprawling, antipodean ghetto ... this social cesspit ... Damn it, these are the badlands. Full of bad people.

Historically, South Auckland was a working class suburb; thriving with textile factories and meat processing plants, and populated with young families in low cost state housing. However, as McIntosh (2004) argues, as it was just such industries and families that bore the brunt of the 1970s oil crisis and the reforms and restructuring of the 1980s, South Auckland suffered greatly. It has since become something of a social laboratory; a prime site for researchers to uncover the realities of poverty, vulnerability, and marginalisation. This scrutiny, it is argued, only contributes to the stigma attached to the area (see McIntosh, 2004).

Significantly, as suggested above, the face of South Auckland is chiefly understood as a brown one. Moreover, as McIntosh (2004) argues, there is no 
particular ethnicity assigned to this 'brown face'; it is presented as a homogenised face so as to suggest that the only variable that is important when talking about minority ethnic groups from South Auckland is their 'otherness' (or more aptly: their brownness). At times, especially when adopted by 'Southsiders' themselves, this homogenisation points towards a positive and unified character: "an urbanised Pan-Pacific identity that is connected by location (Aotearoa, South Auckland); by experience (colonisation, immigration, prejudice); by socioeconomic status and situation and by friendships based on social and musical bonds" (Zemke-White, 2001: 237; see also Borell, 2005). However, for the most part, and for those living outside its parameters, this 'Pan-Pacific identity' is overshadowed by "shallow, negative and marginalising representations" (McIntosh, 2004: 144).

One of the most notorious representations to emerge is the South Auckland youth gang member; the unsupervised and socially disengaged teenager who spends his time with other unsupervised and disengaged teens tagging, doing crime, and defending his territory or 'colours' against other gangs (see Borell, 2005; McIntosh, 2004; "Streets of Shame," 2006). Indeed, so powerful is this stereotype, it was suggested to have aided in the defence of Bruce Emery, a 50 year-old man who had stabbed to death South Auckland youth Pihema Cameron in January 2008. Emery had caught a group 'tagging' his fence, and this so angered him, he returned to his house to get a knife and subsequently stabbed Pihema to death. He was later convicted of manslaughter. ${ }^{96}$ Perhaps more disturbing, however, is that South Auckland children, those younger than what is traditionally ascribed for the adolescent or 'youth', are often reported about in terms that suggest that they are prospective 'gang members'; wayward, out of control, and idolizing their older siblings and others already established in gangs (see Callinan, 2007; "Police Say Youth Gangs," 2005; Purdy, 2001; “Officials Meet Over Gang," 2005). It is further alarming how these bleak and misguided assumptions perpetuate something of a self-fulfilling cycle. Director Juliet Veber,

\footnotetext{
${ }^{96}$ Incidentally, the SST would offer a disclaiming comment on their offender database where Bruce Emery's name appeared: "In this case it was felt by many that the victim's conduct substantially mitigated the offender's conduct” (Sensible Sentencing Trust, 2009).
} 
whose film Trouble is My Business followed the lives of three South Auckland 13 and 14 year-olds for a school term at Aorere College, comments upon the way in which the provocative headlines about South Auckland kids affects:

The kids' self esteem was shockingly low and their sense of disempowerment about their lives was appalling at such a young age. They genuinely believed people from outside the area looked down on them, and I had to agree with them, I knew a lot of people did (Veber, 2009).

My point in this section is that by making clear that Bailey Kurariki was a child of South Auckland, the media drew upon some deep-rooted connotations - what 'everybody knew' - about this area so as to suggest that the associations between criminality and the brown 'other' were due to nothing other than the fact that these were 'bad people'. In this sense, while the use of the term 'killer' sensationalised and dramatised the acts of one child, the classification of this child as New Zealand's was a suggestion - simply because the child it held as the exemplar was understood as brown and innately bad - that brown children living outside of South Auckland had the propensity to be problematic, especially if they were also poor, and/or socially alienated in any manner. I consider in more detail later how this suggestion was informed by, but also superseded by, the location of the imagery of Bailey within the spectacle of the 'other' child.

In the next section I discuss that alongside this 'dog whistling' act of the media would be the intensification of a punitive turn in Aotearoa/New Zealand. This would offer the discourse of moral reprisal another discursive tool - the doctrine of 'common sense.' I examine how, with this punitive turn, the criminality and brown 'other' relationship would once again come into focus, together with the construction of Rita Croskery as the archetypical victim-hero.

\section{Penal Populism}

'Penal populism' refers to a political discourse that champions the voice of the 'common man' in penal affairs. Aotearoa/New Zealand is often seen as a case in point to demonstrate the influence of the penal populism as it has enjoyed 
something of a 'full house' with respects to factors that cause the phenomena (Pratt, 2008a). Though democratic in principle, in practice it consists of the pursuit of policies that have little to do with reducing crime and promoting justice, and more to do with gaining an electoral advantage (see Bottoms, 1995; Roberts, Stalans, Indemaur, \& Hough, 2003). However, Pratt (2008a) argues it represents more than merely 'tapping in' to populist concerns at intermittent times. It is, rather, a product of a realignment of power which now extends across much of the modern social landscape. What characterises this new axis of power is a stronger resonance between governments and extra-establishment individuals, groups, and organisations who claim to represent 'the people'. In effect, this has often meant that rational argument is put aside in favour of public sentiment where issues of crime and punishment are concerned. Indeed, the central paradox that characterises a world-wide (rather, western-wide) trend towards punitive penal reform is that it bears little relationship to actual crime rates. Pratt $(2007,2008 \mathrm{a})$ identifies several forces at work in the penal populist turn. I will overview these forces in brief before considering how the phenomenon would come into play in the episode of 'killer kids'.

The first force at work is the decline of deference - a decline in the assumption and acceptance of the authority of elite figures and establishment bodies to speak on behalf of ordinary people. Related to this decline in deference is a decline in trust of politicians and the political process itself. Pratt $(2007,2008 \mathrm{a})$ argues that this is due, in part, to a perceived inability of political processes to respond to the needs of the constituency of 'ordinary folk'. Pratt $(2007,2008 \mathrm{a})$ attributes a third cause to a sense of ontological insecurity, a familiar argument in many respects in that it refers to the late-modern condition of 'breakdown' in formerly stable structures and pillars of security; that is, full employment, the nuclear family unit, religious practice, and community and trade union group membership; ingredients deemed essential for the binding of an individual to wider society and the transmission of a civic culture, have all but fallen to the wayside.

Pratt $(2006,2008 \mathrm{a})$ argues further, that combined with the new awareness of instability is an ever accelerating crime rate that has plagued all Western nations 
from the 1960's through to the early 1990's. As a result, demands for more stringent laws and harsher penalties became paramount in terms of restoring both the lost sense of trust unto the political processes and forging a sense of security where there now appeared little. However, where moves to respond were slow, or in variation to demand, further public disenchantment and insecurity have followed. As Pratt (2008a: 36) argues, under such circumstances "many citizens will be more likely to put their trust and support in those populist organisations and political movements which claim to have the solutions to such problems magical, commonsense solutions usually based on invocations of some golden period in the past when social stability and social order was unquestioned".

Adding to this vicious circle is a media who depends upon 'emotional', sensational stories which serves to further the idea that the crime problem is acute, out of control, and requires drastic action while simultaneously making it clear that the criminal justice system is ill-equipped to cope. Pratt $(2007,2008 \mathrm{a})$ further claims that the democratisation of the media whereupon the average citizen is able to participate in the news making process via developments in information technology means that broadcasting elites are more subject to alternate voices in the construction of knowledge of crime and other matters. Thus, objective expert analysis is often left aside as the experiences of those in the know - particularly those who have been victims of crime - and the emotive opinions of lay citizens become the framework through which crime and punishment is understood (Pratt, 2008a; Pratt \& Clarke, 2005).

Perhaps the first and most astute observation one can make is that penal populism is marked by the very same underlying assumption of the concept of moral panic; that is, that the constructed problem is disproportional to the objective reality. Indeed, many of the prerequisites for this phenomenon can be wedded to the 'stages' required by moral panic; a concerned constituency (a decline in deference), a view that something must be done (a decline in the trust of politicians and the political process), and the manning of moral boundaries by 'right-thinking' people (trust in populist organisations with common-sense solutions) to be particular. Certainly, in the case of 'killer kids' the phenomenon 
of penal populism can be seen as especially significant for the authority it afforded to the role of Rita Croskery and the SST in the containment phase.

Pratt and Clarke (2005) discuss how penal populism gained momentum in New Zealand beginning with a general shift towards longer sentences and stricter parole requirements in the 1990s. Then in 1999 a Citizens Initiated Referendum (CIR) endorsing greater emphasis upon the needs of victims alongside harsher penalties for violent offenders won a 91.75 per cent public vote. This would become, argue Pratt and Clarke (2005: 305), a "regular referent" against which the subsequent Sentencing, Parole, and Victims Rights Acts of 2002 could be judged. These Acts in unison increased penalties, restricted parole, and extended the rights of (and broadened the category of) victims. Though developed amidst a law and order theme of the general election of 2002, which was not an unusual theme (a similar one was prevalent in the election of 1987), two factors would guarantee the Acts' materialisation.

First, most major political parties had taken a stance to be 'tough' on crime, and so in effect there was a political consensus to address the law and order issue in such a manner. ${ }^{97}$ Second, the SST (in particular) was gaining authority as a lobby group for tougher sentences. Pratt and Clarke (2005: 306) contend that the law and order component of the 2002 general election campaign was effectively led by the SST with "politicians running to catch up with their demands". Indeed, in an article that considered the role of Garth McVicar and the SST in a campaign for harsher penalties for violent offenders, which also made much of his outspoken opposition to visits made by two All Blacks to Bailey in November 2002, it was observed that he and the trust had become "an almost automatic media destination" (Gamble, 2002). This can account for why the exploitative stage of the amplification cycle was dominated by Rita and the SST, and why then, the threads that made up the discourse of criminal risk unfolded as reponses to the anti-expert, common-sensical, and emotional dialogue of the discourse of moral reprisal. In fact, the SST's submission to the Law and Order select committee on the Young Offenders (serious crimes) Bill in July, 2006 exhibits the

${ }^{97}$ The Green party was not part of this consensus (Pratt \& Clarke, 2005). 
intimacy between the two discourses in a way that is inimitable, at the same time as it reveals its alliances to the underbelly of neo-racist thinking active in the community. Its first section, for example, which describes the causes of delinquency and urgency for action, clearly reflects the discourse of moral reprisal's thread of godzone gone wrong:

\footnotetext{
Current policies are failing dramatically ... New Zealand is experiencing a fortyyear crime epidemic and children have been particularly hit - often literally - but regardless of other circumstances contributing to the offending it is time society took stronger measures to protect itself against these serious young offenders. It is hoped that this will be a wake up call for the liberal sector of society that has promoted the disastrous social experiment that has destroyed the family unit (Sensible Sentencing Trust, July 2006: paras. 1, 5, 6).
}

Intertangled with this statement would be a reference to the Kahui twins, who were killed by an unknown assailant in June, 2006, when they were three months old. Through drawing on this most recent example of the thread of feral children, the underclass, and South Auckland (the Kahui family lived in South Auckland, and the case was constructed in the media as one demonstrating the "problem equation' of the brown 'other' and crime), the SST would signify that it was this sector of the population that their submission was concerned with. ${ }^{98}$ The reference is as follows:

The reality is if the Kahui twins had not been murdered they would have ended up inextricably entwined in our Criminal Justice System later in life (Sensible Sentencing Trust, July, 2006: para. 3).

In a second section, the submission focused more directly upon New Zealand's 'disastrous' approaches to youth crime. Here, the family group conference (FGC) is a particular target:

Family Group Conferences are another disaster, the idea may have been wellmeaning but in reality they have been hijacked by the criminal fraternity and are a complete and utter farce that is making a mockery of our justice system. The

\footnotetext{
98 This also reflects what Pratt (2006: 542) identifies as an "ethnic toxicity" inherent in penal populism.
} 
conference is normally held as close as possible to the offender's residence to cause as little disruption to their lives, the victims are often required to travel, even through the victims is supposed to be consulted this rarely happens (sic). A typical family group conference will have the offender or offenders and their support people normally between 6-10, lawyers for the offenders (one for each) the victim and their support person. The offender's family treats it as a special occasion and often bring KFC or McDonalds and everything that goes with it ... A dismal failure without any consequences or accountability shown by the offender (Sensible Sentencing Trust, July 2006: paras. 10, 11, 12, 14).

This attack upon the FGC especially brings into focus that the SST were targeting brown 'others'. FGC's were an initiative of the Children, Young Persons and their Families Act (1989) which sought to implement restorative principles that were congruent with traditional Maori approaches to justice (see Quince, 2007). The definitive aim was to support and maintain the family unit as the ongoing support system in which young people could address their offending, and to be inclusive of different cultural notions of the 'family' (such as extended whanau). ${ }^{99}$ Another aim was to divert young people from formal criminal proceedings, while still holding offenders accountable for their actions (Quince, 2007). A number of Maori scholars have since criticised the model, particularly for its promotion as a 'Maori process' when its authenticity as just that was questionable, but also for its minimal role in the legal system as a whole (see Jackson, 1995; Tauri, 1996). The SST's attack upon the FGC was from quite a different position; one that sought to undermine the Maori worldview of balance, harmony, and reparation that underpinned the model. Indeed, it can be argued that the climate of penal populism allowed the SST - via a pretence of common-sense justice initiatives to launch a fervent critique towards a political initiative designed to negate the biases of the criminal justice system that had in the past contributed to a disproportionate number of Maori and Pasifika young people coming before the formal court (see Walters \& Bradley, 2005).

In quite a different (but ultimately comparable) vein, a variable lending weight to Rita Croskery's voice was her role as a mother. Indeed, this is a role that appears

${ }^{99}$ Whanau is the Maori term for family. 
to be the prerequisite in Aotearoa/New Zealand for the status of 'victim-hero'. The precondition for the CIR of 1999 (which, as argued, provided the political fodder upon which the Sentencing, Parole and Victims Rights Acts were constructed) for example, was the 1997 attack on the mother of Christchurch shopkeeper Norm Withers. As Pratt and Clarke (1995: 314) argue, the attack "was able to provide the appropriate link between public anger over crime and the reforms to the democratic process: his mother seemed the archetypical victim defenceless, innocent and randomly and brutally attacked". ${ }^{100}$ In the next section I examine how the role of the mother is often employed in the construction of both the villain and the victim-hero and how indeed it was for both in the case of 'killer kids'.

\section{A tale of two mothers}

In Imagining Crime: Textual Outlaws and Criminal Conversations, Allison Young (1996: 147) traces the progression of governmental and criminological discourses that "pick out the figure of the single mother as the contemporary embodiment of responsibility for the criminal child" which follows the "figure of the mother [who is] made a scapegoat for the failure of investment in the link between community and child" and it is within this that she locates two of the dominant explanations for delinquent youth in responses to the Bulger murder; the absence of the father and the alleged inadequacy of maternal care. Similarly, in this case, aiding the distinctions between Bailey and his victim Michael Choy, much was made of their mothers who were depicted in opposite terms. Rita Croskery (Mr. Choy's mother), for example, was shown not only to fulfil maternal expectations, but to go beyond them - beyond the grave - in her crusade to keep her son's killers behind bars. This is best illustrated with her pledge to continue campaigning against parole after Bailey had been granted home detention in an article poignantly headlined "Mum's marathon mission stretches on” (Binning, 2008):

\footnotetext{
${ }^{100}$ This trend would continue. In 2009 it was the mother of murder victim Sophie Elliot who commanded the spotlight.
} 
I'm doing it for Michael, because that's what I said to him [when he died] - that I would do what I could to keep these people behind bars for as long as possible ... People think just because that little brat [Kurariki] is out now that is the end of it but it's not (Rita Croskery cited in Binning, 2008).

Bailey's mother Lorraine West, on the other hand, was exposed for her less than adequate care of Bailey and his seven siblings. Described - by none other than Garth McVicar of the SST - as "a factory for producing out-of-control kids" (McVicar cited in Batchelor, 2003), she would defend her practices though recounting her parenting in material terms; "[making] sure they had a shower every day and changed their clothes" (West cited in Wellwood, 2002), and "I always make sure there's food in the house, the rent's paid and the place is clean" (West cited in Wall, 2002a). In hindsight, she wondered if she should have employed physical punishment (Wall, 2002a). Adding to this, the media would employ a series of particularly idiomatic utterances made by Mrs. West to confirm that this was a woman far removed from the likes of Rita Croskery. Indeed, attempting to explain his behaviour in the context of a violence free home, she argued "I think I never beated him or was cruel to him" (West cited in "Child Killer Smart," 2002). Later, admitting that her son had been misbehaving in one of the youth justice centres in which he was held, she was quoted that he was just “answering back and that" (West cited in "Youngest Killer Will Not," 2005).

Operating as a backcloth to these class-maternal differences was a clear Pakeha/Other dichotomy. However, here the relation was by proxy, through each of the women's marital partners. For both women, these intimate associations would locate them in terms of inclusiveness and exclusiveness within 'mainstream' Aotearoa/New Zealand. Bailey's mother, for example, was a Pakeha woman who had married Bailey Kurariki Senior with whom she had four children, but, as it was condescendingly put, she had also had four children "to another Rarotongan" (Wall, 2002a). She was thus a woman who would have appreciation for the complexities of being a brown 'other' in a Pakeha world; her worldview would not therefore be one necessarily related to by the 
'mainstream'. ${ }^{101}$ Michael Choy's mother, by contrast, was an Asian woman married to Pakeha Ken Croskery. Why this is notable is because at the same time as the South Auckland stereotype was emerging as the 'criminogenic other', there was observed amongst the 'mainstream' an ill-ease with a growing Asian immigrant population. This was coined, colloquially, as the 'inv-Asian', and was propelled with a media depiction of the Asian as the 'mysterious other' (Butcher \& Spoonley, 2009; Hannis, 2009). It is significant then, that Rita's Asian heritage would not be mentioned; that seemingly - via her relationship - her 'New Zealand-ness' (and, incidentally, her qualification to speak on behalf of 'New Zealanders') would go unquestioned.

It is additionally significant how the two women were constructed visually. Lorraine West, for example, was initially depicted as a 'wild' and unkempt woman with facial contortions of unbridled anger, suggesting a lack of self control (see Wellwood, 2002). In more recent imagery she appears physically ill (indeed she is) and emotionally defeated (“Bailey Kurariki's Mum: 'I'd," 2010). Rita Croskery, on the other hand, was (and continues to be) routinely presented in demure poses with pensive expressions (see Binning, 2008), or with commanding, authoritative posture (see "Victim's Mum Wants Criminals," 2008). The lighting tends to be soft in these images; in stark contrast to the harsh illumination in Lorraine West's pictures.

This brings me back to the point of the initiation for this study. As argued, it was an encounter with the media presentation of the imagery of Bailey Kurariki and an observation, thereafter, of a marked social reaction resembling a moral panic that caught my attention and has sustained the impetus for a revised approach to moral panic. In Chapter Five I examined the construction of the imagery in relation to news values as it was subject to some extraordinary timing, a series of legal decisions and the accusative argument of the crown. I want to now engage with the imagery as a specific form of communication within a context of an image proliferated society, or society of spectacle; the third of the social phenomena in

\footnotetext{
${ }^{101}$ She could also be understood, morally, as a particular kind of woman, having had two sets of babies to two 'Rarotongans'. That Rita Croskery was on her second marriage was not mentioned.
} 
attendance in this episode. From the dichotomised interpretation of the imagery of Bailey, together with the notion that evil was present, I will propose that it (the imagery) occupied a space between the immediacy of vision, the 'truth' of photography, and the deception of appearance. Crucially, it will be seen in this space that the understanding that brown faces were problematic was informed by an entrenched and complex backdrop of a viewing the brown 'other'.

\section{A Society of Spectacle}

It is not difficult to locate the significance of images and imagery in the construction of late-modern social life. Some scholars for example, argue that we are a 'visual culture' in which there are "particular and historically specific combinations of meanings and subjects" (Evans \& Hall, 1999: 6) privileged by the technical unit of the image (Lister \& Wells, 2001; Mirzoeff, 1999). Others assert that we have always been visual; what are new are the regimes in which we make and distribute images and the questions we ask of the visual object (see Bal, 2003). Post-modern and post-structuralist thinkers take it further, identifying the aestheticisation of everyday life which refers, in part, to "the rapid flow of signs and images which saturate the fabric of everyday life in contemporary society" (Featherstone, 1991: 67) in which the traditional distinction between reality and the image is disrupted (see Baudrillard, 1983). Others suggest the late-modern era is one of a society of 'spectacle', which more concretely describes "a media and consumer society organised around the production and consumption of images, commodities, and staged events" (Kellner, 2003: 2; see also Debord, 1967).

Whichever conjecture one accepts, it follows that as receivers, constituents consumers, we place value upon the act of looking at the same time as we expect to see, for ourselves (McGregor, 2002b; Holland, 2002). This is substantiated and entrenched by the immediacy of images in relation to written text. Barthes (1973: 110) argues:

Pictures ... are more imperative than writing, they impose meaning at one stroke, without analysing or diluting it. 
This will become important in a moment. Aside, this immediacy can explain why, for the commercial media - television in particular - words are written to the pictures or 'opening shots'; they (words) are secondary to what the eye has already witnessed. Yet, at the same time, the act of looking is said to be 'impure'. As Bal (2003: 9) argues, 'looking' is “inherently framed, framing, interpreting, affect-laden, cognitive and intellectual" or the "look of the knowing subject" (Foucault, 1975: ix). In other words, there is always a level of understanding brought to what we 'see' and this is both for the unit of the imagery (a photograph, a painting, a sculpture) and for what that imagery depicts.

The photograph presents as unique in this respect as it appears as a literaltranscription of the real; a stand in for what is seen by the human eye (Hall, 1981; Holland, 2002; Lister \& Wells, 2001). The photograph thus denies itself as a representation (Barthes, 1977). However, because photographs occupy multiple genres, the degree to which a photograph is read as reflection, as opposed to illustration, is dependent upon its immediate context (a newspaper, a billboard, a family album), an understanding of the photographer's intention, and the aesthetic, emotional, and imaginative sensibilities of the viewer (see Barthes, 1977; Hall, 1980; Holland, 2002; Rose, 2001). Such sensibilities, or the process of 'active viewing', can often overpower the intended message. As Biber (2007: 6) observes:

\begin{abstract}
Photographs ... they remind us of happy moments with our family, nostalgic reflections, memories of places we have been, disastrous images of places we never want to go, people we hope never to meet, our obsessions, our dark desires and our fears.
\end{abstract}

The crimino-legal complex, however, endures nothing of photography's manifold tenure nor allows for the rich scope of reception. ${ }^{102}$ The law, for example "looks at photographs as if there were nothing impeding its capacity to see" (Biber, 2007: 5). Thus, though crime's images have always been burdened with a sense of

\footnotetext{
${ }^{102}$ Young (1996) refers to the crimino-legal complex as the intersection between criminology, criminal law, criminal justice, the media, and everyday experience; that which makes up the collective cultural conception of crime.
} 
'staging', partly as criminal acts tend to take place outside of public view (and thus, our witnessing of such events takes place after the fact and via mediated representations), and partly as the construction of 'real' crime is deeply entangled with constructions of fictional crime (see Ferrell \& Websdale, 1999), they are the most analogous with 'truth'; they are evidential.

The same can be argued of news photographs. Just as written 'news', perhaps even more so by virtue of its ability to 'see', photojournalism is underwritten with neutrality and objectivity (Hall, 1981; Holland, 2002). This works to suppress both the construction at its site (setting, lighting, arrangement, author, subject) and dismiss the professional knowledge of the 'decisive moment' whereby the photographer seeks to 'capture' their subjects - often off-guard - at a moment that conveys the essence of the scene (Holland, 2002).

Bailey's imagery was feasibly read first and foremost as news imagery. It was therefore invested with assumptions regarding its authenticity, its objectivity, its truth. It is rare, however, that a news image will appear without linguistic supports which offer a preferred meaning on behalf of the encoder and serve to anchor the interpretation (Hall, 1980; Hall, 1981; Benjamin, 1980). Here the label 'New Zealand's youngest killer' performs such a task. While it was visually true that this was a child, who often smiles, who sometimes looks curiously up at the camera, who cries and bites his lips as he stands in the dock, via the attachment of the label it was also true that this was a killer. Indeed, through the anchorage of it as a crime image - it was evidence of a killer. In the next section I examine how this evidence would be fortified by a 'regime of representation' that depicts brown 'others' in terms that maintain an ongoing colonial project.

\section{The spectacle of the other child}

Hall (1997) argues that representation - the first key 'moment' in the cultural circuit - is a complex practice both at the point of production (or encoding) and at the point of reception (or decoding). This is particular when it deals with aspects of 'difference'; it engages emotions and mobilises anxieties at points and intensities that are not always easy to make sense of (see also Biber, 2007). The 
face of Bailey Kurariki belongs both to the social space in which the image of the child is practised, and within which the representation of a brown 'other' is understood in Aotearoa/New Zealand. Hall (1997) identifies such spaces as regimes of representation.

Earlier in this chapter I argued that the category of the child is permeated by notions of innocence, vulnerability, and dependence, and that we 'work', via various means of socialisation, to maintain this ideal. One of the ways in which we do this is through our images of children. Davies (1997) argues that in conjunction with the professional discourses of regulation and protection, images of the idealised child - from British royal princes and princesses to child stars of Hollywood to winners of local baby shows - proliferated popular culture and consumption as the $20^{\text {th }}$ Century progressed. Holland (2004) contends that as a result childhood has become an elaborate drama in which real children perform roles, emulating the images of themselves around them, and of which adults seek to continually recreate in their making of family memories (with pictures). This authority of imagery in relation to the socialisation of children has, however, some negative aspects. Children are afforded very little agency, for instance, in terms of how they are depicted to others. Moreover, these depictions can move outside the terrain of idealised childhood, and indeed, outside 'our' conscious control. ${ }^{103}$

Bailey's imagery does not stray from how one should portray a child; his captured expressions and mannerisms the epitome of childlike responses. Indeed, he was actively viewed as a 'face of an angel'; an expression that could only be reserved for the quintessential idealised child. The anchorage of him as a 'killer', however, inhibits the interpretation of such a child. It suggests that there is a profound deception inherent to the image, reminiscent of Satan's ability to present himself as an 'angel of light' ( 2 Cor. 11:14, Revised Standard Version). What was evident, this implied, was the presence of evil.

\footnotetext{
${ }^{103}$ Greer and Jewkes (2005) suggest, for example, that part of the reason we 'panic' about the risk of paedophilia may be as we simutaneously tolerate, even enjoy, the overt sexualization of children in commercial endeavours.
} 
This is an important variable in the development of a moral panic. The notion of 'evil in one's midst' works to collapse the complexity of events to terms of a basic confrontation between 'them' and 'us', and necessitates that 'they' be expelled for the protection of the social order (de Young, 2004; Eldridge, Kitzinger, \& Williams, 1997; Muncie, 1999). However, there is usually a laboured process of demonisation as part of that sequence. As Ingebretsen (2001: 52) argues, folk devils are typically "victims of metonymy and metaphor, prey to sloppy habits of public thinking, linguistic failure and a narrative rush to closure". The 'dog whistling' act on behalf of the media as it identified 'New Zealand's youngest killer' as a South Auckland child can be seen as an example of such inventory. However, this was almost unnecessary, as via the imagery there was immediacy to the interpretation of malevolence. Moreover, it was completed by the regime of representation in which the brown 'other' is understood.

Literature concerned with the development of the 'practices of exhibition' of things Maori (McCarthy, 2007) and of things Pasifika (Suaalii, 2000) speak of the 'colonial gaze'. This 'gaze' refers to a historical practice whereby adult Maori and Pasifika peoples were exoticised and fragmented into the specific gender caricatures of the warlike 'savage' and the sexually appealing and accessible ‘dusky maiden’ (see Mikaere, 1994; Paraha, 1993; Suaalii, 2000; Walker, 1990). Importantly, such caricatures were not limited to things 'seen'; indeed, their symbolism permeated both fictional and scientific colonial discourses where they worked to justify colonialism by emphasizing the binary of civilised and barbaric (see Moorehead, 1987; Spoonley, 1988; Walker, 1990).

Many commentators argue that this distortive gaze remains operative, permeating through contemporary representations and narratives of the brown 'other'. ${ }^{104}$ It is also argued that brown children are not immune to its prescriptions. Hokowhitu (2004), for example, locates the notion that Maori and Pasifika men are naturally physical and athletic as a definitive 'recasting' of the savage. He then suggests

\footnotetext{
${ }^{104}$ The racialised notion that brown 'others' are more criminogenic than their white-faced brothers is arguably supported with, if not wholly composed by, the idea of the 'savage'.
} 
that the over-representation of Maori and Pasifika boys in high school sports academies, which in turn are said to 'suit' their 'natural practicalities', is evidence the understanding of the brown 'other' as inherently physical is not restricted to commentary about adult rugby stars (see also Te'evale, 2001). Others lament about the self-perpetuating cycle this understanding sets in motion; noting in particular the 'hero' status accorded to these rugby stars in the absence of alternate male role models for young brown boys. Misa (2005), for instance, argues:

It bothers me that our kids' horizons seem limited to either to gangsta rappers or football players ... Not everyone can become Tana Umaga and it doesn't get us far enough away from the image of the staunch, take-no-prisoners brown male ... The problem for Maori and Pacific Island boys is that they're not encouraged to define themselves in any other way ... it's not that [alternate role models] aren't out there, it's that our boys don't seem to know they're there. And neither, it would seem, does the rest of society.

Conflating this notion that Maori and Pasifika children are more "physically inclined' is an indicator that they are perpetual academic underachievers. Phillips and Mitchell (2010) argue that historically, these groups have not 'fared well' under Aotearoa/New Zealand's mainstream school system, and are more likely to leave school earlier with fewer qualifications, than do Pakeha children. Despite extensive research that demonstrates that brown children do achieve when schooled in culturally appropriate environments, this notion effectively reduces teacher expectations of them, which, in turn, creates another cycle of selfperpetuation (Phillips \& Mitchell, 2010; Rubie-Davies, Hattie, \& Hamilton, 2006). Further, education scholar Linda Smith (1996) suggests that brown children are expected to behave differently to Pakeha children; they are the more wild and uncontrollable students. She attributes this to a range of complex factors, from historical assumptions about the native (and therefore untamed) subject, to the more tangible effects of poverty and disempowerment upon Maori (in particular) communities. 
From another vein, the brown child is often cast as the tragic victim, at the hands of the savage. Jackson (see Judd, 2007), for example, claims that the media disproportionately places focus on instances of Maori and Pasifika child abuse and neglect, assigning negligible attention to cases where the victims and perpetrators are Pakeha (see also Hokowhitu, 2007). Indeed, in the wake of the death of the Kahui twins in 2006, columnists were quick to cite the cases of Decilia Witika, James Whakaruru, Hinewaoriki Karaitiana-Matiaha (Lillybing), and Tangaroa Matiu as they claimed a horrific trend of child killings in Aotearoa/New Zealand, knowing it is these faces that the public have been witness to and will remember, and not those of Timothy Nelson, Natalie Wilson, or the Nelson twins of 2004 (Coddington, 2006; Laws, 2006; Woodham, 2006). ${ }^{105}$ 106107

These arguments would suggest that despite Bailey's appearance as the quintessential 'angelic' child, he was never going to be understood in quite the same way that he would had he been a different child; say, a white-faced child. While brown children are subject, like all children, to the spectacle we create as part of our practices of constructing childhood, they are also vulnerable to a racialised regime of representation that draws upon and maintains the operation of the colonial gaze in Aotearoa/New Zealand. This regime intimates that there is an 'other' childhood where children are understood as inherently physical, as underachievers, as wild and uncontrollable, and as tragic victims of their violent carers. Each time a brown child is represented in terms of these understandings a spectacle of the 'other child' emerges, one that reinforces for the observer that these children do not quite fit the mould of the imagined idealised child.

\footnotetext{
${ }^{105}$ The first group of children I mention here are of Maori or Pasifika descent; the second group are Pakeha children. I explain the case of Kahui twins in the section on penal populism earlier in this chapter.

${ }^{106}$ One commentator, on the back of this apparent divergence, and referring specifically to Maori, went so far to suggest that it was time for the re-introduction of eugenics: “....many Maori parents do not possess the parenting skills to properly care and cater for their children. Letting these people have kids is an invitation to tragedy" (Laws, 2006).

${ }^{107}$ From here it is not hard to imagine how the stereotype of the South Auckland gang member takes hold: he is the tragic victim almost all grown up - emulating and ultimately becoming the savage himself (see Wall, 1995, 1997).
} 
The point of the discussion here is that it is a 'knowing subject' that looks upon the body of the young brown male, presented in truth and offered as evidence. The imagery of Bailey was neither an expose of innocence corrupted, nor was it a vision of deception. Indeed, it was in spite of an angelic appearance; it was proof that brown children could be 'savage'. It can be argued, therefore, that these images were far more formidable in locating the problem to some children than the identification of 'New Zealand's youngest killer' as a child of South Auckland - which suggested that mini-monsters were likely to be brown-faced - could ever be.

\section{The Context of a Panic}

In this chapter I have focused upon exploring the social and cultural context of Aotearoa/New Zealand across the early to mid 2000s in an attempt to answer the first of the 'bigger questions' of this moral panic - why. My contention is that the presence of three intersecting social phenomena supported the materialisation of the real-type features facilitating the amplification cycle. These phenomena were the demonisation of children via race/space relations, a punitive turn characterised by a realignment of power, and a society of spectacle in which the other is exhibited through a racialised regime of representation. Embedded in such a context, it can be seen why the imagery of Bailey Kurariki was central to the episode of 'killer kids' as a whole. The capture of an image of a brown child appearing angelic as he sat in court for his part in a deplorable crime could only resonate where a regime of representation concerning brown children constructs anything but an angelic figure. The label then thrust upon this child would confirm the sharp end of an understanding of the other as the 'criminal other'. Ultimately, together, the understandings constructed unto the image and the label would be adopted as verification that this society was facing inundation with 'mini-monsters' propelled by an aggrieved mother and a lobby group that was gaining authority as the voice of 'ordinary folk' concerned with alleged deficiencies in the criminal justice system. 
I want to now consider how the real-type episode, across the three tiers of the approach inspired by Fairclough's (1995b) framework for Critical Discourse Analysis (CDA), can be captured by Cohen's (1972) opening paragraph, or whether there are significant departures signifying that the ideal-type concept of moral panic is challenged by this case. To aid memoire, Cohen's (1972) paragraph is as follows:

\begin{abstract}
A condition, episode, person or group of persons emerges to become defined as a threat to societal values and interests; its nature is presented in a stylized and stereotypical fashion by the mass media; the moral barricades are manned by editors, bishops, politicians and other right-thinking people; socially accredited experts pronounce their diagnoses and solutions; ways of coping are evolved or (more often) resorted to; the condition then disappears, submerges or deteriorates and becomes more visible (Cohen, 1972: 1).
\end{abstract}

Viewing the case of 'killer kids' in these terms it can be seen that the trajectory was largely archetypical of a moral panic. Bailey Kurariki and his counterparts were defined as a threat to moral decency, Aotearoa/New Zealand's 'godzone' reputation, and the immediate safety of ordinary law-abiding folk. The nature of the threat was orchestrated via the presentation of a set of images in which the quintessential child was amalgamated with the culturally constructed criminal other. Newspaper editors, broadcasters, prison officials, and child-welfare experts called for immediate preventative action, while a media-savvy lobby group with a model victim-hero at its helm would denigrate Aotearoa/New Zealand's 'worldleading' youth justice system while calling for justice for Michael Choy. A private members Bill was put forth to parliament to criminalize children from twelve years of age. The episode comes to a close on the heels of Bailey's release from jail and as the Bill to criminalise children is rejected. Thus, interestingly, it is not so much that the analysis of the real-type demonstrates that there was anything errant about it in ideal-type terms. What it suggests - perhaps confirms - is that the model is far more descriptive than it is formulaic.

This can be seen in that outside of these terms, and by employing the three-part analysis of content, process, and context, a more complex picture emerges than 
the ideal-type model allows for. First, this episode spanned three countable discourses and two conceptual phases. Second, the amplification cycle (the order of discourse in an internal sense) - that would lend itself to the development of the discourse of moral reprisal - was underpinned by a set of real-type features. Third, it was the relationship of those features with three intersecting social phenomena that afforded them their interpretative muscle. None of these nuances, however, offer any kind of formative challenge to Cohen's (1972) description of moral panic in his opening paragraph of Folk Devils.

This challenges my assumption that the ideal-type concept can be rethought in relation how real-type episodes materialise. At the same time it has some implications for how to conjecture what moral panics can be seen as extreme examples of; the first 'big' question in the project of rethinking moral panic. Recall that in Chapter Two (and in the opening paragraphs of this chapter) I argued that the intimacy between the ideal-type and real-types circumscribed that there was an intimacy between why panics happen (the contextual question of real-types) and what they might be seen as extreme examples of (the theoretical question of the ideal-type). In Chapter Seven, the concluding chapter for this dissertation, I explain how, despite the confirmation of Cohen's (1972) model as heuristic, the contextual location of killer kids - why it occurred - is indeed important to the theoretical location of moral panics, and why then the realtype/ideal-type approach, via a three tiered model of analysis, was significant nonetheless.

Preceding this, I want to bend the rules for a moment and move outside of the sample to consider how Bailey Kurariki and his imagery would remain newsworthy long after the episode came to a close. As argued, the episode of 'killer kids' concluded with the release of Bailey from jail in April 2008, which was closely followed by the rejection of the Young Offenders (Serious Crimes) Bill. Despite this, Bailey's movements were still making news through to the time of writing (May, 2010). Just after his release, for example, the front page of the Herald on Sunday sported an image of a 19-year-old Bailey standing in a backyard paddling pool talking on a mobile phone, with the headline "Youngest 
killer's lavish new life" (Meng-Yee, 2008). ${ }^{108}$ The attending text was similarly condescending about Bailey's changed conditions, and about whom it was that found these offensive:

\begin{abstract}
Kurariki might be on home detention, but he isn't missing out on much. Since being released a fortnight ago the 19-year-old baby-faced killer has had KFC, Burger King and pizza delivered most nights to the secret Auckland address where he's staying. At his birthday party on the day he was released, he was presented with gifts including a $\$ 180$ pair of shoes, a stereo and a playstation console. For Rita Croskery, the mother of Kurariki's victim, it's a difficult pill to swallow. 'What this boy needs is hard work and discipline, not to be handed things on a plate. How is that going to teach him anything?' (Meng-Yee, 2008).
\end{abstract}

Inherent in this article, particularly with the emphasis upon the 'rewards' Bailey appeared to be enjoying, is the discourse of criminal risk's discursive thread of just deserts. This is perhaps not altogether unexpected given the media 'story' had for nearly six years (the containment phase of the episode) focused upon the paradoxes of punishment and the uncertain practices and outcomes of rehabilitation. Nevertheless, Mrs. Croskery was not off the mark in her implicit prediction that Bailey could again land himself in trouble. Indeed he has. However, just as Cohen (1972) observed that the response to the initial deviance creates a second order of deviance (the central paradox of moral panics), largely, this trouble has been provoked by the media. In the closing months of 2009 for example, Bailey was again facing a jail term; convicted of wilfully damaging the television camera of a reporter that had been following him. In February 2010, the Herald on Sunday ran the headline "Child killer becomes sex pest". Precluding this latest incident was a visit by two female reporters to Bailey's home intending to interview him about his time in jail. Thereupon they filed a complaint with the police claiming that Bailey had acted in an erratic and distressing manner, had exposed himself to them and attempted to 'grope' them as they left. At the time of writing this alleged incident is still before the courts. Nevertheless, its unfolding was somberly assessed soon after by one commentator as yet another chapter in the relentless pursuit of Bailey by the media throughout the episode:

${ }^{108}$ The Herald on Sunday is the Sunday edition of The New Zealand Herald. 
If Bailey Junior Kuraiki becomes a hardened lifetime criminal, as now seems inevitable, then I'm afraid my fellow journalists will have to accept a large measure of responsibility ... Of the six who were convicted [for the murder of Michael Choy], Kurariki was singled out for continued media attention solely because of his age. I would have thought this very factor was a compelling reason to leave him alone, so he might have had some chance of rehabilitation away from the public eye. In fact the exact reverse happened ... I hope the two Herald on Sunday journalists feel pleased with themselves ... This is not the New Zealand media's proudest moment (Du Fresne, 2010).

Putting aside that this assessment supports my claim of a misaligned focus upon Bailey, my point here is that the media continue to pursue the story beyond the boundaries of the observable moral panic. Inversely this suggests that panic processes are not soley dependent upon media whims and cycles of attention. However, it also suggests that the social and cultural conditions that have provided the backdrop for panic to flourish and take hold remain operative; that the salience of the 'story' beyond the stages of description continues simply because the demonisation of children via race/space relations, a punitive turn characterised by a realignment of power, and a society of spectacle in which the other is exhibited through a racialised regime of representation have not dissipated. Indeed, the episode - as an instance of social practice, affecting - has arguably contributed to their durability. Why then, is there not a permanent state of panic? How do conditions of panic submerge and become (as Cohen peculiarly puts it) more visible? In the next chapter I put forth an idea that suggests that why the conditions - in this case - were susceptible to moral panic can also account for why panics are manifestly acute or volatile.

I want to end this chapter, and the empirical analysis of this case study, with a rare insight from Bailey himself in relation to the prolific press attention he remains subject to. Speaking to a noted campaigner against the populist punitive turn, Kim Workman, he argues: 
Have you ever been to the rubbish tip? You know how the seagulls hover around picking at the choice bits? Well, it feels like I'm the rubbish and the media are the seagulls (Kurariki cited in Workman, 2008). ${ }^{109}$

\footnotetext{
${ }^{109}$ Across all sources, this is the only evidence of Bailey speaking. It is, perhaps, a bittersweet paradox that his parole conditions upon release from prison in 2008 included 'no contact with the media' (Vass, 2008).
} 


\section{Chapter Seven}

\section{Killer Kids, Moral Panic, and the Economy of Excess}

This dissertation has been about moral panic. It has been about a case of moral panic and it has been about how the concept might regain authority as a sociological idea. Guiding the study have been two proposals. The first proposal was that the study of any real-type case of panic must be situated within its context; its socio-cultural-political environment. This is in order to understand why the episode in question occurred. The second proposal was that there needs to be more consideration of the relationship between real-type panics and their contexts with the concept of moral panic; the ideal-type. This is important as a more intricate understanding of why panics happen is crucial for imagining what moral panic may be an extreme example of, and thereupon how the concept might be employed for a more developed understanding of acute and volatile social reactions.

In the first section of this concluding chapter I summarize the development of these proposals in relation to the discussions in Chapter One (Moral Panic), Chapter Two (Rethinking Moral Panic) and Chapter Three (Methodology). In the second section I look at what has been uncovered about the episode of 'killer kids' that erupted in the early 2000s and extended across the socio-political landscape in Aotearoa/New Zealand until the latter part of the decade. I consider how the answer to why this episode materialised can inform how moral panic might be explained. In the third section I reflect upon my approach to moral panic via a framework inspired by Fairclough's (1995b) Critical Discourse Analysis as a methodology for 'rethinking moral panic'. Last, I offer a suggestion for how to keep in check volatile and extreme social reactions such as moral panics and how, relatedly, we might negate the problem of 'normativity' that has long plagued panic research. 


\section{Building Proposals}

In Chapter One I argued that all three of the foundational works on moral panic (Cohen, 1972; Goode \& Ben-Yehuda, 2004a, b; Hall et al., 1978) clearly demonstrated that there was an intimacy between the development of the concept and the real-life reactions it sought to describe. Nevertheless, a transferable sociological tool with which to trace similarities between real-type episodes remained valuable to more or less of a degree. This was reflected most in Cohen's (1972) formulation of a 'model' and in Goode and Ben-Yehuda's (2004a, b) categorisation of 'types' determined by motivation and interest (grassroots, interest-group, and elite). I concluded that the preservation of a transferable idealtype concept was desirable. Indeed, it is this transferability that has lent the concept its extraordinary longevity as a sociological tool.

This success, however, has also proved problematic for panic research. Indeed, the variable behaviours, conditions, persons, and groups of persons to what and to whom panic has been applied has - nearly forty years on - left its meaning somewhat diluted, generalised, and non-specific. Several substantial critiques have also weakened its authority. As discussed in Chapter One, it is argued that moral panic is a polemic idea rather than a neutral analytical concept. I argued that interpretations differ as to what part of the reaction is delineated by the analyst as 'irrational', and that my own reading was that it was the overall outcome of the amplicatory processes of panic that can be seen as 'out of order' and disproportional. It is also argued that the panic concept does not adequately capture the variety of reactions that can follow a moral assertion, and that a diversified media environment makes it more difficult to untangle the relationships between a commercial press, political strategies, and interest group campaigns. I saw that this would mean that the task of deconstruction was perhaps more imperative than for previous accounts, in previous eras. A further prerequisite that we are to be vigorous in our assessments was the appearance of 'risk' problems as the boundaries between issues assessed as 'risky' and concerns about the 'moral' order are often blurred. Panic assessments also vary in how they account for the role of the public. Some argue that media attention equates to 
public attention, while others contend that panic participants are invited through recruiting discourses. Yet because the public tend to be peripheral in policy making generally, a more convincing argument was that the public are an invoked party, present only in references made via other parties. Further, moral panics are often argued to be dependent upon some form of social 'anxiety'. I argued that this is especially problematic as 'anxiety' is notoriously difficult to determine and to quantify, and in relying on it as a explanatory variable panic research then tends to place too much attention on what panics $d o$ instead of thoroughly investigating their cause.

Despite my responses to these critiques I saw that a first step towards renewing the study of moral panic was a need to appraise the ideal-type in relation to realtype panics as they materialise in present-day contexts that are different to that in which the original idea was formulated. Part of my impetus for this exercise was to engage with the debates emerging in a developing project of 'rethinking moral panic'. In the Introduction I noted that this was the 'age of moral panic' (Thompson, 1998). In Chapter Two I identified that a group of contemporary scholars sought to revise the concept so that it could regain some authority as an analytical tool, to be used to assess the ever-increasing prevalance of extreme social reactions. Two questions could be seen to underpin this 'project'. The first was concerned in the main with the ideal-type concept and how it might make connections with or be informed by developments within social theory. It asked, 'what are moral panics extreme examples of?' The second question was directly concerned with the 'age of moral panic' and asked 'why do panics occur in particular spaces and times?' Both questions sought to situate moral panic, though in different ways. The first question aimed to connect the descriptive processes with theoretical ideas with a view to use the ideal-type as a general elucidation, whereas the second wanted a specific contextual explanation for each 'real-type'. My concern that there was a need to assess the relationship between the ideal-type concept and real-type episodes demanded that the relationship between theoretical ideas and contextual evidence also required investigation. Indeed, at this point my proposals were extended from a case-based assessment of how a real-type challenged the ideal-type to how the answer to why this or that case occurred (the 
contextual question) could inform what panics are extreme examples of (the theoretical question).

A review of the work of the scholars involved in the project of 'rethinking moral panic' revealed that both relationships were already under scrutiny by way of the two questions. However, I found that each thinker would place his/her emphasis upon different aspects of the questions and have a different idea of how the relationships were configured. Moreover, each would assume a different position in relation to some of the critiques that I identified in Chapter One; most notably the issue of normativity. Ungar $(1992,2001)$ for example, argued that the move to a 'risk society' meant that societies now faced 'real' existential problems. This contextual shift meant that real-type social reactions could not be appropriately assessed from the constructionist ideal-type model of moral panic. Ungar (1992, 2001) did not, therefore, offer a conjecture of how moral panic could be located theoretically. Critcher's (2003, 2006, 2008, 2009a, b) focus was upon how the ideal-type concept could be renewed for application across many real-type cases. However, by placing emphasis upon the constancies across real-types his assessment removed the need to assess the contexts in which cases emerged, and fortified the boundaries of the ideal-type, leaving it impenetrable to reflections from theory. On the other hand, Hier's (2002a, b, 2008) emphasis upon how shifts in the appearance of internal discourses in real-type panics would lead to an idea of moral panic as an extreme example of moral regulation. This conjecture, however, would negate the specificity of the ideal-type insofar as it would group reactions to relatively benign problems (such as those to overeating) alongside more explosive issues (such as paedophilia). This reflects Hier's (2002b, 2008) interpretation of panic responses as rational, considered action and his concomitant reluctancy to employ the analytical concept as a form of social critique. Rohloff $(2008,2010)$ also adopts this interpretation and this is what attracts her to the figurational sociology of Elias with its 'relative detachment principle'. This perspective then guides her notion of real-type reactions as shortterm decivilising episodes that result from long-term civilising processes. However, the preservation of the ideal-type concept of panic is not apparent in her work. 
Keen to demonstrate why my systematic view of the relationships could be informative for rethinking moral panic, I turned to a line of thought developing in the sociology of punishment. Garland $(1996,2001)$ conceptualised real-type responses to the problem of crime in late-modern life as two currents; the instrumental criminology of everyday life, and the emotional criminology of the other. Drawing from the work of Bataille, Hallsworth (2000) located the latter conception within the abstract spaces of the 'heterogeniac'. Loader (2009), on the other hand, argued that the punitive and emotional nature of the criminology of the other could be seen alongside other social/cultural/political phenomena which could be characterised by appetites for excess. In my view, the relationships developing in this line of thought between material matter (real-type phenomena) and contextual trends, and between conceptual notions and theoretical locations were more clear than those of the project of rethinking moral panic had thus far achieved. Moreover, this literature was less concerned with inflecting a judgment of sorts, as responses to crime tend to be routinely situated along a continuum which has at one end retributive principles and at the other end the ethics of due process and a concern for human rights. Because of the concern with crime (which 'killer kids' was centred around), it also offered a possible theoretical location in which I could situate my case of moral panic. This will become evident in a moment.

My methodology would cement these proposals. Concerned to study the case of 'killer kids' by the ways in which it was 'talked about' I turned to the literature on discourse analysis. I found in Fairclough's (1995b) framework for Critical Discourse Analysis a means by which I could capture the relationship between the real-type and the ideal-type at the same time as I could locate the real-type within its context. Fairclough's (1995b) position that how something is 'talked about' is both affected by and affects the organisational logic of the particular discursive field in which that something is usually constructed by and the social and cultural environment in which it appears. This confirmed my proposals that real-types could affect the ideal-type and that the study of the contexts in which they (realtypes) emerged was fundamental. It followed that the location of the real-type 
(and its relation to the ideal-type) would then enable me to conjecture what this moral panic was an extreme example of.

Reworking Fairclough's (1995b) framework for panic analysis, I argued that I would study my real-type case via the relationships between its content, its process, and its context. I would study the relationship of this real-type with Cohen's (1972) ideal-type model of moral panic at two intersections. The first intersection (which I determined as the internal assessment) would be at the level of process where I would examine the relationship of the real-type practices involved in constructing the episode of killer kids with the cycle of amplification. This cycle is fundamental to the construction of moral panics. The second intersection (identified as the external assessment) would be adjacent to my examination of the 'communicative event' across the three parts of content, process, and context. Here, I would look at if and how the episode as a whole could be captured by Cohen's (1972) opening paragraph as it is this paragraph that is most employed as the criteria by which panics are assessed. My findings are summarized in the next section.

\section{Describing, Interpreting, and Explaining the Case of 'Killer Kids'}

Using documentary data, in Chapter Four (a study of content) I identified three countable discourses that could be seen over two phases. The reactive phase (the acute period of social reaction) was dominated by the discourse of moral reprisal and the discourse of social rescue. Each of these discourses were made up from interconnecting discursive threads which could be seen to follow a particular order; from their accounts of the murder of Michael Choy, to the anticipation of an emerging 'problem', to their identification of a social crisis on a much wider scale. These discourses differed substantially, however, in their character. The discourse of moral reprisal was remarkably conservative in its identification of a course from one pathological child, to dysfunctional families, to a permissive society. The discourse of social rescue, by contrast, took a more liberal position insofar as the crime was seen as a 'prank' gone astray (with less of a focus on Bailey Kurariki as unique), that it happened because of a lack of community co- 
ordination, and that its remedy was in the provision of adequate welfare services. As the furore settled not long following the sentencing of the offenders for the murder of Michael Choy, the 'problem' changed course quite dramatically. At this time the discourse of criminal risk took centre stage. This third discourse questioned the notion of justice and the idea of rehabilitation while advocating community safety and offender accountability. Spanning the next six years, the discourse of criminal risk was overall less concerned with what was wrong and what to do about it, but how to contain the offenders now that the immediate issue - the murder of Michael Choy - had been dealt with. Thereupon I identified that the discourse of criminal risk commanded the field in a phase of containment.

Significant for the identification of a moral panic are the ways by which the discourses would interact and the consequences they would deliver. At the level of content the discourses in the reactive phase were seen to have developed in relation to each other, with the discourse of social rescue disputing and negating the definitions and remedies proposed by the discourse of moral reprisal. True to panic conditions, however, the more punitive discourse of moral reprisal would emerge as triumphant as the reactive phase came to a close. I argued that this could be seen with the degree of severity imposed in the custodial sentences handed down to the offenders and as the discourse of criminal risk emerged with calls for 'just deserts'. Indeed, the conservative and punitive tone of the discourse of moral reprisal would surface and inflect upon the pragmatism of the discourse of criminal risk throughout its course.

In Chapter Five (a study of process) I examined the practices of production and consumption through which the countable discourses described in Chapter Four could develop. I first interrogated the practices of crime news-making in Aotearoa/New Zealand by conducting semi-structured interviews with professional journalists. I discovered that there were seven 'news values' (in three broad sets) by which crime events would be chosen for news that were particular to this social-cultural-political environment. These were bad news/violence, chance/irrationality, extraordinariness, personalisation, dramatic tension, visualness, and emotion. Once chosen according to these values a crime story 
would be constructed. The respondents testified that a narrative would develop according to events relating to the crime as they would come to light and/or the crime response process as it moved through its stages. They would gain knowledge of these developments from sources such as the police and the judiciary, and by what part of the process of court proceedings the event was subject to. To meet the requirements of the hard-news format, and as a result of contemporary shift away from a journalistic ethic to contextualise complex events, the story would be constructed in its most simplified terms. However, bearing upon the development of crime stories from raw events would be an impetus to present a melodramatic narrative whereupon good would triumph over bad. Usually these stories worked with one-dimensional characters (heroes and villains) that were culturally apposite; that is, understood in terms of the 'usual suspects' and 'suitable victims'.

These findings would be compelling for understanding why the Choy case made news, and for why the unfolding narrative subsequently lent itself to the development of a moral panic. First, the events of the crime were violent, seemingly irrational, and extraordinary insofar as the perpetrators were uncommonly young. Intersecting with the potential story was a number of developments in relation to the crime itself. Due to the remarkable timing of the murder in relation to events unfolding on the world stage (the attacks on the World Trade Centre in New York) the events would be refigured from those relating specifically to the murder to those of the trial a year later. These events (those of the trial) would then be subject to a series of unusual legal decisions. First, name suppression was continued for the accused for the duration of the trial. Second, the media were prohibited to take photographs inside the courtroom. Last, the crown was permitted to employ character evidence against the youngest of the accused. As a result, now presenting itself as the event was the name, photograph, and character of the youngest accused; the as-yet-to-be-revealed Bailey Kurariki. Indeed, it was only after his imagery appeared in the Sunday Star Times on August 25, 2002 that the story took a formative shape. I argued that it was at this point that the news value of visualness was met, and via this (the visual) that the values of personalisation (one child out of a possible six), emotion 
(an idealistic child-like depiction), and dramatic tension (the iconologically irreconcilable union of the child as he appeared and the killer as he was known to be) would come into play.

The unveiling of Bailey Kurariki also marked the beginnings of the internal sense of a moral panic 'discursive logic' or 'order of discourse'; the cycle of amplification. Taking care to capture this real-type episode, I examined how this case would erupt and augment itself beyond what I assumed would be a reasonable measure of retribution against the offenders involved in the murder of Michael Choy, and for a perceived 'problem' to materialise that I had measured would turn out to have little to do with an objective reality. I found that the middle stage of the cycle described by Cohen (1972) - dramatisation - was already under way via the visibility of the event. This was then propelled further by the lexical cementation of the illogical association between Bailey's youth and his role in the crime with the media employment of the historically significant label 'New Zealand's youngest killer'. This, I argued, set in motion the spurious attribution by which the discourse of moral reprisal would demonise Bailey as a pathological child, at the same time as it would locate a perpetual danger about his character, constructing the platform from which a campaign for more punitive sentences could later commence. However, in a process of sensitisation, editorials and opinion pieces laboured to put forward the idea that something was indeed out of order, but that it could not yet be determined what exactly it was. Upon a prolific redisplay by the media of the imagery, this something came to be interpreted as the disturbance between semblance and substance; that is, between the appearance of a child and how it was known that this child had not acted accordingly. This would suggest a more far-reaching and uncontrollable threat; that the look of innocence could be deceptive. Touching upon a prophetic statement about an angelic looking child that would be on his way to prison made some sixteen months prior, the media, drawing on some 'expert opinion', prescribed that action must be taken urgently. This process of escalation would prompt a series of identities to come forward and propose a series of remedies. Often opposed to each other (marking the development of the two opposing discourses in the reactive stage) some of these identities (and remedies) would 
achieve success in their campaign via their ability to align themselves with expert opinion and draw into the fold the notion of common sense and an angry public. These identities, in other words, dispersed their version of the problem (to which their remedies addressed) in a process of diffusion. With the sentencing of the offenders the reactive phase came to a close, and the amplification cycle could be seen as almost complete. However, a process of exploitation would mark the beginning of the containment stage, and in doing so, reinvigorate the preceding stages of the cycle. ${ }^{110}$ Largely, this was due to the identities afforded media space at this point; the Sensible Sentencing Trust (SST) and Michael Choy's mother, Rita Croskery (who, incidentally, had recently taken a formative role in the SST). For Mrs. Croskery, particularly, the disturbance between semblance and substance was a principle feature of the offenders (notably Bailey) in the crime against her son, and it was this disturbance she argued the given length of sentence could not control, especially with its routine provision for parole. In turn, she and the SST would support Member of Parliament Ron Mark's development of the Young Offenders (serious crimes) Bill, which sought to subvert the risk of violent children by criminalizing them from the age of twelve.

Concluding this chapter, I argued that the practices at work in the episode of 'killer kids' were underpinned by a label, an interpretation upon the reception of Bailey's imagery, an invoked public, a doctrine of common sense, a lobby group and a victim and a proposal for the criminalization of children from the age of twelve. In other words, it was this compilation of features that facilitated and sustained the productive practices of the media and each stage of the amplification cycle (which, in turn, intersected with each other). These practices enabled the discourse of moral reprisal to be both victorious in the closure of the reactive phase and influential in the development of the discourse of criminal risk in the containment phase.

In order to demonstrate why these features would play an important role in the episode of 'killer kids', in Chapter Six (a study of context) I argued that they were

${ }^{110}$ Cohen (1972) identifies this as the 'feedback' feature of the amplification cycle. 
dependent upon three facets of social phenomena. The first of these phenomena was the demonisation of children via particular race/space relations. The second was a set of punitive penal practices characterised by a realignment of power. Third, I located a society of spectacle in which the exhibition of the 'other' pertains to a racialised regime of representation. Looking at each relationship in turn, it was my argument that the historically significant label 'New Zealand's youngest killer' was more than an immediate artefact of the murder of Michael Choy. It was an affirmation of a cultural correlation between criminality and the brown 'other'. By employing 'dog whistle' politics the variable of race would, however, be masked with references to a particular space - South Auckland. Indeed, South Auckland would operate as a 'code' of sorts insofar as it was understood that this space was inhabited by disaffected and idle brown youth; criminal youth, and by using this code in relation to the murder of Michael Choy, a discourse of 'mini-monsters' that had proliferated western societies from the early 1990s was identified to have a local manifestation. However, through the identification of Bailey as New Zealand's youngest killer, it was also proposed that the problems of South Auckland were potentially non-specific and contagious.

I then discussed how the notion of a proposed infestation of mini-monsters provided just the case in point for the idea that the criminal justice system was inherently flawed. Evidence of this notion was the punitive manner in which the moral boundaries were 'manned', particularly by editors who, in turn, would draw upon a perceived public anger to substantiate their diagnoses. Later, with the development of the discourse of criminal risk in shift to the containment phase, and the proposal for a new law, this phenomenon of 'penal populism' - the trend towards a stronger resonance between governments and extra-establishment individuals and groups speaking on behalf of 'the people' in penal affairs - would accord an almost exclusive authority to both the SST and to Rita Croskery and their interpretation of 'the problem'. For Rita especially, this would be a very personalised sense of victimisation, which she would then lend to the SST in her role as their victims ambassador. 
Last, I explored how the imagery and its interpretation could be understood through the immediacy of vision, the truth of photography, and a fabled notion of appearances as deceptive when evil is at play. I argued that the news story was inexorably structured to follow a particular angle simply because words are secondary to what the eye has already witnessed, and what had been witnessed was the juxtaposition between the child and the criminal inherent in the news imagery of Bailey. As argued, this imagery was already highly constructed; dependent on the timing of the event/s and a series of legal decisions made during the trial. However, as a photograph it denied this construction, presenting itself as objective, truthful. As an image of a criminal, it was more than truthful; it was evidential. Intersecting with this truth evidence nexus, however, was a primordial understanding that the 'face of an angel', which Bailey's imagery was actively received as, could be reminiscent of the anti-Christ's capacity to appear as an 'angel of light'. I argued that it was from this space that an understanding of 'evil in our midst' was cemented. Yet a further intersection would circumscribe that this evil was confinable. I argued that the face of Bailey Kurariki belonged within a regime of representation pertaining to a racialised conception of the 'other' child. Thus, the imagery was not deceptive, but operated as a confirmation of the other child as inherently bad.

At the intersection of process I considered how the practices in the construction of the real-type case could be seen in relation to a cycle of amplification model. At the conclusion of the study of the case via the three-part framework of content, process, and context, I then considered how the episode could be captured by Cohen's (1972) opening paragraph of Folk Devils. In both instances I argued there was little challenge to an ideal-type moral panic by the phenomenon of 'killer kids'. Indeed, though the stages of the cycle of amplification were 'out of order' insofar as the cycle began with the dramatisation of Bailey Kurariki's appearance and would end with the exploitation of the case by Rita Croskery and the SST, and by Ron Mark in his development of the Young Offenders (serious crimes) Bill, this impacted little if at all on the development of each stage nor on the augmentation of the 'problem' as a whole. Indeed, what it does is authenticate the circular nature of deviance amplification (see Cohen, 1972). On the other hand, 
because the episode would be aptly captured by Cohen's (1972) opening paragraph in spite of its real-type particularties, I inferred that the ideal-type is more abstract than perhaps is acknowledged, and definitively more descriptive than it is formulaic. This challenged my assumption that the ideal-type might be rethought in relation to how real-types unfold. My corresponding assumption that why a panic occurred could be informative for what moral panics are extreme examples of was, nevertheless, validated. In the next section I look at how the three social phenomena identified as the backcloth to the emergence of 'killer kids' can all be seen in terms of the appetites for excess that were discussed in Chapter Two.

\section{Moral Panic as an Extreme Example of the Expenditure of Excess Energy}

I suggest, tentatively, that the three phenomena that can explain why the case of killer kids emerged, can all be seen for their 'festive' features. Moreover, for each this festivity can be seen as the product of an appetite. The 'holy war' against dissident children, for example, labours to make spectacular its identification of the 'other child' as it evicts this child from the category of the quintessential child. At the heart of this eviction is a desire to maintain the innocence and naivity of the 'child' as it has been constructed in modern life. Yet, this 'war' has no time or the will to invest in the welfare of this 'other child', nor address the conditions and ideologies that sustain its segregation. Similarly, as seen, the punitiveness of late-modern penal order thrives upon the magical and commonsensical notions of populist organisations and power-savvy politicians. It has little patience for research based, long-term solutions to the problem of crime. Last, the society of spectacle is marked by a demand for immediacy. Where crime is concerned, this spectacle is obliged to give evidence, and this evidence is accepted as truth regardless of how 'staged' the visuality of a criminal event might be. Indeed, what marks these appetites is the very same shortsighted drive for instant selfgratification that Loader (2009) speaks of in relation to features of late-modern living. 
Intersecting with the festivity apparent in each of these phenomena is the appetite of the modern media. This is a feature emphasised by those concerned to demonstrate that developments in media practices have implications for moral panic construction (see McRobbie, 1994b; Watney, 1987). My own research revealed that guiding what is selected for crime news are the festivities inherent in violence, irrationality, drama and emotion. My respondents declared that media professionals will 'wring the emotion' and 'maximise the drama' in order to 'appeal to' a constituency they understand to have become numb to the problem of crime. They then argued that their craft draws upon and reinforces stereotypes along the primary stratifications of race, gender, class, age, and sexuality as a melodrama of good versus evil is inflected upon crime news stories. Further, it was seen that the modern media regularly employ and exploit the connotative qualities of images to shape their narratives. In the case of 'killer kids' the media drew upon the stereotype of the criminal brown youth and fortified it with the truth of a news image, and the evidence of a crime image. Indeed, so powerful was this nexus that it over-rode Bailey's immediate appearance as the quintessential child, and firmly placed him in the childhood of the 'other'.

If, as I have proposed, the why of 'killer kids' is intimate to an understanding of what the ideal-type concept might be an extreme example of, it would follow that the notion of appetites for excess might also be what each process of moral panic describes. In turn, it might be argued that moral panic can be explained as an processual expenditure of energy where, in any particular instance, appetites are charged and discharged. Indeed, each independent stage of Cohen's (1972) opening paragraph can be seen to describe the routine and regular discharge of excess energy (for instance, a deviant minor is portrayed in a stereotypical way by the media). It is energy that is discharged into nothing productive should this stage remain unconnected to any other appetite. A moral panic can be said to occur when appetites meet and are discharged at the same time (the deviant minor is portrayed in a stereotypical way at the same moment as 'right-thinking' people call for retributive justice). In this way, the energy discharged by each stage charges another and becomes productive as a cycle of amplification gets to work. However, ultimately the process is still an expenditure, or the discharge of surplus 
energy. This can be seen in - and would explain - its volatile, temporal nature, and the ways by which the measures that are put in place as solutions are often only symbolic. Indeed, it is my proposal that a moral panic can be understood as an extreme example of the expenditure of surplus energy.

\section{Content, Process, Context: An Approach to Moral Panic}

I stated in the Introduction that my contribution to the scholarship of moral panic would be my approach - a real-type/ideal-type assessment via the three-part framework of content, process, and context. This remains so, despite the above conjecture. For moral panic to regain some authority as a sociological concept, it is imperative that assessments demonstrate the complexity of individual cases at the same time as they identify the commonalities or constancies between panics as these shift or remain the same (see Critcher, 2003, 2006). Thus I contend there must be a first commitment to the relationship between the analytical concept and its real-life manifestations (the real-type/ideal-type equation). Second, because a real-type is always dependent upon its social/cultural/political environment, there needs to be a commitment to examining the relationship between real-type contexts and ideal-type speculations. This is especially so if we are to continue to 'rethink' moral panic as an 'extreme example' of something.

My approach through the three tiers of content, process, and context has offered one way by which to assess the real-type/ideal-type relationship and to understand why a said reaction occurred. Through identifying how the content of 'killer kids' was constructed via a set of practices and processes, and by then locating the substance of these practices and processes within wider social 'goings-on', my understanding of what this episode uncovered established a firm foundation for explaining moral panic. Of course, whether a moral panic is indeed an extreme example of the expenditure of excess energy can only be suggestive at this stage, with the assessment of only one case. I look forward to what further studies will offer; if the concept will be understood in relation to real-type manifestations, whether the study of context will be important, how these contexts are employed toward locating moral panic theoretically, and what those locations entail. 


\section{Some Closing Thoughts}

To close I want to consider how my approach and the conjecture it has facilitated can address two related things; how to subvert reactions that we deem disproportional, and how to negate the charge of normativity that has become something of an Archilles heel for moral panic research.

Loader (2009) poses the question of how to get off the infinite treadmill of insecurity that politicians in many western societies appear to have jumped upon. As I was nearing the end of my writing for this thesis I attended a symposium on punishment at Victoria University of Wellington, where I am a student. The discussion turned, after much despair had gone back and forth about the direction in which punishment in Aotearoa/New Zealand was heading, to the question of how to abort the punitive turn; to diffuse the emotion and disconnect the varied practices that have come together in its development. Answers were not forthcoming. Perhaps I have one here. By understanding extreme social reactions (like moral panics) as processual discharges of excess energy, we could diffuse the fever and disconnect the practices that propel them by anticipating that surplus energy will be present, accepting that it needs to be discharged, and by directing or channelling that energy in ways that differ to how it materialises presently. Hallsworth (2000) warns of a return to a premodern spectacle of justice, however. $\mathrm{He}$ argues that the modern principles of rationality (inherent in the restricted economy of limits) have (perhaps inadvertently) facilitated the humanistic goals of the enlightenment and that these should be retained. One can not but agree, but the question is, thereupon, how to avoid such a return. Bataille (1988) argues that only when loss has been experienced can the true value of something be known. This loss - or the profitless expenditure of excess energy - ensures an equilibrium is coded into the exchanges of social relations. Bataille (1988) determines that any such expenditure will be either glorious or catastrophic in nature. But perhaps it need not be so dramatic, and involve only some form of non-constructive or inconvenient activity on behalf of the practitioner. Perhaps, for example, the state could direct its energies not into the making of retributive laws, but into the 
unprofitable (unprofitable in terms that the state's sovereignty is not strengthened) redress (say, financially) to victims of crime. Perhaps the media could also pay a financial dividend to those whom it stalks outside courtrooms and from behind private fences, given that it sells papers with stories forged from such actions. This would arguably change some decision making about what is newsworthy and what is not. Perhaps, alternatively, children could be allowed to make mistakes, to be forgiven for their premature impulses and not categorised into a binary of ideals and infractions. I suggest that it is ironic that the ultimate moral expression: the act of punishment, is tempered - eventually - by cost. It is also wholly ironic that underpinning Aotearoa/New Zealand's 'world-leading' approach to youth justice - in particular the FGC (family group conference) that was under attack in the episode of 'killer kids' - are equalizing principles (see Becroft, 2003).

Relatedly, the notion that panics are where surplus energy is expended may diffuse the problem of normativity. The first step, of course, is to contextualise the reaction; the panic. In this way an understanding of why it erupted is gained. If the episode can then be understood as dependent upon phenomena which in turn can be seen as appetites, its appropriateness as a discharge of the energy those appetites have mustered may be appraised. This is because the appraisal relies upon locating the panic research within the 'restricted economy of limits' (where thought is accepted as 'rational') and the panic in question as a manifestation of the alternate but equally valid 'economy of excess' (where all hell breaks loose). It proposes that if the principles of the Enlightenment are to be retained, it is the direction of that energy that is astray rather than its presence per se. Indeed, by thinking, as students and scholars of these extreme social reactions, not in terms of irrational 'panic' but in terms of 'energy in this or that direction', or 'energy in the service of', the way by which our 'judgment' is received may shift. Perhaps, with that, our concept will once again prove quite delicious. 


\section{Appendix}

\section{Interview Questions}

1. Could you describe for me a perfect crime story (either one you have covered, or one you can imagine). What about it makes it ideal?

2. Where do you source your information for crime stories? Why?

3. What narrative structures would you follow in developing a crime story for news? Are these structures particular to crime stories?

4. Who are you most likely to call upon to give your story 'balance', or to emphasize a particular angle? Why?

5. If you are reporting on a story that is already 'in the news', how important is it for you, professionally, to follow the existing angle?

6. Who do you imagine your audience is? How does this impact upon the way you write the story?

7. What level of responsibility do you accord the media for how a crime or social issue is understood by the public?

8. What are your thoughts on the statement "in recent years there has been an increasing emphasis on entertainment in New Zealand [television] news, with a higher priority being given to conflict, drama, and emotion"? (Abel, 1997: 10).

9. In relation to question 8 , what impact might this have on how you construct a story?

10. It has been argued by one media commentator that "there is little evidence of biculturalism in news agendas, but rather a focus - consistent over time - on Maori as problems, criminal, radical, dangerous" (Matheson, 2007: 93). As a professional in the field, what are your thoughts on this observation? 


\section{References}

Abel, S. (1997). Shaping the news: Waitangi Day on television. Auckland, New Zealand: Auckland University Press.

Aggravating and mitigating factors [Discussion paper]. (2009). Ministry of Justice. Retrieved from http://www.justice.govt.nz/publications/globalpublications/s/sentencing-policy-and-guidance-a-discussion-paper/5.-aggravatingand-mitigating-factors?searchterm=mitigating September 7, 2009.

Aldridge, M. (2003). The ties that divide: regional press campaigns, community and populism. Media, Culture, and Society, 25, 491-509.

Alexander, J. C. \& Jacobs, R. N. (1998). Mass communication, ritual and civil society. In T. Liebes and J. Curran (Eds.), Media, ritual, and identity (pp. 23-41). London, England: Routledge.

Alleged murder decoy 'street wise' beyond years, court told. (2002, August 21). The New Zealand Herald. Retrieved from http://www.nzherald.co.nz

Allison, C. \& Markby, R. (2002, August 27). Clear warning in truancy link. The Timaru Herald, p. 1.

Altheide, D. (1996). Qualitative media analysis. Newbury Park, CA: Sage.

Altheide, D. (2002). Creating fear: News and the construction of crisis. New York, NY: Aldine de Gruyter.

Altheide, D. (2009). Moral panic: From sociological concept to public discourse. Crime, Media, Culture, 5 (1), 79-99.

Althusser, L. (1971). Ideology and the ideological state apparatuses. In B. Brewster (Trans.) Lenin and Philosophy and Other Essays (pp. 127-186). London, England: New Left Books.

Anae, M. (2004). From kava to coffee: The 'browning' of Auckland. In I. Carter, D. Craig, and S. Matthewman (Eds.), Almighty Auckland? (pp. 89-110). Palmerston North, New Zealand: Dunmore Press.

Anderson, B. (1983). Imagined communities: Reflections on the origin and spread of nationalism. London, England: Verso.

Andrew, K. (2002, September 4). It's too tough - killer. The Press, p. A1.

Andrew, K. \& Warren, A. (2002, August 29). Crime action slated. The Press, p. A7. 
Aronson, C. (2002, August 24). Two found guilty of murdering pizza worker. The New Zealand Herald. Retrieved from http://www.nzherald.co.nz

Bailey Kurariki's mum: 'I'd shoot him' [current affairs item]. (2010, March 25). Campbell Live. Retrieved from http://www3news.co.nz

Bal, M. (2003). Visual essentialism and visual culture. Journal of Visual Culture, 2, 5-32.

Barthes, R. (1977). Image, music, text. New York: NY, Hill and Wang.

Bataille, G. (1988). The accursed share, vol. 1 (R. Hurley Trans.). New York, NY: Zone Books.

Batchelor, K. (2003, March 1). Girls without conscience. Taranaki Daily News, p. 19.

Bauman, Z. (1991). Modernity and ambivalence. Cambridge, England: Polity Press.

Beals, F. (2006). Reading between the lines: Representations and constructions of youth and crime in Aotearoa/New Zealand (unpublished doctoral dissertation). Victoria University of Wellington, Wellington, New Zealand.

Beck, U. (1992). Risk society: Towards a new modernity. London, England: Sage.

Beck, U. (1998). World risk society. Cambridge, England: Polity Press. Check pages in thesis used.

Becker, H. (1963). Outsiders: Studies in the sociology of deviance, New York, NY: The Free Press.

Becker, H. (1967). Whose side are we on? Social Problems, 14, 239-247.

Becroft, A. (2003, December). Youth Justice - The New Zealand Experience: past lessons and future challenges, Paper presented at the Australian Institute of Criminology/NSW Department of Juvenile Justice, Juvenile Justice Conference. Retrieved from http://www.judgesandmagistrates.org/bec.htm

Benefits disappear in uproar over rugby icons' visit. (2002, November 13). Taranaki Daily News, p. 8.

Benjamin, W. (1980). A short history of photography. In A. Trachtenberg (Ed.), Classic Essays on Photography (pp.199-216). New Haven, CT: Leete's Island Books. 
Best, J. (1989). Images and issues: Typifying contemporary social problems. New York, NY: Aldine de Gruyter.

Best, J. (1990). Threatened children: Rhetoric and concern about child-victims. Chicago, IL: University of Chicago Press.

Best, J. (1993). But seriously folks: The limitations of the strict constructionist interpretation of social problems. In G. Miller and J. A. Holstein (Eds.), Constructionist controversies: Issues in social problems theory (pp. 109-130). New York, NY: Aldine de Gruyter.

Best, J. (2008). Social problems. New York, NY: Norton.

Best, J. (2011, forthcoming). Locating moral panics within the sociology of social problems. In S. P. Hier (Ed.), Tightening the focus: The past, present and future of moral panic studies (pp. not yet known). London, England: Routledge.

Beston, A. (2002, June 17). Act invites voters to punish soft Labour. The New Zealand Herald. Retrieved from http://www.nzherald.co.nz

Biber, K. (2007). Captive images: Race, crime, photography, Oxon, England: Routledge-Cavendish.

Bill urges jail for 12-year-olds. (2006, March 17). The Dominion Post, p. 3.

Bingham, E. (2002, August 31). Boy killer a special case. The New Zealand Herald. Retrieved from http://www.nzherald.co.nz

Binning, E. (2008, April 26). Mum's marathon mission stretches on. The New Zealand Herald. Retrieved from http://www.nzherald.co.nz

Bloyce, D. (2004). Research is a messy process: A case study of a figurational sociology approach to conventional issues in social science research. Graduate Journal of Social Science, 1 (1), 144-166.

Boland, M. (2007, July 22). Child in time. Sunday Star Times, p. A2.

Booker, J. (2003, October 8). Parole board denies bid by Kurariki for home detention. The Press, p. A3.

Borell, B. (2005). Living in the city ain't so bad: Cultural diversity of South Auckland rangatahi (Unpublished masters dissertation). Massey University, Auckland, New Zealand.

Bottoms, A. E. (1995). The philosophy and politics of punishment and sentencing. In C. Clarkson and R. Morgan (Eds.) The politics of sentencing reform (pp. 1749). Oxford, England: Clarendon. 
Boy, 12, one of 8 arrested after killing. (2001, September 17). The Dominion Post, p. 3.

Boy did not plan Choy killing court told. (2003, June 12). The Dominion Post, p. A5.

Boyd. S. (2005, March 26). Nicked in the bud. The Dominion Post, p. WM2.

Broadmore, U. \& Broadmore, C. (2002, November 19). Role models needed before crimes occur [Letter]. Taranaki Daily News, p. 6.

Brookfield, F. M. (2006). Waitangi and indigenous rights: Revolution, law and legitimation. Auckland, New Zealand: Auckland University Press.

Burns, R. \& Crawford, C. (1999). School shootings, the media, and public fear: Ingredients for a moral panic. Crime, Law, and Social Change, 32, 147-168.

Burr, V. (2003). Social constructionism. London, England: Routledge.

Butcher, A. \& Spoonley, P. (2009). Reporting superdiversity: The mass media and immigration in New Zealand. Journal of Intercultural Studies, 30 (4), 355372.

Callinan, R. (2007, July 5). Tribal trouble. Time. Retrieved from http://www.time.com

Carney, P. (2010). Crime, punishment and the force of photographic spectacle. In K. J. Hayward \& M. Presdee (Eds.) Framing crime: Cultural criminology and the image (pp. 17-35). Oxon, England: Routledge.

CCCS Mugging Group (1976). Some notes on the relationship between the societal control culture and the news media. In S. Hall and T. Jefferson (Eds.), Resistance through rituals: Youth subcultures in post-war Britain (pp 75-79). London, England: Hutchison.

Child killer smart, confident: judge. (2002, September 17). Waikato Times, p. 2.

Children who kill: Don't be surprised. (2002, August 27). The Dominion Post, p. B4.

Children who turn to killing. (2002, September 19). Waikato Times, p. 6.

Chouliaraki, L. \& Fairclough, N. (1999). Discourse in late modernity: Rethinking critical discourse analysis. Edinburgh, Scotland: Edinburgh University Press.

Choy [news item]. (2002, September 16). One News, Auckland, New Zealand: Television New Zealand. 
Choy sentencing [news item]. (2002, September 13). One News, Auckland, New Zealand: Television New Zealand.

Claridge, A. (2003, July 5). Truants go bad, police say. The Press, p. A2.

Claridge, A. (2005, November 1). The truth on youth crime. The Press. Retrieved from http://www.stuff.co.nz

Clarke, A. (2002, September 3). Who will take the rap for BJ? The Nelson Mail [Edition 2), p. 7.

Coddington, D. (2006, February 12). Time for a clear Maori message. New Zealand Herald. Retrieved from: http://www.nzherald.co.nz

Cohen, A. (1974). The elasticity of evil: Changes in the social definition of deviance, Oxford, England: Basil Blackwell.

Cohen, S. (1972). Folk devils and moral panics. Herts, England: Paladin.

Cohen, S. (2002). Folk devils and moral panics ( $3^{\text {rd }}$ Edition), London, England: Routledge.

Collins, A. (2002, September 1). Loss of innocence. Sunday News, p. 7.

Collins, J. (2005, November 8). Ethnic minorities and crime in Australia: Moral panic or meaningful policy responses. Paper presented to a public seminar organized by the Office of Multicultural Interest, Western Australia: Perth, Australia.

Conway, A. (2010, January 26). Responding to the deconstruction of the family and the technical options. Paper presented at the National Colloquium for Catholic Bioethicists, Australian Catholic University, Melbourne: Australia.

Cook, S. (2007, January 1). Don't let him out, begs murder victim's mother. The New Zealand Herald. Retrieved from http://www.nzherald.co.nz

Crean, M. (2003, October 6). Home detention possible for killer. The Press, p. A2.

Crimes Act (No. 43) 1961, 126-130.

Critcher, C. (2002). Media, government and moral panic: The politics of paedophilia in Britain 2000-1. Journalism Studies, 3 (4), 521-535.

Critcher, C. (2003). Moral panics and the media. Buckingham, England: Open University Press. 
Critcher, C. (Ed.) (2006). Critical readings: Moral panics and the media. Berkshire, England: Open University Press.

Critcher, C. (2008). Moral panic analysis: Past, present and future. Sociology Compass, 2 (4), 1127-1144.

Critcher, C. (2009a). Widening the focus: Moral panics as moral regulation. British Journal of Criminology, 49, 17-34.

Critcher, C. (2009b, November). Onto the highway or up a cul-de-sac? The future destination of moral panic analysis. Paper presented at the Special Research Seminar on Moral Panics, Department of Sociology \& Communications, School of Social Sciences, Brunel University, London, England.

Cumming, G. (2008a, March 15). Beyond the prison gate. The New Zealand Herald. Retrieved from http://www.nzherald.co.nz

Cumming, G. (2008b, March 15). Kurariki finds God and culture. The New Zealand Herald. Retrieved from http://www.nzherald.co.nz

CYF blamed for lack of action. (2002, August 26). The Press, p. A3.

Davies, S. (1997). A sight to behold: Media and the visualization of youth, evil and innocence. In J. Bessant \& R. Hil (Eds.), Youth, crime and the media (pp. 5563). Hobart, Australia: National Clearinghouse for Youth Studies.

Davis, J. (2007, January 22). Parole hearing for young killer. The Press, p. A1.

Davis, H. \& Bourhill, M. (1997). 'Crisis': The demonization of children and young people. In P. Scraton (Ed.), 'Childhood' in 'Crisis' (pp. 28-57). London, England, Routledge.

De Coster, S. \& Heimer, K. (2006). Crime at the intersections: Race, class, gender, and violent offending. In R. D. Peterson, L. J. Krivo, \& J. Hagan (Eds.), The many colors of crime: Inequalities of race, ethnicity, and crime in America (pp. 138-156). New York, NY: New York University Press.

de Young, M. (2004). The day care ritual abuse moral panic. Jefferson, NC: McFarland \& Company.

de Young, M. (2008). The day care ritual abuse moral panic: A sociological analysis. Sociology Compass, 2 (6), 1719-1733.

Debord, G. (1967). Society of the spectacle. Detroit, MI: Black and Red.

Dekker, D. (2002, September 7). Are we failing our children? The Southland Times, p. 31. 
Dilemma over what to do with BJ. (2002, November 12). The Nelson Mail, p. 7.

Doing the time. (2003, September 13). The Press, p. A8.

Don’t blame social workers. (2002, September 9). Waikato Times, p. 6.

Doubtful the Choy quest for justice served by appeals. (2002, September 18). Taranaki Daily News, p. 8.

Douglas, M. (1992), Risk and blame: Essays in cultural theory, London: Routledge.

Dreyfus, H. L. \& Rabinow, P. (1982). Michel Foucault: Beyond structuralism and hermeneutics. Brighton, England: Harvester.

Du Fresne, K. (2010). If we'd left Kurariki alone, would he have turned out any better? The Dominion Post. Retrieved from http://www.stuff.co.nz

Dunning, E. (1992). Figurational sociology and the sociology of sport: Some concluding remarks. In E. Dunning \& C. Rojek (Eds.), Sport and leisure in the civilizing process: Critique and counter-critique (pp. 221-284). Basingstoke, England: MacMillan.

Durkheim, E. (1984). The division of labour in society (W.D. Halls Trans), London, England: MacMillan.

Dye, S. (2007, January 27). Why youngest killer isn't getting parole. The New Zealand Herald. Retrieved from http://www.nzherald.co.nz

Elias, N. (1978). What is sociology? New York, NY: Columbia University Press.

Elias, N. (2000). The civilizing process: Sociogenetic and psychogenetic investigations (revised edition). Oxford, England: Blackwell.

Eldridge, J., Kitzinger, K. \& Williams, K. (1997). The mass media and power in modern Britain. Oxford, England: Oxford University Press.

Epstein, E. J. (2000). News from nowhere: Television and the news ( $2^{\text {nd }}$ edition). New York, NY: Random House.

Ericson, R.V., Baranek, P.M., \& Chan, J.B.L. (1987). Visualizing deviance: A study of news organization. Toronto, Canada: University of Toronto Press.

Ericson, R.V., Baranek, P.M., \& Chan, J.B.L. (1989). Negotiating control: A study of news sources. Milton Keynes, England: Open University Press.

Ericson, R.V., Baranek, P.M., \& Chan, J.B.L. (1991), Representing order: Crime, law and justice in the news media, Toronto, Canada: University of Toronto Press. 
Erikson, K. T. (1966). Wayward puritans: A study in the sociology of deviance. New York, NY: MacMillan.

Evans, J. \& Hall, S. (1999). What is visual culture? In J. Evans \& S. Hall, (Eds), Visual culture: The reader. London, England: Sage.

Fairclough, N. (1989). Language and power. London, England: Longman.

Fairclough, N. (1992). Discourse and social change. Cambridge, England: Polity Press.

Fairclough, N. (1995a). Critical discourse analysis. Boston, MA: Addison Wesley.

Fairclough, N. (1995b). Media discourse, London, England: Edward Arnold.

Featherstone, M. (1991). Consumer culture and postmodernism. London, England: Sage.

Fergusson, D., Harwood, M. T., \& Lynskey, M. T. (1993). Ethnicity, social background, and young offending: A 14-year longitudinal study. Australian and New Zealand Journal of Criminology, 27, 155-170.

Ferrell, J. \& Websdale, N. (1999). Materials for making trouble. In J. Ferrell and N. Websdale (Eds.), Making trouble: Cultural constructions of crime, deviance, and control (pp. 3-21). New York, NY: Aldine de Gruyter.

Fletcher, J. (1997). Violence and civilization: An introduction to the work of Norbert Elias. Cambridge, England: Polity Press.

Fortuin pleads for tolerance after attacks. (2001, September 21). The Dominion Post, p. 7.

Foucault, M. (1972). Archaeology of knowledge. New York, NY: Pantheon.

Foucault, M. (1975). Discipline and punish: The birth of the prison (A. Sheridan Trans. 1977). New York, NY: Pantheon.

Foucault, M. (1980). Power/Knowledge. Brighton, England: Harvester.

Four-seat sweep sets up Maori Party to make a difference. (2005, September 18). Sunday Star Times. Retrieved from http://www.sundaystartimes.co.nz

Franklin, B. and Petley, J. (1996). Killing the age of innocence: newspaper reporting of the death of James Bulger. In J. Pilcher and S. Wagg (Eds.), Thatcher's children: Politics, childhood and society in the 1980s and 1990s (pp. 134-154). London, England: Falmer. 
Furedi, F. (1997). The culture of fear: Risk taking and the morality of low expectations. London, England: Cassell.

Gag order for teens attacked. (2002, July 10). The New Zealand Herald. Retrieved from http://www.nzherald.co.nz

Gamble, W. (2002, November 15). Justice campaigners in it for the longer term. The New Zealand Herald. Retrieved from http://www.nzherald.co.nz

Garfinkel, H. (1956). Conditions of successful degradation ceremonies. American Journal of Sociology, 61, 420-424.

Garland, D. (1990). Frameworks of inquiry in the sociology of punishment. British Journal of Sociology, 41, 1-14.

Garland, D. (1996). The limits of the sovereign state: Strategies of crime control in contemporary society. British Journal of Criminology, 36 (4), 445-471.

Garland, D. (1997). Governmentality and the problem of crime. Theoretical Criminology, 1 (2), 173-214.

Garland, D. (2001). The culture of control. Oxford, England: Oxford University Press.

Garland, D. (2003). The rise of risk. In R.V. Ericson and A. Doyle (Eds.), Risk and morality (pp. 48-86). Toronto, Canada: University of Toronto Press.

Garland, D. (2008). On the concept of moral panic. Crime, Media, Culture, 4, 930 .

Gay, E. (2007, July 14). Funeral vow helps mum stay strong. The New Zealand Herald. Retrieved from http://www.nzherald.co.nz

Gee, J. P. (1999). An introduction to discourse analysis: Theory and method. London, England: Routledge.

George, G. (2002, August 29). How we managed to turn some of our kids into killers. The New Zealand Herald. Retrieved from http://www.nzherald.co.nz

Giddens, A. (1990). The consequences of modernity. Cambridge, England: Polity.

Giddens, A. (1991). Modernity and self-Identity. Self and society in the late modern age. Cambridge, England: Polity.

Gill, R. (2000). Discourse Analysis. In G. Gaskell \& M. Bauer (Eds.), Qualitative researching with text, image and sound: A practical handbook for social research (pp. 172-190). Thousand Oaks, CA: Sage. 
Godzone failing its children. (2002, August 26). Waikato Times, p. 6.

Goode, E. \& Ben-Yehuda, N. (1994a). Moral panics: The social construction of deviance. Oxford, England: Blackwell.

Goode, E. \& Ben-Yehuda, N. (1994b). Moral panics: Culture, politics, and social construction. Annual Review of Sociology, 20: 149-171.

Goode, E. \& Ben-Yehuda, N. (forthcoming). Grounding and defending the sociology of moral panic. In S. P. Hier (Ed.), Tightening the focus: The past, present and future of moral panic studies (pp. not yet known). London, England: Routledge.

Gordon, L. (2002, September 4). Reclaiming our lost youth. The Press, p. A15.

Green, D. A. (2008a). When children kill children: Penal populism and political culture. Oxford, England: Oxford University Press.

Green, D. A. (2008b). Suitable vehicles: Framing blame and justice when children kill a child. Crime, Media, Culture, 4 (2), 197-220.

Greenberg, J. \& Hier, S. (2001). Crisis, mobilization and collective problematisation: 'Illegal' Chinese immigrants and the Canadian news media. Journalism Studies, 2 (4), 563-583.

Greer, C. (2004). Crime, media and community: Grief and virtual engagement in late modernity. In J. Ferrell, K. Hayward, W. Morrison \& M. Presdee (Eds.), Cultural criminology unleashed (pp. 109-118). London, England: Cavendish.

Greer, C. \& Jewkes, Y. (2005). Extremes of otherness: Media images of social exclusion. Social Justice, special edition on 'Emerging imaginaries of regulation, control and oppression', 32 (1), 20-31.

Greer, C., Ferrell, J. \& Jewkes, Y. (2007). It's the image that matters: Style, substance and critical scholarship. Crime, Media, Culture, 3 (1), 5-10.

Griffiths, R. (2005). Darkness, death and distortion: A sociological examination of moral panic theory and the gothic subculture (Unpublished doctoral dissertation). University of Auckland, Auckland, New Zealand.

Habermas, J. (1989). The structural transformation of the public sphere (T. Burger Trans.). Cambridge, England: Polity Press.

Hall, S. \& Jefferson, T. (Eds.). (1976). Resistance through rituals: Youth subcultures in post-war Britain. London, England: Hutchinson. 
Hall, S., Critcher, C., Jefferson, T., Clarke, J., \& Roberts, B. (1978). Policing the crisis: Mugging, the state, and law and order, London, England: MacMillan.

Hall, S. (1980). Encoding/decoding. In S. Hall (Ed.) Culture, media, language: Working papers in cultural studies, $1972-79$ (pp. 128-138). London, England: Hutchinson and Co.

Hall, S. (1981). The determinations of news photographs. In S. Cohen and J. Young (Eds.), The manufacture of news: Social problems, deviance, and the mass media. (Communication and Society, 4) (Revised Edition) (pp. 226-243). London, England: Constable.

Hall, S. (1997). The work of representation. In S. Hall (Ed.), Representation: Cultural representation and signifying practices (pp. 13-74). London, England: Sage.

Hallsworth, S. (2000). Rethinking the punitive turn: Economies of excess and the criminology of the other. Punishment and Society, 2 (2), 145-160.

Hannis, G. (2009). Reporting diversity in New Zealand: The 'Asian Angst' controversy. Pacific Journalism Review. 15 (1), 114-130.

Harawira, H. (2008). Young offenders (serious crimes) bill ( $2^{\text {nd }}$ reading). New Zealand Parliamentary Debates, 647, 16192.

Hay, C. (1995). Mobilisation through interpellation: James Bulger, juvenile crime, and the construction of a moral panic. Social and Legal Studies, 4, 197-223.

Hay, C. (1996). Narrating crisis: The discursive construction of the 'winter of discontent'. Sociology, 30 (2), 253-277.

Henzell, J. (2003, November 29). Teens too young to face rape charge. The Press, p. A1.

Hier, S. (2002a). Raves, risk, and the ecstacy panic: A case study in the subversive nature of moral regulation. Canadian Journal of Sociology, 27 (1), 3359.

Hier, S. (2002b). Conceptualizing moral panic through a moral economy of harm. Critical Sociology, 28 (3), 311-334.

Hier, S (2003). Risk and panic in late modernity: Implications of the converging sites of social anxiety. British Journal of Sociology, 54 (1), 2-20.

Hier, S. (2008). Thinking beyond moral panic: Risk, responsibility, and the politics of moralization. Theoretical Criminology, 12 (1), 73-190. 
Hill, M. (1998). Satan's excellent adventure in the antipodes. Issues in Child Abuse Accusations, 10, 112-121.

Hill, R. S. (2004). State authority, indigenous autonomy: Crown-Maori relations in New Zealand/Aotearoa 1900-1950, Wellington, New Zealand: Victoria University of Wellington Press.

Hockey, J. \& James, A. (1993). Growing up and growing old: Ageing and dependency in the life course. London, England: Sage.

Hodgetts, D., Masters, B., \& Robertson, N. (2004). Media coverage of 'decades of disparity' in ethnic mortality trends in Aotearoa. Journal of Community and Applied Social Psychology, 14, 1-18.

Hokowhitu, B. (2004). Tackling Maori masculinity: A colonial genealogy of savagery and sport. The Contemporary Pacific, 16 (2), pp. 259-284.

Hokowhitu, B. (2007). The silencing of Maori men: Deconstructing a 'space' for Maori masculinities. New Zealand Journal of Counselling, 27 (2), pp. 63-76.

Holland, P. (2004). Picturing childhood: The myth of the child in popular imagery.

London, England: I. B. Tauris \& Co.

Hood, L. (2001). A city possessed: The Christchurch civic crèche case. Dunedin, New Zealand: Longacre Press.

Hume, M. (2004, December). What makes a hero today? Spiked. Retrieved from http://www.spiked-online.com/index.php/site/printable/1812/

Hunt, A. (1997). Moral panic and moral language in the media. British Journal of Sociology, 48 (4), 629-648.

Hunt, A. (1999). Anxiety and social explanation: Some anxieties about anxiety. Journal of Social History, 32 (3), 509-528.

Hunt, A. (2003). Risk and moralization in everyday life. In R. Ericson and A. Doyle (Eds.), Morality and risk (pp. 165-192). Toronto, Canada: University of Toronto Press.

Hunt, A. (forthcoming). Fractious rivals? Moral panics and moral regulation. In S. P. Hier (Ed.), Tightening the focus: The past, present and future of moral panic studies (pp. not yet known). London, England: Routledge.

Hyde, L. (1983). The gift, imagination and the erotic life of property. New York, NY: Random House. 
If it's not broken no reason trying to fix it. (2007, July 23). Taranaki Daily News, p. 8.

Ingebretsen, E. J. (2001). At stake: Monsters and the rhetoric of fear in public culture. Chicago, IL: University of Chicago Press.

Innes, M. (2005). A short history of the idea of moral panic. Crime, Media, Culture, 1 (1), 106-111.

Interview with Paul Holmes and Nigel Latta [current affairs item]. (2002, August 27). Holmes. Auckland, New Zealand: Television New Zealand.

Jackson, M. (1988). He whaipaanga hou. Maori and the criminal justice system: A new perspective. Ministry of Justice, Wellington, New Zealand.

Jackson, M. (1995). Cultural justice: A colonial contradiction or a rangatiratanga reality? In Judge F. W. M. McElrea (Ed.), Rethinking criminal justice vol 1: Justice in the community (pp. 33-35). Auckland, New Zealand: Legal Research Foundation.

Jacobs, R. N. (1996). Producing the news, producing the crisis: Narrativity, television and news work. Media, Culture, Society, 18 (3), 373-397.

James, A. \& Jenks, C. (1996). Public perceptions of childhood criminality. British Journal of Sociology, 47 (2), 315-333.

James, A. \& James, A. L. (2004). Constructing childhood: Theory, policy and social practice. Houndmills, England: Palgrave Macmillan.

Jefferson, T. (2008). Policing the crisis revisited: The state, masculinity, fear of crime and racism. Crime, Media, Culture, 4 (1), 113-121.

Jenkins, P. (1992). Intimate enemies: Moral panics in contemporary Great Britain. New York, NY: Aldine DeGruyter.

Jenkins, P. (1998). Moral panic; Changing concepts of the child molester in modern America. New Haven, CT: Yale University Press.

Jenkins, P. (1999). Synthetic panics: The symbolic politics of designer drugs. New York, NY: New York University Press.

Jenkins, P. (2009). Failure to launch: Why do some issues fail to detonate moral panics? British Journal of Criminology, 49 (1), 35-47.

Jenks, C. (1996). Childhood. London, England: Routledge.

Jermyn, D. (2003). Photo stories and family albums: Imaging criminals and victims on Crimewatch $U K$. In P. Mason (Ed.) Criminal visions: Media 
representations of crime and justice (pp. 175-191). Devon, England: Willan Publishing.

Jewkes, Y. (2004). Media and crime. London, England: Sage.

Johnson-Cartee, K. S. (2005). News narratives and news framing: Constructing political reality. Lanham, MD: Rowman \& Littlefield.

Jones, P. \& Wardle, C. (2008). 'No emotion, no sympathy': The visual construction of Maxine Carr. Crime, Media, Culture, 4 (1), 53-71.

Jorgensen, M.W. \& Phillips, L. (2002). Discourse analysis as theory and method, London, England: Sage.

Judd, S. (2007, November 11). Notes from PGSA terrorism in New Zealand symposium: Moana Jackson. [Web log message]. Retrieved from http://vital.org.nz/entry/title/notes_from_pgsa terrorism_in_new zealand_sympos ium

Jury told of stolen pizzas on birthday. (2002, August 7). The New Zealand Herald. Retrieved from http://www.nzherald.co.nz

Jury reach verdict [news item]. (2002, August 24). One News. Auckland, New Zealand: Television New Zealand.

Karam, J. (1997). David and Goliath: The Bain family murders. Auckland, New Zealand: Reed.

Katz, J. (1995). What makes crime 'news'? In R. Ericson (Ed.), Crime and the media (pp. 47-75). Brookfield, VA: Dartmouth.

Kay, M. (2003, October 4). Questions over young killer's behaviour. The Dominion Post, p. A5.

Kitzinger, J. (1999). The ultimate neighbour from hell? Stranger danger and the media framing of paedophiles. In B. Franklin (Ed.) Social policy, the media, and misrepresentation (pp. 207-221). London, England: Routledge.

Kitzinger, J. (2004). Framing abuse: Media influence and public understanding of sexual violence against children. London, England: Pluto Press.

Klocke, B. V. \& Muschert, G. W. (2010). A hybrid model of moral panics: Synthesizing the theory and practice of moral panic research. Sociology Compass, 4 (5), 295-309.

Kosalka, D. (1999). Georges Bataille and the notion of the gift. Retrieved from http://www.lemmingland.com/bataille.html 
Kress, G. (1989). Linguistic processes in sociocultural practice (2nd edition). Oxford, England: Oxford University Press.

Kurariki out of prison. (2008, May 6). Otago Daily Times, p. 30.

Kurariki's release puts fear in victim's mum. (2008, July 1). The New Zealand Herald. Retrieved from http://www.nzherald.co.nz

Laclau, E, \& Mouffe, C. (1985). Hegemony and socialist strategy: Towards a radical democratic politics. London, England: Verso.

Lash, S. (1993). Reflexive modernisation: The aesthetic dimension. Theory, Culture \& Society, 10 (1), 1-25.

Laws, M. (2006, June, 25). The Kahui Shame. Sunday Star Times. Retrieved from http://www.mayormichael.co.nz/columns/060623-sst-kahui.html

Laws, M. (2007, July 27). Maori and Child Abuse. Sunday Star Times. Retrieved from http://www.mayormichael.co.nz/columns/070727-sst-abuse.html

Laws, M. (2008, September 12). Fight guns with guns. Sunday Star Times. Retrieved from http://www.stuff.co.nz

Lemert, E. (1951). Social pathology. New York, NY: McGraw-Hill.

Life pushing 5-year-old into violence. (2001, May 25). The New Zealand Herald. Retrieved from http://www.nzherald.co.nz

Lining up to kill? (2002, August 27). The Timaru Herald, p. 4.

Lister, M. \& Wells, L. (2001). Seeing beyond belief: Cultural studies as an approach to analyzing the visual. In T. Van Leeuwen \& C. Jewitt (Eds.) Handbook of visual analysis (pp. 61-91). London, England: Sage.

Loader, L. (2009). Ice cream and incarceration: On appetites for security and punishment. Punishment and Society, 11 (2), 241-257.

Lobby seeks truancy cash. (2002, September 4). Waikato Times, p. 5.

Locke, T. (2004). Critical discourse analysis. London, England: Cromwell Press.

Lupton, D. (ed.) (1999). Risk and sociocultural theory: New directions and perspectives. Cambridge, England: Cambridge University Press.

McBride, A. (2002, August 31). Task for society [Letter]. Waikato Times, p. 6.

McCarthy, C. (2007). Exhibiting Maori: A history of colonial cultures of display. Oxford, England: Berg. 
McCreanor, T. (1993). Mimiwhangata: Media reliance on Pakeha commonsense in interpretations of Maori actions. Sites, 26, 79-90.

McDonald, G. (2008, February 2). Teens on knife edge of society. The Dominion Post, p. A17.

McGregor, J. (1993). Crime news as prime news in New Zealand's metropolitan press. Legal Research Foundation Publication No. 36.

McGregor, J. (2002a). Crime news: The cutting edge. In J. McGregor and M. Comrie (Eds.), What's news? Reclaiming journalism in New Zealand (pp. 81-95). Palmerston North, New Zealand: Dunmore Press.

McGregor, J. (2002b) Terrorism, war, lions and sex symbols: Restating news values. In J. McGregor and M. Comrie (Eds.), What's news? Reclaiming journalism in New Zealand (pp. 111-125). Palmerston North, New Zealand: Dunmore Press.

McIntosh, T. (2004) Living Southside In I. Carter, D. Craig, \& S. Matthewman (Eds.), Almighty Auckland? (pp. 135-147). Palmerston North, New Zealand: Dunmore Press.

McLoughlin, D. (2001a, September 18). Boy on murder count shocks court. The Dominion Post, p. 3.

McLoughlin, D. (2001b, December 15). Pizza murder accused remanded in custody. The Dominion Post, p. 4.

McRobbie, A. (1994a). Folk devils fight back. New Left Review, 203, 107-116.

McRobbie, A. (1994b). Postmodernism and popular culture, London, England: Routledge.

McRobbie, A. \& Thornton, S. L. (1995). Rethinking 'moral panic' for multimediated social worlds. British Journal of Sociology, 46 (4), 559-574.

Maguire, J. (1988). Doing figurational sociology: Some preliminary observations on methodological issues and sensitizing concepts. Leisure Studies, 7, 187-193.

Manukia, J. (2002, September 1). Teen killer thinks he is a hero. Sunday News, p. 2.

Matheson, D. (2005). Media discourses: Analysing media texts. Berkshire, England: Open University Press. 
Matheson, D. (2007). The interpretative resources of Aotearoa New Zealand journalists reporting on Maori. New Zealand Journal of Media Studies, 10 (2), 91105.

Mathiesen, T. (1997). The viewer society: Michel Foucault's 'panoptican' revisited. Theoretical Criminology, 1 (2), 215-234.

Matthews, L. (2002), Home invasion: The role of the New Zealand media in a moral panic case study (Unpublished master's thesis). Auckland University of Technology, Auckland, New Zealand.

Meng-Yee, C. (2008, May 18). Youngest killer's lavish new life. Herald on Sunday. Retrieved from http://www.nzherald.co.nz

Mennell, S, (1990). Decivilising processes: Theoretical significance and some lines of research. International Sociology, 5 (2), 205-223.

Mikaere, A. (1994). Maori Women: Caught in the contradictions of a colonized reality. Waikato Law Review 2 (1), 125-149.

Miller, D. \& Kitzinger, J. (1998). AIDS, the policy process and moral panics. In D. Miller, J., Kitzinger, K., Williams, K. \& P. Beharrell (Eds.), The circuit of mass communication: Media strategies, representation, and audience reception in the AIDS crisis (pp. 213-241). London, England: Sage.

Mills, S. (1997). Discourse, London, England: Routledge.

Milne, C. (2002, September 27). Law is unfriendly [Letter]. The Dominion Post, p. B4.

Mirams, C. (2002, August 26). Children who kill: Stand by for more. The Dominion Post, p. A1).

Mirzeoff, N. (1999). An introduction to visual culture. London, England: Routledge.

Misa, T. (2002, October 29). Sense of shame is no bad thing in ethnic families. The New Zealand Herald. Retrieved from http://nzherald.co.nz

Misa, T. (2005, August 10). Failing brown boys in need of the right role models. The New Zealand Herald. Retrieved from http://www.nzherald.co.nz

Misa, T. (2008, April 28). Ex-prisoners need space to learn how to be free. The New Zealand Herald. Retrieved from http://www.nzherald.co.nz

Mitchell, W. (1994). Picture theory: Essays on verbal and visual representation. Chicago, IL: University of Chicago Press. 
Moon, P. (2002). The path to the Treaty of Waitangi: Te ara ki Te Tiriti. Auckland, New Zealand: David Ling Publishing.

Moore, D. \& Valverde, M. (2000). Maidens at risk: 'Date rape drugs' and the formation of hybrid risk knowledges. Economy and Society, 29 (4) 514-531.

Moorehead, A. (1987). The fatal impact: The invasion of the South Pacific 1767 1840. Sydney, Australia: Mead and Beckett

Morrison, B. (1997). As if. London, England: Gantra.

Muncie, J. (2004). Youth and crime (2 ${ }^{\text {nd }}$ edition). London, England: Sage.

Murder accused aimed for 'home run'. (2002, August 20). The New Zealand Herald. Retrieved from http://www.nzherald.co.nz

Murder accused could be 'kid next door'. (2002, August 23). The New Zealand Herald. Retrieved from http://www.nzherald.co.nz

Mythen, G. (2007). Reappraising the risk society thesis: Telescopic insight or myopic vision? Current Sociology, 55 (6), 793-813.

Nicholas, L. \& Kitchin, P. (2005). Louise Nicholas: My story. New Zealand: Random House.

NZ's youngest convicted killer released from jail. (2008, May 5). The New Zealand Herald. Retrieved from http://www.nzherald.co.nz

NZ's youngest killer denied parole. (2007, January 26). The New Zealand Herald. Retrieved from http://www.nzherald.co.nz

NZ's youngest killer fails in bid for early release. (2007, July 13). The New Zealand Herald. Retrieved from http://www.nzherald.co.nz

NZ's youngest killer up for parole. (2008, March 5). The New Zealand Herald. Retrieved from http://www.nzherald.co.nz

No words, no peace for mum as killers jailed. (2002, September 17). Manawatu Evening Standard, p. 2.

O’Conner, T. (2002, September 24). Retribution gets us nowhere. The Nelson Mail, p. 7.

O’Malley, P. \& Mugford, S. (1991). Moral Technology: The political agenda of random drug testing. Social Justice, 18 (4), 122-227.

Officials meet over gang violence [news item]. (2005, October 26). NZ News. Retrieved from http://tvnz.co.nz 
Orange, C. (1987). The Treaty of Waitangi. Wellington, New Zealand: Allen and Unwin.

Pahara, G. (1993). He Pounamu Kakano Rua: Construction of Maori women - a visual discourse (Unpublished masters thesis), The University of Auckland, Auckland, New Zealand.

Parole [current affairs item]. (2007, January 22). Breakfast. Auckland, New Zealand: Television New Zealand.

Parole board got it right. (2004, January 23). The Southland Times, p. 6.

Parole hearings cause anguish. (2007, May 24). Otago Daily Times, p. 13.

Perrott, A. (2007, August 4). Pasifika - identity or illusion? The New Zealand Herald. Retrieved from http://www.nzherald.co.nz

Phillips, L. (2000). Mediated Communication and the Privatization of Public Problems. European Journal of Communication, 15 (2), 171-207.

Phillips, N. \& Hardy, C. (2002). Discourse analysis: Investigating processes of social construction. Thousand Oaks, CA: Sage.

Pihama, L. (1994). Are films dangerous? A Maori woman's perspective on 'The Piano' in Hecate, 20 (2), 239-241.

Pihama, L. (2000). Ebony and ivory: Constructions of Maori in 'The Piano'. In H. Margolis (Ed.) Jane Campion's The Piano (pp. 114-134), Cambridge, England: Cambridge University Press.

Police need support as violence grows. (2002, July 16). The Dominion Post, p. B4.

Police say youth gangs out of control [news item]. (2005, October 24). NZ News. Retrieved from http://tvnz.co.nz

Poster, M. (2002). Visual Studies as Media Studies. Journal of Visual Culture, 1 (1), 67-70.

Pratt, J. (1997). Governing the dangerous. Annandale, Australia: Federation Press.

Pratt, J. \& Clarke, M. (2005). Penal Populism in New Zealand. Punishment and Society, 7 (3), 303-322.

Pratt, J. (2006). The dark side of paradise: Explaining New Zealand's history of high imprisonment. British Journal of Criminology, 46 (4), 541-560. 
Pratt, J. (2007). Penal Populism. London, England: Routledge.

Pratt, J. (2008a). Penal scandal in New Zealand. In A. Freiberg \& K. Gelb (Eds.), Penal populism, sentencing councils and sentencing policy (pp. 31-44). Sydney, Australia: Hawkins Press.

Pratt, J. (2008b). When penal populism stops: Legitimacy, scandal and the power to punish in New Zealand. The Australian and New Zealand Journal of Criminology, 41 (3), 364-383.

Purdy, K. (2001, September 16). Pizza delivery murder brings fear. Sunday Star Times, p. A6.

Put the family back around the table. (2002, September 18). The Dominion Post, p. B4.

Quince, K. (2007). Maori and the criminal justice system. In J. Tolmie \& W. Brookbanks (Eds.), The New Zealand Criminal Justice System, Auckland, New Zealand: Lexisnexus.

Rita Croskery [current affairs item]. (2003, September 9). Breakfast. Auckland, New Zealand: Television New Zealand.

Roberts, J. V., Stalans, L., Indermaur, D., \& Hough, M. (2003), Penal Populism and Public Opinion, New York, NY: Oxford University Press.

Robson, M. (2002, September 15). Early prevention of criminality more effective than cure. The New Zealand Herald. Retrieved from http://www.nzherald.co.nz

Rocheron, Y. \& Linne, O. (1989). Aids, moral panic and opinion polls. European Journal of Communication, 4 (4), 409-434.

Rock, P. (2007). Untitled paper presented at a symposium to mark the retirement of Professor Stanley Cohen, London School of Economics, London, England.

Rohloff, A. (2008). Moral panics as decivilising processes: Towards an Eliasian approach. New Zealand Sociology, 23 (1), 66-76.

Rohloff, A. (2010). Extending the concept of moral panic: Elias, climate change and civilization. Manuscript submitted for publication.

Rohloff, A. \& Wright, S. (2010). Beyond the heuristic: Moral panic and social theory. Current Sociology, 58 (3), 403-419.

Rose, G. (2001). Visual methodologies: An introduction to the interpretation of visual materials. London, England: Sage Publications. 
Rubie-Davies, C., Hattie, J., \& Hamilton, R. (2006). Expecting the best for students: Teacher expectations and academic outcomes. British Journal of Educational Psychology, 76 (3), pp. 429-444.

Rudman, B. (2002, August 28). Textbook case of child fated to go off the rails. The New Zealand Herald. Retrieved from http://www.nzherald.co.nz

Ruscoe, K. (2009, March 20). Youngest killer Kurariki attacks media. Stuff. Retrieved from http://www.stuff.co.nz

Schlesinger, P. \& Tumber, H. (1994). Reporting crime: The media politics of criminal justice. Oxford, England: Oxford University Press.

Scollon, R. (2001). Action and text. In R. Wodak and M. Meyer (Eds.), Methods of critical discourse analysis (pp. 139-183). London, England: Sage.

Scott, S., Jackson, S. \& Backett-Milburn, K. (1998). Swings and roundabouts: Risk anxiety and the everyday worlds of children. Sociology, 32 (4), 689-705.

Scraton, P. (2002). The demonisation, exclusion, and regulation of children: From moral panic to moral renewal. In A. Boran (Ed.), Crime: Fear or fascination? (pp. 9-39). Chester, England: Chester Academic Press.

Sentencing for all offences [Discussion paper]. (2009). Ministry of Justice. Retrieved from http://www.justice.govt.nz/publications/global-publications/j/justpublished-a-summary-of-conviction-and-sentencing-of-offenders-in-new-zealand1996-to-2005/conviction-and-sentencing-of-offenders-in-new-zealand-1996-to2005-1/3-sentencing-for-all-offences\#3.4 September 7, 2009.

Sensible Sentencing Trust. (2003, January 26). Call for parole to be abolished [Press release]. Retrieved from http://www.safe-nz.org.nz/Press/2003call.htm

Sensible Sentencing Trust. (2006, July). Submission to the law and order committee on the Young Offenders (Serious Crimes) Bill [Submission]. Retrieved from http://www.safe-nz.org.nz/Submissions/youthsub.htm

Sensible Sentencing Trust. (2009). Bruce Emery. [Offender database entry]. Retrieved from http://www.safe-nz.org.nz

Sentences upheld for Choy killers. (2003, September 6). The Dominion Post, p. A4.

Seven-year term for youngest killer. (2002, September 17). The Timaru Herald, p. 1.

Seven years for Bailey Junior as Choy killers sentenced. (2002, September 16). The New Zealand Herald. Retrieved from http://www.nzherald.co.nz 
Sharp, K. (2001, September 28). Violent robbery reminds us evil is close to home [Letter]. Manawatu Standard, p. 4.

Shuker, R., Openshaw, R., \& Soler, J. (1990). Youth, media and moral panic in New Zealand: From hooligans to video nasties. Palmerston North, New Zealand: Massey University, Department of Education, Delta Research Monograph No. 11.

Silverstone, R. (2007). Media and morality: On the rise of the mediapolis, Cambridge, England: Polity Press.

Simmel, G. (1950), The Sociology of Georg Simmel (Kurt Wolff Trans.). New York, NY: Free Press.

Smith, L. (1996). Nga aho o te kakahu matauranga: The multiple layers of struggle by Maori in education (unpublished doctoral dissertation). The University of Auckland, Auckland, New Zealand.

Smith, P. (1996). Executing executions: Aesthetics, identity, and the problematic narratives of capital punishment ritual. Theory and Society, 25, 235-261.

Sorting out children before they turn on the adults. (2002, August 26). Taranaki Daily News, p. 8.

Sparks, R. (2000). Perspectives on risk and penal politics. In T. Hope and R. Sparks (Eds.), Crime, risk and insecurity (pp. 129-145). London, England: Routledge.

Spoonley, P. (1988). Racism and ethnicity. Oxford, England: Oxford University Press.

Stabile, C. A. (2001). Conspiracy or consensus? Reconsidering the moral panic. Journal of Communication Inquiry, 25 (3), 258-278.

Statistics New Zealand. (2008). Apprehension statistics 2002-2008. Retrieved from http://www.stats.govt.nz

Statistics New Zealand. (2009). Apprehension statistics 2009. Retrieved from http://www.stats.govt.nz

Steen, S. \& Bandy, R. (2007). When the policy becomes the problem: Criminal justice in the new millennium. Punishment and Society, 9 (5), 5-26.

Streets of shame [current affairs item]. (2006, October 24). Sunday. Auckland, New Zealand: Television New Zealand.

Suaalii, T. (2000). Deconstructing the 'exotic' female beauty of the Pacific Islands. In A. Jones, P. Herda, \& T. Suaalii (Eds.), Bittersweet: Indigenous 
women in the Pacific (pp. 93-108). Dunedin, New Zealand: University of Otago Press.

Surette, R. (1988). Media, crime, and criminal justice: Images and realities $\left(2^{\text {nd }}\right.$ Edition). Belmont, CA: Wadsworth.

Tait, M. (2002, August 27). Kids behaving badly - lawyer's view. The Press, p. A7.

Tannenbaum, F. (1938). Crime and the community. New York, NY: Columbia University Press.

Tauri, J. (1996). Indigenous justice or popular justice? In P. Spoonley, D. Pearson \& C. MacPhearson (Eds.), Nga Patai - Racism and ethnic relations in Aotearoa/New Zealand (pp. 202-216). Palmerston North, New Zealand: Dunmore Press.

Te'evale, T. (2001). We are what we play: Pacific peoples, sport and identity in Aotearoa. In C. Macpherson, P. Spoonley, \& M. Anae (Eds.), Tangata o te moana nui: The evolving identities of Pacific peoples in Aotearoa/New Zealand (pp. 212227). Palmerston North, New Zealand: Dunmore Press.

Teenage criminal's terrible message. (2002, August 30). The Dominion Post, p. A1.

The film the Mongrel Mob didn't want you to see. (2008, May 4). The Sunday Star Times. Retrieved from http://www.stuff.co.nz

Thompson, G. (1997). Where goes economies and the economies? Economy and Society, 26 (4), 599-610.

Thompson, K. (1998). Moral panics. London, England: Routledge.

Thomson, A. \& Milne, J. (2005, September 18). Maori party small but new force in parliament. Herald on Sunday. Retrieved from http://www.nzherald.co.nz

Time to act on child crime. (2002, August 25). The Sunday Star Times, p. A8.

Tonry, M. (2001). Symbol, substance, and severity in western penal policies. Punishment and Society, 3 (4), 517-536.

Truancy linked to teenager's conviction. (2002, August 26). Otago Daily Times, p. 3.

TVNZ. (2008). About TVNZ. Retrieved from http://www.tvnz.co.nz/view/about tvnz index_skin/816472 
Underage [current affairs item]. (2006, March 17). Breakfast. Auckland, New Zealand: Television New Zealand.

Underclass of young crims. (2002, April 2). The Dominion Post, p. 10.

Ungar. S. (1992). The rise and (relative) decline of global warming as a social problem. The Sociological Quarterly, 33 (4), 483-501.

Ungar, S. (2001). Moral panic versus the risk society: The implications of the changing sites of social anxiety. British Journal of Sociology, 52 (2), 271-192.

Valentine, G. (1996). Angels and devils: Moral landscapes of childhood. Environment and Planning D: Society and Space, 14, 581-599.

Valverde, M. (1994). Moral capital. Canadian Journal of Law and Society, 9 (1), 213-232.

Valverde, M. (2006). Law and order: Images, meanings, myths. Oxon, England: Routledge-Cavenish.

Van Dijk, T. (1988a). News as Discourse. Hillsdale: Lawrence Erlbaum.

Van Dijk, T. (1988b). Semantics of a press panic: The Tamil invasion. European Journal of Communication, 3, 167-187.

Van Dijk, T. (1991). Racism and the press. London, England: Routledge.

Vass, B. (2008, April 25). Young killer faces strict parole rules. The New Zealand Herald. Retrieved from http://www.nzherald.co.nz

Veber, J. (2009). Director's statement [Web post]. Retrieved from http://www.troubleismybusiness.com/directors statement.html

Victim's mum wants criminals tagged. (2008, March 5). Stuff. Retrieved from http://www.stuff.co.nz

Victor, J. S. (1998). Moral panics and the social construction of deviant behavior: a theory and application to the case of ritual child abuse. Sociological Perspectives, 41 (3), 541-565.

Waddington, P. A. J. (1986). Mugging as a moral panic. British Journal of Sociology, 37 (2), 245-259.

Wall, M. (1995). "Being a Maori is...": media constructions of the Maori race as the black other (Unpublished masters thesis). University of Auckland, Auckland, New Zealand.

Wall, M. (1997). Stereotypical constructions of the Maori 'race' in the media. 
New Zealand Geographer, 53 (2), 40-45.

Wall, T. (2002a, August 26). Cherub's long, ruthless career in 13 short years. The New Zealand Herald. Retrieved from http://www.nzherald.co.nz

Wall. T. (2002b, August 26). Welfare failed boy killer says police officer. The New Zealand Herald. Retrieved from http://www.nzherald.co.nz

Wallace, C-L. (2006). Menace or moral panic? Methamphetamine and the New Zealand press (Unpublished masters thesis). Auckland University of Technology, Auckland, New Zealand.

Walker, R. (1990). Ka whawhai tonu matou: Struggle without end. Auckland, New Zealand: Penguin.

Walker, R. (2002). Maori news is bad news. In J. McGregor and M. Comrie (Eds.), What's news? Reclaiming journalism in New Zealand (pp. 215-232). Palmerston North, New Zealand: Dunmore.

Walters, R. \& Bradley, T. (2005). Introduction to criminological thought. Auckland, New Zealand: Pearson Education New Zealand.

Wardle, C. (2007). Monsters and angels: Visual press coverage of child murders in the USA and UK, 1930-2000. Journalism, 8, 263-284.

Wasteland. (2002, September 12). The Timaru Herald, p. 4.

Weber, M. (1904/1949). The methodology of the social sciences. (E. A. Shils \& H. A. Finch, Trans.). New York, NY: Free Press.

Welch, M., Price, E. A., \& Yankey, N., (2002). Moral panic over youth violence: Wilding and the manufacture of menace in the media. Youth and Society, 34 (1), 3-30.

Welfare blamed over young killer. (2002, August 26). Waikato Times, p. 2.

Wellwood, E. (2002, August 25). Our youngest killer. Sunday Star Times, p. A1.

Wetherell, M. (2001). Themes in discourse research: The case of Diana. In M. Wetherell, S. Taylor, \& S. Yates (Eds.), Discourse theory and practice (pp. 1428). London, England: Sage.

White, R. \& Cunneen, C. (2006). Social class, youth crime and justice. In B. Goldson \& J. Muncie (Eds.), Youth, crime and justice: Critical issues (pp. 17-29). London, England: Sage.

Who is responsible? (2002, August 29). The Otago Daily Times, p. 16. 
Why no inquiry on BJ Kurariki case? (2002, August 28). The Nelson Mail, p. 11.

Wilson, G. (1990). New Zealand journalists: Only partly professional. In P. Spoonley \& W. Hirsh (Eds.), Between the lines: Racism and the New Zealand media (pp. 47-52). Auckland, NZ: Heinemann Reed.

Wodak, R. (2001). What CDA is about - a summary of its history, important concepts and developments. In R. Wodak \& M. Meyer (Eds.), Methods of critical discourse analysis (pp. 1-13). London, England: Sage.

Woodham, K. (2006, June 24). Blood on the hands of the Kahui family. The New Zealand Herald. Retrieved from: http://www.nzherald.co.nz

Workman, K. (2008, March 15). In G. Cumming, Beyond the Prison Gate. The New Zealand Herald. Retrieved from http://www.nzherald.co.nz

Workman, K. (2008, October 20). Politics and punitiveness: Overcoming the criminal justice dilemma. Paper presented at the School of Government and the Institute of Policy Studies Election 2008, Victoria University of Wellington, Wellington, New Zealand.

Young, A. (1996). Imagining crime: Textual outlaws and criminal conversations. London, England: Sage.

Young, A. (2007). Foreword. In K. Biber, Captive images: Race, crime, photography (pp. vii-ix). Oxon, England: Routledge-Cavendish.

Young and bad. (2002, September 2). The Press, p. A8.

Young, J. (1971). The drugtakers: The social meaning of drug use. London, England: Paladin.

Young, J. (2007). Slipping away: moral panics each side of 'the golden age'. In D. Downes, P. Rock, C. Chinkin \& C. Gearty (Eds.), Crime, social control and human rights: From moral panics to states of denial. Essays in honour of Stanley Cohen (pp. 53-65). Cullompton, England: Willan.

Young, J. (2009). Moral panic: Its origins in resistance, ressentiment, and the translation of fantasy into reality. British Journal of Criminology, 49, 4-16.

Young killer applies for home detention. (2003, September 9). The New Zealand Herald. Retrieved from http://www.nzherald.co.nz

Young killer is no star. (2002, September 2). The Southland Times, p. 6.

Young killer thinks he's a star. (2002, August 29). The New Zealand Herald. Retrieved from http://www.nzherald.co.nz 
Young, W. \& Kelsey, J. (1982). The gangs: Moral panic as social control. Wellington, New Zealand: Institute of Criminology, Victoria University of Wellington.

Youngest killer tries for home jail. (2003, October 6). The New Zealand Herald. Retrieved from http://www.nzherald.co.nz

Youngest killer will not apply for parole. (2005, January 9). The New Zealand Herald. Retrieved from http://www.nzherald.co.nz

Zemke-White, K. (2001). Rap music and Pacific identity in Aotearoa: Popular music and the politics of opposition. In C. Macpherson, P. Spoonley, \& M. Anae (Eds.), Tangata o te moana nui: The evolving identities of Pacific peoples in Aotearoa/New Zealand (pp. 228-242). Palmerston North, New Zealand: Dunmore Press.

Zimring, F. E. (1999). The 1990s assault on juvenile justice: Notes from an ideological battleground. Federal Sentencing Reporter, 11, 260. 